Portland State University

PDXScholar

1985

\title{
Transient flow inverse study calculation of unsaturated permeability of wood
}

Farid Piroozmandi

Portland State University

Follow this and additional works at: https://pdxscholar.library.pdx.edu/open_access_etds

Part of the Environmental Engineering Commons, and the Mechanical Engineering Commons Let us know how access to this document benefits you.

\section{Recommended Citation}

Piroozmandi, Farid, "Transient flow inverse study calculation of unsaturated permeability of wood" (1985). Dissertations and Theses. Paper 3573.

https://doi.org/10.15760/etd.5457

This Thesis is brought to you for free and open access. It has been accepted for inclusion in Dissertations and Theses by an authorized administrator of PDXScholar. Please contact us if we can make this document more accessible: pdxscholar@pdx.edu. 
AN ABSTRACT OF THE THESIS OF Farid Piroozmandi for the Master of Science in Engineering:Mechanical presented March 1, 1985.

Title: Transient Flow Inverse Study Calculation of Unsaturated Permeability of Wood.

APPROVED BY MEMBERS OF THE THESIS COMMITTEE:

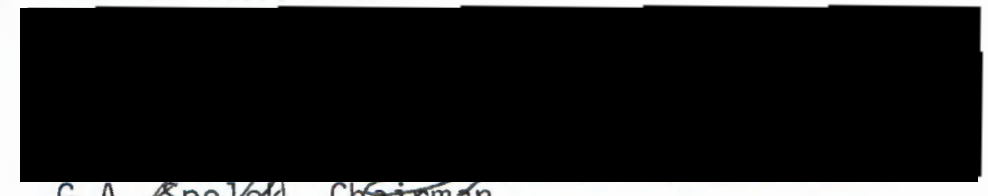

G.A. Spolek, Chairiman
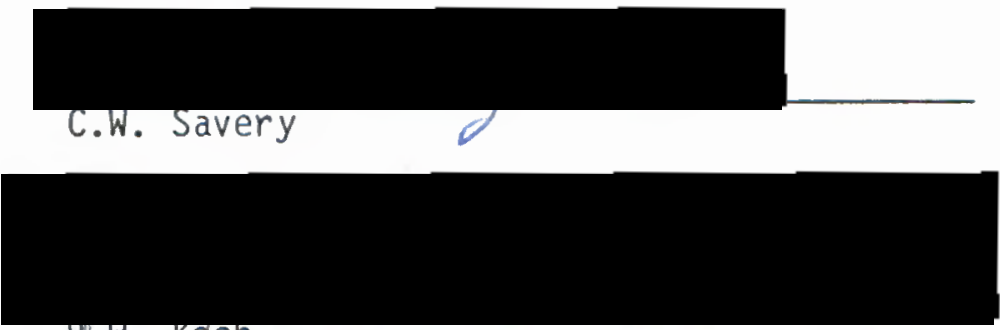

K.W. KqCh

One of the major processes in lumber industry is wood drying. This process consumes large amounts of energy and capital, and due to the length of time it takes, it acts as a governing factor in lumber production levels. Development of improvements in processes and equipment used in wood drying can be expedited through computer simulation of various drying procedures. These numerical simulations depend on the accuracy of numerical models representing wood transport properties, including functional dependency of liquid permeability through wood with respect to local saturation level. Data available in 
the literature mainly represent wood permeability properties at fully saturated levels. This is an indication of steady state flow methods used in determining these values which are based on wide spread use of similar methods utilized in studies on fluid flow through soil. This research determines unsaturated wood permeability using transient liquid flow methods that are more representative of actual drying process. Initially saturated wood samples are spun in a low speed centrifuge to induce liquid migration through the celi structures. Transient local moisture profiles along the sample are measured using a scanning gamma ray densitometer. Numerical integration and curve fitting procedures are used to process these data. Finally, utilizing liquid continuity equation the functional dependency of permeability with respect to saturation is calculated. Some permeability results appear to be reasonable when compared with actual wood behavior during drying. Measurement procedures prove to yield accurate results for moisture content and saturation levels in wood with less than $5 \%$ relative error in average saturation level of .75 . However, due to natural inhomogeneities in wood cellular structure, the final calculated results for unsaturated permeability show high levels of uncertainty (up to $112 \%$ relative error). 


\title{
TRANSIENT FLOW INVERSE STUDY CALCULATION \\ OF UNSATURATED PERMEABILITY OF WOOD
}

\author{
by
}

FARID PIROOZMANDI

A thesis submitted in partial fulfillment of the requirements for the degree of

\author{
MASTER OF SCIENCE \\ in
}

ENGINEERING: MECHANICAL

Portland State University 
TO THE OFFICE OF GRADUATE STUDIES AND RESEARCH:

The members of the Committee approve the thesis of Farid Piroozmandi presented March 1, 1985.

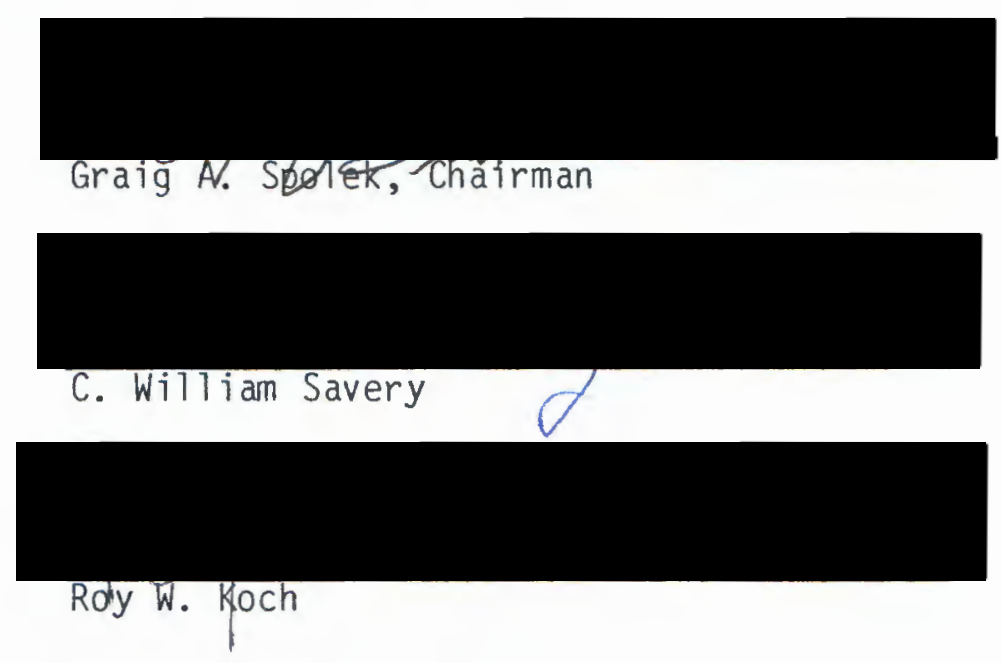

APPROVED:

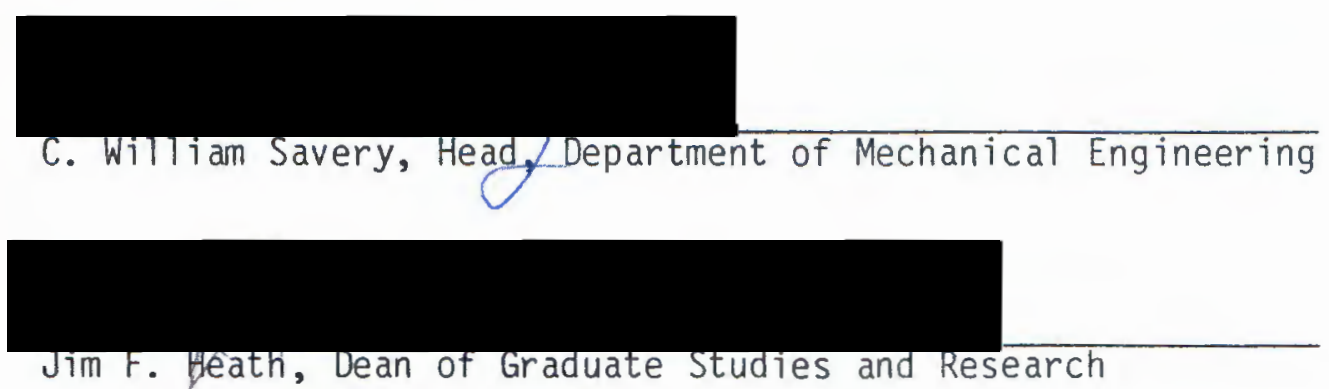




\section{ACKNOWLEDGEMENT}

I wish to express my thanks and appreciation to Dr. C.W. Savery, Dr. R.W. Koch, and in particular to Dr. G.A. Spolek who assisted me with the preparation of this thesis.

Thanks are also given to Weyerhaeuser Company who provided the samples required for the experiments, and to $\mathrm{Dr}$. Plumb and Mr. Chow at Washington State University who arranged for the experimentation and provided the raw data.

I would also like to acknowledge the financial support provided by the National Science Foundation through grant number MEA82-15193 which made this research possible. 
TABLE OF CONTENTS

PAGE

ACKNOWLEDGEMENTS ..............................

LIST OF TABLES...................... . . . . $v$

LIST OF FIGURES . . . . . . . . . . . . . . . . . vi

NOMENCLATURE ...................... . . .

CHAPTER

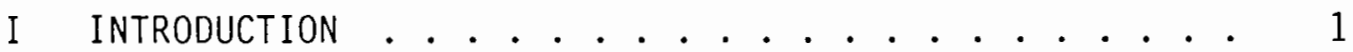

II BACKGROUND ................. 3

I I MATHEMATICAL MODELING . . . . . . . . . . . 21

IV EXPERIMENTATION PROCEDURE ............. 31

$\checkmark$ RESULTS AND DISCUSSION ................. 36

SUMMARY AND CONCLUSION ............ 89

BIBLIOGRAPHY . . . . . . . . . . . . . . . . . 91 APPENDICES

A UNCERTAINTY ANALYSIS ................ . . 93

B RAW DATA GAMMA COUNTS FOR SAMPLE \#3......... . 116

C SATURATION LEVELS S(Z,T) FOR SAMPLE \#3 . . . . . 123

D CURVE FIT RESULTS FOR SAMPLE \#3.......... . . 125

E UNSATURATED PERMEABILITY VALUES FOR SAMPLE \#3 . . . . 128

F SAMPLE DATA REDUCTION . . . . . . . . . . . 132

G COMPUTER SOFTWARES DEVELOPED IN BASIC FOR COMMODORE 64146 


\section{LIST OF TABLES}

TABLE PAGE

I Specimen Centrifuge Spin Data . . . . . . . 32

II Range of Location $Z_{j}$ for Curve Fits . . . . . . . 64

II Saturation Uncertainty Values . . . . . . . 102

IV Relative Permeability Uncertainty Values . . . . 113

V Sample \#3, Initialization Data . . . . . . 117

VI Sample \#3 Raw Data Gamma Counts . . . . . . . . 118

VII Finalize Data (Dry Wood Data) for Sample \#3 . . . . 122

VIII Specimen \#3, Saturation $(Z, T) \ldots . . . . . . .124$

IX Specimen \#3, Saturation as a Function of Location . . 126

$X$ Specimen \#3 and \#4, Capillary Pressure as a Function of Location . . . . . . . . . 127

XI Specimen \#3, Unsaturated Permeability Values . . . 129

XII Specimen \#3, Unsaturated Permeability Values

Calculated at Varying Upper Range Locations . . . 130

XIII Sample \#3 Experiment Time Periods . . . . . . . 137

XIV Bad Data Points Caused by Wet Gamma Counts . . . . 140

XV Bad Data Points Caused by Dry Gamma Counts . . . . 141 


\section{LIST OF FIGURES}

FIGURE

PAGE

1. Capillary Pressure Versus Saturation . . . . . . 12

2. Liquid Rise in Capillary Tubing . . . . . . . . . . 12

3. Mechanistic Model of Soft Wood (Comstock, 1970) . . . . 14

4. Moisture Distribution for Unsaturated Mechanistic Softwood Model (Spolek, 1981) ........... 14

5. Wood Cell Structure (Saiu, 1971) . . . . . . . . 16

6. Flow through Porous Media, Apparatus for Developing Darcy's Law................... 23

7. Wood Sample Housing Cup Schematic and Centrifuge Notation . . . . . . . . . . . . . . . . 29

8. Scanning Gamma Ray Densitometer . . . . . . . . . . 33

9. Legend for Figures 10 to 27 . . . . . . . . . . . 37

10. Saturation vs. Location, Sample \#1 . . . . . . . . 38

11. Saturation vs. Location, Sample \#2 . . . . . . . 39

12. Saturation vs. Location, Sample \#3 . . . . . . . . 40

13. Saturation vs. Location, Sample \#4 . . . . . . . . . 41

14. Saturation vs. Location, Sample \#5 . . . . . . . 42

15. Saturation vs. Location, Sample \#6 . . . . . . . . 43

16. Saturation vs. Location, Sample \#7 . . . . . . . . . 44

17. Saturation vs. Location, Sample \#8 . . . . . . . . 45

18. Saturation vs. Location, Sample \#9 . . . . . . . . 46 
19. Saturation vs. Location, Sample \#10 . . . . . . . 47

20. Saturation vs. Location, Sample \#11 . . . . . . . 48

21. Saturation vs. Location, Sample \#12 . . . . . . . . 49

22. Saturation vs. Location, Sample \#13 ......... 50

23. Saturation vs. Location, Sample \#14 . . . . . . . 51

24. Saturation vs. Location, Sample \#15 . . . . . . 52

25. Saturation vs. Location, Sample \#16 . . . . . . . . 53

26. Saturation vs. Location, Sample \#17 . . . . . . . 54

27. Saturation vs. Location, Sample \#18 . . . . . . 55

28. Curve Fit Results for S vs. Z, Sample \#3 . . . . . . 57

29. Curve Fit Results for S vs. Z, Sample \#5 . . . . . . 58

30. PC vs. S Data Points, Sample \#3 .......... 59

31. PC vs. S Data Points, Sample \#5 .......... 60

32. Curve Fit Results for $P_{C}$ vs. $S$, Sample \#3 . . . . . 62

33. Curve Fit Results for $P_{C}$ vs. S, Sample \#5 ....... 63

34. Unsaturated Permeability Results Comparison ....... 66

35. Relative Permeability vs. Saturation, Sample \#2.... . 68

36. Relative Permeability vs. Saturation, Sample \#3 . . . . 69

37. Relative Permeability vs. Saturation, Sample \#3, Acceptable Range of Permeability Results . . . . . 70

38. Relative Permeability vs. Saturation, Sample \#4 ... . 71

39. Relative Permeability vs. Saturation, Sample \#5 . . . 72

40. Relative Permeability vs. Saturation, Sample \#9 .... 73

41. Relative Permeability vs. Saturation, Sample \#15

Partial Result Presentation........... 74

42. Relative Permeability vs. Saturation, Sample \#15

Total Result Presentation........... 75 
43. Relative Permeability vs. Saturation, Sample \#17

Partial Result Presentation........... 76

44. Relative Permeability vs. Saturation, Sample \#17

Total Result Presentation . . . . . . . . . . 77

45. Relative Permeability vs. Saturated Permeability, Sample \#2................ 79

46. Relative Permeability vs. Saturated Permeability, Sample \#3................. 80

47. Relative Permeability vs. Saturated Permeability, Sample \#4................ 81

48. Relative Permeability vs. Saturated Permeability, Sample \#5............... 82

49. Relative Permeability vs. Saturated Permeability, Sample \#9................. 83

50. Relative Permeability vs. Saturated Permeability, Sample \#15................ 84

51. Relative Permeability vs. Saturated Permeability, Sample \#17................ 85

52. Tangential Permeability Results .......... 87

53. Tangential Permeability Results, Acceptable Range Presentation ............. 88

54. Wood Sample Typical Dimensions ........... . 97

55. Uncertainty Analysis, 1st Run, Sample \#3 ...... . 105

56. Uncertainty Analysis, 2nd Run, Sample \#3 ...... 106

57. Uncertainty Analysis, 3rd Run, Sample \#3 . . . . . . 107

58. Uncertainty Analysis, 4th Run, Sample \#3 ....... 108

59. Uncertainty Analysis, 1st Run, Histogram . . . . . . 109

60. Uncertainty Analysis, 2nd Run, Histogram . . . . . . 110

61. Uncertainty Analysis, 3rd Run, Histogram ........ 111

62. Uncertainty Analysis, 4th Run, Histogram . . . . . . 112 
63. Photocopy of Wood Samples 1 to 6 Reduced 65\% . . . . . 142

64. Photocopy of Wood Samples 1 to 6 Reduced $65 \%$. . . . . 143

65. Photocopy of Wood Samples 13 to 18 Reduced 65\% . . . . . 144

66. Photocopy of Wood Samples 13 to 18 Reduced 65\% . . . . 145 
NOMENCLATURE
A
Surface area
Body force; constant characterizing pore geometry
Wood sample height
EMC Equilibrium moisture content.
FSP Fiber saturation point.
F
Force; wood sample length
9
Gravitational acceleration.
k
Permeability.
(L) Upper range location in wood sample.
(1) Lower range location in wood sample.
L Length
$\mathrm{L}_{\mathrm{c}} \quad$ Characteristic dimension of pore space
Lwd Absorption length (dry wood).
$L_{w d+w} \quad$ Absorption length (wet wood).
M Moisture content.
m Mass
m Average volume rate of evaporation of 1 iquid
N Gamma ray count.
$n \quad$ Number of locations scanned in wood sample.
P Pressure.
q Volumetric flux 
$R \quad$ Centrifugal arm length; radius of pit opening.

ReLC Reynold Number.

$r \quad$ Radius of capillary tubing.

$r_{1}, r_{2}$ Principal radii of curvature of interface between two phases.

S Saturation.

$S_{n} \quad$ Standard deviation.

t Time.

$\checkmark \quad$ Volume.

$+$

v Velocity.

W Angular velocity.

y Random number.

Z Position.

$\emptyset \quad$ Void franction, porosity.

$\sigma$

Specific free energy of the interface (surface tension); standard deviation.

$\mu \quad$ Liquid viscosity.

$\lambda \quad$ Mean free path of gas molecules.

$\rho \quad$ Density.

$-$

$\quad$ Average density.

$\mu_{w d} \quad$ Wood gamma ray attenuation coefficient.

$\boldsymbol{u}_{\mathrm{W}} \quad$ Water gamma ray attenuation coefficient.

G Specific gravity.

$\tau$ Instrument dead time (gamma ray densitometer),

$\psi \quad$ Volume fraction. 
Subscripts

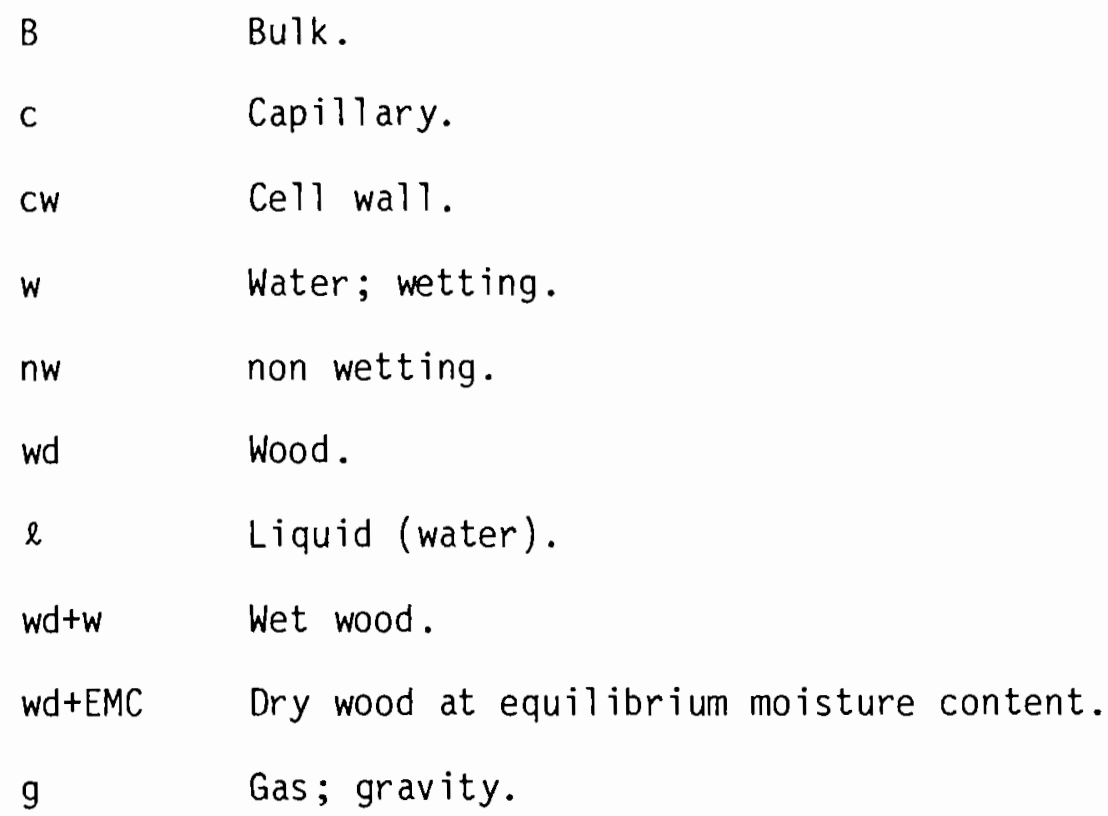


"... if comparison be made with the sum total of all former human achievements it will be found that the discoveries, scientific advancement and material civilization of this present century have equalled, yea far exceeded, the progress and outcome of one hundred former centuries."

-Abdu1 Baha' (1844-1921) 
CHAPTER I

INTRODUCTION

There is a well founded interest in the Pacific Northwest where the lumber industry is so large in developing a better understanding of the lumber drying process. In order for green wood to attain desirable strength and dimensional stability it has to be dried below a set saturation level. The drying process is done in industrial kilns where hot dry air is blown over lumber and moisture is removed from the surface of the wood. This process requires large supplies of energy and also is a major capital cost. To optimize the drying process a rather inexpensive approach is to study the effects of varying the various parameters involved in a computer simulation of the moisture transport process in wood.

Recent studies (Spolek 1981a, Spolek 1980) on the process of wood drying indicates that during the initial periods of drying, while wood is moist enough, moisture easily migrates from within the wood cell structures to the surface of the lumber. Thus, the governing factor on the drying rate is the rate at which moisture is removed from the surface of the wood. Consequently one would conclude that drying time can be reduced through enhancing convective transport during the initial period of the drying process.

At the later stages of the drying process this enhancing capability is no longer available, because now the governing factor on 
drying time is the rate at which moisture migrates through low moisture content wood cells toward the surface. The point within the drying cycle where this occurs can be predicted through understanding the transport mechanisms in wood. The liquid transport phenomenon is modeled by using Darcy's law. The mathematical model is used to predict moisture flow in wood cell structure. Permeability, the flow coefficient in Darcy's law, is the measure of wood conductance for moisture transport and depends on wood saturation level. Therefore, the accuracy and reliability of the computer simulation model of the drying process is strongly dependent on an accurate functional representation of permeability with respect to saturation. It is the intent of this research to develop a reliable procedure for determining unsaturated permeability of different woods and to demonstrate the technique for Southern Pine. 
CHAPTER II

\section{BACKGROUND}

The general subject of this report deals with fluid flow through porous material. In order to better understand the main factors involved in this process, some of the characteristics of porous materials are discussed. In addition to properties of porous medium the state of fluid in the medium is also explained briefly along with the factors that cause fluid flow. For a detailed discussion of fluid flow through porous material, the reader is referred to books by collins (1961), Bear (1979), Dullien (1979), and Siau (1971). Books by Collins (1961) and Bear (1979) study the subject from a soil scientist point of view, i.e. water flow through layers of ground. Dullien (1979) and Greenkorn (1981) discuss the general area of porous media and fiuid transport, and Siau (1971) specifically covers the fluid flow through wood.

A porous material is a solid that contains voids or holes. The holes are either connected or not, and are distributed throughout the material on a regular or random basis. The interconnected voids are the effective pore space in terms of fluid flow through the porous media. The porous media can be either consolidated as in wood or standstone, or unconsolidated as in beach sand. Other examples of porous material are bread, human lung, or a package of glass beads. Because of the 
complexity of pore structure of porous material the macroscopic properties of such material is studied.

One of the properties of porous material is its porosity. Porosity is the fraction of the total volume of the material which is occupied by voids. Porosity is a dimensionless number and is calculated as follows:

$$
\phi=\frac{V_{p}}{V_{B}}=\frac{\text { Pore space volume }}{\text { Bulk Volume }}
$$

Total porosity represents the total void space in the porous media, and effective porosity represents the interconnected void space. The value of porosity in a porous material depends on the shape and size of parts forming the material and also the pattern with which they are located with respect to each other. The range of porosity theoretically is between 0 and 1 , where at $\phi=0$ the material is all solid with no void in it, and at $\phi=1$ there is no solid part and material is all void space. As an example porosity of Southern Pine wood is about 0.63 and porosity of sandstone is between 0.08 to 0.38 (Collins, 1961).

In order to calculate the porosity of porous material one should measure the volume of void space and also the total volume of the sample. There are various methods utilized to measure porosity (Collins, 1961; Siau, 1971). Here we will discuss two direct methods which will result in total and effective porosity values.

In the first method the bulk volume of sample is measured. Then the sample is crushed and void spaces within the sample are eliminated, and volume of the solid part is measured. Finally the porosity is calculated as follows: 


$$
\phi=\frac{V_{\text {void }}}{V_{\text {bulk }}}=\frac{V_{\text {bulk }}-V_{\text {solid }}}{V_{\text {bulk }}}
$$

This method yields total porosity and is usually used for brick, ceramics and similar porous material.

The other method is called mercury injection (Collins, 1961). In this method porous sample is immersed in mercury. Because of high surface tension of mercury (surface tension of mercury is $484 \times 10^{-3} \mathrm{~N} / \mathrm{m}$ as opposed to that of water of $72.8 \times 10^{-3} \mathrm{~N} / \mathrm{m}$ ) and its non-wetting properties under atmospheric pressure mercury will not enter the pore spaces. Therefore the total, bulk, volume of sample is determined by volume displacement of mercury due to immersion of the sample. Then the mercury chamber is closed and the hydrostatic pressure of mercury in the chamber is increased to a very great value. Mercury will enter the void spaces in the sample compressing the trapped air in them to a negligible volume. The volume of mercury injected is equal to the volume of void space. Knowing bulk volume and void volume, porosity is calculated. This method will yield in effective porosity but is not very precise because the volume of compressed air is not determined. Sample will be mercury contaminated after this test and may not be suitable for further experiment.

Another property of a porous media is permeability. Permeability is defined as a mechanical property of porous material characterizing the ease with which a fluid may be made to flow through the material by an applied pressure gradient. In brief, permeability is the fluid conductivity of the porous material. Permeability $(k)$ is better explained through utilization of Darcy's law (for a discussion on Darcy's law refer to Chapter III, Mathematical Modeling) (Collins, 
1961). A horizontal laminar flow of an incompressible newtonian fluid through porous material is formulated by:

$$
\text { Darcy's law } k=\frac{q \mu}{A(\Delta P / L)}
$$

where

$q=$ volumetric Flux $\left[\mathrm{cm}^{3} / \mathrm{sec}\right]$

$\mu=$ Dynamic (absolute) viscosity of fluid [centi pose $=.01 \mathrm{gm} /(\mathrm{cm} . \mathrm{sec})]$

$A=$ Surface area $\left[\mathrm{cm}^{2}\right]$

$\Delta P / L=$ Pressure gradient over length of porous material in direction of flow $[\mathrm{atm} / \mathrm{cm}]$

$k$ = Porous material fluid flow permeability [darcy]

In other words, if a steady state flow of $1 \mathrm{~cm}^{3} / \mathrm{sec}$ of a fluid with one centipoise dynamic viscosity is induced through a cube of porous material with $1 \mathrm{~cm}$ sides (normal to a surface of the cube) by a pressure gradient of one atmosphere, then the porous media has a permeability of one darcy.

$$
1 \text { darcy }=\frac{1\left(\mathrm{~cm}^{3} / \mathrm{sec}\right) \cdot 1(\text { centipoise })}{1\left(\mathrm{~cm}^{2}\right) \cdot 1(\mathrm{~atm} / \mathrm{cm})}=9.87 \times 10^{-9} \mathrm{~cm}^{2}
$$

As is indicated, permeability has units of length square. Collins (1961) indicates that permeability is proportional to mean square pore diameter in a porous media, and the spread of pore size of passages of fluid flow has a governing factor in determining the value of permeability. A porous material that has the same permeability value in all directions, such as beach sand, is called isotropic. Porous materials that have different permeabilities in different directions, such as wood, are called anisotropic. 
Permeability of a porous material may be expressed as hydraulic conductivity. This form of permeability is dependent on the measuring fluid's viscosity and density. In order to get the intrinsic permeability (the version that was specified using Darcy's law and is a function of the size and number of pore spaces) the following equation is used (Bear, 1979):

$$
k=\left(\text { hydraulic conductivity) } \times \frac{\mu}{\rho g}\right.
$$

where: $\mu=$ viscosity

$$
\begin{aligned}
& \rho=\text { fluid density } \\
& g=\text { gravitational acceleration }
\end{aligned}
$$

Hydraulic conductivity is mostly used by soil scientists who study water flow through layers of soil. In this report we will mainly utilize permeability (intrinsic permeability) because the results of the study can be applied to any liquid regardless of their viscosity and density.

One factor in the fluid flow that was used to express Darcy's law is that it should be a no slip fluid flow, that is, the fluid velocity at solid surfaces within the porous media should be zero. If a gas is used as flowing fluid it can show slip flow characteristics and the rate at which the gas will flow through the pore spaces will depend on its molecular mean free path (given the mean free path of gas molecules are smaller than pore size) which is dependent on the mean pressure at which gas is flowing. As one can anticipate, the actual permeability of a porous material to gas is higher than the permeability to liquid. The relation between gas permeability $\left(\mathrm{k}_{\mathrm{g}}\right)$, and no slip liquid flow permeability ( $k$ ) of a porous media is represented by $k l$ inkenberg equation (Collins, 1961). 


$$
k_{g}=k\left(1+\frac{b}{p}\right)
$$

where: $p=$ mean flowing pressure

$\mathrm{b}=$ constant characteristic of both the gas and porous medium Siau (1971) has presented klinkenberg equation for flow through wood by:

$$
k_{g}=k\left(1+\frac{3.8 \lambda}{R}\right)
$$

where: $\lambda=$ mean free path of gas molecules (for air at $20^{\circ} \mathrm{C}$,

$$
\lambda=1.03 \times 10^{-5} \mathrm{~cm} \text { ) }
$$

$R=$ radius of pit opening (sample value $4 \mu \mathrm{m}$ ). Pits are orifices connecting the wood cells together and fluid flows through them.

According to Darcy's law, permeability is a representation of the ratio of volumetric fluid flow divided by the pressure gradient that induces the flow. The same principal is used to measure the single phase, steady state fluid flow permeability of a porous material. A steady state fluid flow is induced on a porous material sample, the volumetric flux and pressure gradient is measured and then the permeability of sample is calculated. As an example of the permeability values Comstock (1970) has found the tangential permeability of Southern Pine wood to be between $0.5 \times 10^{-4}$ to $3 \times 10^{-4}$ darcy, and permeability of sand stone ranges between $5 \times 10^{-4}$ to 3.0 darcy (Collins, 1961).

Based on the method that we have defined permeability, permeability is only dependent on the characteristics of the pore space in the porous material and the path that fluid flow has to follow. Therefore any factor that affects the pore space or the flow path will affect the value of permeability. Such factors as compaction of porous 
media which will reduce porosity, and swelling of walls of passages in the media (as in clay) that will reduce pore space will cause a reduction in permeability (Collins, 1961). Another factor that can cause reduction of permeability is eliminating the paths that fluid can use to flow. For liquid flow in a porous media, liquid will establish routes to flow, in case the flow is reduced there will not be enough fluid to support all the routes and some of them will be eliminated which will cause permeability reduction (this subject will be discussed in more detail later on). One factor that can increase permeability is enlarging the pore spaces. This is sometimes done in sand stones through disolving some parts of the pore space solid walls by the fluid. This phenomena is called leaching (Colins, 1961).

When a fluid is present in the porous material, saturation ( $s$ ) is a dimensionless number that is used to express the amount of fluid present.

$$
S=\frac{\text { volume of fluid in a medium }}{\text { total volume of voids in the medium }}
$$

Saturation ranges between 0 and 1 . At $S=0$ no fluid exists in the medium, and at $S=1$, the medium is filled with fluid. In studying the flow through porous media there are almost always two fluids involved. In the case of water and air flow through a media, the fluids are immiscible. Water is a wetting ( $w$ ) fluid and air is a non-wetting (nw) fluid. In a medium that both these fluids co-exist each one has its own saturation level, and we should have:

$$
S_{W}+S_{n W}=1
$$

To calculate the saturation level of a fluid one needs to know the void volume and also fluid volume in media. For example, wetting fluid 
(water) saturation in a porous media with bulk volume $V_{B}$ and porosity

$\emptyset$ is:

$$
S_{w}=\frac{v_{w}}{\emptyset v_{B}}
$$

where: $\quad V_{W}=$ water volume

A direct method for calculation of saturation is through weighing the sample at dry stage, $\left(w_{1}\right)$, and then weighing it when it is partially saturated with a liquid with density $p_{\ell},\left(w_{2}\right)$. Calculating the maximum weight of liquid possible in the sample with $\left(\emptyset_{\ell} g V_{B}\right)$ the saturation is calculated by:

$$
S_{\ell}=\frac{w_{2}-w_{1}}{D \rho_{\ell} g V_{B}}
$$

This method will yield the average saturation of the porous media. In formulation of this method the weight of the gas phase present in the sample is assumed negligible.

Another method that can yield local saturation levels in a porous media is through gamma radiation absorption (Brown, 1982; Spolek, 1981a). Gamma radiation is absorbed by hydrogen molecules. If a sample of porous material is partially filled with water, through scanning the sample with gamma radiation its local moisture content and respectively saturation level can be determined. This very method is used in this research and it will be discussed later in the report.

When a porous media is partially saturated with a wetting liquid, there exists a gas phase within the pore space in contact with liquid phase. The liquid forms a meniscus in the pore space. At the interface between the two fluids the force of surface tension $(\sigma)$ of liquid pulls the liquid phase toward the gas phase. Therefore, in order to have 
mechanical equilibrium gas phase pressure $\left(P_{n w}\right)$ has to be greater than liquid phase pressure $\left(P_{W}\right)$. The difference between these two pressures is called capillary pressure $\left(P_{C}\right)$.

$$
P_{C}=P_{n w}-P_{w} \quad(\text { Collins, 1961) }
$$

Capillary pressure is also calculated by Laplace's equation

$$
P_{c}=\sigma\left(\frac{1}{r_{1}}+\frac{1}{r_{2}}\right)
$$

where:

$$
\begin{aligned}
& r_{1}, r_{2}=\text { principal radii of curvature of interface between the two } \\
& \text { phases. } \\
& \sigma=\text { specific free energy of the interface (surface tension) }
\end{aligned}
$$

The values of $r_{1}$ and $r_{2}$ depends on the pore space, the smaller the pore spaces the smaller $r_{1}$ and $r_{2}$ would be which in turn will indicate a higher capillary pressure. In a porous material which is fully saturated with liquid, since there is no gas-liquid interface, there is no capillary pressure present. However, if one starts to drain out the porous material by applying a pressure gradient or body force, menisci of liquid start forming and capillary pressure becomes apparent. The lower the saturation, the smaller principal radii at the interface become and a higher pressure gradient would be required to oppose the capillary pressure and drain out more moisture. Eventually a stage is achieved whereby capillary pressure becomes so large the pressure gradient can not drain any more moisture out of the sample. Saturation at this stage approaches irreducible saturation level $\left(S_{i r}\right)$ (Spolek, 1981b). As it is indicated in Figure 1, capillary pressure is a function of saturation in a porous material, at $S=1$ capillary pressure is zero and at saturation levels near $S_{i r}$ capillary pressure is very high. 


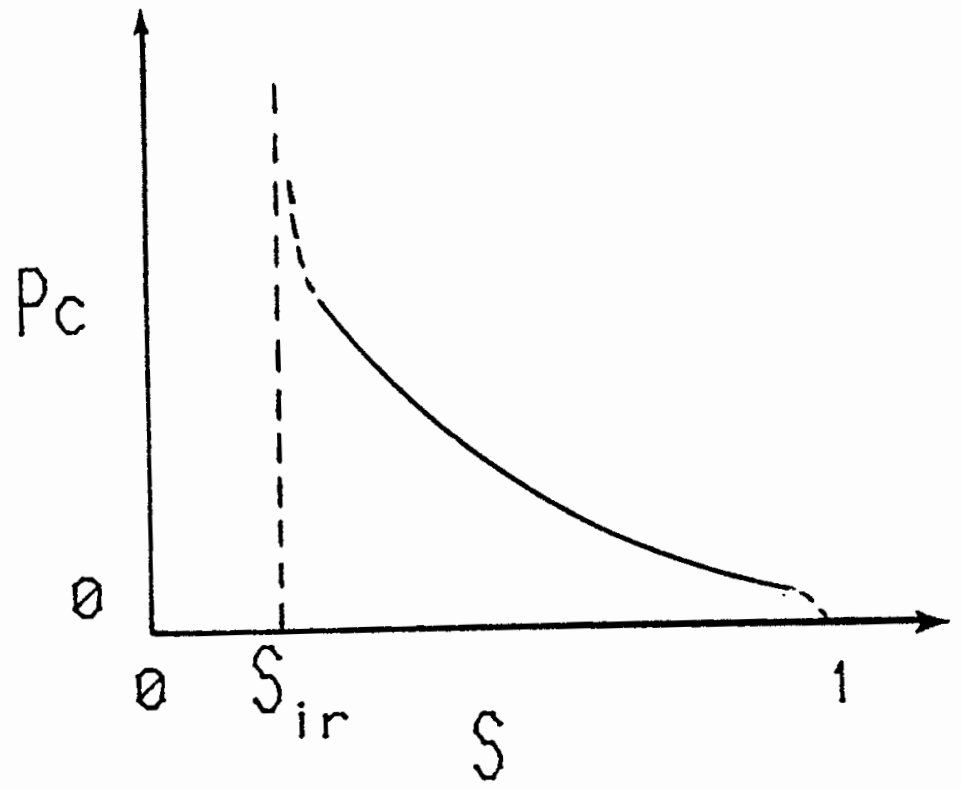

Figure 1. Capillary pressure versus saturation.

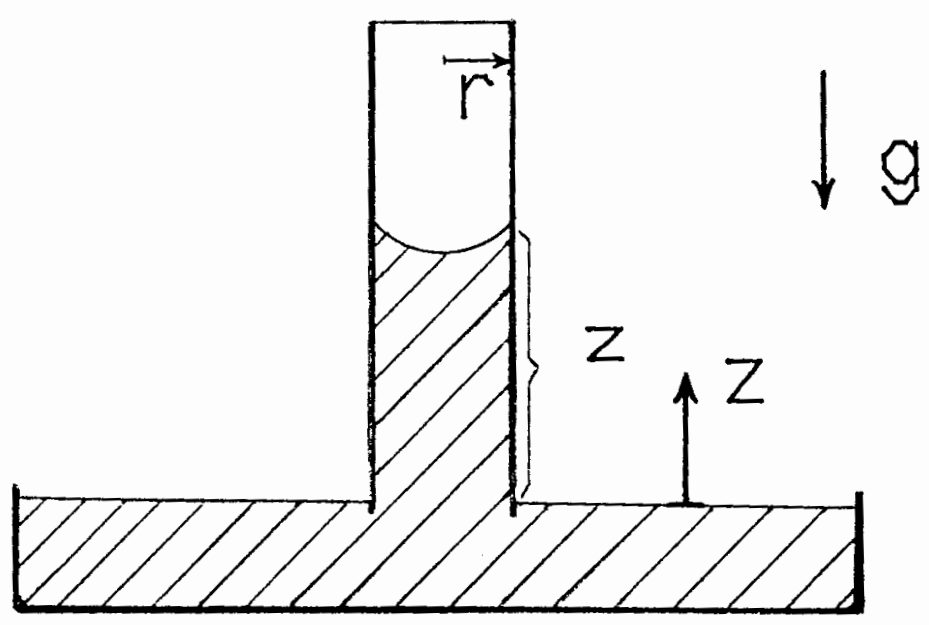

Figure 2. Liquid rise in capillary tubing. 
Capillary pressure is usually measured through measuring the pressure gradient that is required to counteract it at equilibrium. One method of measurement called the gravimetric method (Collins, 1961) is used to calculate capillary pressure for two fluid phase (gas = non-wetting, nw; liquid = wetting, $w$ ) in a round capillary tubing, Figure 2.

Here $P=$ pressure

$$
\begin{aligned}
\rho= & \text { density } \\
r= & \text { radius of capillary tubing } \\
g= & \text { gravitational acceleration } \\
Z= & \text { height of liquid in capillary tubing } \\
& P_{W}(Z)=P_{W}(0)-\rho_{W} g Z \quad \text { (a) } \\
& P_{n W}(Z)=P_{n W}(0)-\rho_{n W} g Z \text { (b) }
\end{aligned}
$$

(a) and (b) will result in

$$
\begin{aligned}
& P_{c}=P_{n w}-P_{w} \\
& P_{C}(Z)=P_{C}(0)+\left(\rho_{w}-\rho_{n w}\right) g Z
\end{aligned}
$$

at $Z=0$ we have full saturation therefore $P_{C}(0)=0$

$$
P_{C}(Z)=\left(\rho_{W}-\rho_{n W}\right) g Z
$$

To model wood as a porous material Comstock (1970) has modeled wood as a series of interconnected cells that have tapered ends which overlap on the radial surfaces and contain pits (small holes less than 4 micrometers in diameter interconnecting wood cells together) oniy on these tapered ends, Figure 3. Figure 4, based on this model, represents the situation where two immiscible fluids are present, and the path through pits that liquid follows (Spolek, 1981a) in tangential fluid flow through wood. Comstock (1970) shows that wood is a highly 


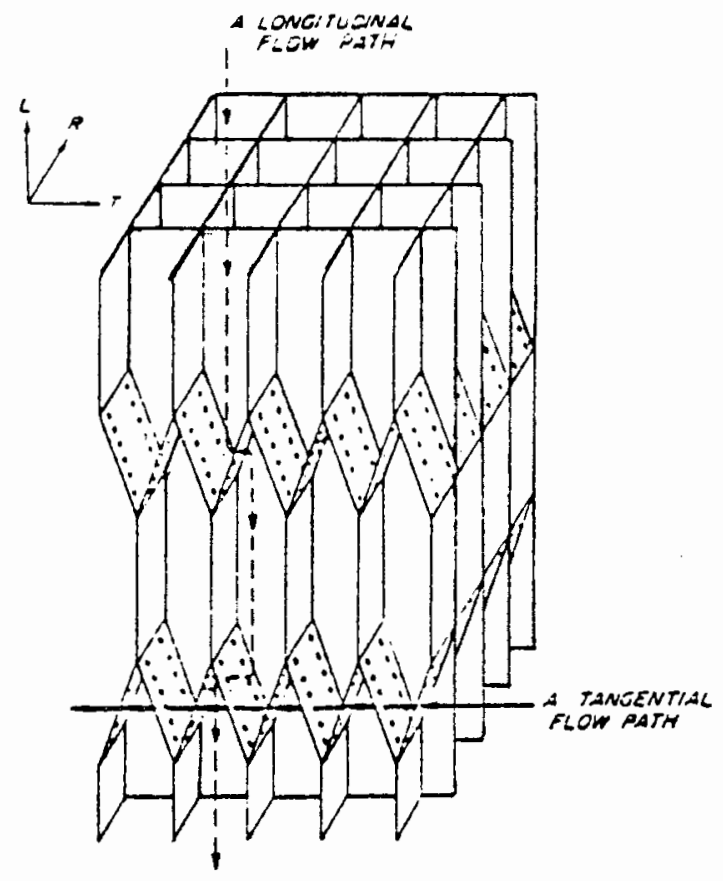

Figure 3.. Mechanistic model of softwood. (Comstock 1970)

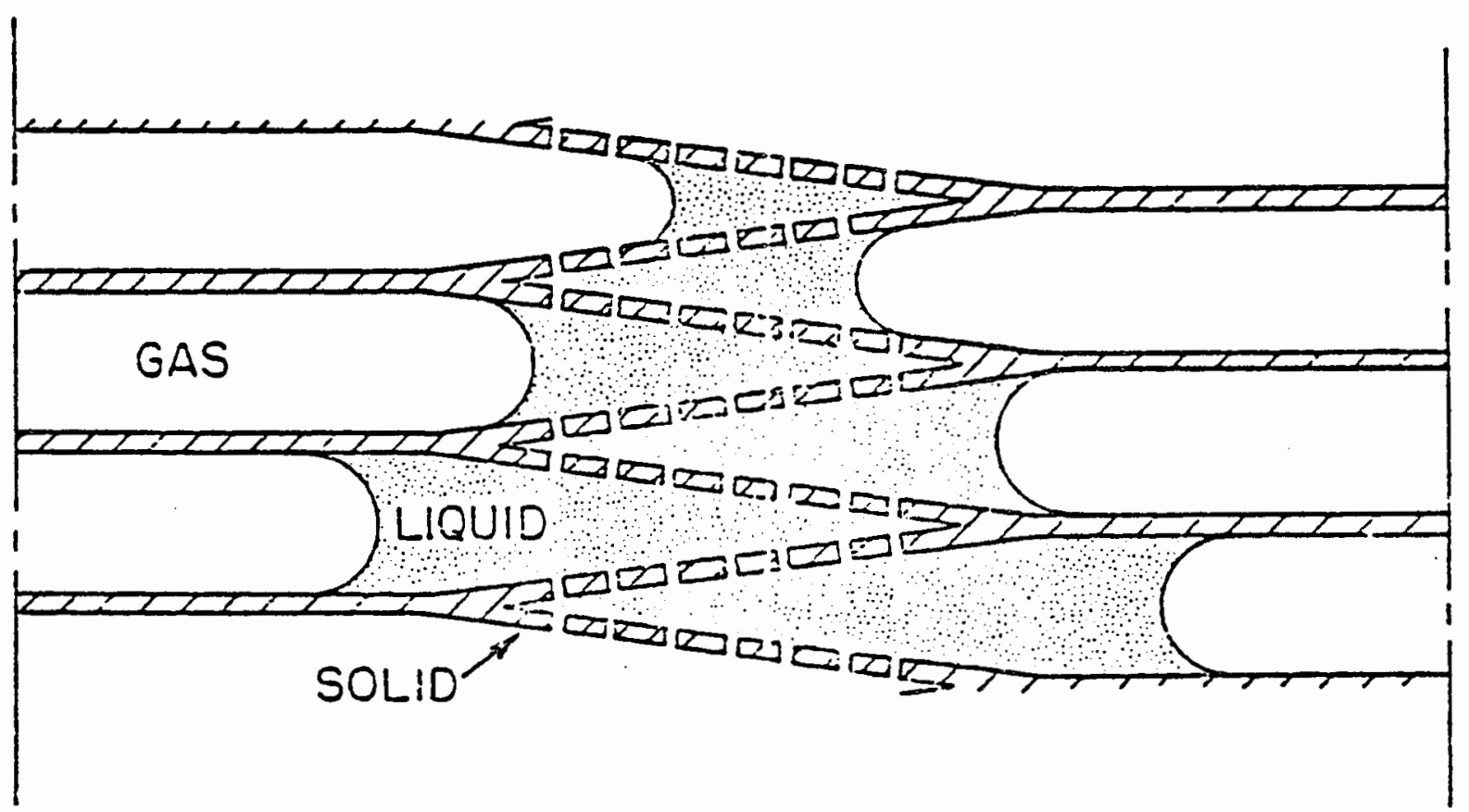

Figure 4.- Moisture distribution for unsaturated mechanistic softwood model. (Spolek 1981a) 
anisotropic material. The assumptions that Comstock (1970) makes for

his model are as follows:

"1. Wood cellular structure is homogeneous: ray cells and earlywood latewood differences are ignored.

2. Flow is through the cell cavity - pit system, and the pits offer the only significant resistance to flow.

3. Cells are square in cross section.

4. Pits are of uniform size and located only on the radial walls of the cells.

5. A sufficient number of cells are traversed so that end effects can be ignored.

6. Tracheids (cells) have tapered ends that overlap on the radial surfaces, but not on the tangential surfaces.

7. Pits are uniformly distributed on the overlapping portion, but lacking elsewhere."

Spolek (1981a) has used the same model and has studied the model when two fluid phases, air and water, are present. In his study, Spolek (1981b) has shown that capillary pressure behavior is dependent on the radius of lumens (inner parts of trachieds, wood cells) and not dependent on radius of pit openings. Figure 5 (Siau, 1971) represents an actual cell structure of wood. Typical dimensions for a softwood structure are as follows (Siau, 1971)

Tracheid length $=3500$ micrometer

Tracheid diameter $=33$ micrometer

Tracheid lumen diameter $=20-30$ micrometer

Overall diameter of pit chambers of bordered pits $=6-30$ micrometer 


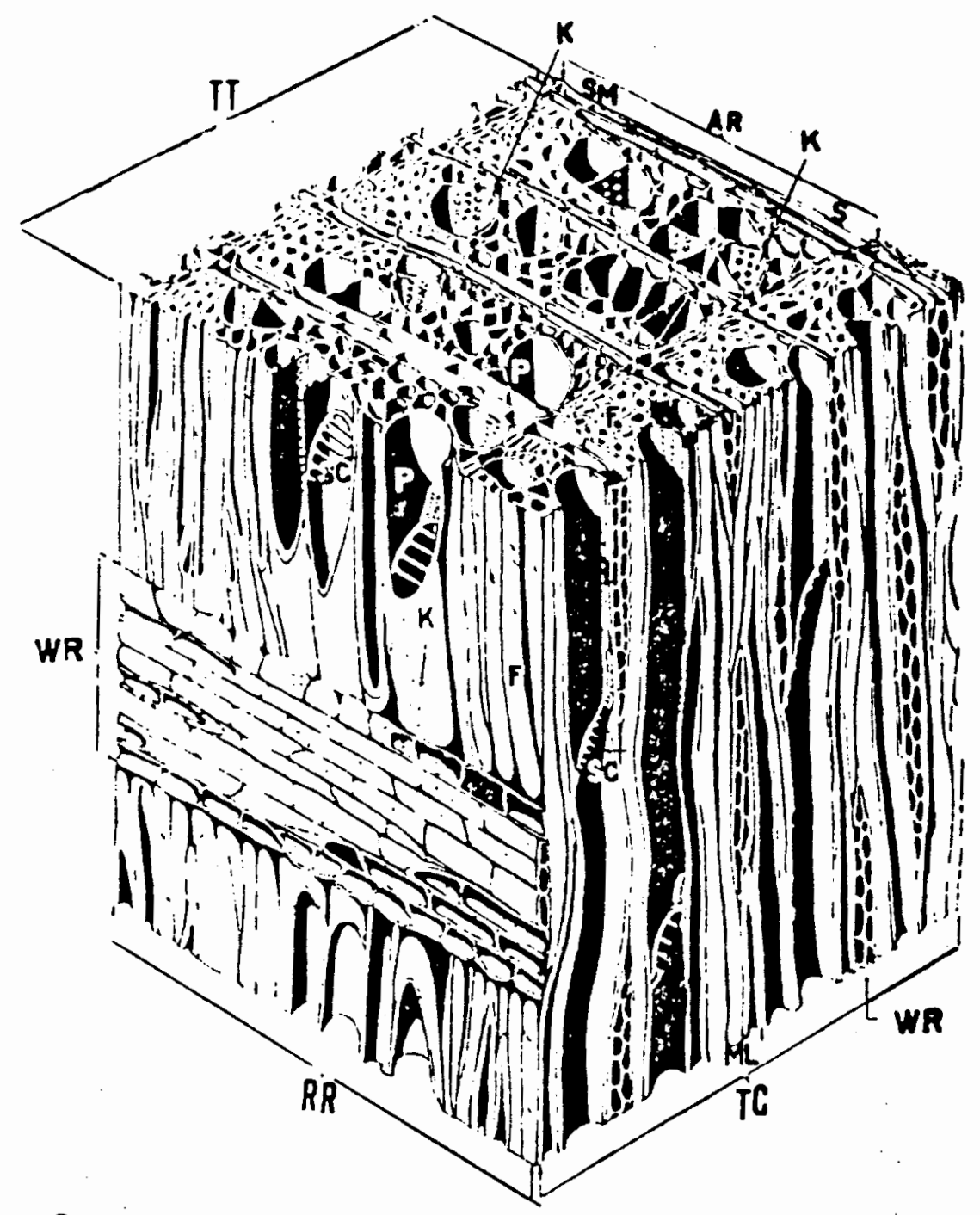

Gross structure of a typical hardwood. Plane TT is the cross section, $R R$ is the radial surface, and TG is the tangential surface. The vessels or pores are indicated by $P$. and the
elements are separaled by scalariform perforation plates, SC. The fibers, F. have small cuvities
and thick walls. Pits in the walls of the fibers aween the sells. The "we kalls of the fibers and vessels, K, provide fur the lluw of liquid bewoud (opringwoud) is desighated $S$, while the la WR. AR indicalles one annual ring. The earlylamella is locialed all $M$ IL.

(Courtesy of U.S.D.A. Furest Service.)

Figure 5. Wood cell structure (Saiu, 1971). 
Effective radii of pit openings $=0.01-4$ micrometer

As is shown in Figure 4 fluid, in order to flow from one cell to another, has to go through pits. When wood is fully saturated with liquid all flow paths are open and permeability is high. However, when saturation drops the liquid meniscus in cells starts entering the tapered ends of the cells. When a pit is not covered by liquid, the liquid flow path through that pit discontinues and this will cause permeability reduction. In fact, at irreducible saturation the menisci in adjacent cells reach the point of overlap and the continuous liquid phase path is broken and liquid permeability goes to zero (Spolek, 1981b).

Most of the studies on wood permeability focus on steady state methods (Comstock, 1970; Stamm, 1963; Resch, 1964). The steady state method consists of inducing a steady state flow (gas or liquid) across a wood sample using a known pressure gradient. Then permeability of wood sample is calculated as the ratio of flow over the pressure gradient. Due to the steady state flow nature of the method, wood samples are kept fully saturated during the experiment and permeability results are all for saturated wood. The steady state method is a widely used method because it is most often utilized by soil scientists and experimentation methods are established. Soil scientists most often deal with a very homogeneous porous material (i.e. beach sand) and since in their studies usually direction of flow and body force on fluid is the same, they use a general term called flow potential that contains all the pressures acting on the fluid. In addition to simplification of pressure gradients since the soil studies mainly deal with water as fluid, a hydraulic conductivity is used as flow conductance parameter, instead of 
permeability, which depends both on liquid and porous media properties.

It is necessary to avoid these simplifications in wood permeability studies because in flow through wood different fluids are studied and also effects of different pressure inducing factors need to be studied.

To study the actual phenomenon of moisture transport through porous media, one should consider unsaturated stages of the phenomenon as well as fully saturated stages. Soil scientists have approached the problem through utilizing steady state flow of two immiscible fluids, air and liquid, while assuming macroscopic homogeneity within the porous maedia. Tessoro (1974) has applied the same technique to wood. In Tessoro's experiment a steady state flow of Nitrogen gas $\left(\mathrm{N}_{2}\right)$ and water was induced through wood and then permeability of each phase was calculated. Through varying the ratio of gas and liquid, Tessoro calculated the permeability at different saturation levels. Tessoro (1974) has concluded that wood permeability approaches zero when saturation drops below 70\%. However, another study by Spolek (1981b) indicates that wood permeability does not drop to zero for saturation levels as low as 10\%. Tessoro (1974) might have come to his conclusion based on the assumption that during steady state flow of two fluid, gas and liquid, both phases are uniformly distributed throughout the wood specimen. Conceptually gas phase forms large bubbles in the flow path obstructing the liquid flow. A layer of bubbles formed at the entrance to the porous structure of wood specimen reduces the liquid permeability to a large degree at an early stage of two phase flow causing a bottle neck effect. In two phase flow experiments, this bottle neck permeability is measured as the liquid permeability. 
Another method used for calculating the unsaturated permeability of a porous medium is transient flow through the medium (Watson, 1966; Casse1, 1968). Watson (1966) studied the drainage of an initially saturated sand column, using a gamma radiation densitometer to measure the instantaneous local moisture content of the sand column. Having the plots of instantaneous local moisture content and flow potential (inducing pressure gradients) Watson calculated the flow velocity profile and flow potential gradients profiles through graphical integration and differentiation. By dividing the flow velocity over potential gradient, the hydraulic conductivity of sand column at different moisture content levels was calculated. Watson utilized Darcy's law for back calculating the hydraulic conductivity, and indicated that the results prove that Darcy's law can be used for flow through unsaturated porous media. Due to the nature of calculating hydraulic conductivity, back calculation of Darcy's 1 aw, and transient fluid flow, we will call this approach the "Inverse Study of Transient Flow". A similar method may be used to calculate the unsaturated permeability of wood. There are two main virtues inherent with this method. First, since actual moisture distribution can be measured along the wood sample without disturbing the drainage process, there is no requirement for assuming uniform distribution of liquid and gas through the wood sample. Second, during the experiment liquid is drained out of the initially saturated wood sample, the transient behavior of the sample more accurately represents the process of wood drying. As for the measurement of the local moisture content along the wood sample, it has been demonstrated that gamma ray absorption methods are capable of accurately measuring this value (Spolek, 1981a). Although gravitational 
body forces are sufficient to maintain a transient flow condition in soil column, they are not large enough to do the same for wood samples of manageable size with their very small porous cellular structure. In order to maintain the required transient flow in the wood sample, an enhanced body force can be produced through utilization of a low speed centrifuge (Spolek, 1981a). 


\section{CHAPTER III}

\section{MATHEMATICAL MODELING}

In order to develop a mathematical model representing fluid flow through porous media, Dracy's law will be applied to liquid phase continuity equation within the porous media. In studying the liquid flow through porous media some assumptions must be made. We assume a quasistatic flow; that is, the rate of change of the flow velocity is small, therefore one can assume that with in the porous body the flow acceleration and deceleration averages to zero and no net force is generated due to acceleration or deceleration of liquid. A second assumption is that flow is laminar. Since the characteristic dimension $L_{c}$ of the pore space is very small, the Reynold number

$$
\operatorname{Re}_{L C}=\frac{\vec{v} \cdot L C \cdot \rho}{\mu}
$$

where $\operatorname{Re}_{\mathrm{LC}}=$ Reynold number

$$
\begin{aligned}
& \vec{V}=\text { Average velocity } \\
& \rho=\text { liquid density } \\
& \mu=\text { liquid dynamic viscosity }
\end{aligned}
$$

$\operatorname{Re}_{L C}$ is very smal1, e.g. $\operatorname{ReLC}_{L}<10$, (or most of the time $\operatorname{Re}_{L C}<1$ ). In such flows, which are called creeping flow, the viscous forces acting on the liquid are much greater than the inertial forces. 
Although Darcy's law is an empirical equation, we derive it from an intuitive basis (Collins, 1961). Consider steady state liquid flow through a porous material induced by a pressure difference $\left(\mathrm{P}_{\mathrm{a}}-\mathrm{P}_{\mathrm{b}}\right)$ as in Figure 6 with positive in upward direction. The pressure force involved is

$$
F_{p}=\left(P_{a}-P_{b}\right) \emptyset A t=-\left(P_{a}-P_{b}\right) \emptyset A
$$

where: $\quad A=$ cross section area of porous material

$$
\emptyset=\text { porosity of porous material }
$$

The gravitational body force on the liquid is:

$$
F_{g}=\rho(\emptyset \mathrm{AL}) \mathrm{g} \downarrow=-\rho(\emptyset \mathrm{AL}) \mathrm{g}
$$

where: $\rho=1$ iquid density

$$
\begin{aligned}
& \mathrm{L}=\text { length of porous material in flow direction } \\
& \mathrm{g}=\text { gravitational acceleration }
\end{aligned}
$$

The viscous forces on the liquid act opposite to the direction of flow and are proportional to the viscosity of liquid and flow velocity gradient

$F_{\mu} \propto \alpha \frac{d \vec{V}}{d \vec{n}}$

where $\vec{n}$ is some unit vector normal to the local surface.

Since $\vec{V}$ is the flow average velocity

$$
\vec{V} \propto \frac{\vec{q}}{A}
$$

where $\vec{q}=$ volumetric fluid flux

Since on a macroscopic point of view the surface area of the pore spaces within the porus media is involved and these pore surfaces are related to the bulk volume of the media $(A L)$ we can write the viscous force acting on the fluid as: 


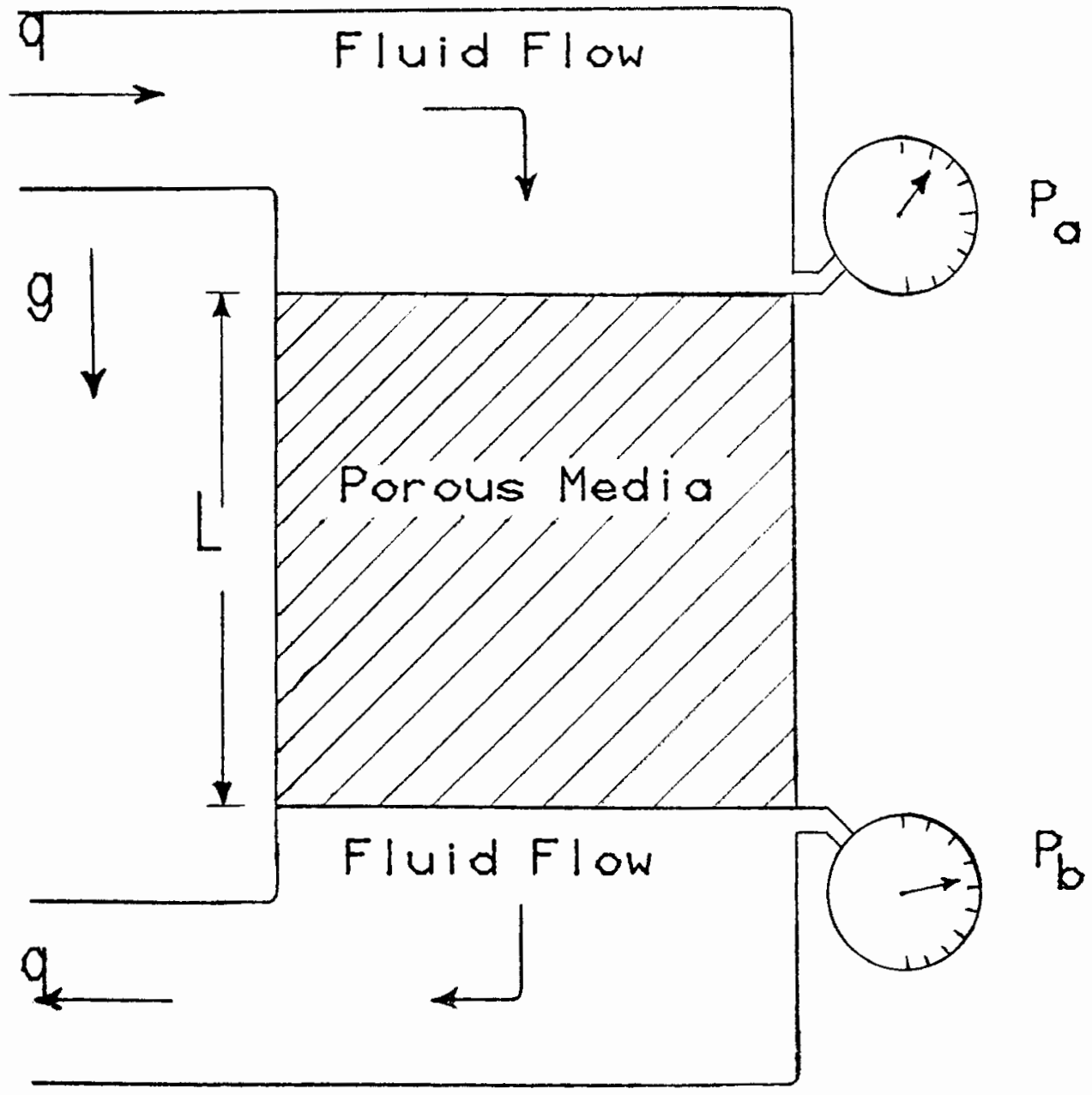

Figure 6. Flow through porous media, apparatus for developing Darcy's law. 


$$
F_{\mu}=B \mu\left(\frac{q}{A}\right)(A L)=B \mu q L \uparrow=+B \mu q L
$$

where $B=$ constant with dimensions of $\left[L^{-2}\right]$ as a characteristic of pore geometry.

In equilibrium the pressure gradient force should be counteracted by viscous and body force.

$$
\begin{aligned}
& F_{\mu} \uparrow+F_{g} \downarrow=F_{p} \downarrow \\
& B \mu q L-\rho(\emptyset A L) g=-\left(P_{a}-P_{b}\right) \emptyset A \\
& q=\frac{-\left(P_{a}-P_{b}\right) \emptyset A+\rho(\emptyset A L) g}{B \mu L}=\frac{\emptyset}{B} \cdot \frac{1}{\mu L}\left[-\left(P_{a}-P_{b}\right) A+\rho(A L) g\right]
\end{aligned}
$$

Taking $k=\frac{\emptyset}{B}$ as a constant characteristic of porous media we will have:

$$
\begin{aligned}
& q=\frac{-k A}{\mu L}\left[\left(P_{a}-P_{b}\right)-\rho g L\right]=\frac{-k A}{\mu L}[\Delta P-\rho L g] \\
& q=\frac{-k A}{\mu}\left(\frac{\Delta P}{L}-\rho g\right) \\
& \frac{q}{A}=V=\frac{-k}{\mu}\left(\frac{\Delta P}{L}-\rho g\right)
\end{aligned}
$$

Equation (9) is called Darcy's law and $k$ is permeability of the porous media. The negative sign indicates that fluid flow is in the direction of pressure reduction. The differential form of Darcy's law is:

$$
\vec{V}=\frac{-k}{\mu}(\nabla P-\rho \vec{g})
$$

or, when $Z$ is in the direction of the gravitational acceleration

$$
V=\frac{-k}{\mu}\left(\frac{d P}{d Z}-\rho g\right)
$$

Darcy's law is also valid for variable flow rates because viscous forces dominate inertial forces.

Liquid phase continuity equation is

$$
\nabla \cdot \vec{V}_{\ell}=0
$$

where we assume that liquid phase is incompressible. 
Through defining volume fraction for liquid $\left(\psi_{l}\right)$

$$
\psi_{\ell}=\frac{V_{\ell}}{V}=\frac{\text { Liquid Volume }}{\text { Total Bulk Volume }}
$$

and volume averaging within the porous media, Spolek (1981a) has

developed the following liquid phase continuity equation from equation (12).

$$
\frac{\partial}{\partial t}\left(\rho_{\ell} \psi_{\ell}\right)+\nabla \cdot\left\langle\rho_{\ell} \vec{V}_{\ell}\right\rangle+\langle\dot{m}\rangle=0
$$

where:

$$
\begin{aligned}
& t=\text { time } \\
& \rho_{\ell}=\text { liquid density } \\
& \vec{v}_{\ell}=\text { liquid velocity } \\
& \dot{m}=\text { average mass rate of evaporation of liquid } \\
& \langle>=\text { average values }
\end{aligned}
$$

Within a porous material the rate of liquid evaporation and vapor condensation averages to zero. Therefore

$$
\langle\dot{m}\rangle=0
$$

Since liquid is assumed to be incompressible, and considering an uni-directional fluid flow we will have:

$$
\frac{\partial}{\partial t}\left(\psi_{\ell}\right)+\frac{\partial}{\partial Z}\left(v_{\ell}\right)=0
$$

Since

$$
\psi_{\ell}=\frac{S \emptyset \text { (Bulk volume) }}{\text { Bulk volume }}
$$

where $S$ = saturation level; then

$$
\frac{\partial(S \emptyset)}{\partial t}=-\frac{\partial\left(V_{\ell}\right)}{\partial Z}
$$


Applying equation (10) on equation (18), and assuming unidirectional

flow we will have:

$$
\frac{\partial(S \emptyset)}{\partial t}=\frac{-\partial}{\partial Z}\left[-\frac{k}{\mu}\left(\frac{\partial P}{\partial Z}-\rho g\right)\right]
$$

assuming $\emptyset$, porosity, is constant (i.e. the solid part of porous media is rigid) we will have

$$
\emptyset \frac{\partial S}{\partial t}=\frac{\partial}{\partial Z}\left[\frac{k}{\mu}\left(\frac{\partial P}{\partial Z}-\rho+\right)\right]
$$

In equation (20) the $\frac{\partial P}{\partial Z}$ term refers to liquid pressure gradient. Spolek (1981b) indicates that liquid pressure is related to gas pressure and capillary pressure present in the porous media at unsaturated stages. Therefore

$$
\nabla P_{\ell}=\nabla P_{g}-\nabla P_{C}
$$

where

$$
\begin{aligned}
& P_{\ell}=\text { liquid pressure } \\
& P_{g}=\text { gas pressure } \\
& P_{C}=\text { capillary pressure }
\end{aligned}
$$

However, in a quasi-static liquid flow through porous media the pressure gradient required for gas to replace drained liquid is very small and one can assume that gas pressure during the liquid flow remains unchanged (Spolek, 1981a).

$$
\nabla P_{g} \simeq 0
$$

then

$$
\nabla P_{\ell}=-\nabla P_{C}
$$

replacing the liquid pressure gradient with its equivalent capillary pressure in equation (20) we will have

$$
\emptyset \frac{\partial S}{\partial t}=\frac{\partial}{\partial Z}\left[\frac{k}{\mu}\left(-\frac{d P_{C}}{d Z}-\rho_{\ell} \vec{g}\right)\right]
$$


since $\vec{g}$ is in negative direction of $Z$ by using chain rule and

remembering that capillary pressure is a function of saturation we will have:

$$
\emptyset \frac{\partial s}{\partial t}+\frac{\partial}{\partial Z}\left[\frac{k}{\mu}\left(+\frac{\partial P}{\partial s} \cdot \frac{\partial s}{\partial Z}-\rho_{\ell} g\right]=0\right.
$$

Integrating equation (25) on $Z$ from $Z=0$ to $Z=L$ we will have:

$$
\begin{aligned}
\mu \emptyset \int_{Z} \frac{\partial s}{\partial t} & d z=k(s(0))\left[\left(\frac{\partial P_{C}}{\partial s}\right)_{0} \cdot\left(\frac{\partial s}{\partial Z}\right)_{0}-\left(\rho_{\ell} g\right)_{0}\right] \\
& -k(s(L))\left[\left(\frac{\partial P}{\partial s}\right)_{L} \cdot\left(\frac{\partial S}{\partial Z}\right)_{L}-\left(\rho_{\ell} g\right)_{L}\right]
\end{aligned}
$$

to get to equation (26) we have assumed that fluid flow is isothermal and therefore liquid viscosity is constant. Also we are treating permeability a function of saturation. Let

$$
\left.\left.\frac{\partial P}{\partial S}\right]_{Z}=C(s(Z)), \quad \frac{\partial s}{\partial Z}\right]_{Z}=S^{\prime}(Z), \quad \text { and }\left.\rho g\right|_{Z}=B(Z)
$$

then

$$
k(s(L))=\frac{k(s(0))\left[C(s(0)) \cdot S^{\prime}(0)-B(0)\right]-\mu \emptyset \int_{Z} \frac{\partial s}{\partial t} d Z}{C(s(L)) \cdot S^{\prime}(L)-B(L)}
$$

Equation (27) can be used to calculate permeability of a porous media. Consider an experiment where an initially saturated porous material sample is drained so that one end of sample $(Z=0)$ is kept continually at full saturation for reference and the drainage flow is induced through a body force $B(Z)$ on the liquid. Here $+Z$ is in the opposite direction of fluid flow. If one can measure the instantaneous local saturation levels of the sample, and also can calculate the functional dependency of capillary pressure on saturation, knowing the 
fully saturated permeability of the sample $k(s(0))$ and also its porosity $\emptyset$ along with the liquid viscosity $\mu$, it is possible to calculate the porous media permeability at the saturation level at location $Z=L$.

In a system developed by Spolek (1981a) and utilized by Brown (1982), an initially saturated wood sample is placed in a cup and then is spun in a centrifuge. The body force induced on the liquid within wood will cause the liquid to drain out of the wood. The cup holding the sample will provide a level of water at one end $(z=0)$ of wood sample to ensure full saturation at that end (Figure 7 ). A gamma radiation densitometer is used to measure local moisture content within wood between periods of run. Detailed discussion of the experimentation method will be done in Chapter IV "Experimental Procedure".

Utilizing this system the body force term on the liquid within wood is calculated by:

$$
B(Z)=\rho_{\ell} g=\rho_{\ell} w^{2}(R-Z)
$$

where:

$$
\begin{aligned}
& \rho_{\ell}=\text { liquid density } \\
& W=\text { angular velocity of centrifuge } \\
& R=\text { centrifuge arm (Figure } 7 \text { ) } \\
& Z=\text { distance from liquid surface kept within the cup }
\end{aligned}
$$

After the specimen has been in the centrifuge and the body force can induce no more moisture drainage (steady state equilibrium stage) capillary pressures within the wood is counteracted by the body force. Since $\frac{\partial P}{\partial Z}=-\rho_{\ell} g$

and equation (23) indicates

$$
\frac{\partial P_{\ell}}{\partial Z}=-\frac{\partial P_{C}}{\partial Z}
$$




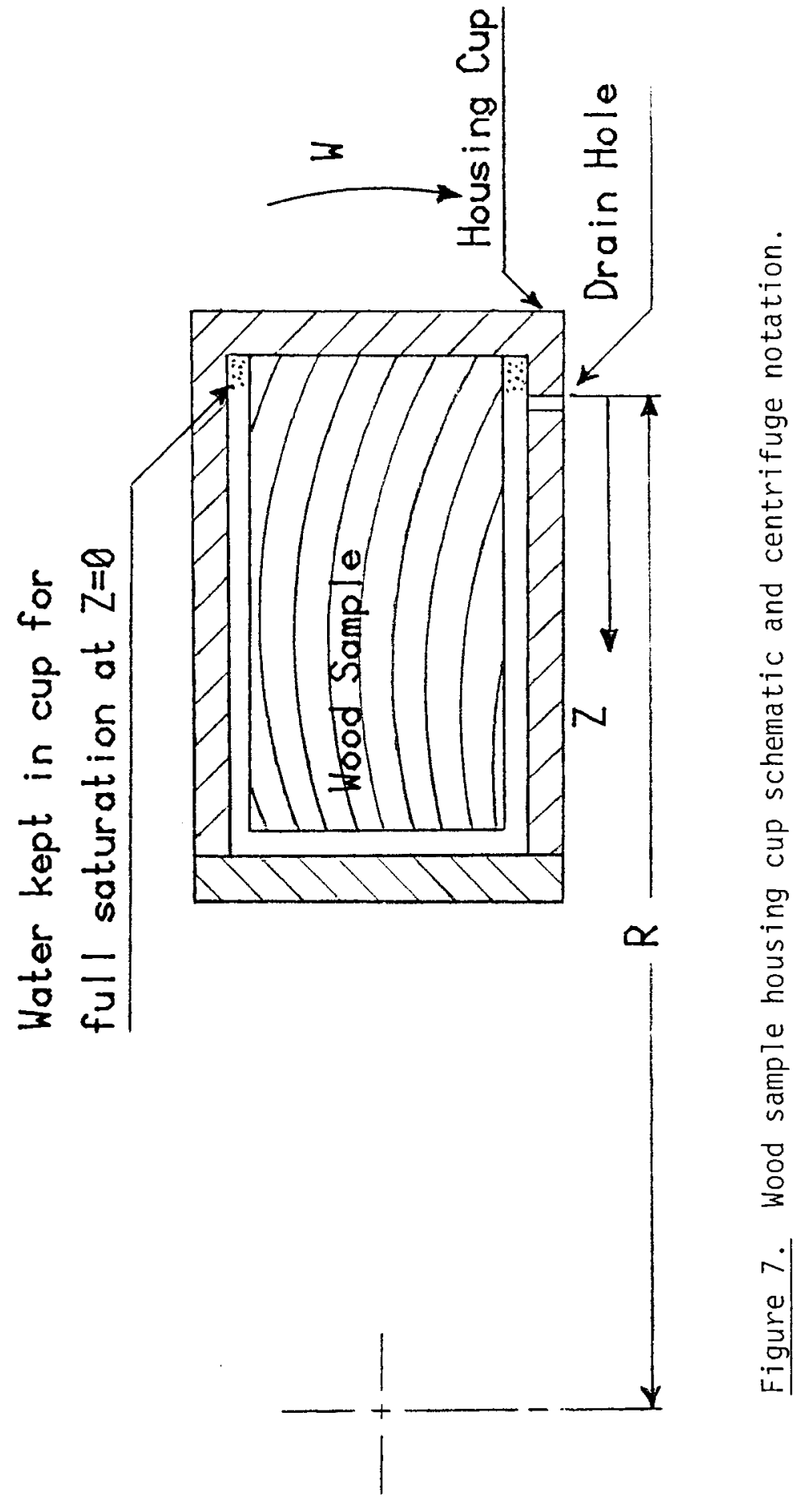


we have

$$
\frac{\partial P}{\partial Z}=\rho_{\ell} W^{2}(R-Z)
$$

Integrating equation (30) over $Z$ and remembering that capillary pressure at full saturation $(Z=0)$ does not exist $\left(P_{C}=0\right.$ at $\left.Z=0\right)$ we will have

$$
P_{C}=\rho_{\ell} w^{2} Z(R-Z / 2)
$$

Utilizing equations (31) and (28) along with the saturation profiles

$S(z, t)$ generated by the gamma radiation densitometer one can solve equation (27) for unsaturated permeability values $k(s(L))$. 


\section{CHAPTER IV}

\section{EXPERIMENTAL PROCEDURE}

Experiments were conducted using Southern Pine as the test wood species. Southern Pine is a widely used softwood, and its large permeability allows faster moisture movement, therefore reducing experimental time. The wood was initially in flat sawn, green, two by six lumber. The specimens were cut in rectangular blocks of about $9 \mathrm{~cm}$ $\times 5 \mathrm{~cm} \times 5 \mathrm{~cm}$. The long side paralled the direction of intended water movement, grain orientation was considered while cutting the samples.

Initial saturation level of specimens was increased to $80 \%-90 \%$ through water impregnation. The specimens were submerged in water and subjected to alternating periods of low pressure $(3 \mathrm{in} . \mathrm{Hg}$ ) and high pressure (atmospheric), causing water to replace the air that was removed during the low pressure cycles.

The specimens (six at a time) were loaded into a centrifuge and spun. The angular velocities used in experimentation are detailed in table I.

The spin generated the body force required to induce liquid motion. The higher RPM's which generated higher body forces did not affect the permeability of samples under study because according to Haugen (1970) permeability in porous media is independent of the driving pressure gradient. Special plastic cups were used to house the specimen. Close to the end of each cup a hole provided an outlet to 
Table I

SPECIMEN CENTRIFUGE SPIN DATA

\begin{tabular}{c|c|c|c} 
Specimen \# & $\begin{array}{c}\text { Angular } \\
\text { Velocity RPM }\end{array}$ & $\begin{array}{c}\text { Angular velocity } \\
\text { change occured at } \\
\text { spin period \# }\end{array}$ & $\begin{array}{c}\text { Total number of } \\
\text { spin periods }\end{array}$ \\
\hline 1 to 6 & 500 & - & 8 \\
7 to 12 & 845 and 580 & 6 & 9 \\
13 to 18 & 200 and 360 & 8 & 11
\end{tabular}

drain excess water; it also provided a constant reservoir of water to the bottom of the specimen. At the bottom ( $z=0$, free water surface) of the specimen due to existance of water a full saturation condition was maintained, Figure 7 . The cups were sealed to inhibit air drying of samples during the experiment. These precautions were taken in order to achieve the objective of isothermal moisture movement through wood where the only forces on the water within wood cells were body forces and capillary forces.

Periodically, after specimens were spun for a period of time ranging from one to twenty days, they were removed from the centrifuge and placed in the scanning apparatus. The scanning apparatus (Figure 8) consists of a gamma radiation source, a radiation detection device, and a mechanical housing that moves the specimen. The scanning gamma ray densitometer measures the local moisture content at a specific location within the specimen by measuring the attenuation of a collimated beam of gamma rays as it passes through the wood specimen. Since this measurement indicates the attenuation of radiation caused by wood, water, and the plastic cup container, the results are compared with dry wood in plastic cup container scanning results to find what portion of 


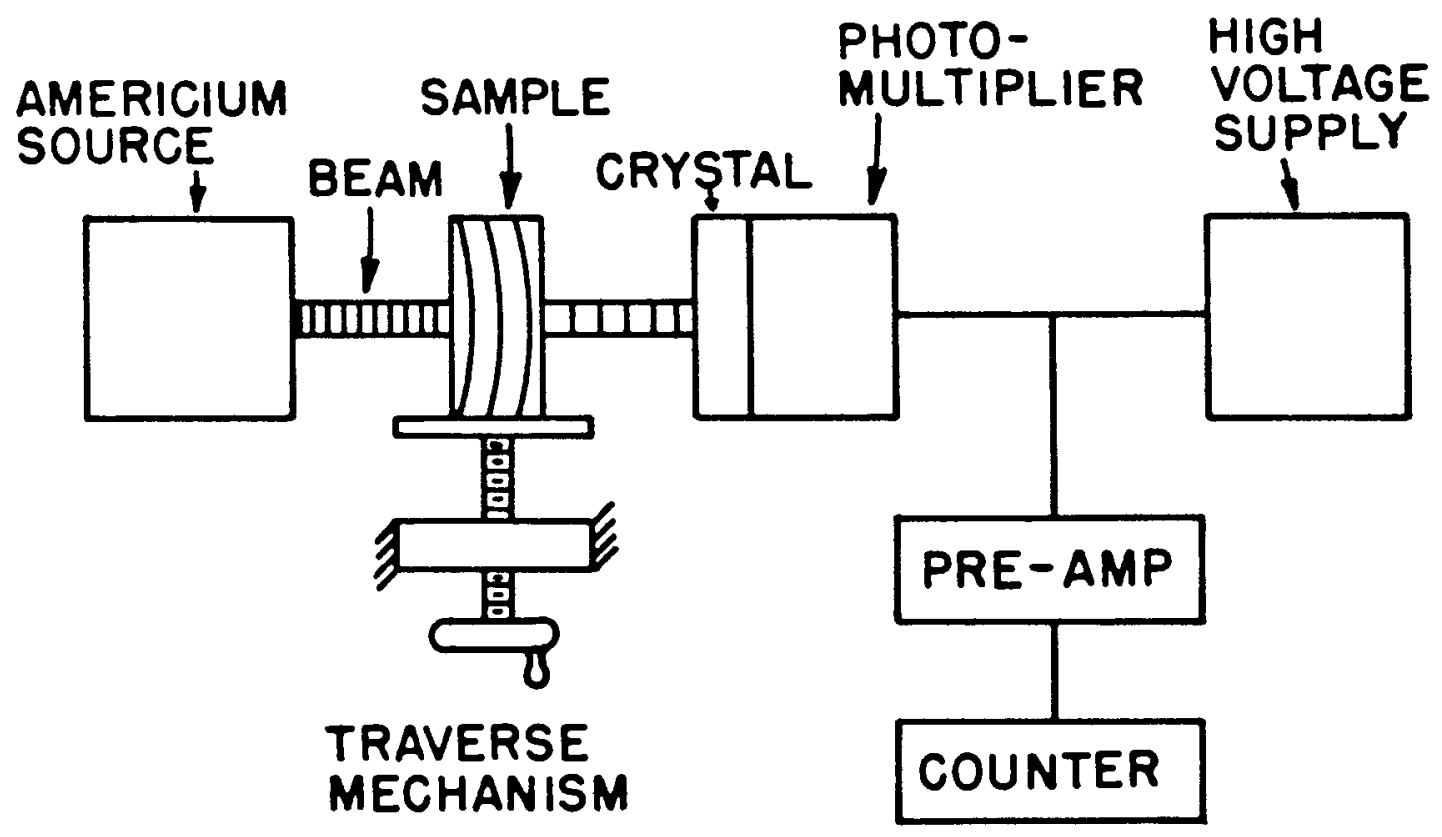

Figure 8. Scanning gamma ray densitometer. 
results correspond to that caused by water. By controlling and measuring the position of the radiation beam along the wood, the moisture profile is determined. The beam position was controlled by a traverse mechanism driven by a micro computer actuated stepper motor. The positions were measured with respect to the side drain hole in the housing cup because that position corresponded to the full saturation level. The gamma beam attenuation was measured by a pulse counter which was attached to the same micro computer. Thus, gamma count data acquisition was controlled by the micro computer. The local gamma counts along with other data such as sample weight, dimensions, and the time between runs, which were manually measured and then entered into the computer, were automatically stored on cassette tape.

Spinning and scanning of each specimen was repeated until the difference between two subsequent weight measurements was negligible. At that stage, the steady state moisture distribution was assumed to exist within the wood. After the last wet wood moisture profile was measured the specimens were oven dried at $103 \pm 2{ }^{\circ} \mathrm{C}$ down to 0.005 equilibrium moisture content. During the drying process the specimens were weighed periodically and when no further change was detected drying was terminated. The dried specimens were then scanned with gamma ray densitometer to measure the radiation beam attenuation caused by the dry wood and plastic cup at the same locations where wet wood moisture profiles were taken before. Wood shrinkage due to drying, which altered the measured locations with respect to the datum (side drain hole), was taken into consideration with the assumption that local shrinkage was linearly distributed. 
After the dry specimens were scanned and their physical properties such as weight and dimensions were measured, these data were also stored on the same tape. A total of eighteen specimens were tested; twelve for tangential permeability and six for longitudinal permeability. At each set of experiment, six specimens were tested simultaneously. The two experiment sets for tangential permeability, first 12 samples, required about 45 and 50 days for completion of each set consecutively, and the longitudinal permeability experiment, last six samples, required about 24 days for completion. The first set had nine wet scans and one dry scan. The second set had ten wet scans and one dry scan, and the final set (longitudinal permeability) had twelve wet scans and one dry scan. The errors introduced into the measured quantities due to equipment and procedure were dealt with through an uncertainty analys is (appendix A). To provide sample results specimen number three was used (appendix B). Some intermediate results of data reduction are presented in appendices $C$ and $D$, and the final unsaturated permeability results for sample number three is presented in appendix $E$.

Data reduction (sample data reduction in appendix $F$ ) was done on a micro computer (Commodore 64, computer codes in appendix G). With appropriate correction factors, local moisture contents and saturation levels along the specimens were calcuated for different runs. Thus, the distributions of $S(z, t)$ were calcuated. From the steady state saturation profiles, the functional dependency of the capillary pressure on saturation $\mathrm{P}_{\mathrm{C}}(\mathrm{s})$ (Spolek, 1981b) was calculated for each specimen. Then utilizing numerical integration and differentiation for equation (27), the permeability as a function of saturation $k(s)$ was evaluated for both tangential and longitudinal permeability. 
CHAPTER $V$

\section{RESULTS AND DISCUSSION}

Intermediate and final results will be presented in addition to a discussion of curve fitting techniques utilized in calculation. Figures 10 to 27 present saturation versus location profiles for wood samples. Each profile in a plot represents local saturations at the end of a centrifuge spinning period. Figure 9 indicates the order in which the profiles in Figure 10 to 27 correspond with spinning periods. First profile (scan TIME $\emptyset \emptyset$ ) in each plot is for the beginning of experiment and last profile (e.g. scan time $\emptyset 8$ for first six samples) present the local saturations after the last spinning period. As it is evident from saturation versus location plots at wood locations furthest away from the saturated end (at $Z=0 \mathrm{~cm}$ a full saturation was maintained during experiment), there is a trend of saturation depletion as spinning time (accumulated spinning durations) increases, while the saturation of the other end remains relatively unchanged regardless of spinning time. The specimen behavior at the saturated end is expected because the capillary forces are sufficient to maintain a liquid column about two centimeters in height (Spolek, 1984).

The abrupt variation in saturation in adjacent points as is indicated in saturation versus location plots is caused by two major factors. The first factor is the inhomogeneity of wood itself. There 


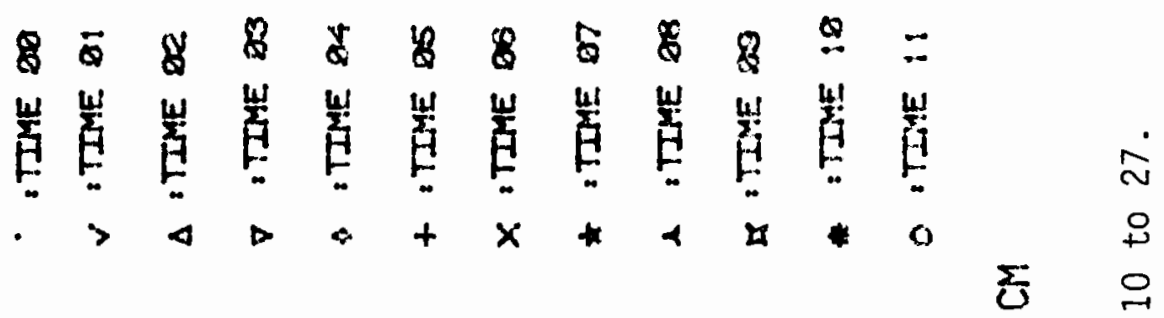

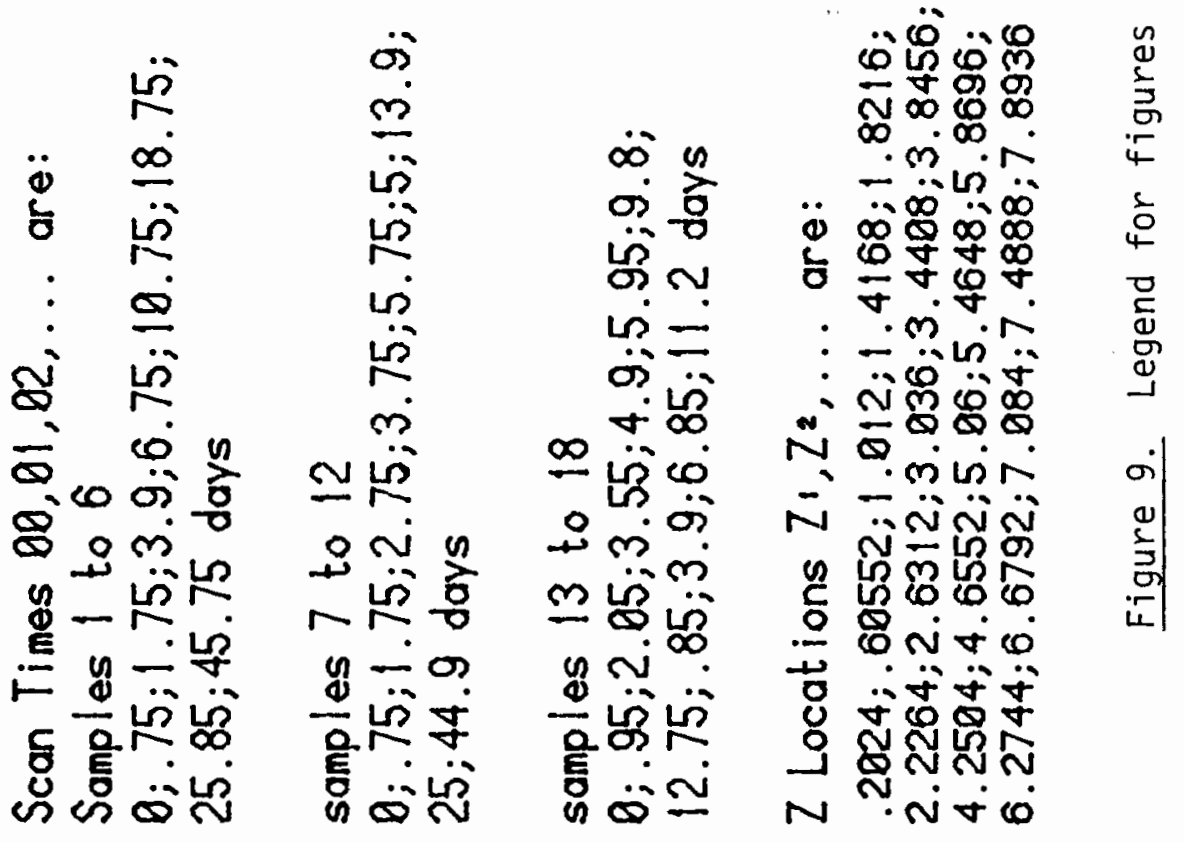




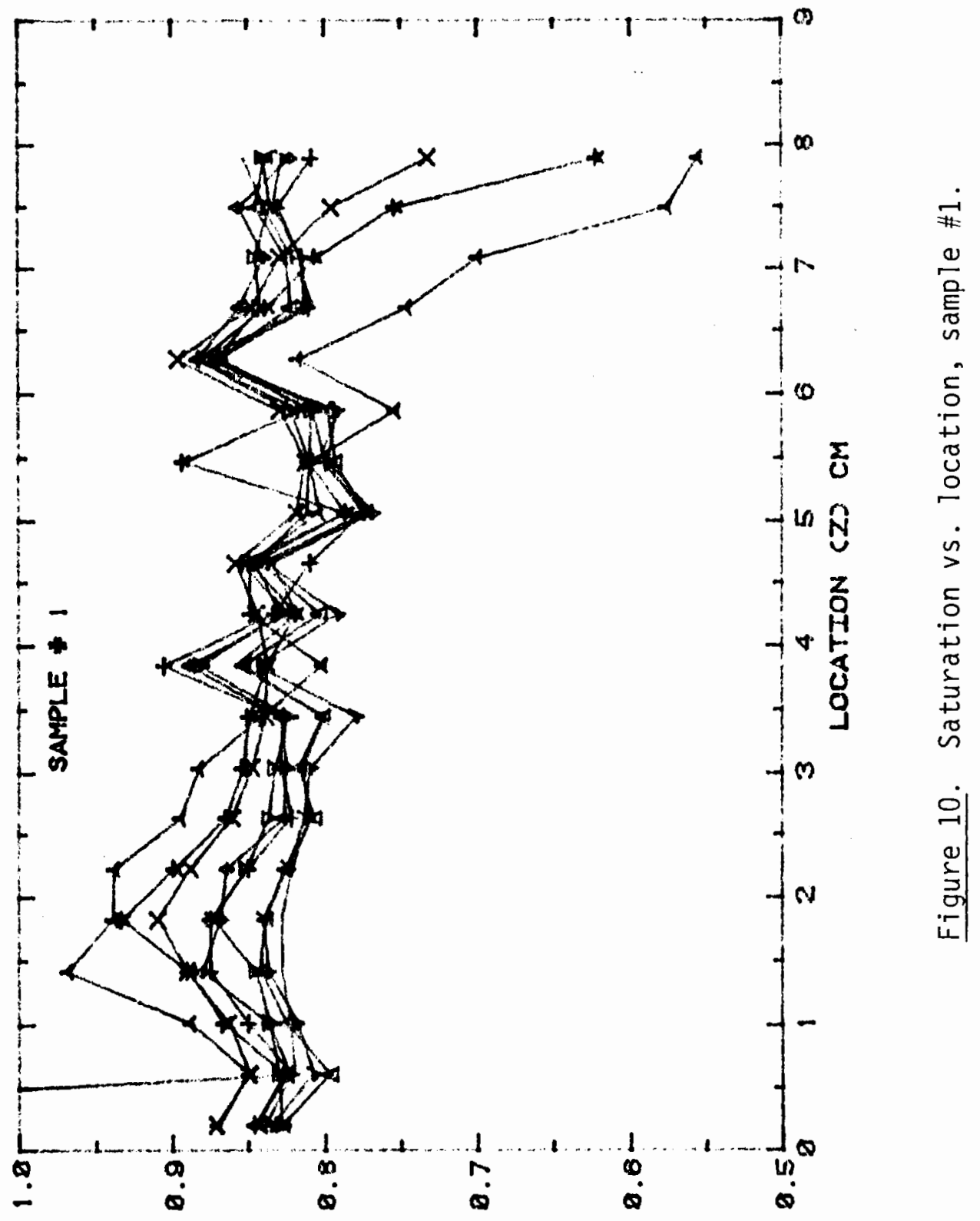

$73 \wedge \exists 7$ NaIL $\forall y n \perp \forall S$ 


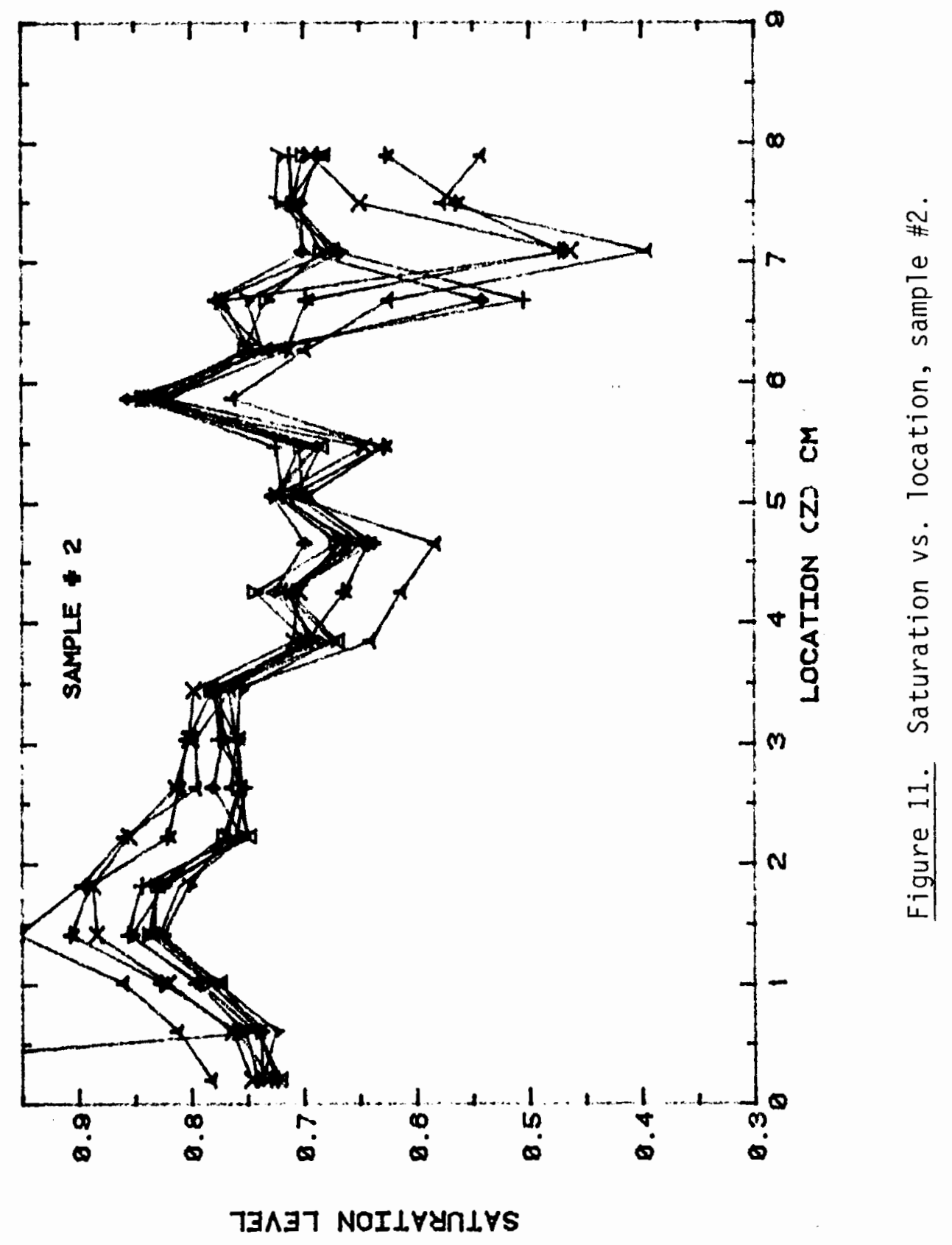




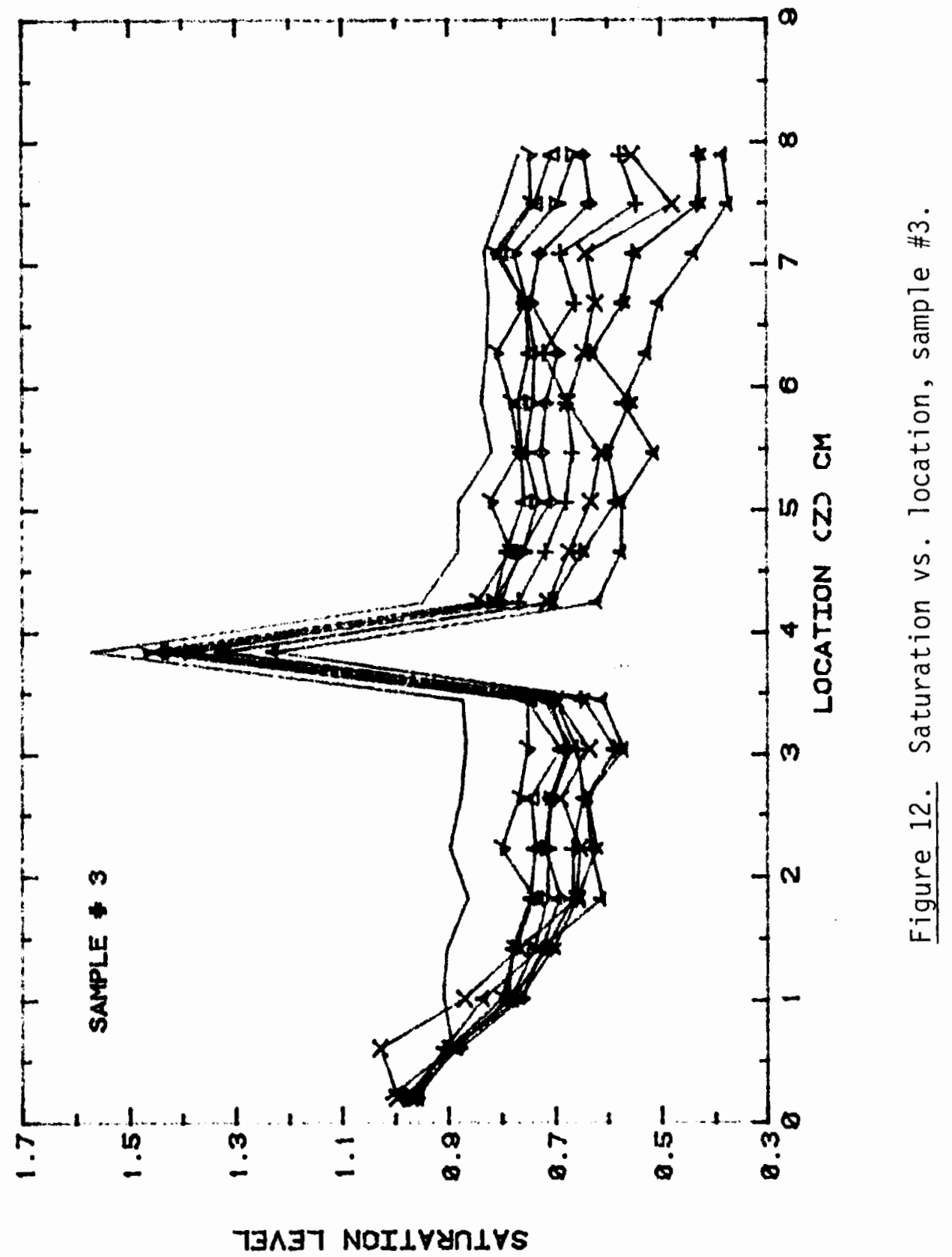




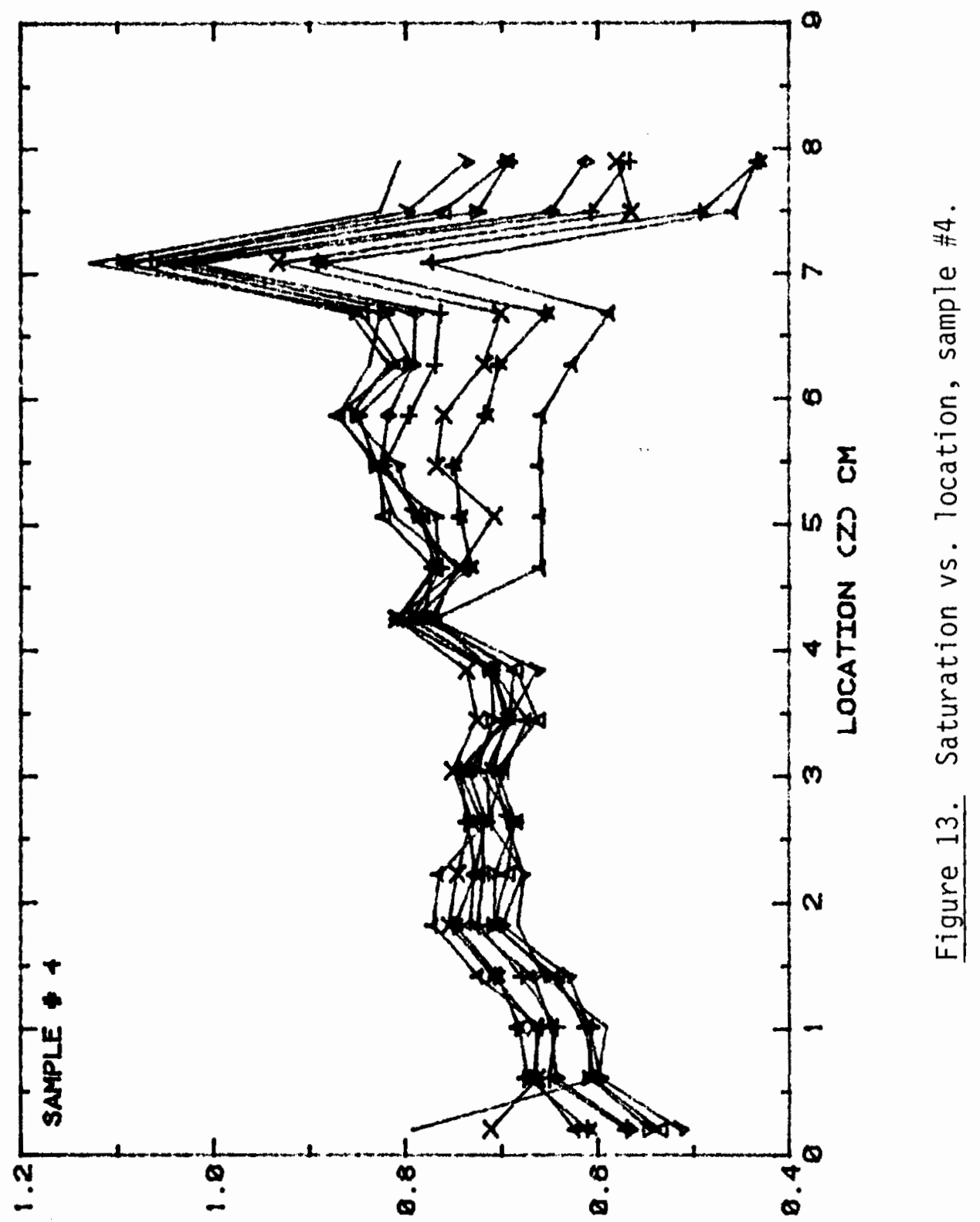

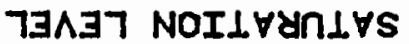




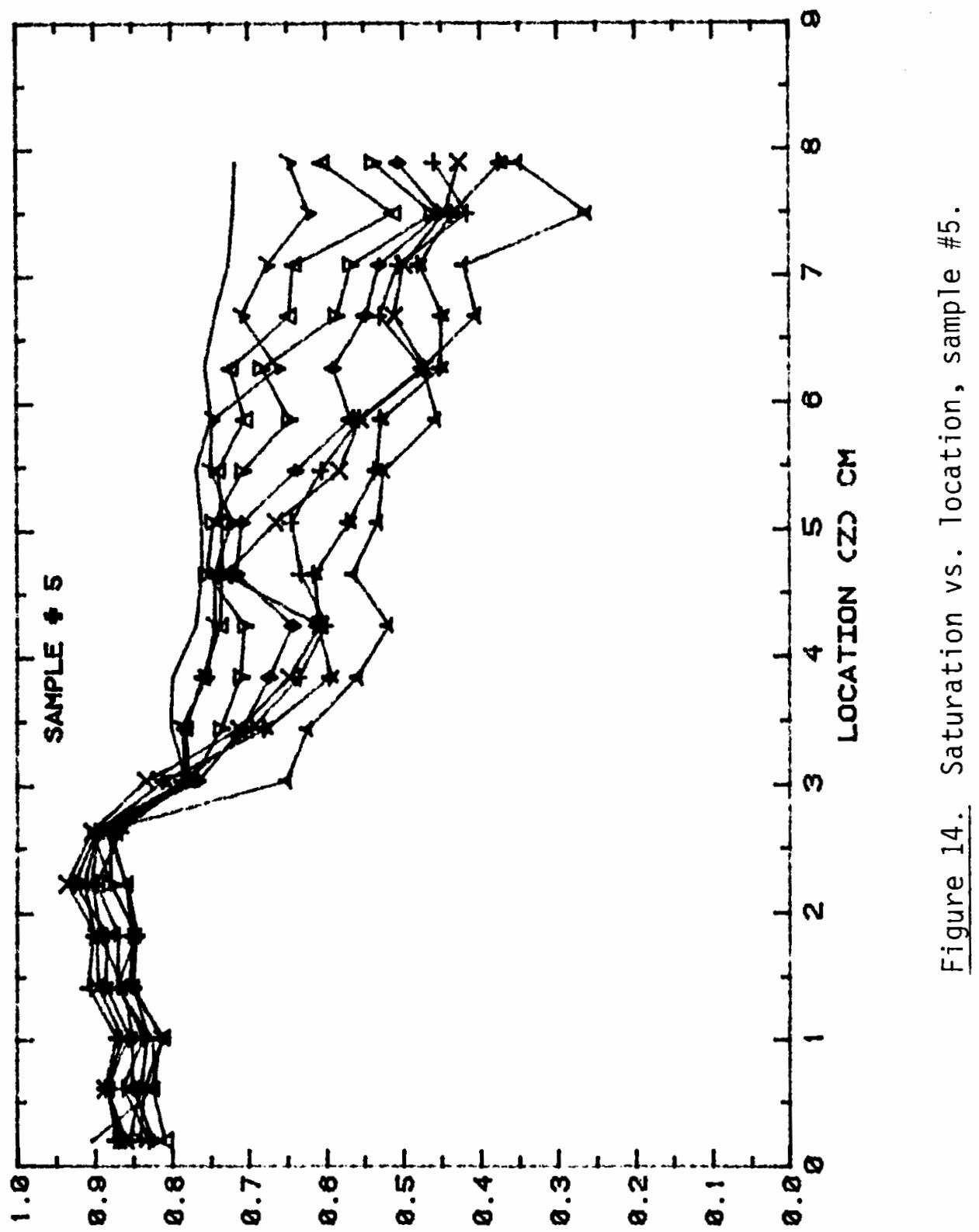

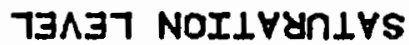




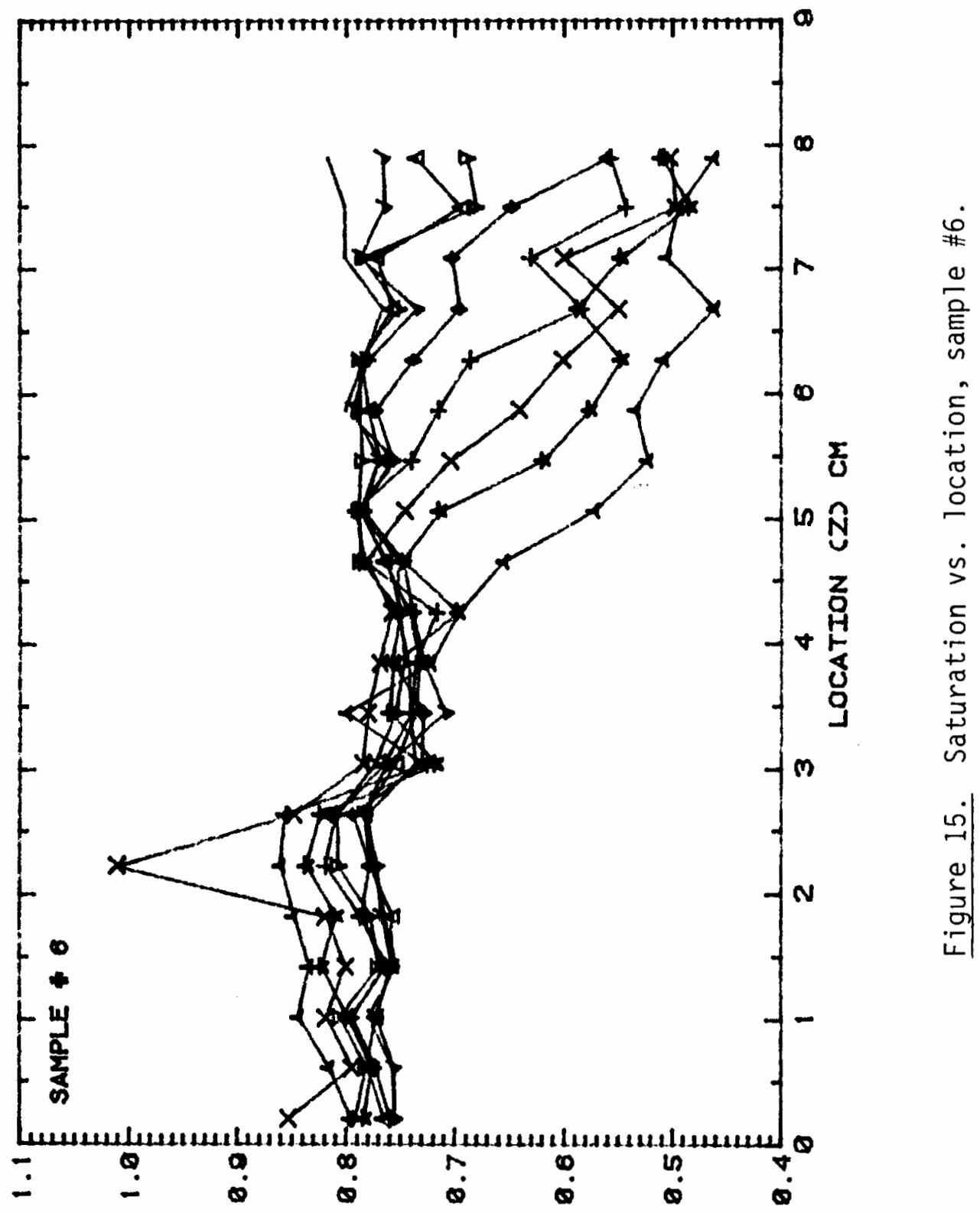

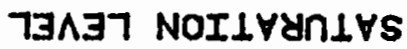




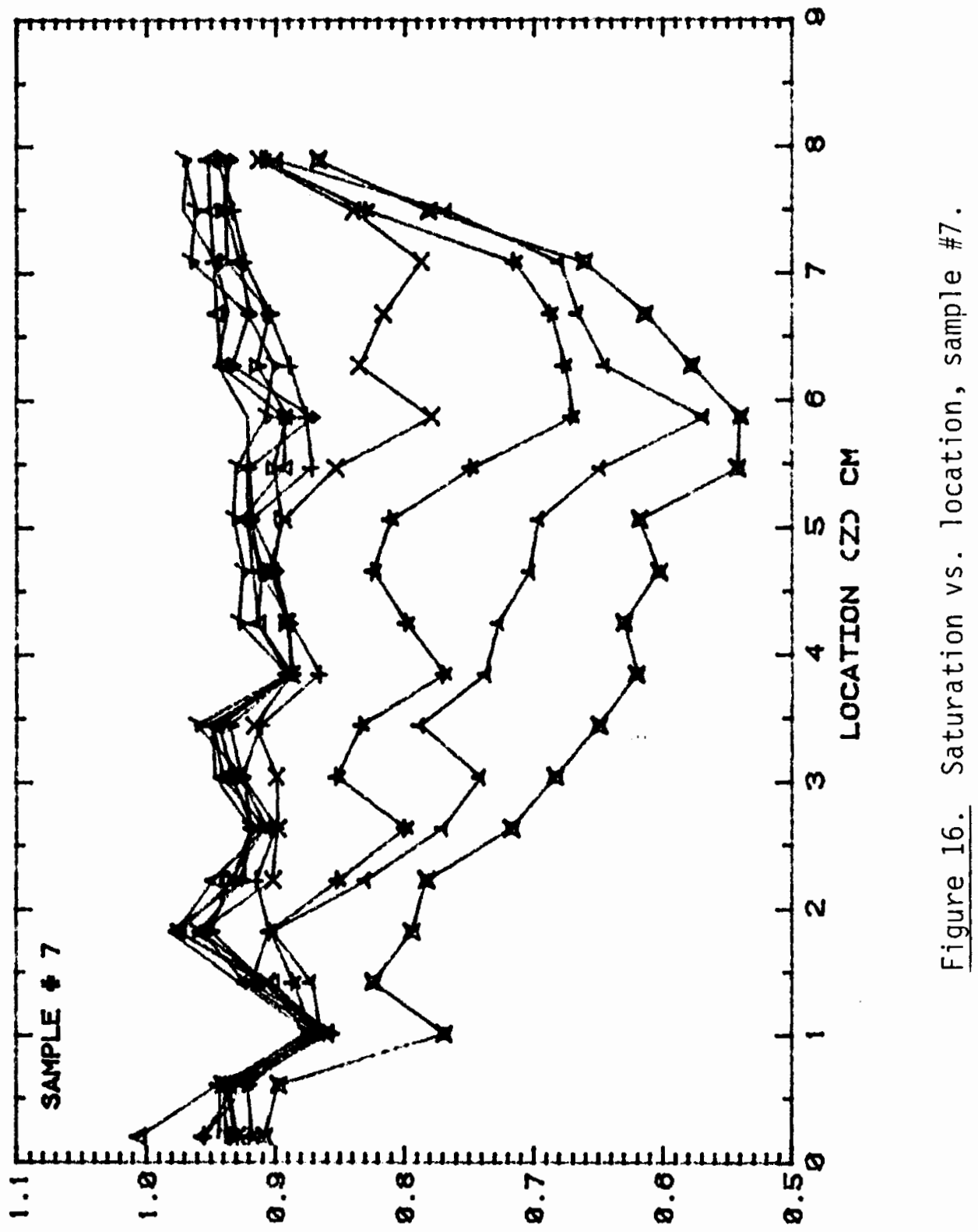

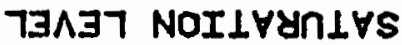




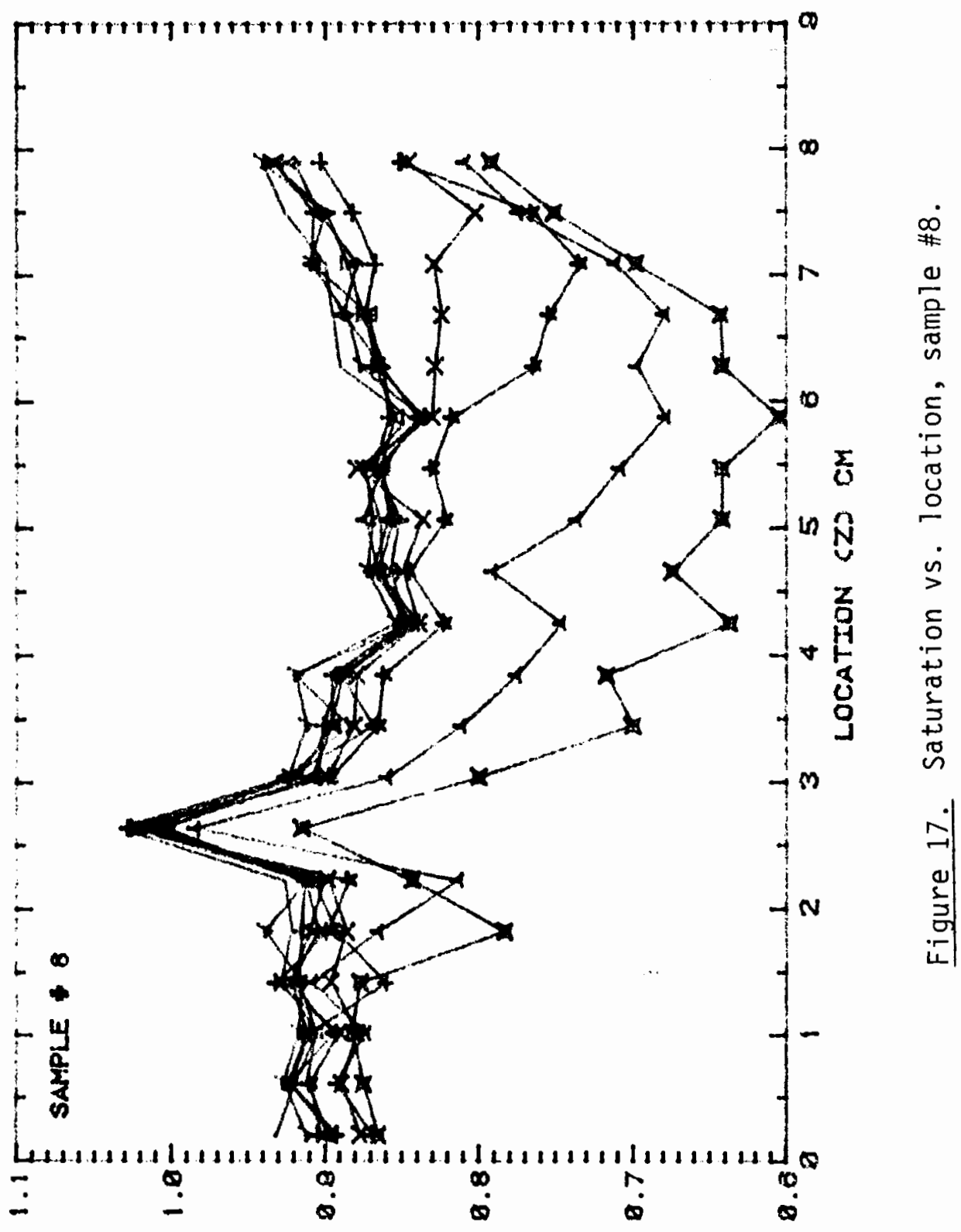

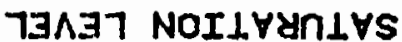




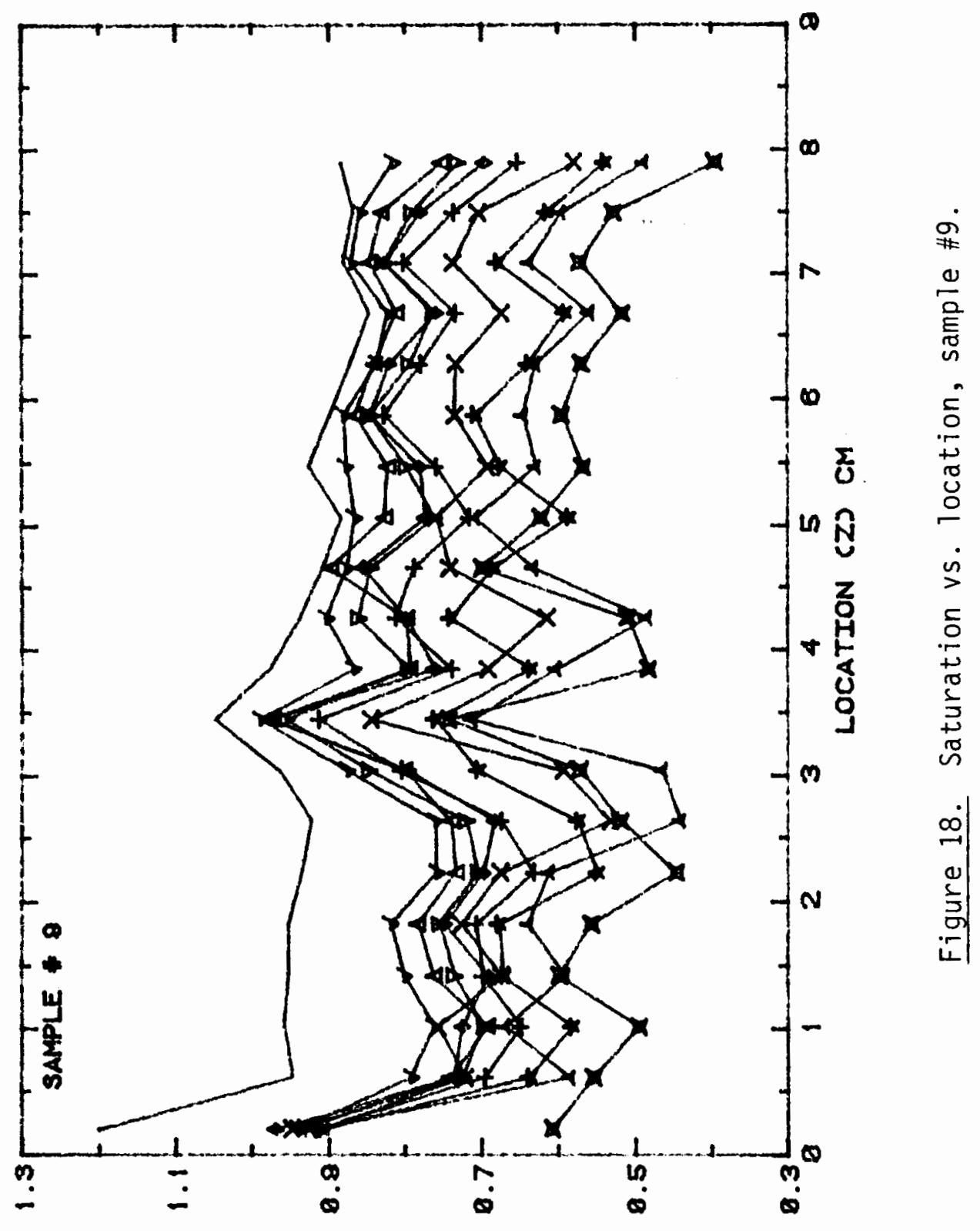

$73 \wedge 37$ NOILVYnLVS 


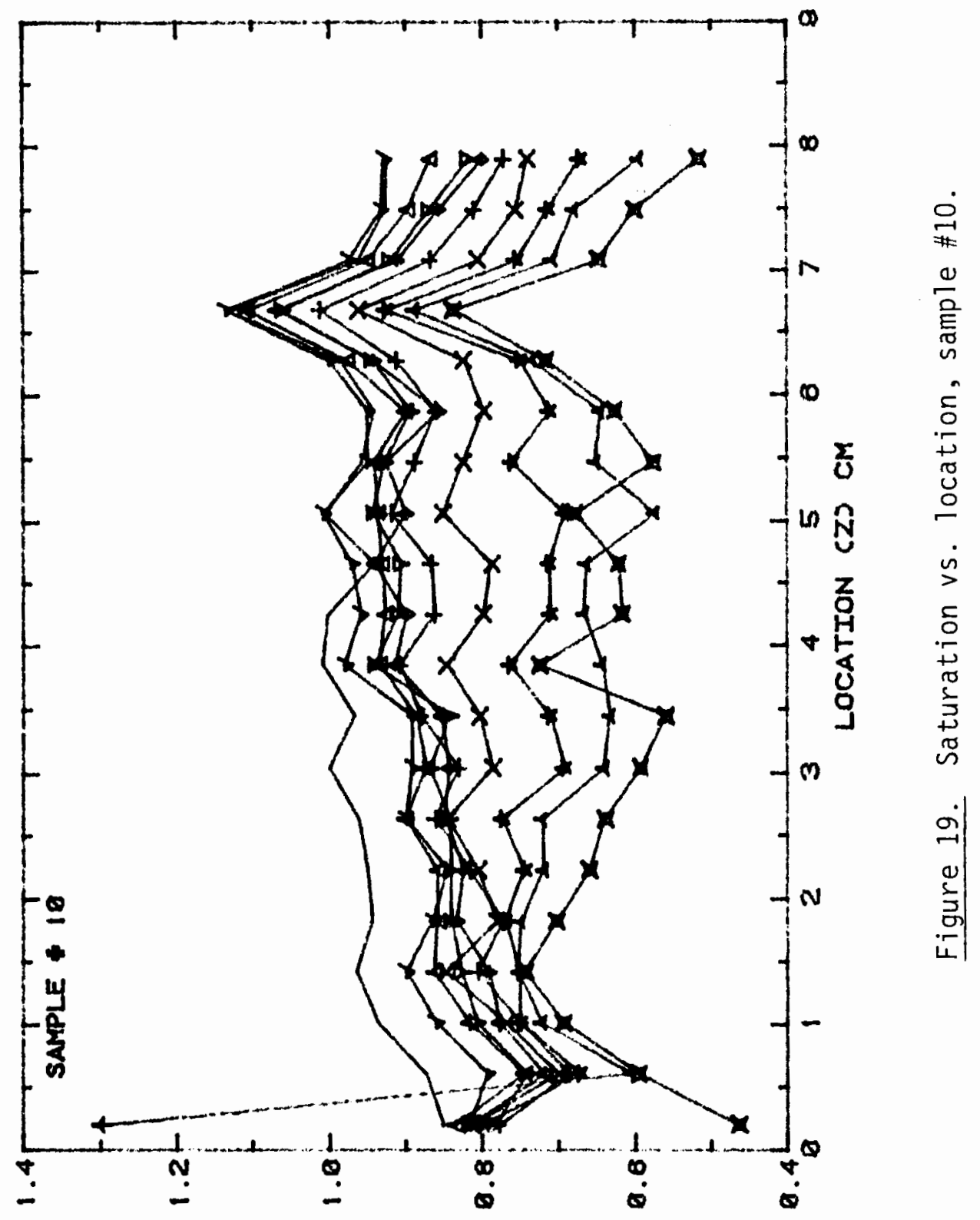

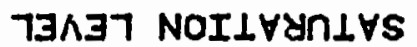




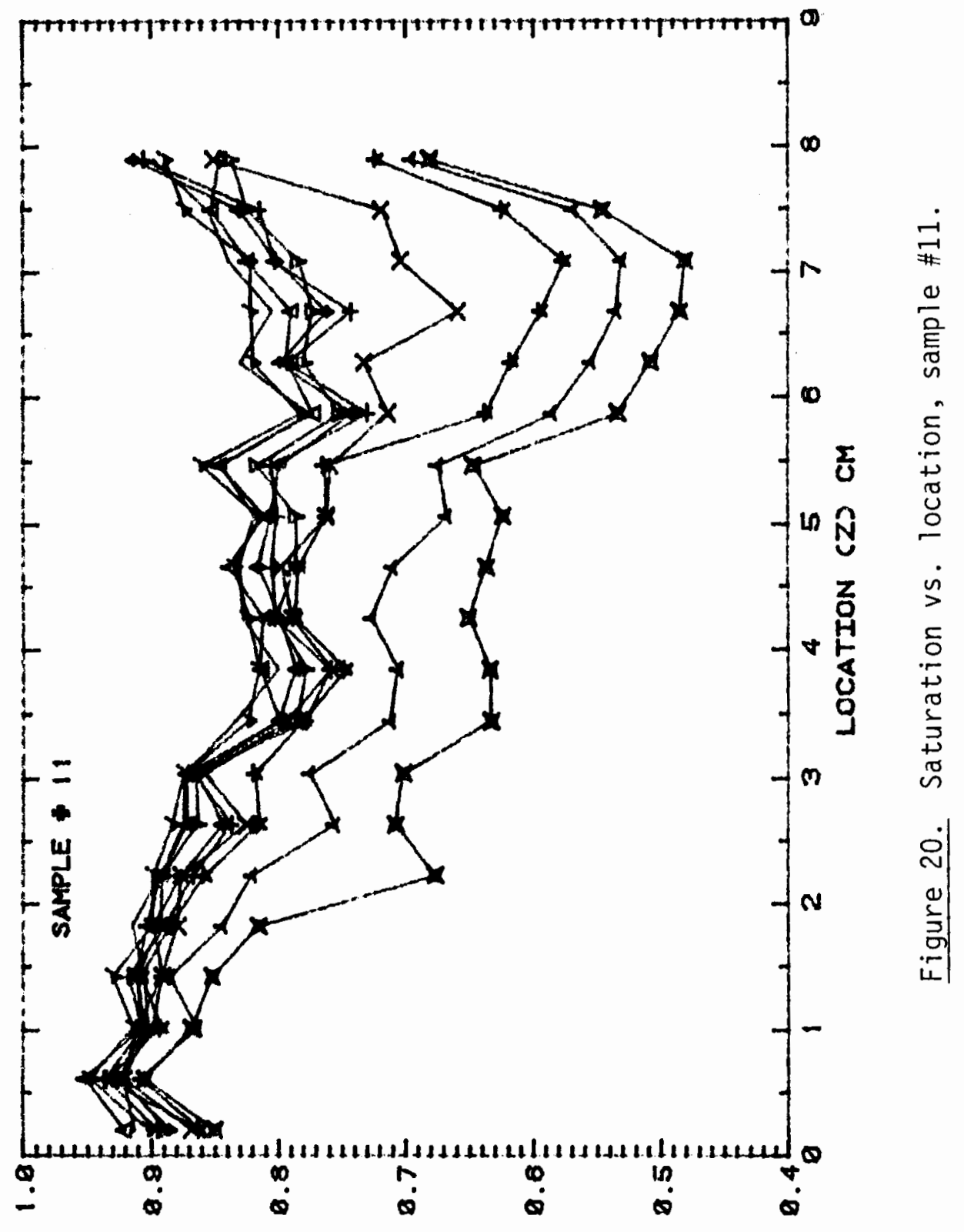

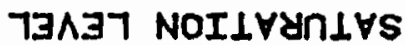




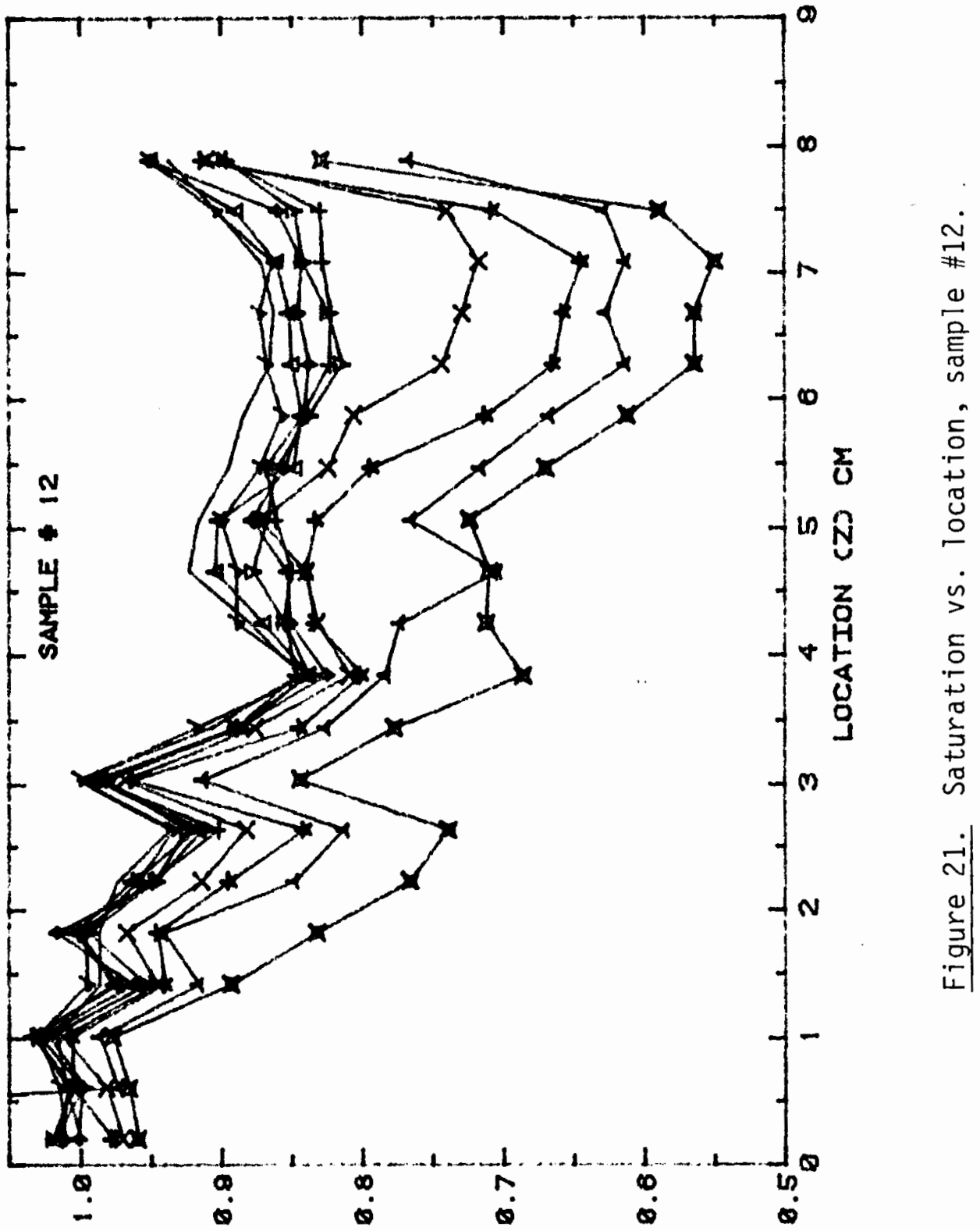

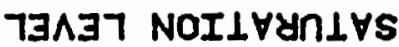




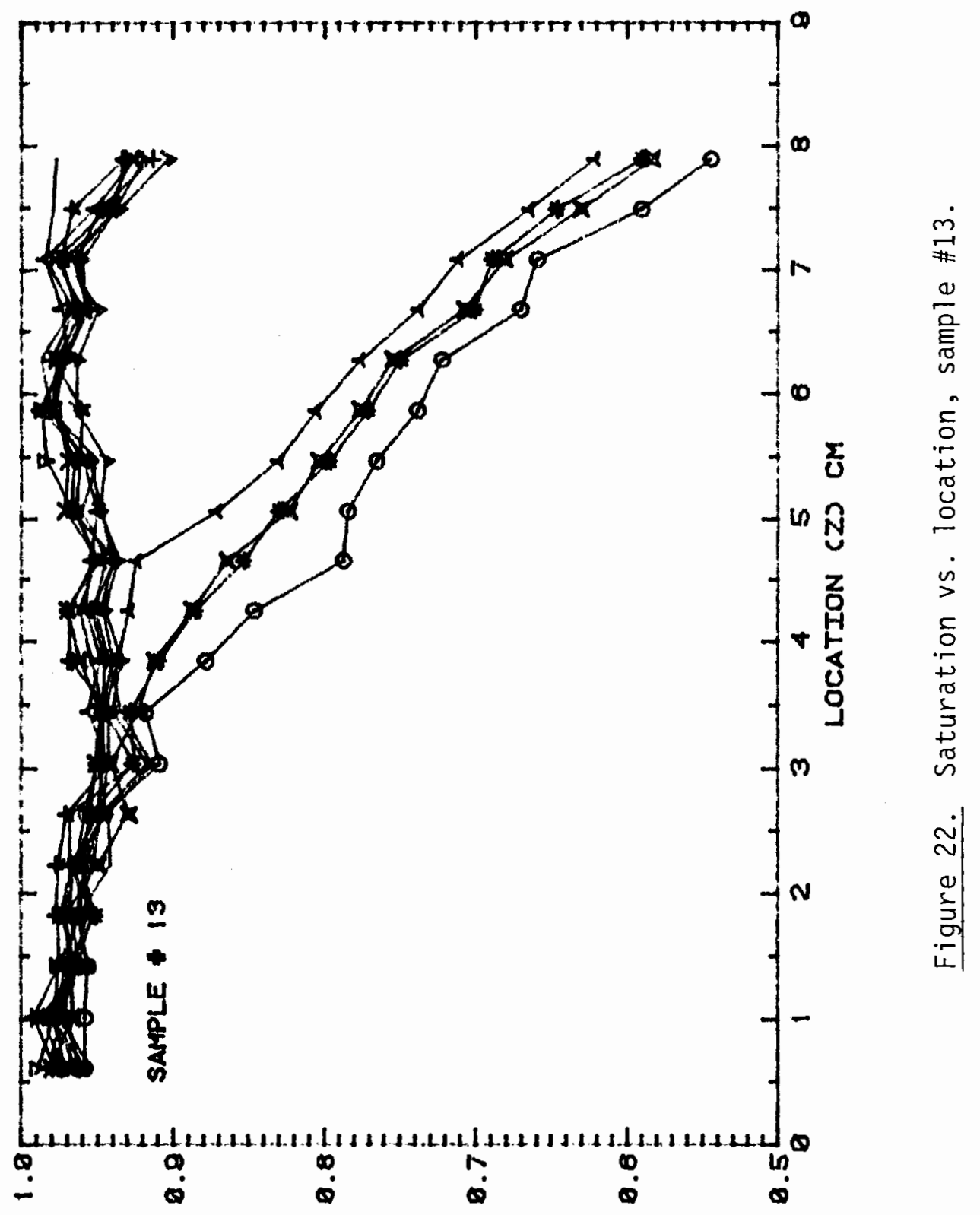

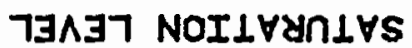




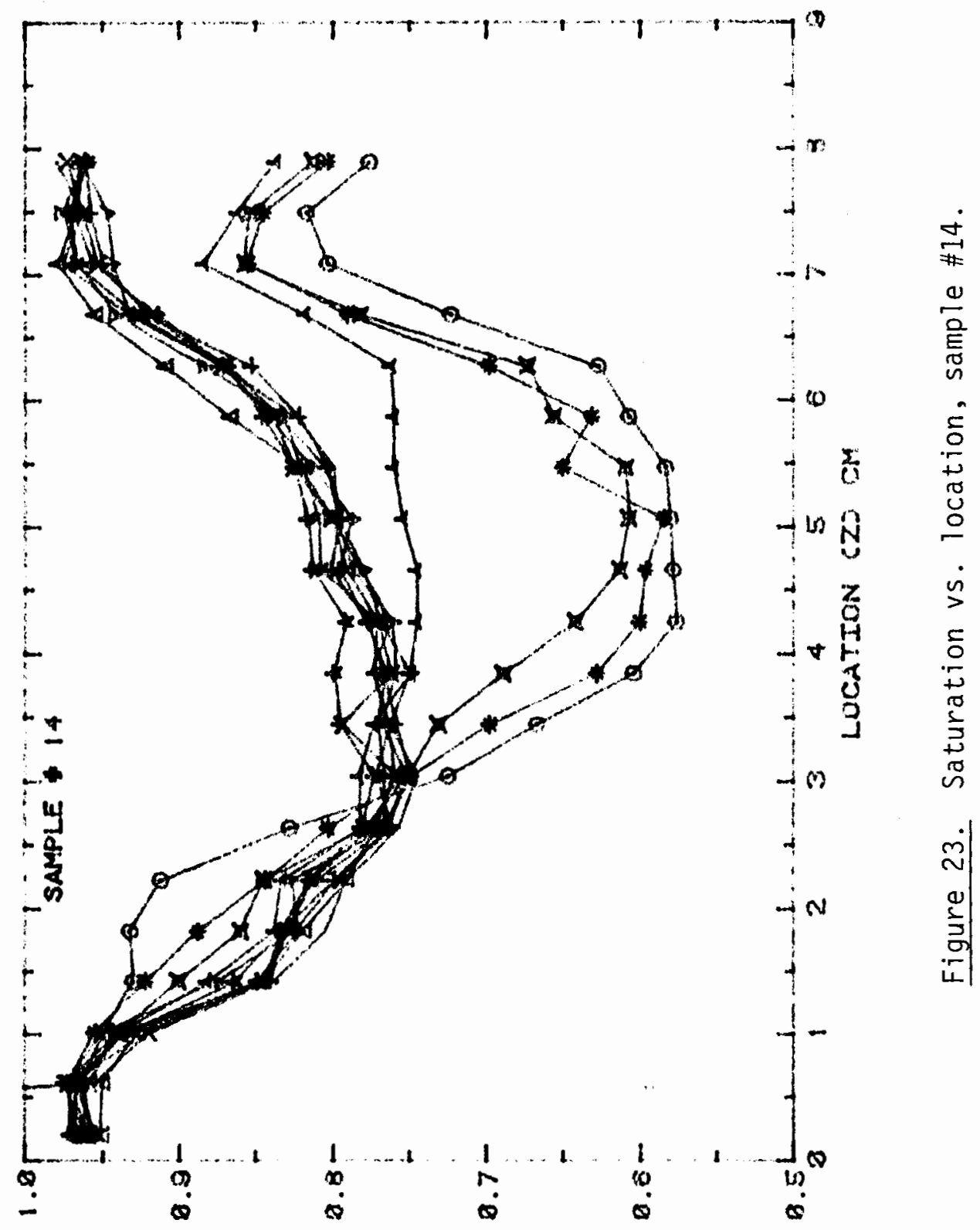

73八37 NOILYUกLYS 


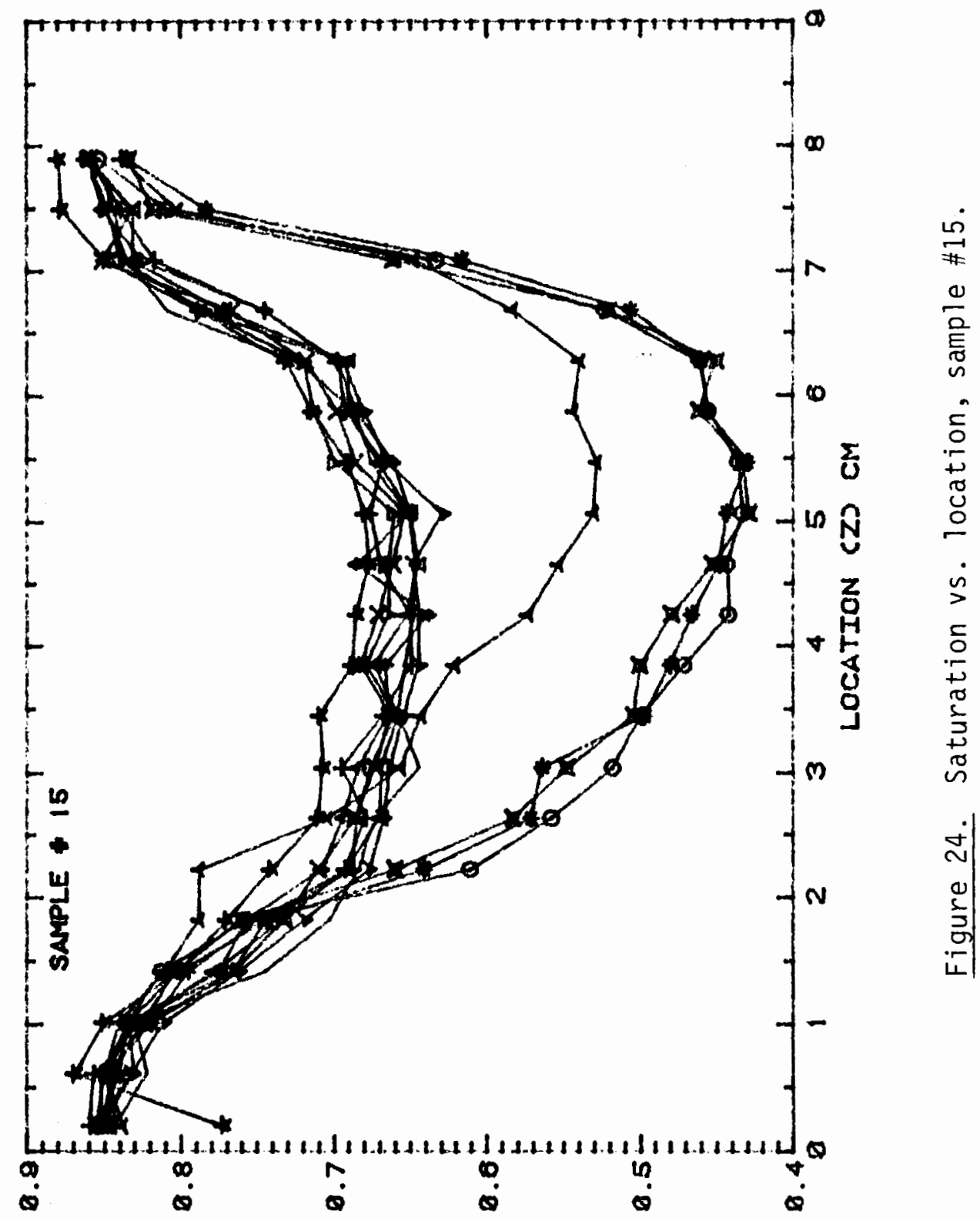

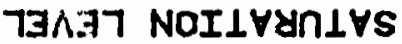




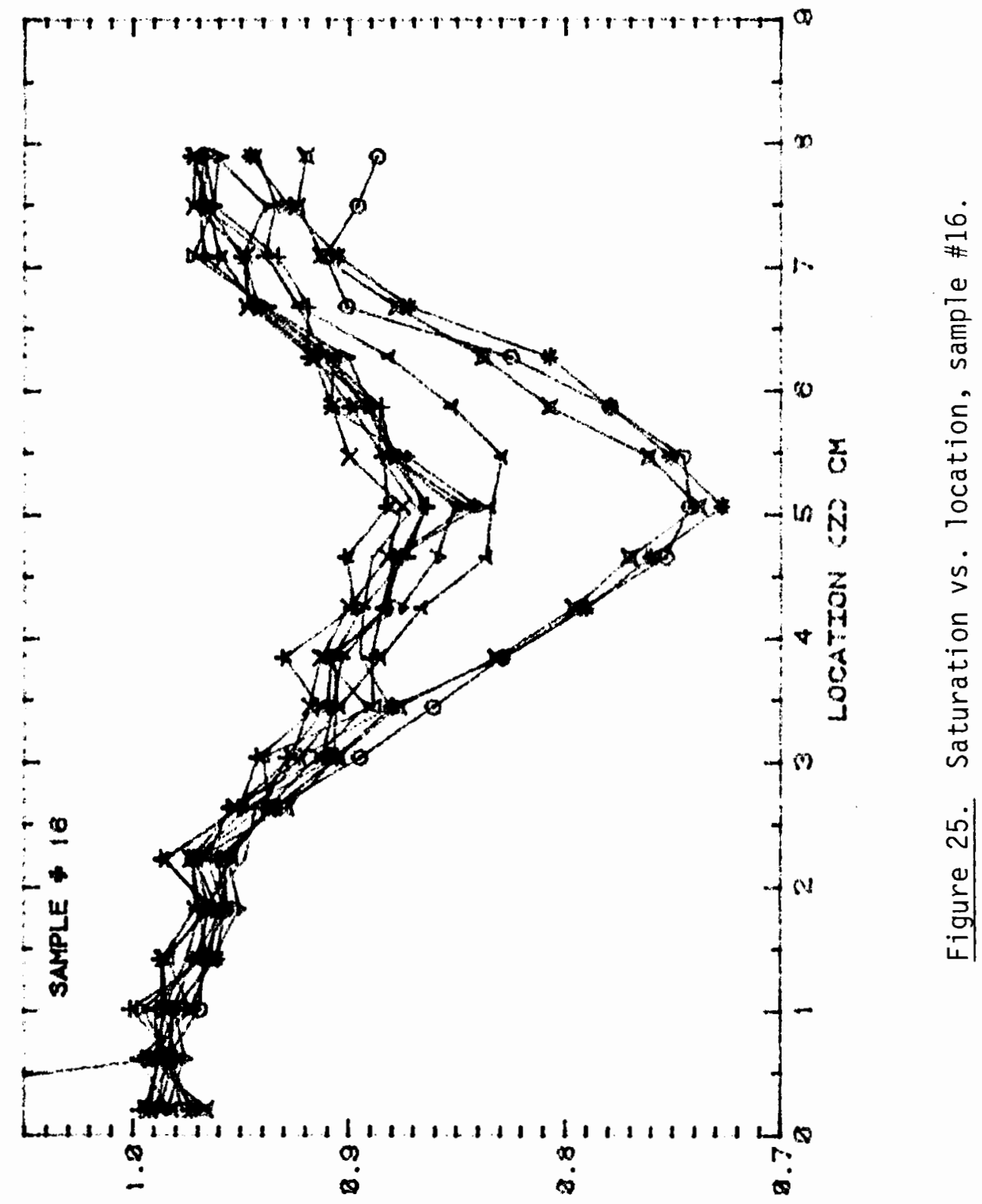

$7 \exists \wedge \exists 7$ NoILYYกLY 


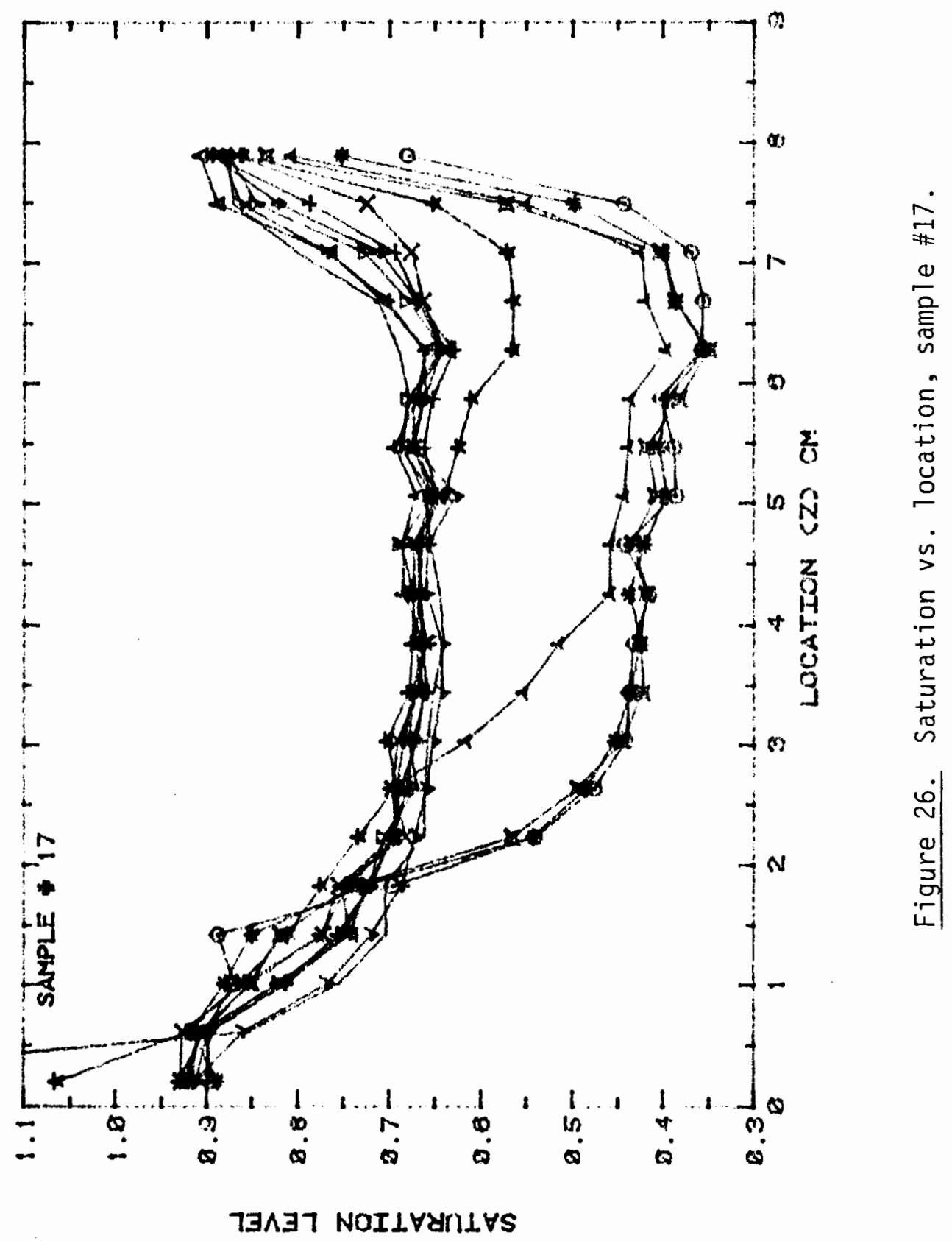




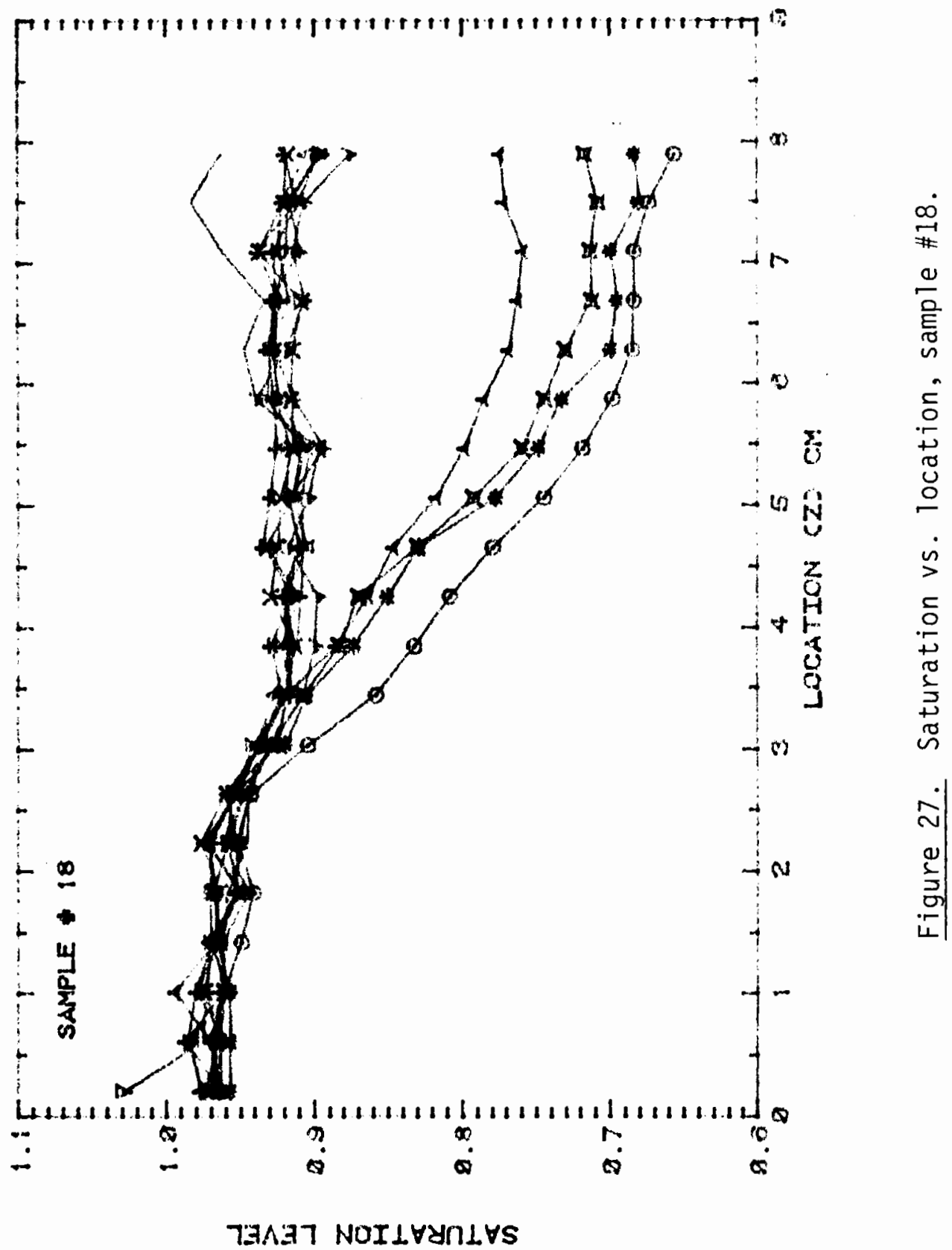


are biological variations within wood in terms of local wood density,

cell structure and cell orientation. Beside these inherent

inhomogeneities, cracks develop in wood due to drying. In calculating local moisture content and consequently the saturation levels dry wood gamma radiation scans were used (refer to appendix F, Sample Data Reduction). Wherever a scan is done through a crack (due to increase of gamma counts) a false higher saturation level is calculated. The bad saturation level data points due to cracks were detected by statistical methods (refer to appendix F) and corrected. However, not much could be done for general inhomogeneous characteristics of the wood sample. To calculate saturation levels, local wood density and fiber saturation point (FSP) were required. The author had to assume an overall uniform density and FSP (appendix F) and accept the resulting saturation fluctuations. Since the solution of equation (27) requires the gradient of saturation profile, a least square curve fit was used to smooth out local fluctuations in order to avoid differentiation of actual data. Since a trend of descending saturation levels from $Z=0 \mathrm{~cm}$ to $Z=L$ was expected a power equation curve fit was used (Figures 28 and 29). With each curve fit the corresponding correlation coefficient was also calculated as a measure of its goodness of fit. In most cases curve fits showed to be very good representatives of actual data. Nevertheless, one should bear in mind that curve fits do not alter the actual fluctuating nature of data, which is of concern.

Figures 30 and 31 represent typical functional dependence of capillary pressure on saturation. Experimental results presented in these figures indicate this dependence as expected (Spolek, 1981b; Collins, 1961), with increasing capillary pressure as the saturation 


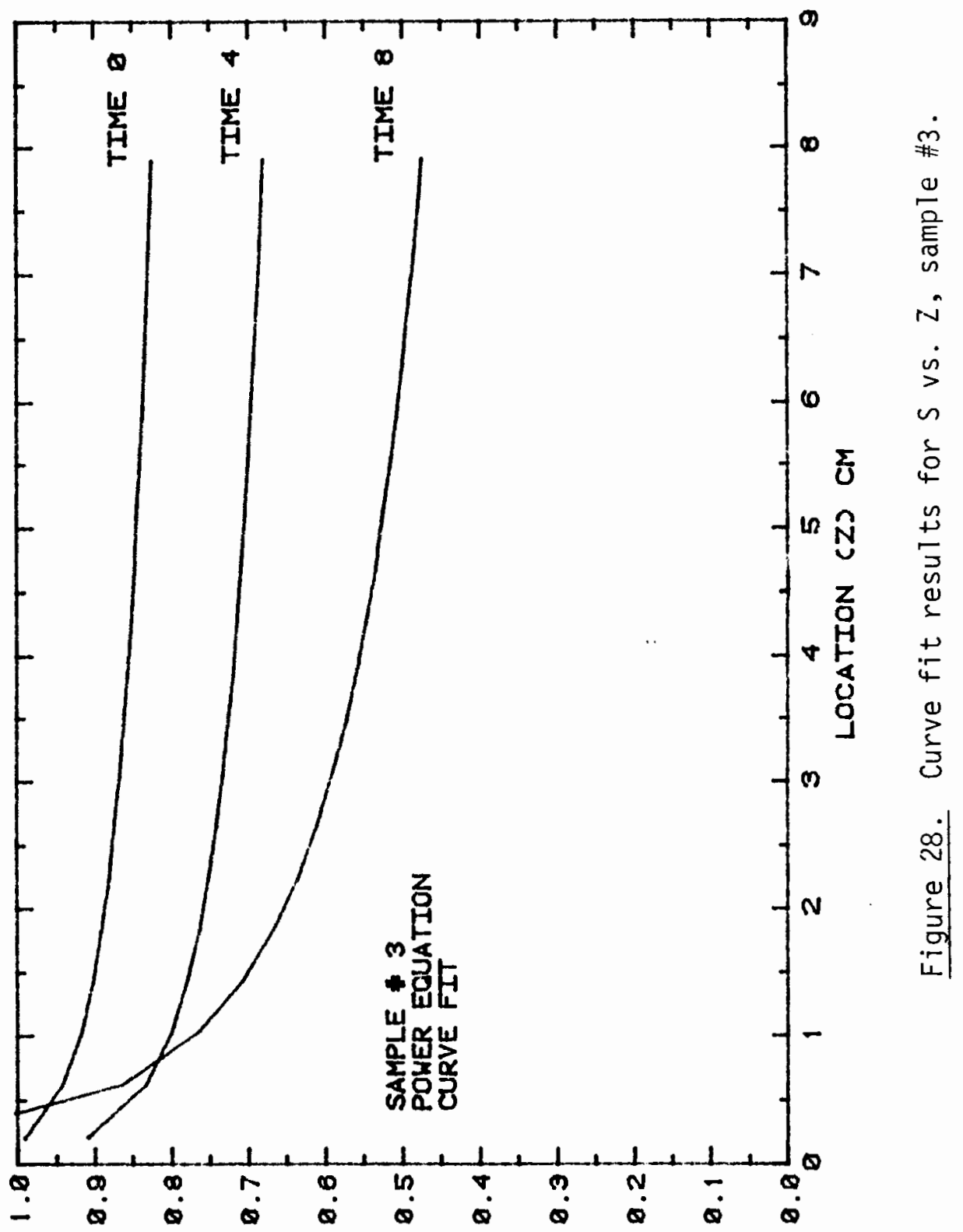

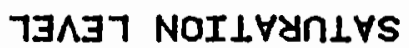




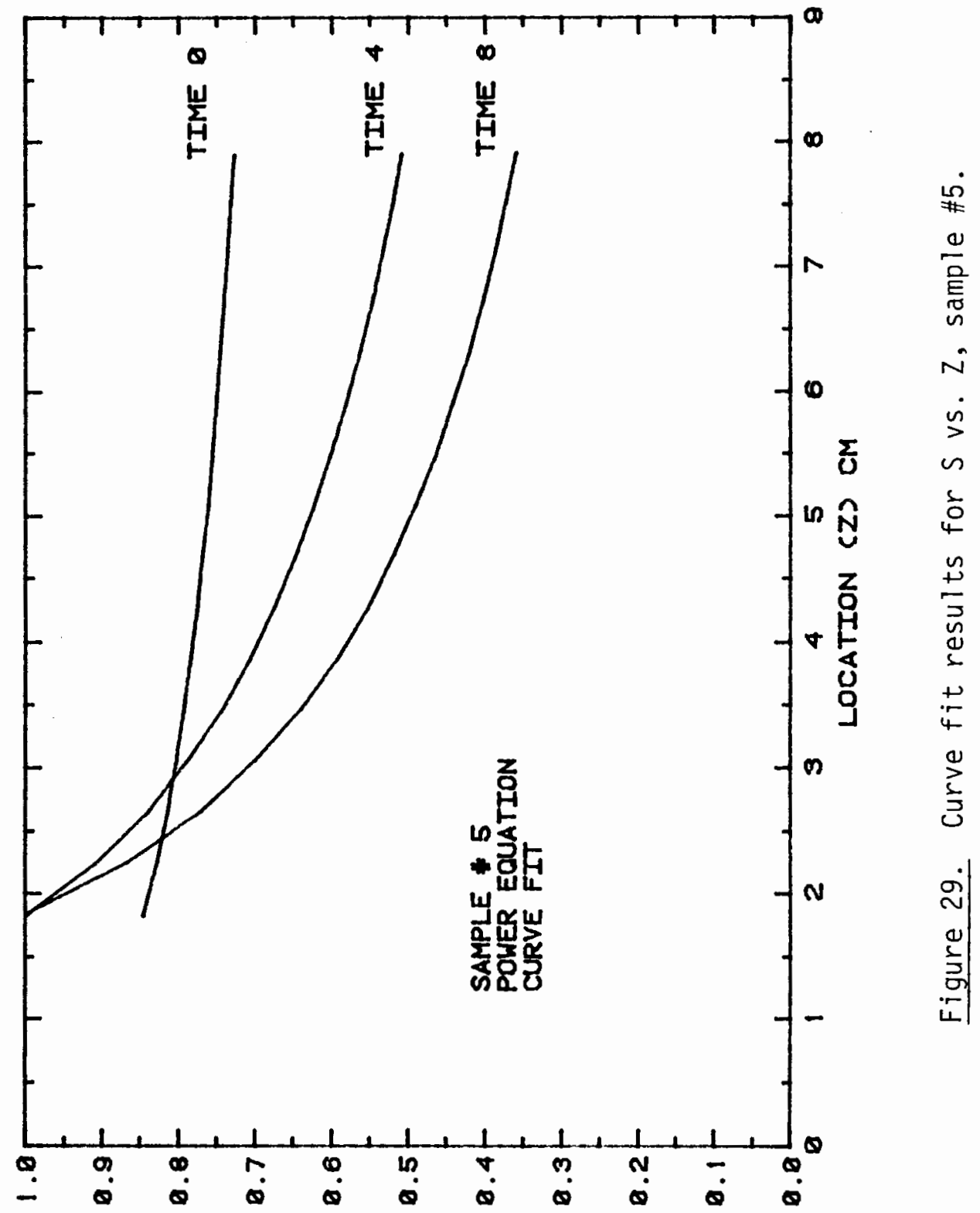

ᄀ 


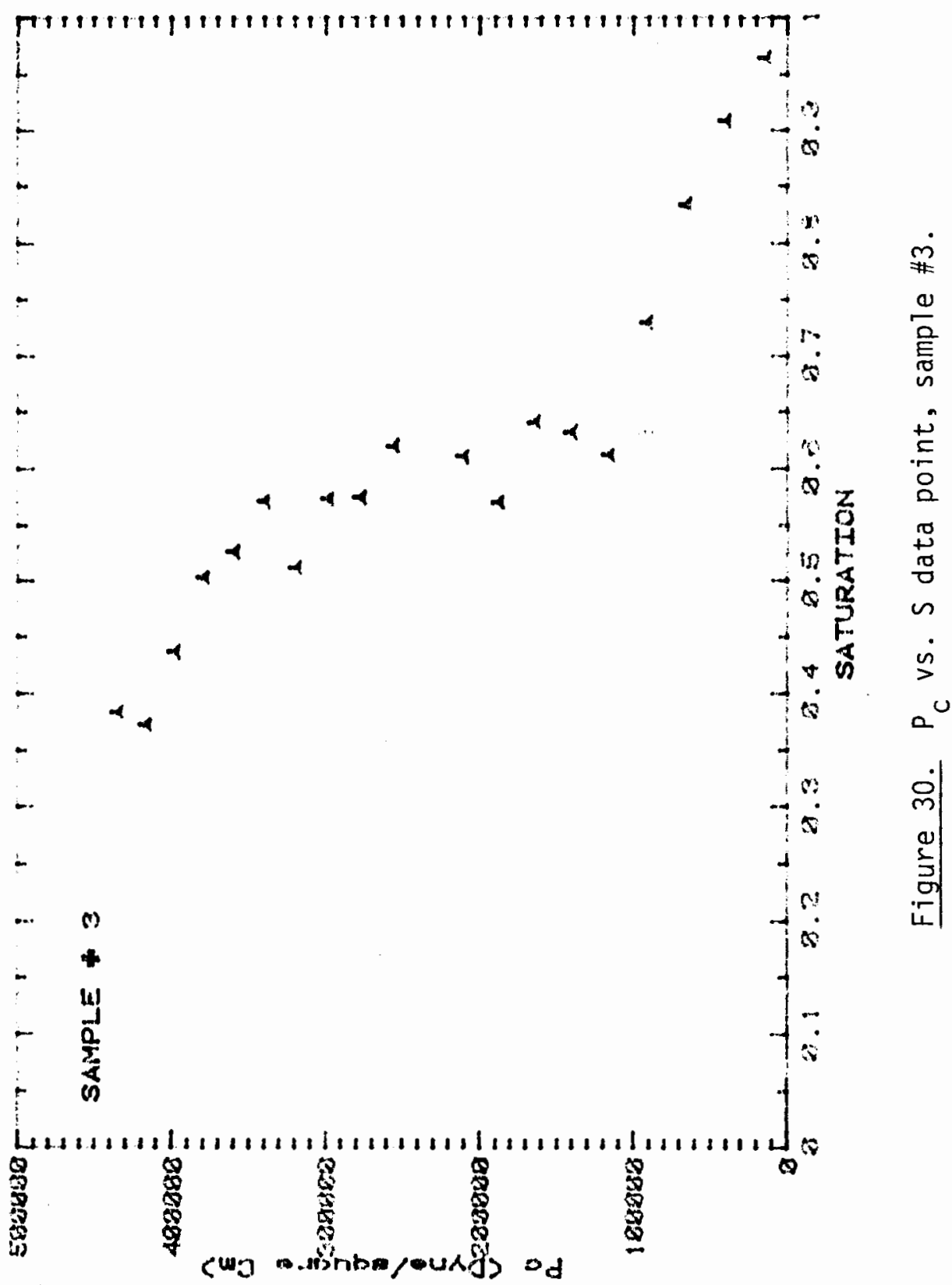




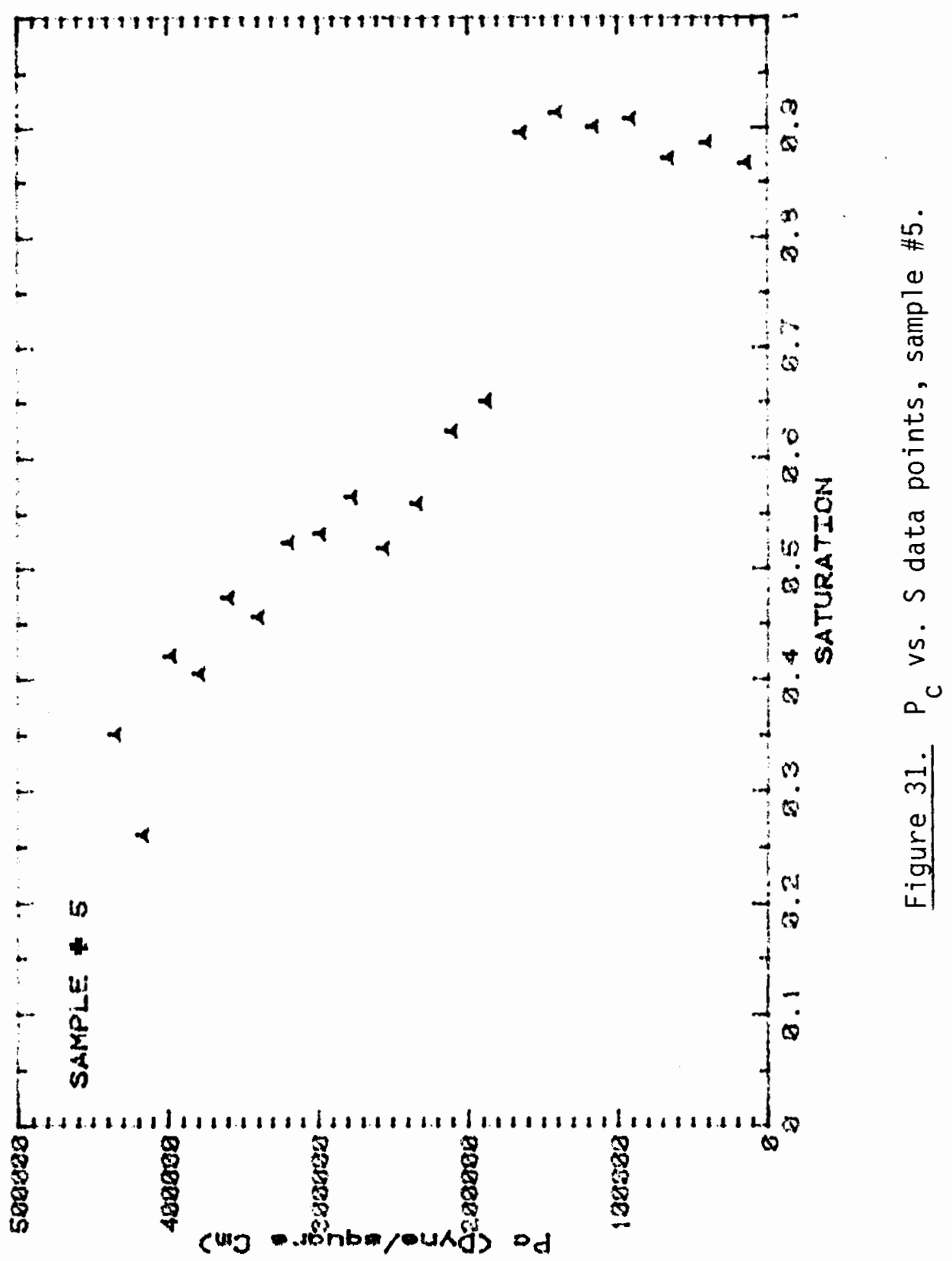


decreases. Since the gradient of this curve (capillary pressure versus saturation) is also needed for solution of equation (27), a least square curve fit was used to fit a power equation onto the data points. Again the power equation curve fit was used to ensure that the curves had a negative slope all through the desired range to meet the expected trend of increasing capillary pressure with reducing saturation level. For the data points the capillary pressures (refer to appendix $F$ for calculation) were plotted against the final saturation profile for each sample. Figure 32 and 33 represent typical curve fit results.

For all curve fits, $S$ vs. $Z$ and $P_{C}$ vs. $S$, two major criteria were considered. First, the data points which corresponded to crack locations on wood samples were not used (these points were statistically singled out, refer to appendix F). In addition to elimination of "crack" data points some other data points (very few, 12 points out of a total of 3720 points) that seemed to be bad data points caused by bad wet wood gamma radiation scans were corrected. For a list of eliminated and corrected data points reader is referred to appendix $F$. The other criterion was selecting a range for the data points used in curve fits for different samples. Initially, saturation versus location curves were observed; based on that, suitable ranges of location within which the corresponding section of curves indicated a "power equation curve" trend were picked for each sample. Next, the plots of capillary pressure versus saturation were studied for each sample; if they showed the same "power equation curve" trend with in the selected $r$ ange then the range was used for curve fits, otherwise the data range was corrected to get the proper trend for the $P_{C}$ vs. S curve. Table I summarizes the location ranges used for each sample. Note that each sample is divided 


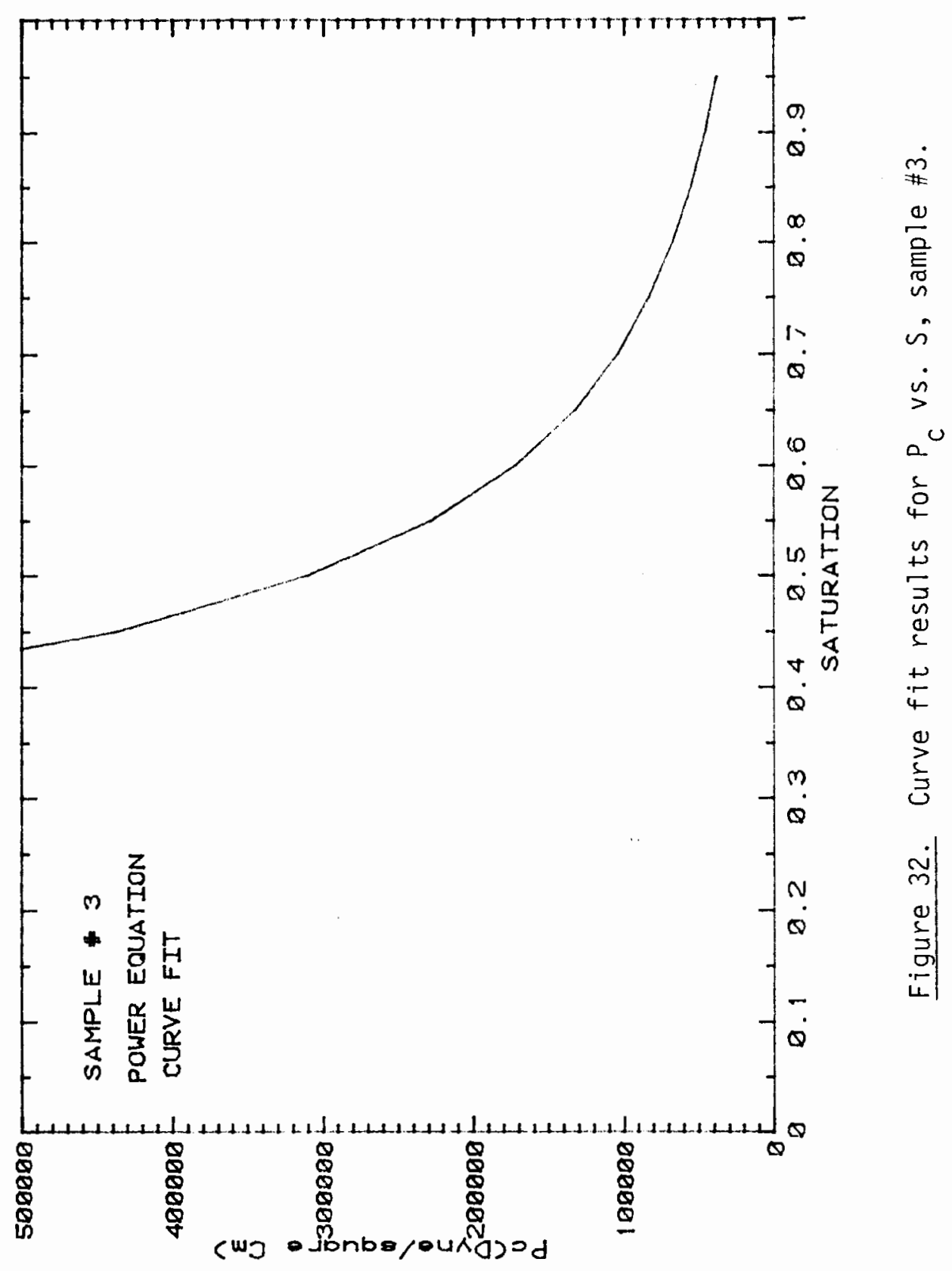




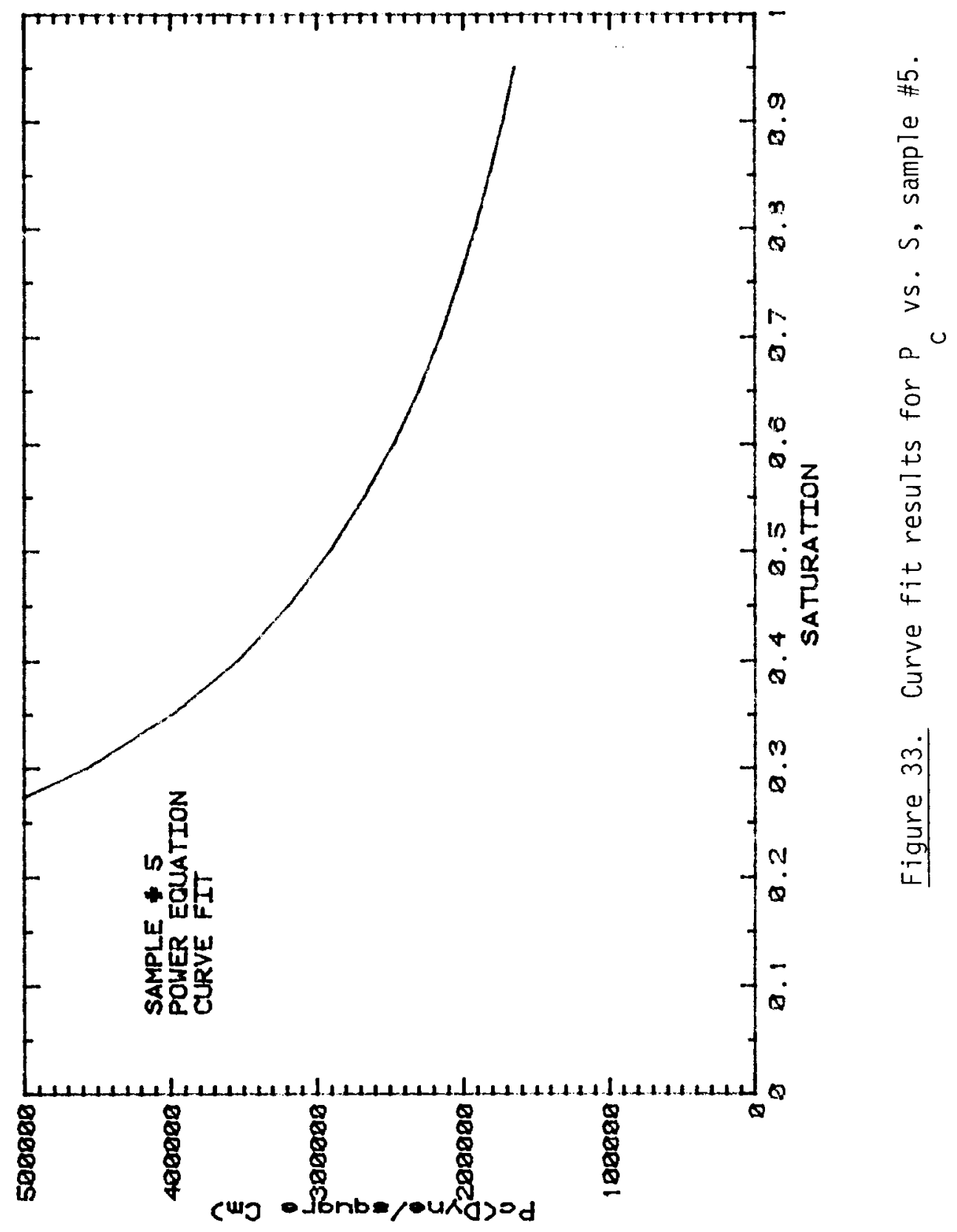


into $20 \mathrm{scan}$ locations $Z_{0}$ to $Z_{20}$ where $Z_{0}$ is at $0.2024 \mathrm{~cm}$ and location intervals are $\Delta Z=0.4048 \mathrm{~cm}$.

Table II

RANGE OF LOCATION $z_{j}$ FOR CURVE FITS

\begin{tabular}{|c|c||c|c||c|c||c|c|}
\hline Sample \# & Range of i & $\#$ & Range of i & $\#$ & Range of i & $\#$ & Range of i \\
\hline 1 & $4-20$ & 6 & $7-20$ & 11 & $2-18$ & 16 & $5-13$ \\
2 & $4-18$ & 7 & $4-15$ & 12 & $3-18$ & 17 & $4-16$ \\
3 & $1-20$ & 8 & $6-15$ & 13 & $7-20$ & 18 & $7-20$ \\
4 & $11-20$ & 9 & $1-20$ & 14 & $7-13$ & & \\
5 & $7-19$ & 10 & $4-20$ & 15 & $5-14$ & & \\
\hline
\end{tabular}

Equation (27) results in permeability at the local saturation a distance $L$ from the base of the specimen. At different runs as centrifuge times increase and $(L)$ location saturation $S(L)$ changes, the permeability subsequently changes. Considering the form of equation (27) one expects that by reducing the upper range location ( $L$ ) in calculations the results yield new permeability values at new saturation levels, thus increasing the number of data points representing permeability as a function of saturation. However, as it will be discussed later, through reducing the upper range location $(L)$ higher saturations $S(L)$ resulted but computed $k(S(L))$ permeabilities indicated a decreasing trend which is contrary to the general phenomenon that higher saturation level in a porous media will cause higher permeability properties. This behavior in calculated unsaturated permeabilities is due to sensitivity of the equation (27) to the calculating gradients of saturation and capillary pressure. 
The remaining variables in equation (27) were estimated based on data available in literature (i.e. water viscosity, wood porosity, saturated permeability value). The fully saturated permeability for each wood sample proved to be the most difficult to estimate. Comstock (1970) provides a range of values for saturated permeability of Southern Pine. However, in order to correctly calculate the unsaturated permeability of a wood sample, one needs to know the sample's correct saturated permeability value. Values of $k$ (sat.) in the range provided by Comstock (1970) were used as a parameter. The unsaturated permeability results calculated with the $k$ (sat.) range provided by Comstock (1970) showed a functional dependence on $k$ (sat.) for tangential permeability, however such dependence was not shown in the case of longitudinal permeability.

Results of two other studies (Tesoro, 1974; Spolek, 1981b) which provide values for unsaturated permeability are compared with tangential permeability results in this study, Figure 34. Mechanistic model predicted permeability (Spolek, 1981b) is based on mathematical modeling, and experimentally predicted permeability (Tesoro, 1974) is based on two phase fluid flow. It seems that current study results indicate that wood behavior tends to comply with the mechanistic model. Figures 35 to 44 are representative samples of unsaturated permeability results obtained in this study. These figures plot relative permeability values (ratio of unsaturated permeability to saturated permeability) against saturation levels. The acceptable range for both axis are 0 to 1 . Each point on the "k(s)/k(sat.) vs. S" plots refers to an experiment run with a specific $k$ (sat.) value. For example, for the first six samples, since there was eight centrifuge runs (and 


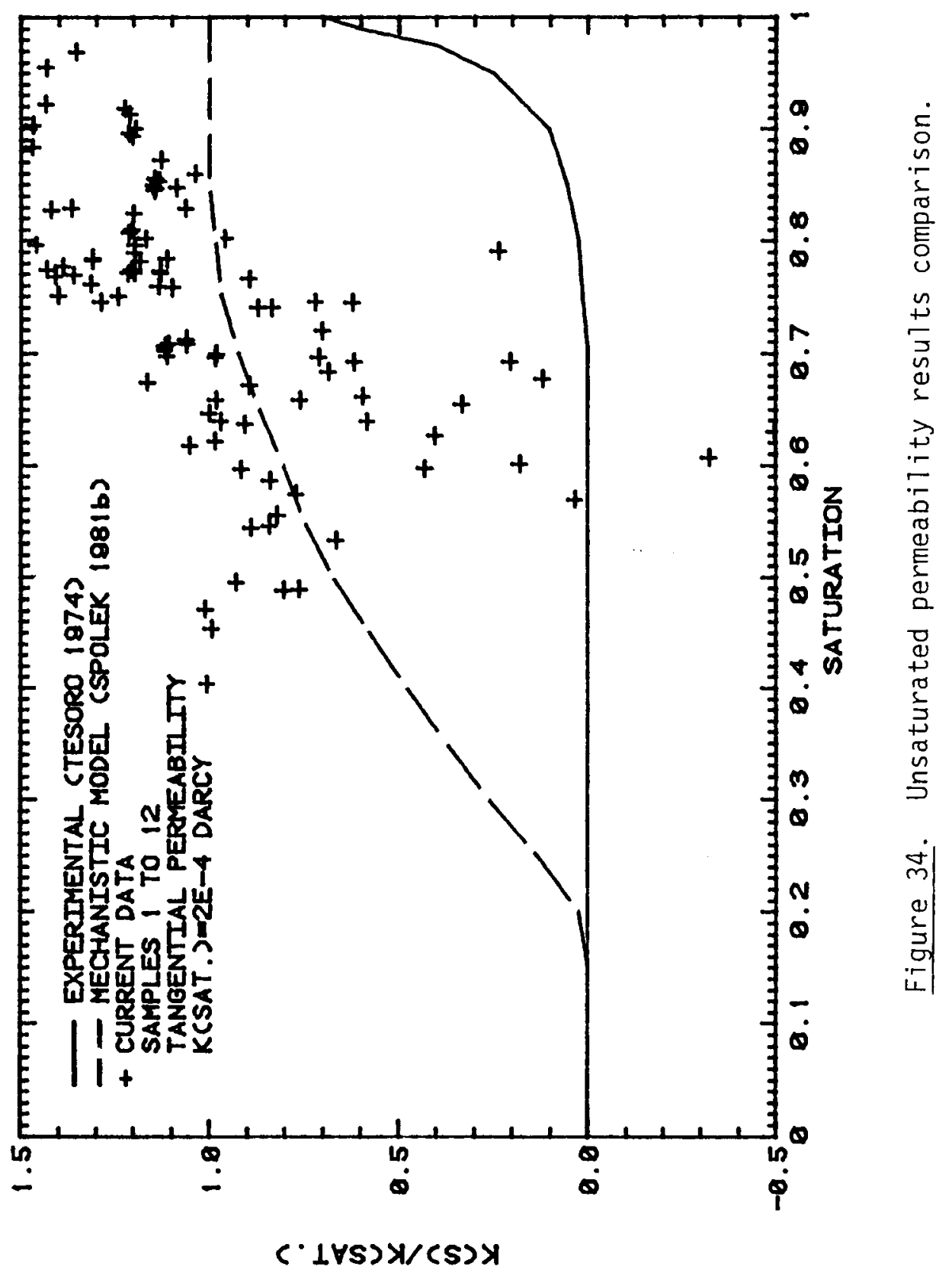


nine gamma scans), the figure for sample 2 (Figure 35 ) has eight data points for each $k$ (sat.) value. The range of $k$ (sat.) used for the plots was based on the range suggested by Comstock (1970). For tangential permeability range is $0.5 \times 10^{-4}$ to $3 \times 10^{-4}$ Darcy, and for longitudinal permeability range is .039 to 2.15 Darcy. As it is indicated on Figures 35 to $44, k(s) / k$ (sat.) values range from -4 to 1.4 for tangential permeability and up to 8 for longitudinal permeability. Whereas as mentioned before, the acceptable range is only 0 to 1 . This is an indication of the sensitivity of equation (27) to the gradients terms that are used to calculate $k(s(L)$. The procedure utilized to measure local time dependent saturation levels of wood samples (gamna radiation densitometer) yields accurate results with less than $5 \%$ relative error (refer to appendix A, Uncertainty Analysis). However, it seems impractical to calculate unsaturated permeability of wood with this method. The uncertainty analysis presented in appendix $A$ indicates that using equation (27) will result in $k(s(L))$ values with about $112 \%$ relative error (with $95 \%$ confidence interval) despite low relative errors in saturation. Because of the inhomogeneous nature of wood, a high degree of fluctuation is observed in measured local, time dependent saturation levels. These fluctuations affect the gradient terms in equation (27) through their corresponding curve fit results. The result of wood inhomogeneity is well observed in the uncertainty results of $k(S(L))$.

Although the calculated unsaturated permeabilities as single data points can not be used to generate any functional dependency of permeability versus saturation, the total results for each wood sample indicates some general trends. It can be seen that for tangential 


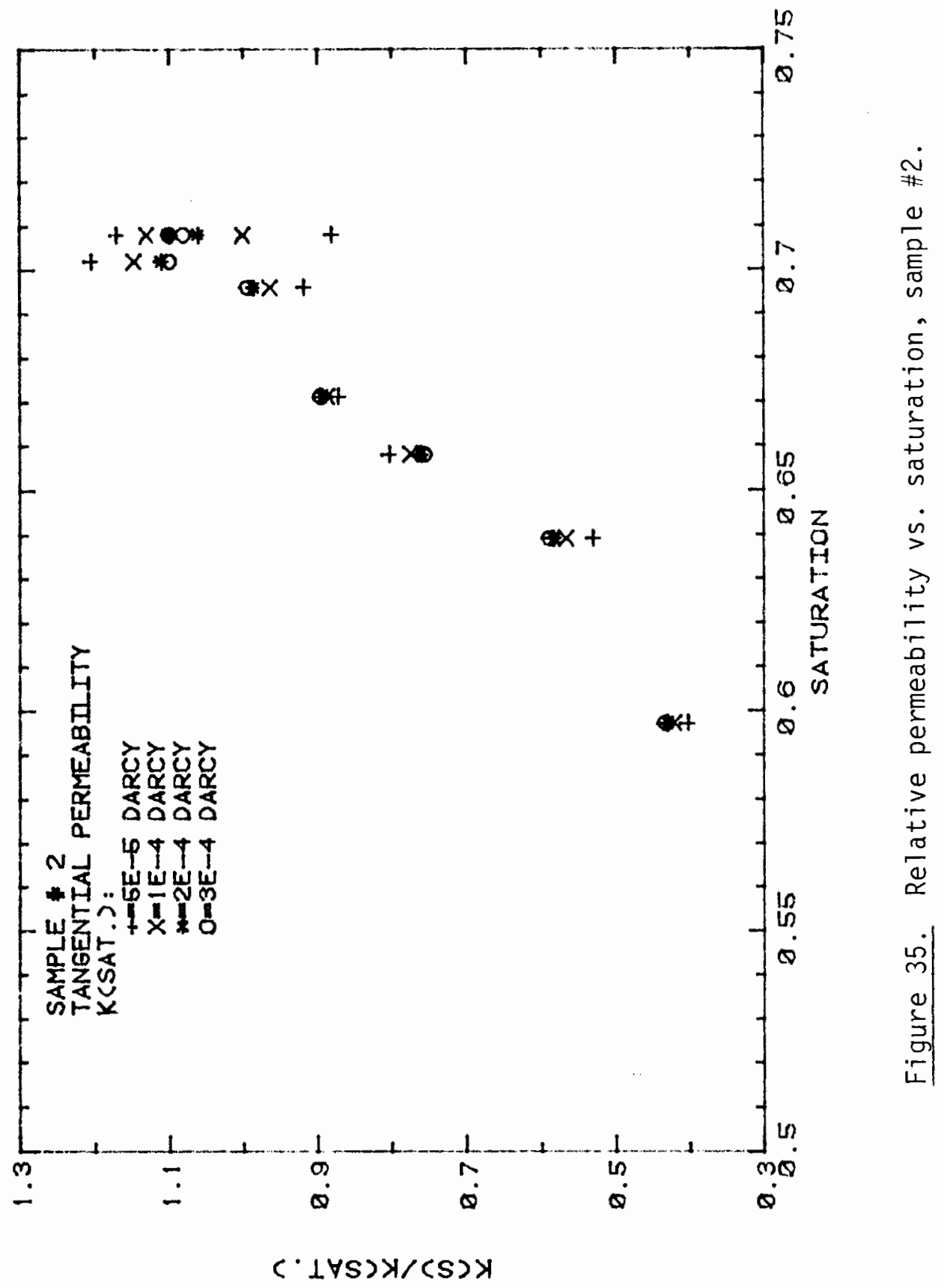




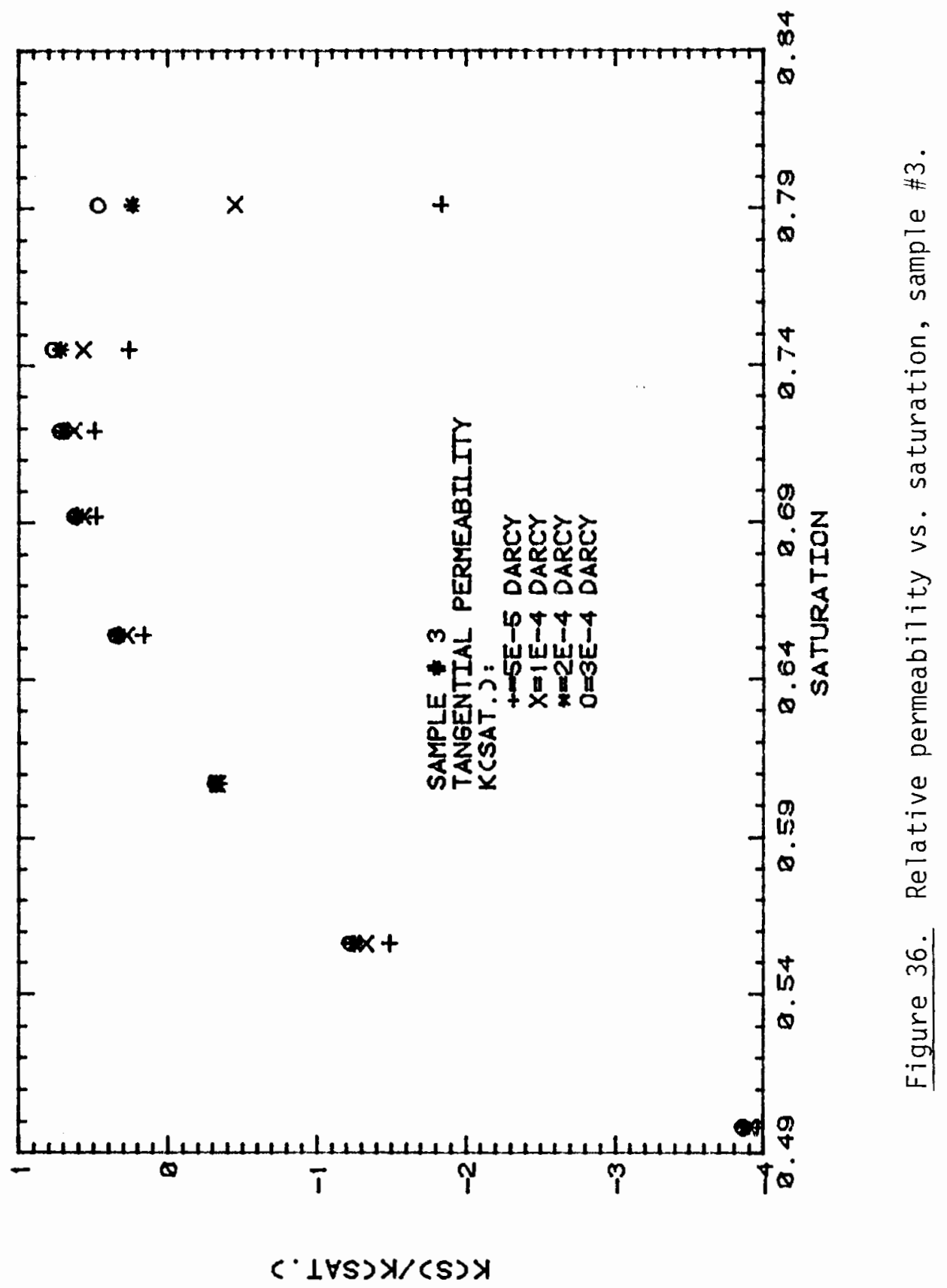




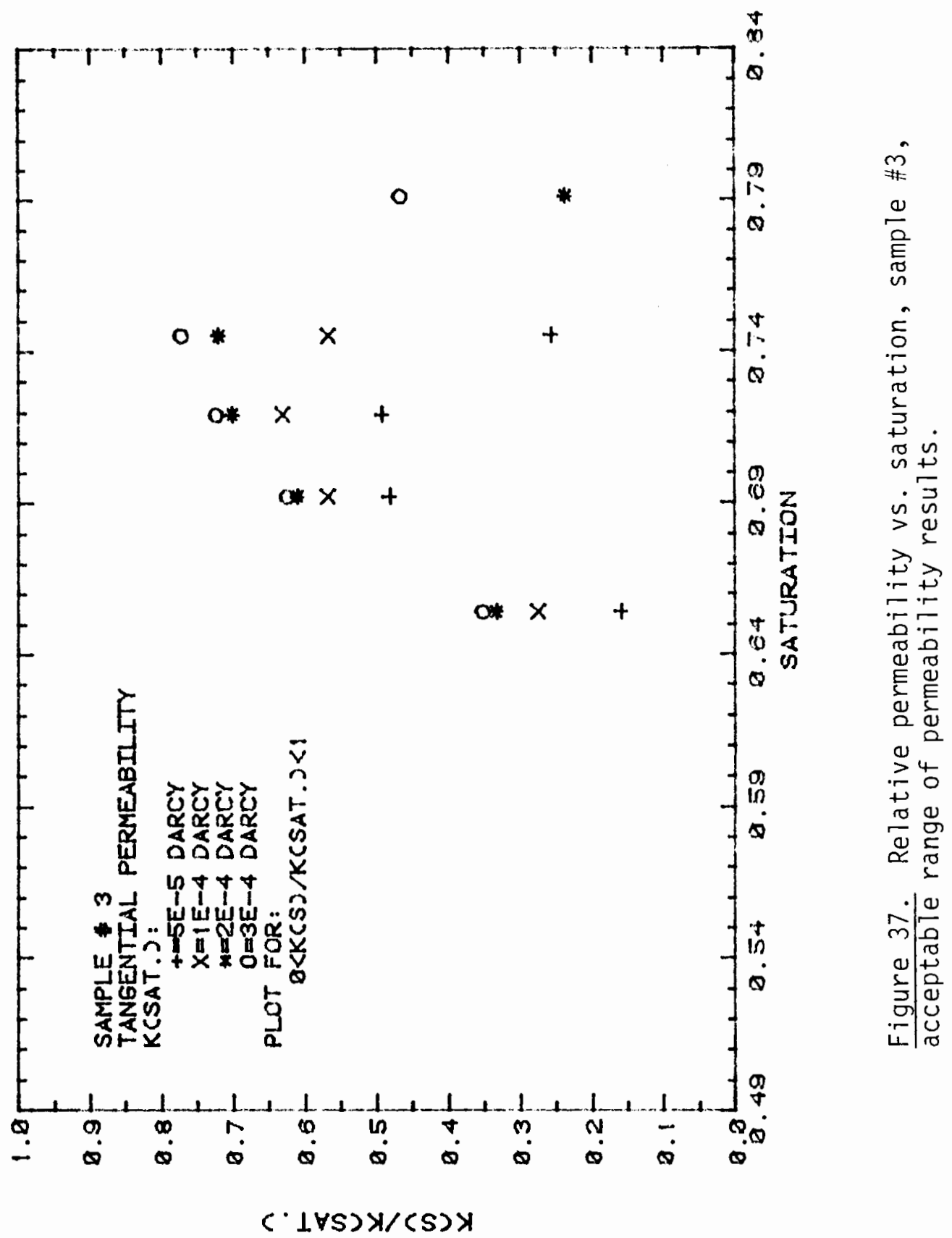




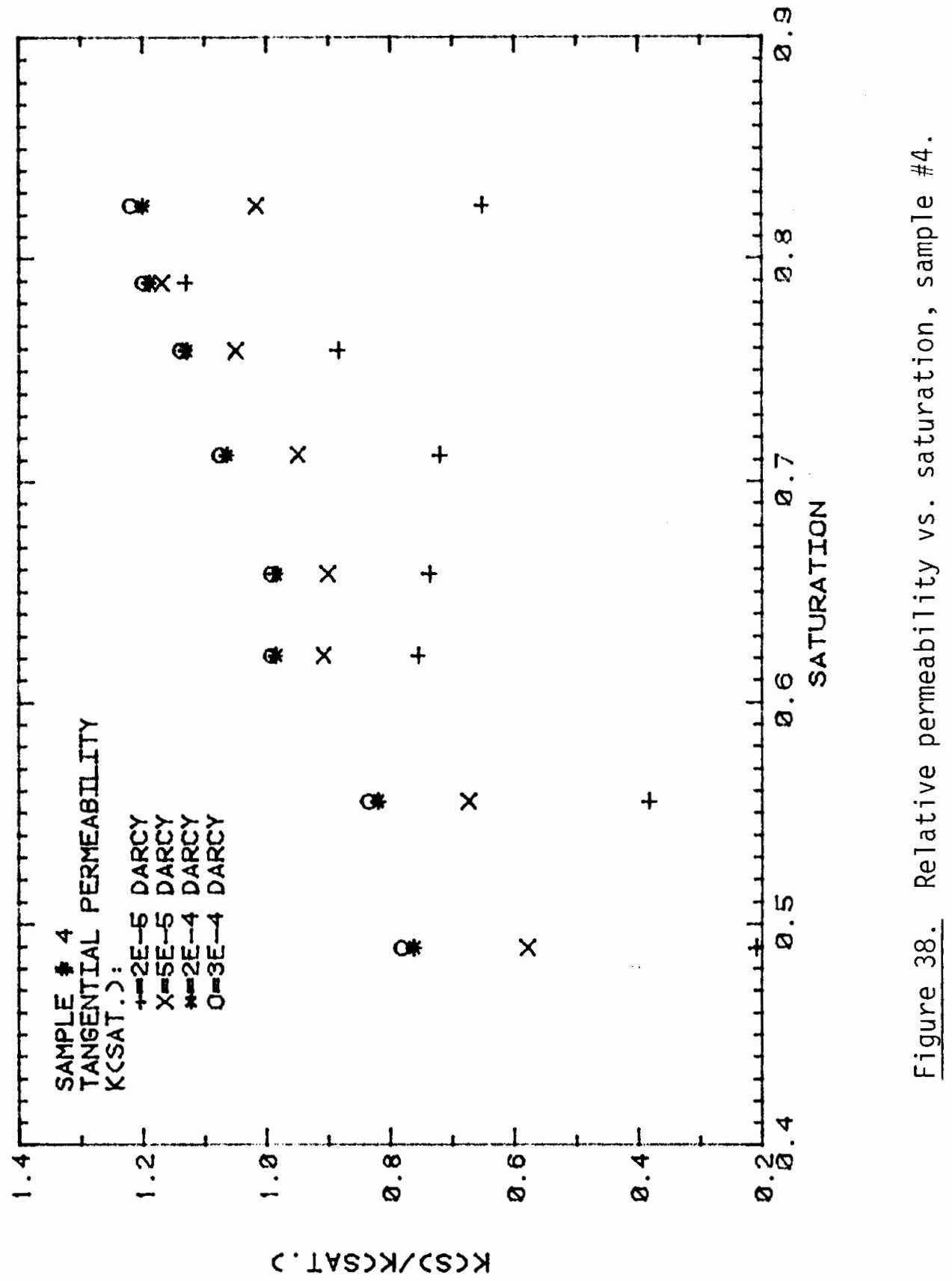




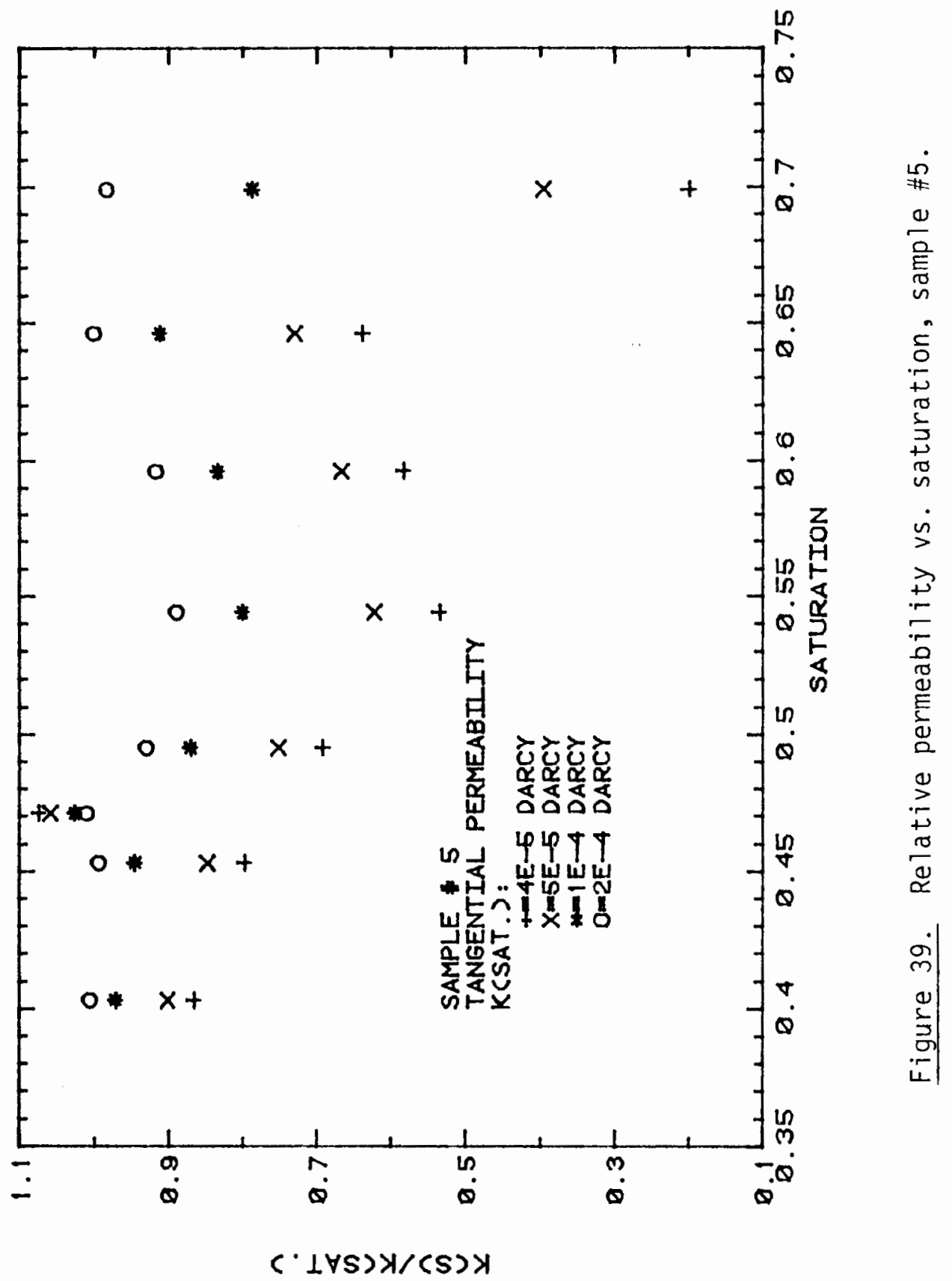




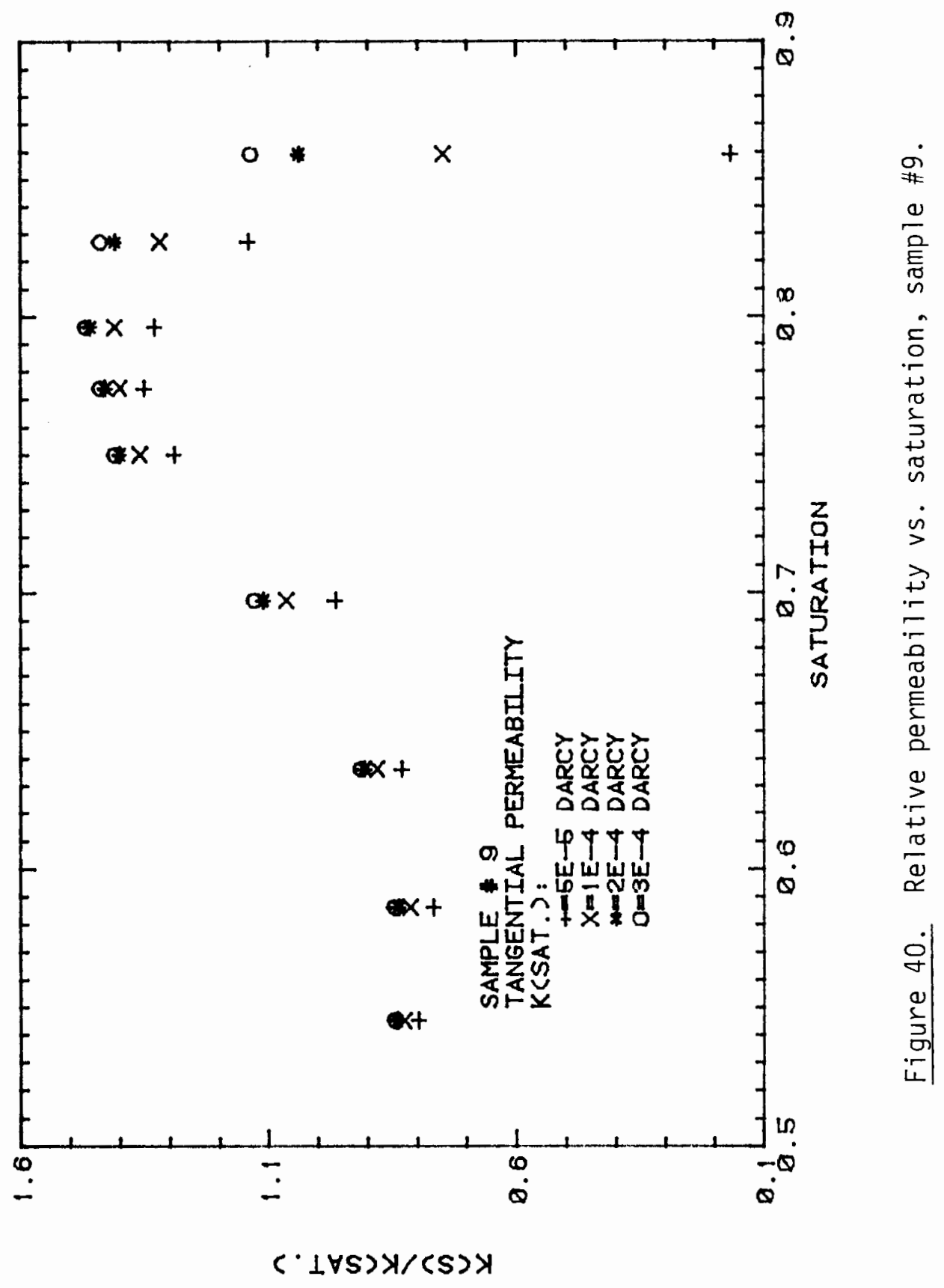




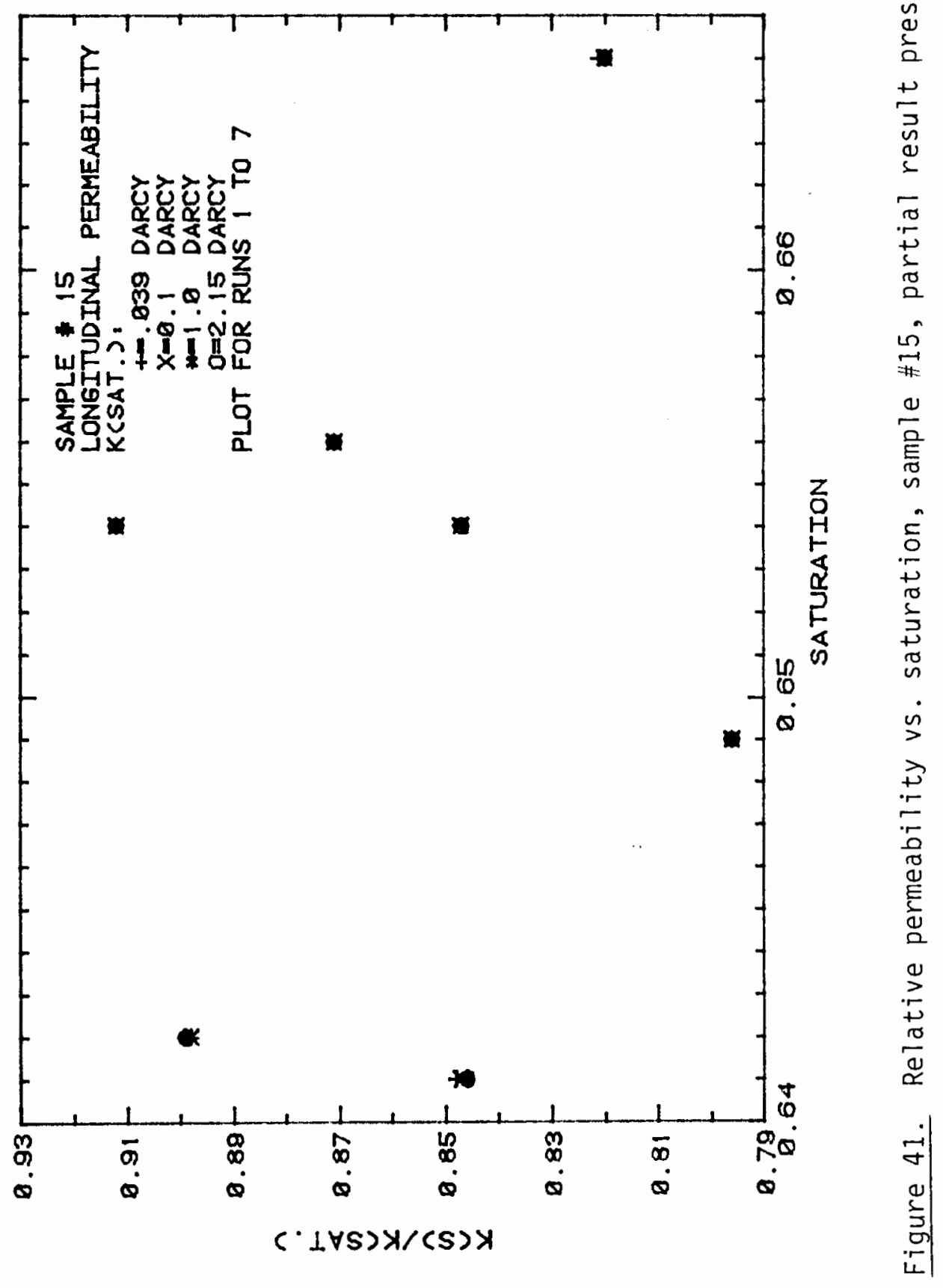




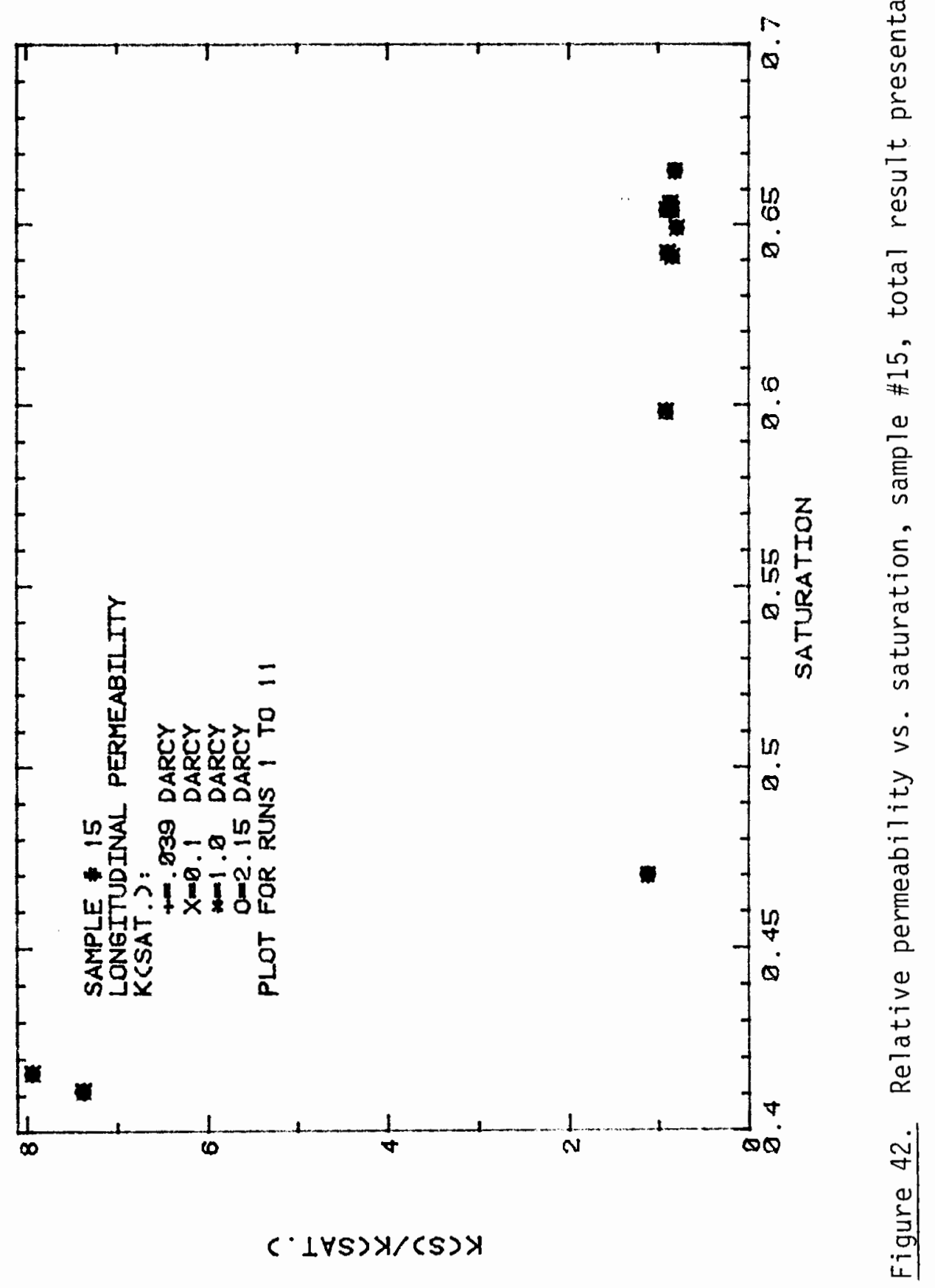




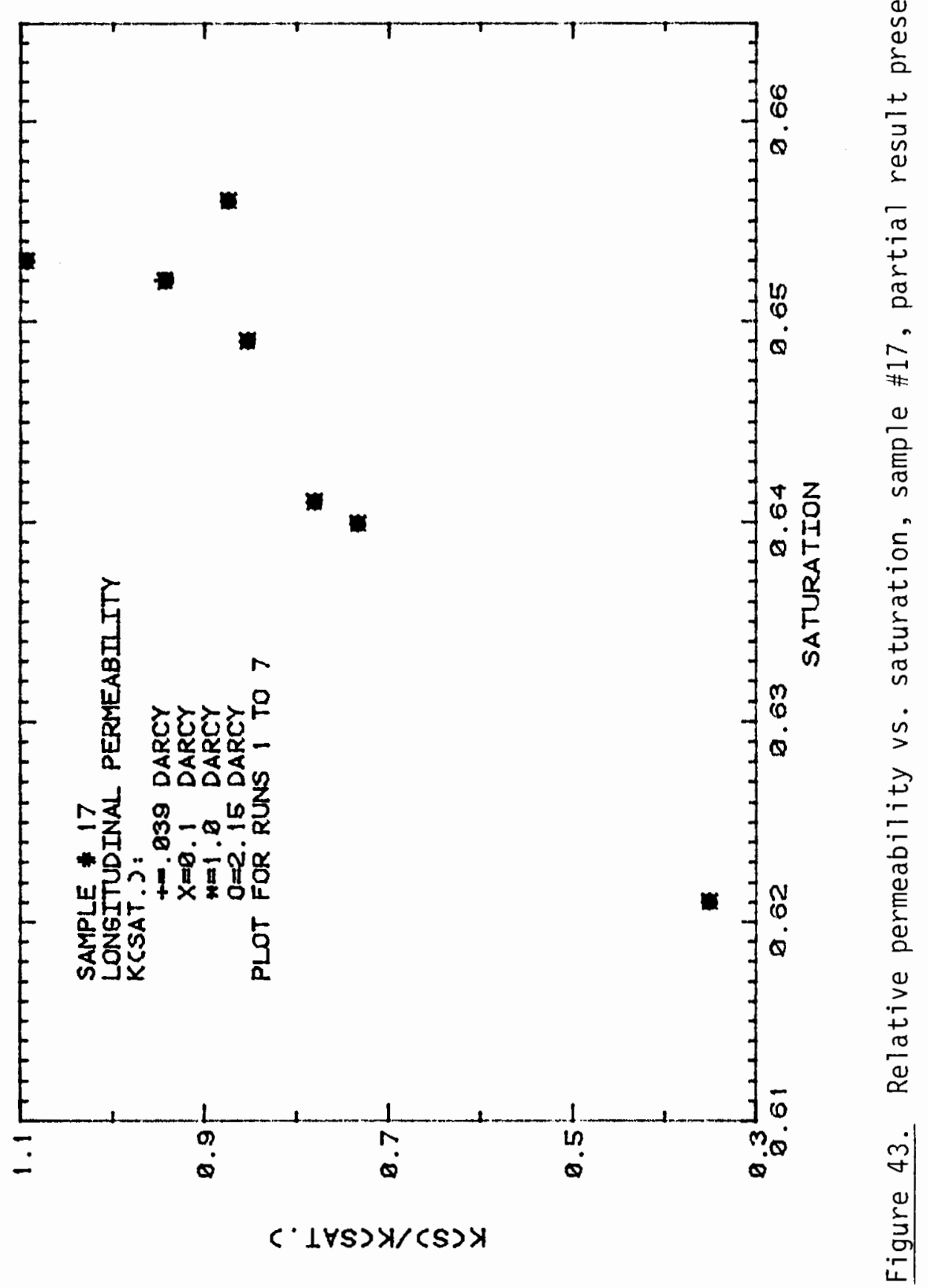




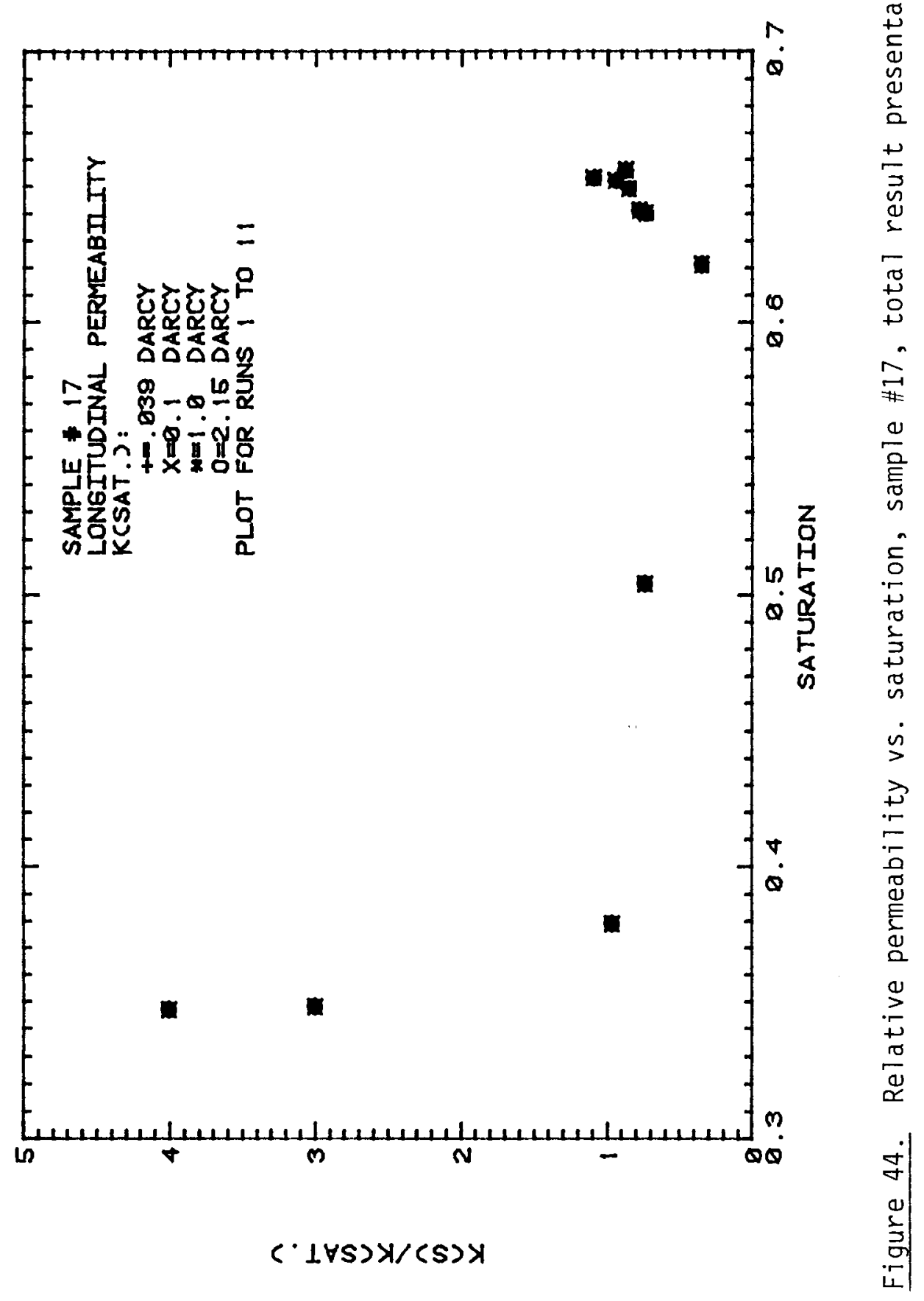


permeability plots (Figures 35 to 40 ), a general trend is demonstrated that indicates the relative permeability values increase with an increase in the assumed value for saturated permeability values (positive trend). This trend is better shown in Figures 45 to 49 . Each line on these plots refers to a specific experiment run used to calculate unsaturated permeability at various saturated permeability values. Figures for samples \#2 (RUN 6) and sample \#5 (RUN 6) indicate that some runs demonstrate a behavior contrary to what the author refers to as a positive trend. However, from a total of 102 runs, 85 runs indicated positve trend $(83.3 \%)$ and 17 indicated a negative trend $(16.7 \%)$. In any case, when the calculated results are studied as a whole for tangential permeability one can result that calculated unsaturated permeability is a function of saturated permeability. This behavior is not observed in the results for longitudinal permeability samples Figures 50 and 51 ; it seems that calculated unsaturated permeabilities are not dependent on saturated permeabilities in this case. This lack of sensitivity of unsaturated permeability results to assumed values for saturated permeability values indicates that in equation (27) the denominator (flow inducing pressure gradient at the end of sample $Z=L$ ) and the integral part (the term representing moisture drainage) are dominant in terms of order of magnitude over the term (pressure gradient at $z=0$ ) including the saturated permeability value.

As is shown in appendix F, Sample Data Reduction, to calculate the gradients in equation (27) the curve fit values for data points are used. If measured data points show a slightly more convex form, although the overall representation of actual saturation profile in wood 


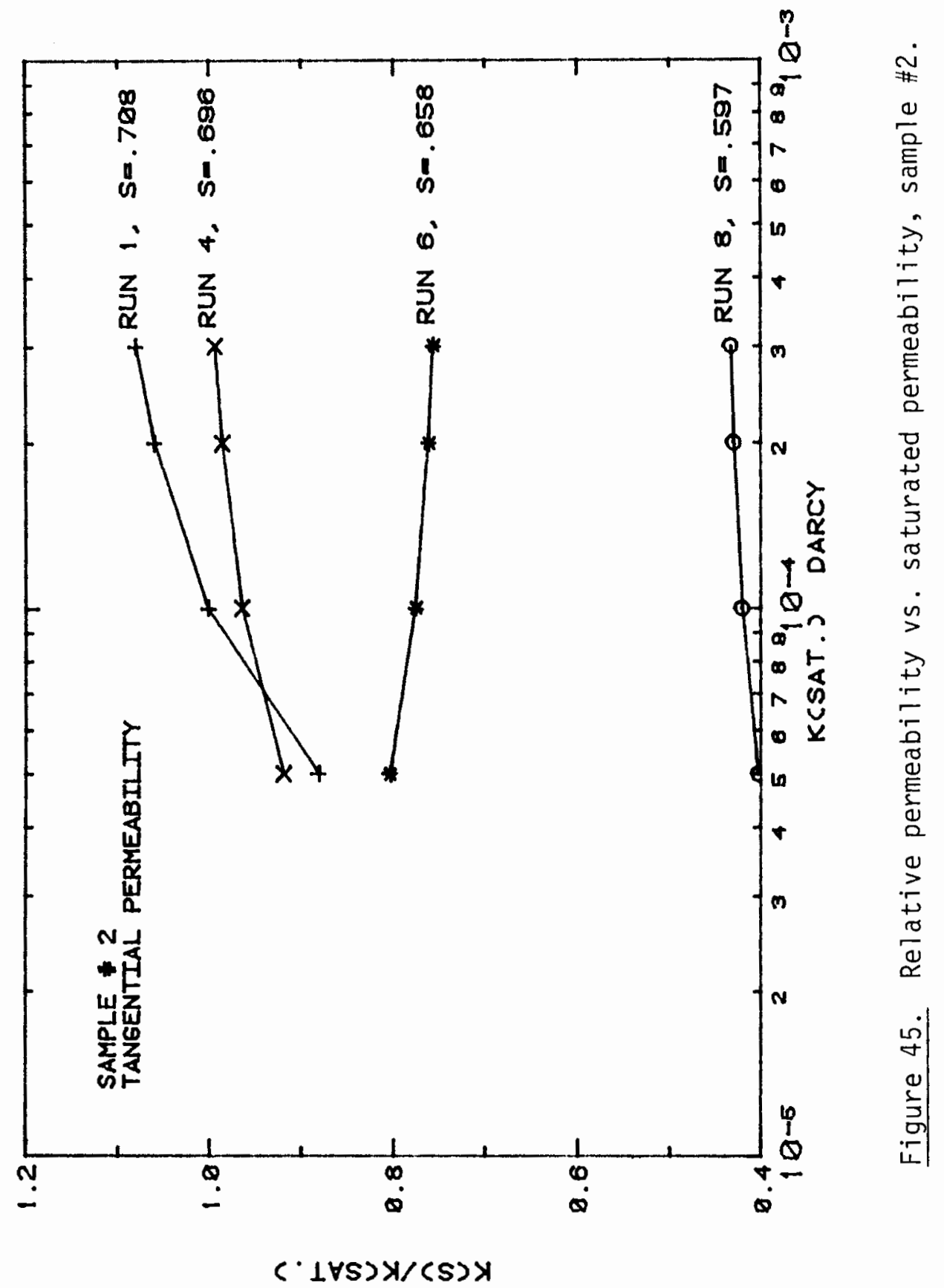




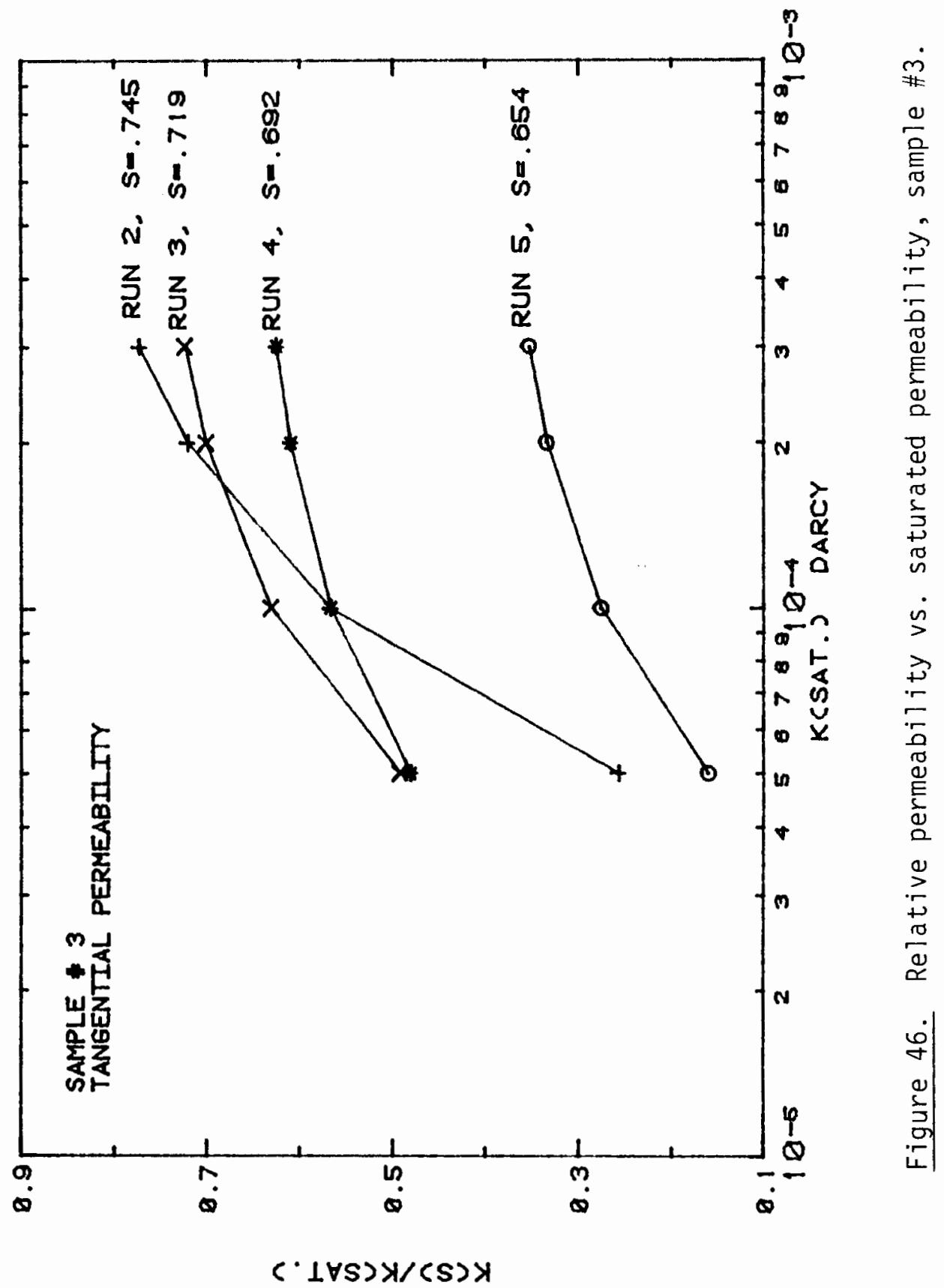




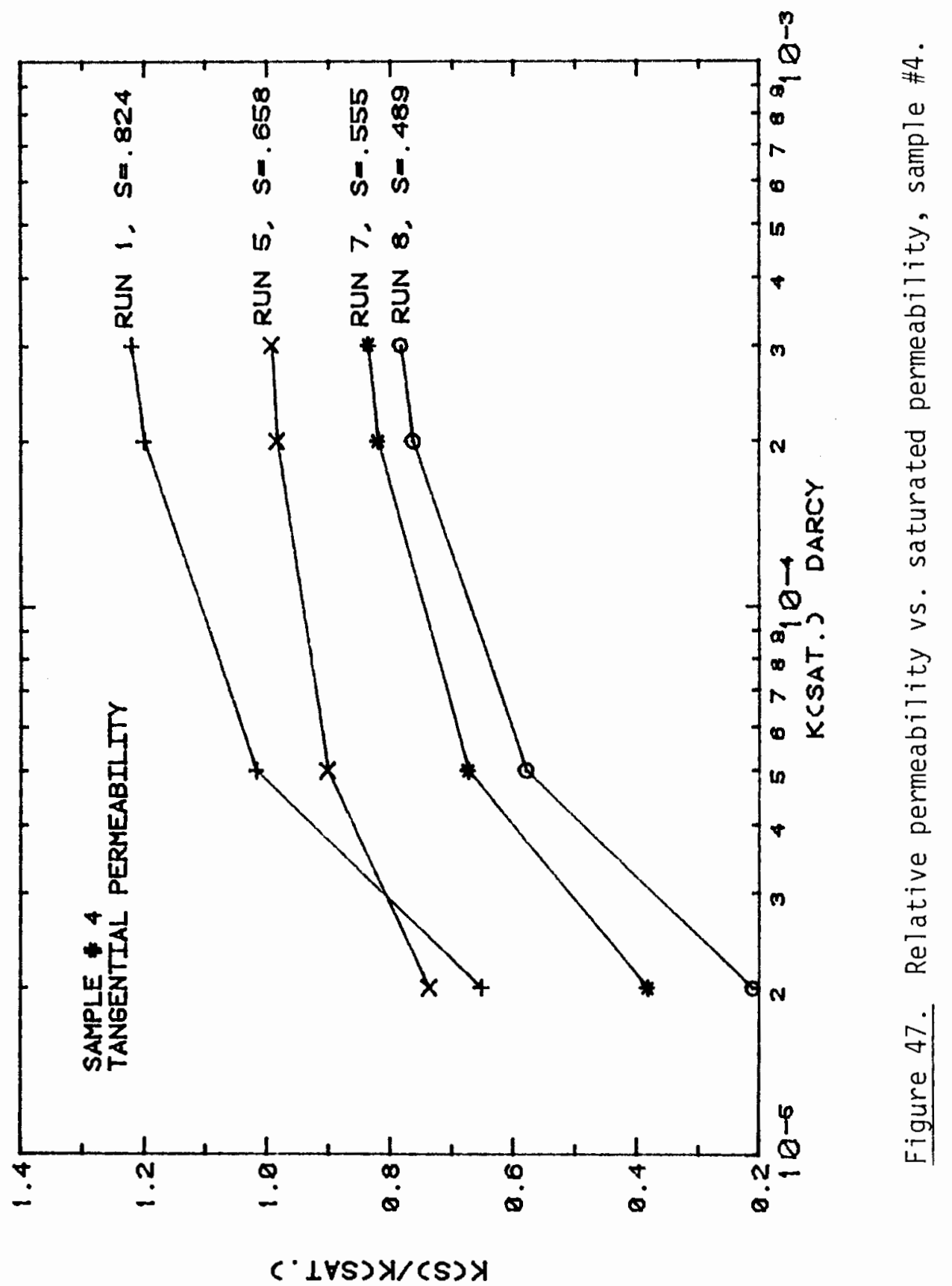




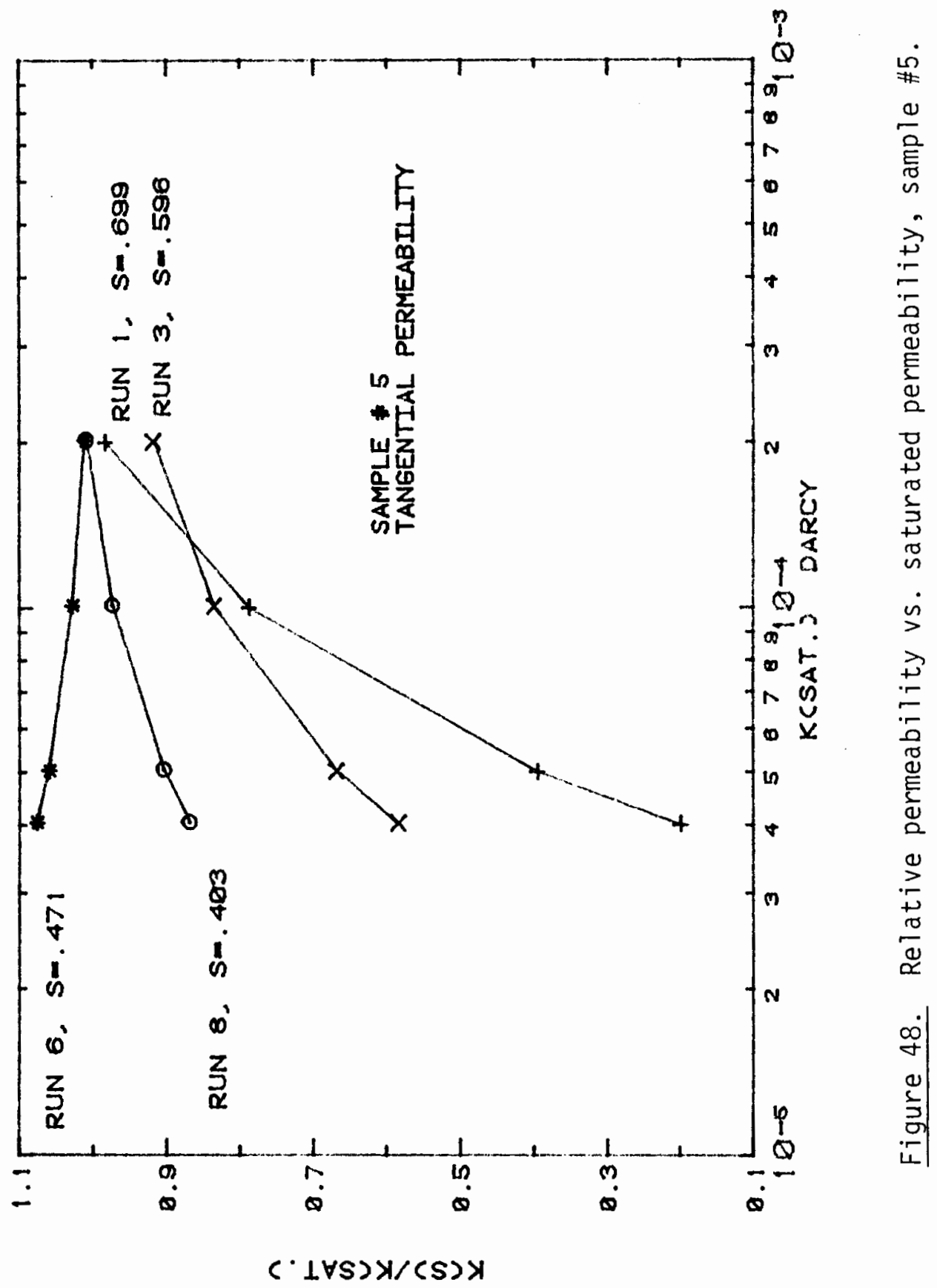




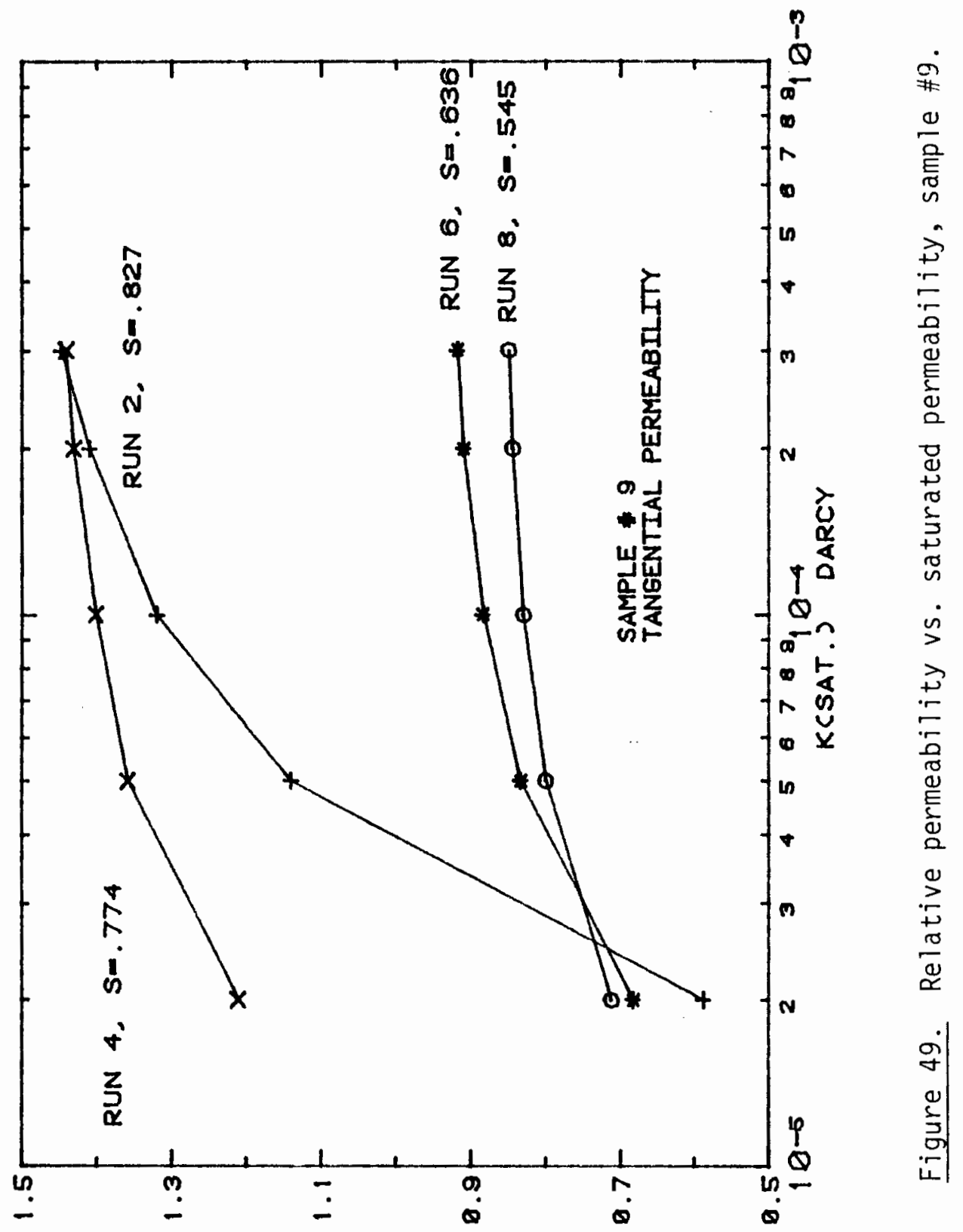

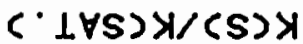




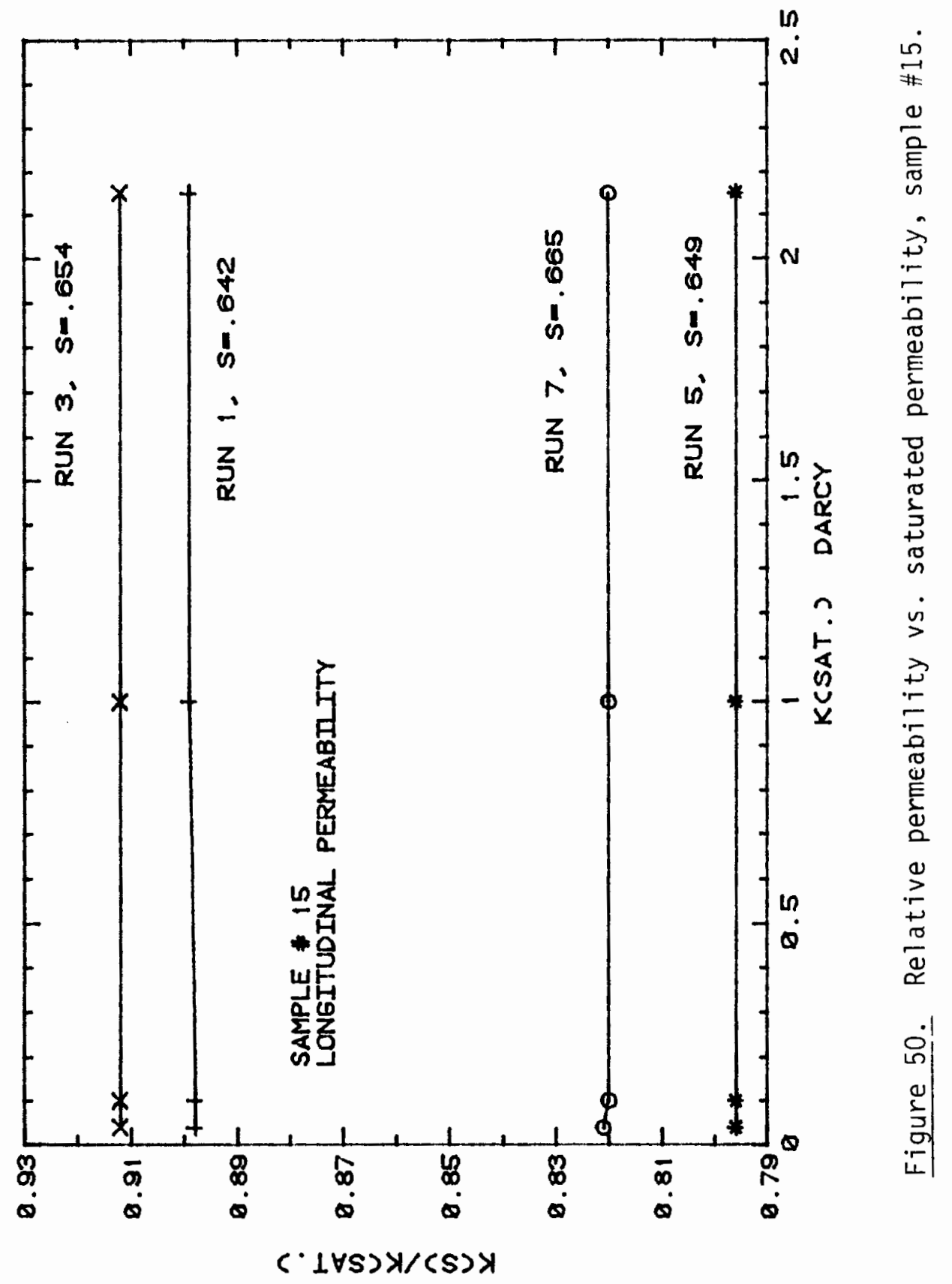




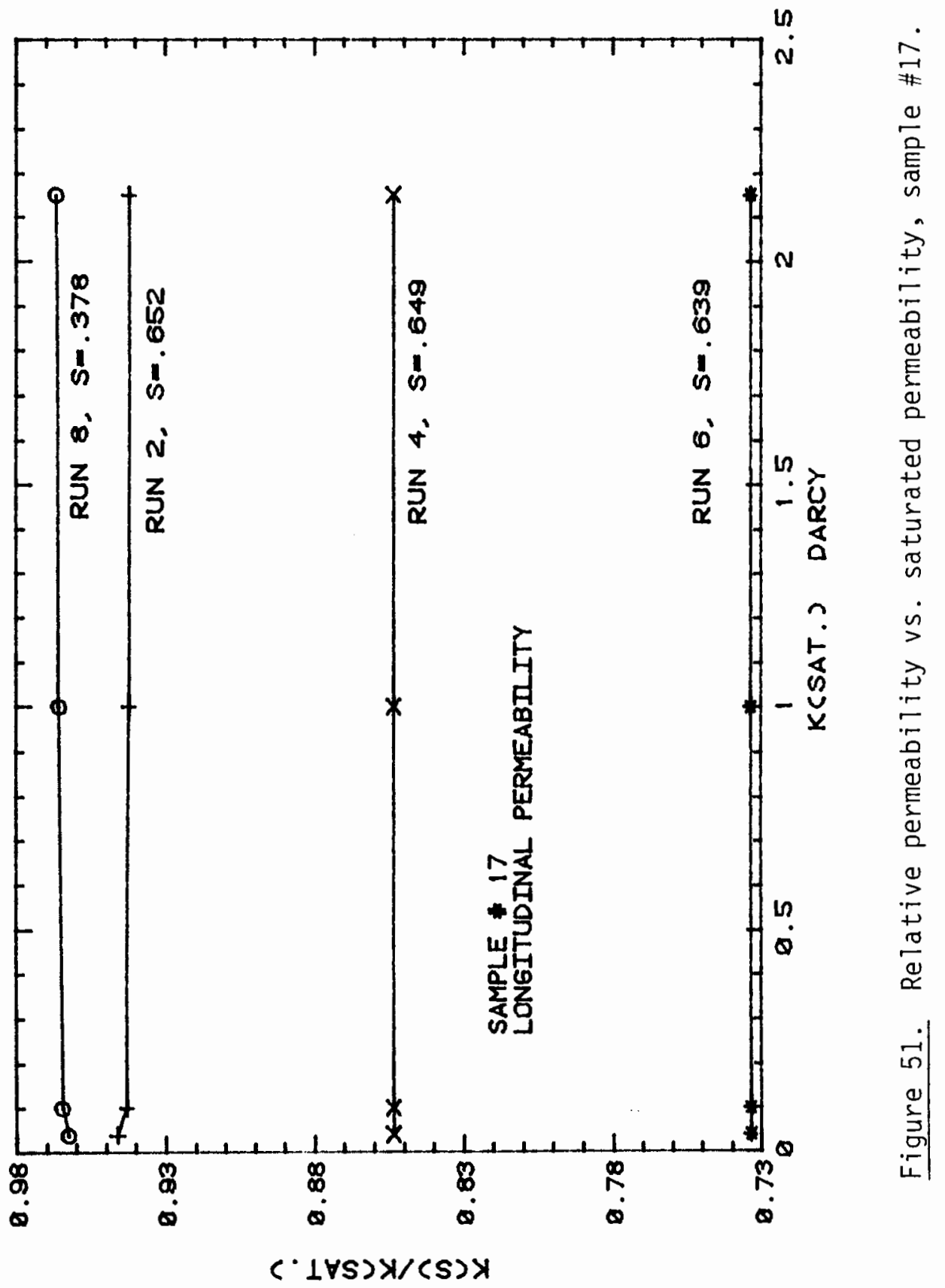


sample is still accurate, the slopes of their curves are affected to an extent that will affect the final results of $k(S(L))$. This is a major cause that invalidates the method of this study for calculating unsaturated permeability, and also prevents one from altering the range of limits on the integration (which resulted in equation (27)) in order to obtain more data points representing $k(s(L))$.

In order to get a general idea what the whole study resulted in, Figures 52 and 53 show the results of "k(s)/k(sat.) vs. S" for all tangential permeability wood samples for saturated permeability value of $2 \times 10^{-4}$ Darcy (mid-range as suggested by Comstock (1970)). Studying Figure 53 indicates that at saturation levels down to $50 \%$ still permeability does not drop to zero. This supports the mechanistic model for wood behavior which is presented by Spolek (1981a). Figure 34 presented the correspondence between results of this study and mechanistic model. 


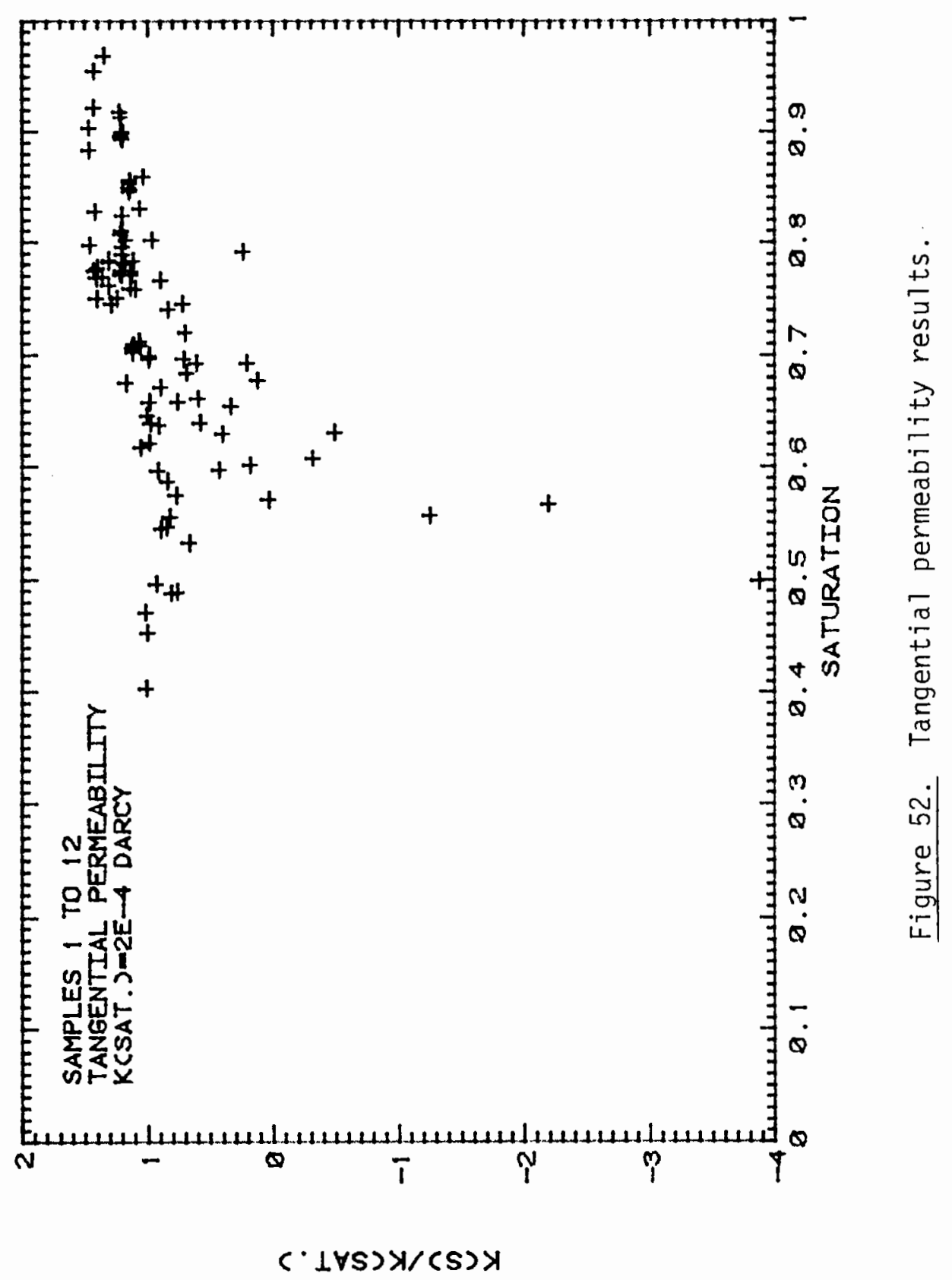




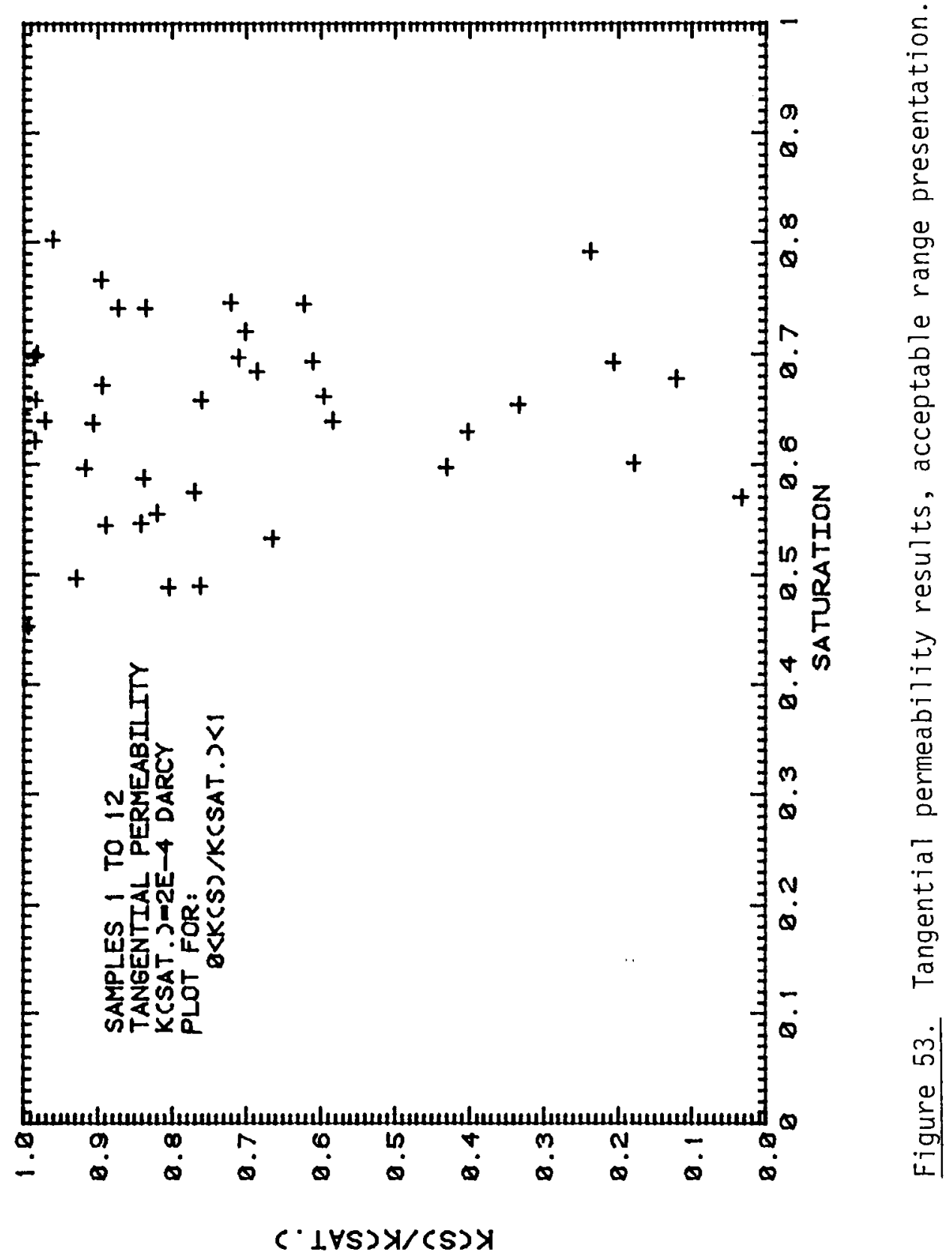


The intent of this study was to develop a practical and scientific procedure for determining the unsaturated liquid permeability of wood using transient flow method. The procedure consists of inducing liquid drainage from wood and then through utilization of noninvasive measurement methods, saturation profiles along wood are measured. With the liquid flow data and saturation profiles, unsaturated permeablity is back calculated from the liquid phase continuity equation. The transient flow is a far better representation of fluid flow through wood during drying processes than steady state single fluid or mixed fluids (gas and liquid) flow methods utilized up to present. Results of this study based on saturated permeability values generated through a steady state flow study by Comstock (1970) show some strong indications that a mechanistic flow model based on mathematical modeling (Spolek, 1981b) can describe fluid flow through wood. However, the number of data points generated in this study and the uncertainty level associated with them is insufficient to confirm the accuracy of the mechanistic model. Although the experimentation part of the study, which resulted in values for local time dependent saturation levels along the wood samples, proved to be adequately accurate (with less than $5 \%$ relative error) the final results for unsaturated permeability values proved to have high level of uncertainty ( $112 \%$ relative error). The high level of uncertainty in the final results can be attributed to the local fluctuation in data which is caused by the natural inhomogeneities in wood. Additional testing for unsaturated permeability while performed along with saturated permeability measurements for similar wood samples will provide more accurate results which can be used to provide 
representative data averages. In conclusion, this study confirmed the validity and reliability of experimentation procedure and provided more backing for mechanistic based predictive model for fluid flow through wood in tangential direction (Spolek, 1981b). 


\section{BIBLIOGRAPHY}

Bear, Jacob, Hydraulics of Ground Water, McGraw-Hill, Inc., New York, (1979).

Brown, Craig A., Design and Development of an Experimental System Employing Gamma Ray Attenuation to Investigate Wood Drying, Master's Thesis, Washington State University (1982).

Cassel, D.K., Warrick A.W., Nielsen, D.R., and Biggar, J.W., "Soil-Water Diffusivity Values Based Upon Time Dependent Soil-Water Content Distrubtions," Soil Sci. Amer. Proc., 32, 774-777 (1968).

Collins, R.E., Flow of Fluid through Porous Materials, Reinhold Publishing Corp., New York (1961).

Comstock, G.L., "Directional Permeabilty of Softwood," Wood and Fiber, $1(4), 283-289$ (1970).

Dullien, F.A.L., Porous Media Fluid Transport and Pore Structure, Academic Press, Inc., New York (1979).

Greenkorn, R.A., "Steady Flow Through Porous Media," AIChE Journal, $27(4), 529-545(1981)$.

Haugen, R.L., and Wennerstrom A.J., "On Predicting Flow Through Porous Media," Journal of Applied Mechanics, 37, 1179-1180 (1970).

Holman, J.P., Experimental Methods for Engineers, McGraw-Hill Book Company, New York (1978)

Kline, S.J., and McClintock, F., "Describing Uncertainties of Single Sample Experiments," Mech. Eng., Vol. 75, p.3, (January 1953).

Miller, Irwin, and Freund, E. John, Probability and Statistics for Engineers, Prentice-Ha11, Inc., New Jersey (1977).

Resch, H., and Ecklund, B.A., "Permeability of Wood Exemplified by Measurement on Redwood," Forest Products Journal, 14(5), 199-206 (1964).

Schenck, Hilbert, Theories of Engineering Experimentation, Hemisphere Publishing Corporation, Washington (1979). 
Siau, John F., Flow in Wood, Syracuse University Press, Syracuse, New York (197i).

Spolek, G.A., "The Measurement of Unsaturated Wood Permeability," presented to and published in the Proceedings to the $11 \mathrm{th}$ Conference on Production Research and Technology, Carnegie-Melion University, Pittsburgh, Pennsylvania (1984).

Spolek, G.A., "A Model of Simultaneous Convective, Diffusive, and Capillary Heat and Mass Transport in Drying Wood," Ph.D. Dissertation, Washington State University (1981a).

Spolek, G.A., and Plumb, 0.A., "Capillary Pressure in Softwoods," Wood Science and Technology, 15, 189-199 (1981b)

Spolek, G.A., and Plumb, O.A., "A Numerical Model of Heat and Mass Transport in Wood During Drying," presented to, and published in the Proceedings of Second International Symposium of Drying, Montreat (1980).

Stamm, A.J., "Permeability of Wood to Fluids," Forest Products Journal, 13(11), 503-507 (1963).

Tesoro, F.A., Choong, E.T., and Kimbler, O.K., "Relative Permeability and the Gross Pore Structure of Wood," Wood and Fiber, 6(3), 227-232 (1974).

Watson, K.K., "An Instantaneous Profile Method for Determining the Hydraulic Conductivity of Unsaturated Porous Materials," Water Resources Research, 2(4), 709-715 (1966). 
APPENDIX A

UNCERTAINTY ANALYSIS 
UNCERTAINTY ANALYSIS

Following is an uncertainty analysis for measured saturation levels and calculated unsaturated permeability based on $\mathrm{Kl}$ ine and McClintock theores (Kline, 1953). The experimental data used for this analysis is from wood sample number three which was tested for tangential permeability. A $95 \%$ confidence interval (20:1 odds) is assumed throughout the analysis. Starting with governing equation (27) we have:

$$
k(S(L))=\frac{k(S(0))\left[C(S(0)) \cdot S^{\prime}(0)-B(0)\right]-\mu \phi \int_{0}^{L}\left(\frac{\partial S}{\partial t}\right) d Z}{C(S(L)) \cdot S^{\prime}(L)-B(L)}
$$

since

$$
C(S(z)) \cdot S^{\prime}(z)=\frac{\partial P C}{\partial S} \cdot \frac{\partial S}{\partial z}=\frac{d P C}{d Z}
$$

we have:

$$
k(S(L))=\frac{k(S(0))\left[\left.\frac{d P}{d Z}\right|_{z 0}-B(0)\right]-\mu \phi \int_{0}^{L}\left(\frac{\partial S}{\partial t}\right) d Z}{\left.\frac{d P}{d Z}\right|_{Z_{L}}-B(L)}
$$

where

$$
\begin{aligned}
& B(Z)=\rho_{\ell} \omega^{2}(R-Z) \\
& P_{C}=\rho_{\ell} \omega^{2} Z(R-Z / 2) \quad(\text { at steady state conditions) } \\
& \int \frac{\partial s}{\partial t} d Z=\frac{\Delta Z}{\Delta t}\left[\sum_{i=1}^{20} S_{z_{i}}\left|t_{2}-\sum_{i=1}^{20} S_{z_{i}}\right| t_{1}\right]=\frac{\Delta Z}{\Delta t} \cdot n \cdot\left[S_{\text {ave }}\left|t_{2}-S_{a v e}\right| t_{1}\right]
\end{aligned}
$$

In equation (U3) saturation term can be singled out for individual uncertainty analysis because it has no common factor with other terms in equation (U3).

$$
S=\frac{M-F S P}{M_{\max }-F S P}=\frac{M-F S P}{\Delta M}
$$




$$
\begin{aligned}
& M=\frac{-V_{w d+w}}{V_{w d}} \cdot \frac{1}{\mu_{w} \rho_{w d} L_{w d+w}}\left[\ln \frac{N_{w d+w}}{N_{w d}}+\rho_{w d} \mu_{w d}\left(L_{w d+w}-L_{w d}\right)\right] \\
& N=\frac{1}{1 / N-T}
\end{aligned}
$$

where $N=$ gamma counts

$$
\begin{aligned}
& \tau=\text { instrument dead time (ganma ray densitometer) } \\
& N_{w d}=N_{w d+E M C} \times \exp \left(\mu_{w d} \cdot \rho_{w d} \cdot L_{w d} \cdot E M C\right) \\
& \rho_{\text {measured }}=\frac{m_{w d+E M C}}{V_{w d+E M C}} \\
& \rho_{w d}=\frac{\rho_{\text {measured }}}{1+E M C\left(V_{w d} / V_{w d+E M C}\right)}
\end{aligned}
$$

Therefore:

$$
S=\frac{1}{M M} \times\left[\frac{-V_{w d+w}}{V_{w d}} \cdot \frac{1}{{ }_{w d} \cdot L_{w d} \cdot\left[\frac{m_{w d+E M C}}{V_{w d}+E M C} \cdot \frac{1}{1+E M C\left(V_{w d} / V_{w d+E M C}\right)}\right]} \times\right.
$$

$\left[\ln \frac{\frac{1}{1 / N_{w d+w^{-\tau}}}}{\left(\frac{1}{1 / N_{w d+E M C}-\tau}\right) \exp \left(\mu_{w d} \cdot \frac{m_{w d+E M C}}{V_{w d+E M C}} \cdot \frac{1}{1+E M C\left(V_{w d} / V_{w d+E M C}\right.} \cdot L_{w d} \cdot E M C\right)}+\right.$

$\left.\left.\left.\frac{m_{w d+E M C}}{V_{w d+E M C}} \cdot \frac{1}{1+E M C\left(V_{w d} / V_{w d+E M C}\right.}\right) \cdot \mu_{w d}\left(L_{w d+w}-L_{w d}\right)\right]-F S P\right\}$

Assume: (for values refer to appendix F)

$a_{1} ;\left(V_{W d} / V_{W d}+E M C\right)=1$ with no error involved.

$a_{2} ;$ no error in $E M C=0.005$

$a_{3} ; a_{1}$ and $a_{2}$ result in $\Delta \rho=f\left(\Delta m, \Delta V_{w d}\right)$

$\mathrm{a}_{4} ;$ no error in $\mu_{w d}=0.189 \mathrm{~cm}^{2} / \mathrm{gm}$

a 5 ; no error in $\mu_{W}=0.201 \mathrm{~cm}^{2} / \mathrm{gm}$ 
$a_{6}$; no error in $F S P=0.3$

a $;$ no error in $\Delta M=1.86$

a 8 ; no error in $\tau$ (instrument dead $t$ ime), $\tau=10^{-7}$ seconds $/$ count

$a_{g} ; \quad V_{w d}=V_{w d}+E M C$

$S=\frac{1}{1.86} \times\left\{\frac{-V_{w d+w}}{V_{w d}} \cdot \frac{1}{0.2 \times L_{w d+w} \cdot \frac{W_{w d+E M C}}{V_{w d+E M C}}}\right.$.

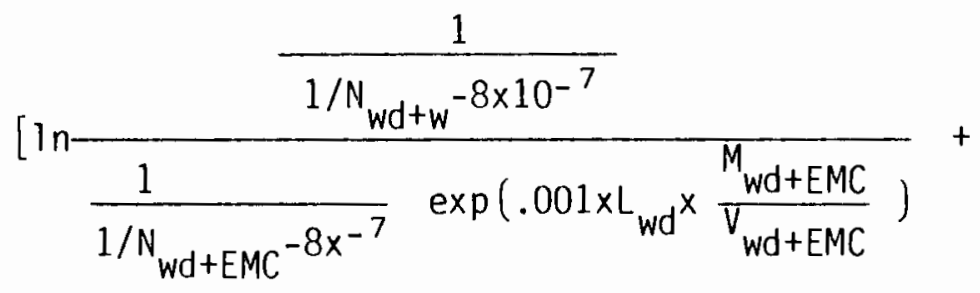

$\left.\left.0.188 \times \frac{M_{w d+E M C}}{V_{w d+E M C}}\left(L_{w d+w^{-}} L_{w d}\right)\right]-0.3\right\}$

As sume:

$\mathrm{a}_{10}$; Sample dimensions are ExFxL (Figure 54) with (wd+w) and (wd) subscripts refering to (wet wood) and (dry wood) respectively, where $F$ corresponds with same direction as $Z$ along the sample length, and $\mathrm{L}$ corresponds with radiation absorption length.

a 11 ; In measurements $\mathrm{Z}_{0}, \mathrm{Z}_{\mathrm{L}}$ and $\Delta \mathrm{Z}$ are treated as separate measurement from overall dimension measurements.

$$
k(S(L))=\frac{k(S(0))\left[\left.\frac{d P}{d Z}\right|_{z_{0}}-B(0)\right]-\mu \emptyset \cdot n \cdot \frac{\Delta Z}{\Delta t}\left[S \text { ave }\left|t i+1-S_{\text {ave }}\right| t i\right]}{\left.\frac{d P}{d Z}\right|_{z_{L}}-B(L)}
$$

Here $n=$ number of scanned locations between $Z_{0}$ and $Z_{L}$. 


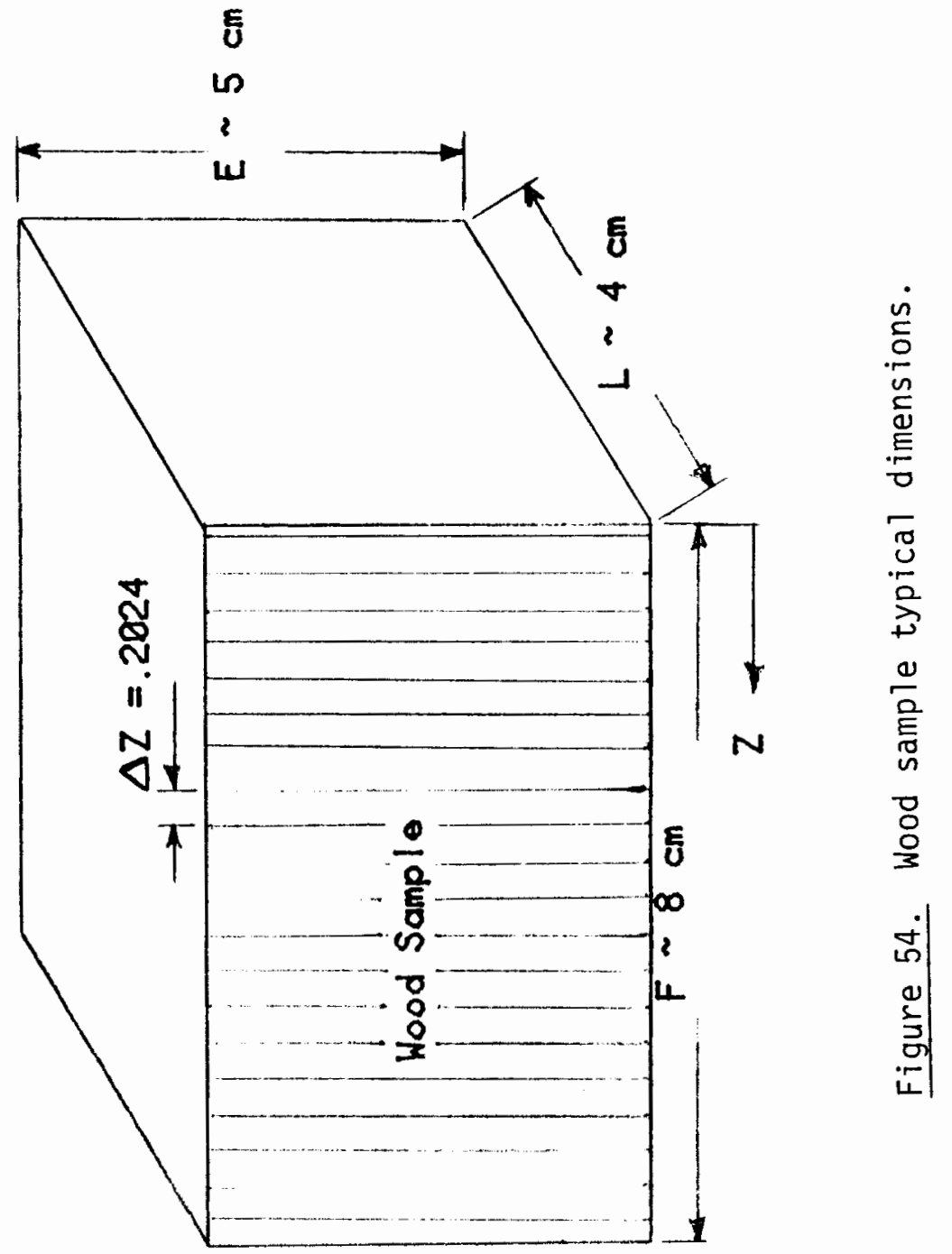


Note: The uncertainty analys is will be done for sample \#3 with a location range of $Z_{O}=0.2024 \mathrm{~cm}$ to $Z_{L}=7.8936 \mathrm{~cm}$ and $n=$ 20 for $k(S(L))$.

Since there is no common variable between parameters used to calculate S (saturation) and other terms used in calculating $k(S(L))$, the uncertainty of $S$ is calculated separately. As an average representative set of values scan times 03 and 04 are used.

$V_{w d+w}=E_{w d+w} \times F_{w d+w} \times L_{w d+w}$

$v_{w d}=E_{w d} \times F_{w d} \times L_{w d}$

Applying equations (U15) and (U16) to (U13) will result in:

$$
\begin{aligned}
& S=\frac{1}{1.86}\left\{\frac{-E_{w d+w} \times F_{w d+w}}{.2 \times m_{w d+E M C}} \times\left[\ln \frac{1 / N_{w d+E M C}-8 \times 10^{-7}}{\left(1 / N_{w d+w}-8 \times 10^{-7}\right) \cdot \exp \left(0.001 \times \frac{m_{w d+E M C}}{E_{w d} \times F}\right)}\right.\right. \\
& \left.\left.+0.188 \times \frac{m_{w d+E M C}\left(L_{w d+w}-L_{w d}\right)}{E_{w d} \times F_{w d} \times L_{w d}}\right]-0.3\right\}
\end{aligned}
$$

To determine the effect of the term $\exp \left(\mu_{w d} \cdot \rho_{W d} \cdot L_{w d} \cdot E M C\right)$, equation (U10), on uncertainty in $S$, its uncertainty is analyzed separately.

$$
\begin{gathered}
\exp \left(\mu_{w d} \cdot \rho_{w d} \cdot L_{w d} \cdot E M C\right)=\exp \left(.001 \times \frac{m_{w d}+E M C}{E_{w d} \times F}\right)=0 \\
\Delta D=\left[\left(\frac{\partial D}{\partial m_{w d}+E M C} \cdot \Delta m_{w d+E M C}\right)^{2}+\left(\frac{\partial D}{\partial E_{w d}} \cdot \Delta E_{w d}\right)^{2}+\left(\frac{\partial D}{\partial F_{w d}} \cdot \Delta F_{w d}\right)^{2}\right]^{1 / 2} \\
\frac{\partial D}{\partial m_{w d+E M C}}=\left[\exp \left(.001 \times \frac{m_{w d+E M C}}{E_{w d} \times F_{w d}}\right)\right] \times \frac{0.001}{E_{w d} \times F_{w d}} \\
\frac{\partial D}{\partial E_{w d}}=\left[\exp \left(.001 \times \frac{m_{w d+E M C}}{E_{w d} \times F_{w d}}\right)\right] \frac{-0.001 \times m_{w d+E M C}}{E_{w d}^{2} \times F_{w d}}
\end{gathered}
$$




$$
\frac{\partial D}{\partial F_{w d}}=\left[\exp \left(.001 \times \frac{m w d+E M C}{E_{w d^{x F}}{ }_{w d}}\right)\right] \times \frac{-0.001 \times m}{w d+E M C}
$$

with

$$
\begin{aligned}
& m_{w d}+E M C=75 \pm 0.5 \mathrm{gm} \\
& E_{w d}=5.047 \pm .1 \mathrm{~cm} \\
& F_{w d}=8.573 \pm .1 \mathrm{~cm}
\end{aligned}
$$

we will have

$$
\Delta \mathrm{D}=0.024 \text { and } \mathrm{D}=1.002
$$

since $\frac{\Delta D}{D}=0.024=2.4 \%$, and $D \simeq 1$ is used as a correction factor for $N_{W d+E M C}$, we assume the error that $D$ (exponential correcting factor) introduces is negligible and it does not affect the error introduced in the final result of unsaturated permeability.

Thus we have:

$$
S=\frac{1}{1.86}\left\{\frac{-E_{w d+w} \times F_{w d+w}}{.2 \times m} \times\left[\frac{1 / N_{w d+E M C}}{\left(1 / N_{w d+w^{-8}} \times 10^{-7}\right) \times 1.002}+0.188 \times\right.\right.
$$

$$
\left.\left.\frac{m_{w d+E M C}\left(L_{w d+w^{-L}}{ }_{w d}\right)}{E_{w d} \times F_{w d} \times L_{w d}}\right]-.3\right\}
$$

and

$$
\begin{gathered}
\Delta S=\left[\left(\frac{\partial S}{\partial E_{w d+w}} \cdot \Delta E_{w d+w}\right)^{2}+\left(\frac{\partial S}{\partial F_{w d+w}} \cdot \Delta F_{w d+w}\right)^{2}+\left(\frac{\partial S}{\partial L_{w d+w}} \cdot \Delta L_{w d+w}\right)^{2}+\right. \\
\left(\frac{\partial S}{\partial E_{w d}} \cdot \Delta E_{w d}\right)^{2}+\left(\frac{\partial S}{\partial F_{w d}} \cdot \Delta F_{w d}\right)^{2}+\left(\frac{\partial S}{\partial L_{w d}} \cdot \Delta L_{w d}\right)^{2}+\left(\frac{\partial S}{\partial m_{w d+E M C}} \cdot \Delta m_{w d+E M C}\right)^{2}+ \\
\frac{\left.\left(\frac{\partial S}{\partial N_{w d+E M C}} \cdot \Delta N_{w d+E M C}\right)^{2}+\left(\frac{\partial S}{\partial N_{w d+W}} \cdot \Delta N_{w d+w}\right)^{2}\right]^{1 / 2}}{\text { (U24) }}
\end{gathered}
$$


let

$$
B=\ln \frac{1 / N_{W d+E M C}-8 \times 10^{-7}}{\left(1 / N_{W d+W}-8 \times 10^{-7}\right) \times 1.002}
$$

then:

$$
S=\frac{1}{1.86}\left\{\frac{-\beta \times E_{w d+w} \times F_{w d+w}}{.2 \times m_{w d+E M C}}-.94 \times \frac{E_{w d+w} \times F_{w d+w}\left(L_{w d+w}-L_{w d}\right)}{E_{w d} \times F_{w d} \times L_{w d}}-.3\right\}
$$

and

$$
\begin{aligned}
& \frac{\partial S}{\partial E_{w d+w}}=\frac{1}{1.86}\left\{\frac{B \times F_{w d+w}}{.2 \times m_{w d+E M C}}-.94 \times \frac{F_{w d+w}\left(L_{w d+w}-L_{w d}\right)}{E_{w d} \times F_{w d} \times L_{w d}}\right\} \\
& \frac{\partial S}{\partial F_{w d+w}}=\frac{1}{1.86}\left\{\frac{\beta \times E_{w d+w}}{.2 \times m_{w d+E M C}}-.94 \times \frac{E_{w d+w}\left(L_{w d+w}-L_{w d}\right)}{E_{w d} \times F_{w d} \times L_{w d}}\right\} \\
& \frac{\partial S}{\partial L_{w d+w}}=\frac{1}{1.86}\left\{-.94 \times \frac{E_{w d+w} \times F_{w d+w}}{E_{w d} \times F_{w d} \times L_{w d}}\right\} \\
& \frac{\partial S}{\partial E_{w d}}=\frac{1}{1.86}\left\{.94 \times \frac{E_{w d+w} \times F_{w d+w}\left(L_{w d+w}-L_{w d}\right)}{F_{w d} \times L_{w d} \times E^{2}{ }_{w d}}\right\} \\
& \frac{\partial S}{\partial F_{w d}}=\frac{1}{1.86}\left\{.94 \times \frac{E_{w d+w} \times F_{w d+w}\left(L_{w d+w}-L_{w d}\right)}{E_{w d} \times L_{w d} \times F^{2} w d}\right\} \\
& \frac{\partial S}{\partial L_{w d}}=\frac{1}{1.86}\left\{-.94 \times \frac{E_{w d+w} \times F_{w d+w}}{E_{w d} \times F_{w d}} \cdot \frac{-L_{w d+w}}{L_{w d}^{2}}\right\} \\
& \frac{\partial S}{\partial m_{w d+E M C}}=\frac{1}{1.86}\left\{\frac{\beta x E_{w d+w} \times F_{w d+w}}{.2\left(m_{w d+E M C}\right)^{2}}\right\} \\
& \frac{\partial S}{\partial N_{w d+E M C}}=\frac{1}{1.86}\left[\frac{E_{w d+w} \times F_{W d+w}}{.2 \times m_{w d+E M C}}\right] \times \frac{\left(1 / N_{w d+E M C}^{2}\right) \times 1.002}{1 / N_{w d+E M C}-8 \times 10^{-7}} \\
& \frac{\partial S}{\partial N_{w d+w}}=\frac{-1}{1.86}\left[\frac{E_{w d+w} \times F_{w d+w}}{.2 \times m_{w d+E M C}}\right] \times \frac{1 / N^{2}}{1 / N_{w d+w}-8 \times 10^{-7}}
\end{aligned}
$$


In calculating the error involved in measuring gamma counts $N$, since gamma emissions have poisson distribution of intensity, the standard deviation of $N$ is $S_{n}=N^{1 / 2}$. For a $95 \%$ confidence interval:

$$
\Delta N=2 S_{n}=2 N 1 / 2
$$

Therefore:

$$
\begin{aligned}
& \Delta N_{w d+w}=2 N_{w d+w}^{1 / 2} \\
& \Delta N_{w d+E M C}=2 N_{w d+E M C}^{1 / 2}
\end{aligned}
$$

Assuming on average (for sample \#3, scan times 03 and 04).

$$
\begin{aligned}
& E_{w d+w}=5.065 \pm .1 \mathrm{~cm}, \quad, E_{w d}=5.047 \pm .1 \mathrm{~cm} \\
& F_{W d+w}=8.956 \pm .1 \mathrm{~cm} \quad, F_{W d}=8.573 \pm .1 \mathrm{~cm} \\
& L_{W d+w}=4.483 \pm .1 \mathrm{~cm}, \quad L_{w d}=4.341 \pm .1 \mathrm{~cm} \\
& m_{W d+E M C}=75 \pm .5 \mathrm{gm} \\
& N_{W d+w}=5 \times 10^{4} \pm 447 \text { counts } \\
& N_{W d+E M C}=9 \times 10^{4} \pm 600 \text { counts }
\end{aligned}
$$

Evaluating equation (U24) we have:

$$
\Delta S=0.03503 \simeq 0.035
$$

for an average saturation of $S=0.7459$

Thus $\frac{\Delta S}{S}=4.69 \%$ 
Calculating the uncertainty for maximum and minimum values of saturation will result in:

Sample \#3, location $z_{1}$ at scan time we have:

$$
\begin{aligned}
& S_{\max }=1.015 \\
& N_{W d+E M C}=94586 \pm 615 \text { counts } \\
& N_{W d+W}=47252 \pm 434 \text { counts }
\end{aligned}
$$

Sample \#3, location $\mathrm{Z}_{20}$ at scan time 08 we have:

$$
\begin{aligned}
& S_{\min }=.383 \\
& N_{w d+E M c}=87973 \pm 593 \text { counts } \\
& N_{w d+w}=63655 \pm 504 \text { counts }
\end{aligned}
$$

Calculating equation (U24), the following table will result.

\section{Table III}

SATURATION UNCERTAINTY VALUES

Min. Saturation

Average Saturation

Max Saturation

\begin{tabular}{c|c|c}
$S$ & $\Delta S$ & $\frac{\Delta S}{S}$ \\
\hline 0.383 & 0.0283 & $7.38 \%$ \\
0.7459 & 0.03503 & $4.69 \%$ \\
1.015 & 0.0382 & $3.76 \%$
\end{tabular}

Calculating the uncertainty in calculated unsaturated permeability $k(S(L))$ proved to be practically impossible through an analytical method. This was mainly due to the fact that for the gradient parts $\frac{\partial P}{\partial S}$ and $\frac{\partial S}{\partial Z}$ values of curve fits were used. Therefore, the best possible method for calculating the uncertainty of $k(S(L))$ seemed to be through actual numerical calculation. All the parameters involved in calculating $k(S(L))$ were perturbed randomly and $k(S(L))$ was calculated. 
This was repeated 51 times and through statistical analysis the uncertainty in $k(S(L))$ was calculated. Following is a detailed description of perturbation procedures utilized.

Since the uncertainty of saturation levels was calculated, the perturbation was done on saturation level and other parameters in the process of calculating $k(S(L))$. The values (averages) and their corresponding uncertainty levels used in calculation were:

$$
\begin{aligned}
& \Delta S=0.03503 \text { (uncertainty in saturation), for } S \text { values refer to } \\
& \text { appendix } C . \\
& Z_{0}=0.2024 \pm 0.1 \mathrm{~cm} \\
& Z_{L}=7.8936 \pm 0.1 \mathrm{~cm} \\
& \Delta Z=0.4048 \pm 0.01 \mathrm{~cm} \text { (integration interval) } \\
& \omega=500 \pm 20 \mathrm{rpm} \\
& \Delta t=30 \text { seconds (uncertainty in time measurement) for } t \text { values } \\
& \text { refer to appendix } F
\end{aligned}
$$

51 curve fit values for $P_{C}(S)$ and $S(Z)$ were calcualted with perturbed parameter and then their values (for gradient terms in equation (U1)) along with other perturbed parameter were used to calculate $k(S(L))$ 'S.

The variations enforced on parameters had to be of a random nature and since a normal distribution of errors had to be assumed, the random perturbation had to have a normal distribution. The computer used to perform the calculations was capable of generating a uniformly distributed random number between 0 and 1 (code: RND(1)). To generate a normally distributed random number the following codes were utilized: 
$y=\emptyset . \emptyset$

FOR I $=1$ to 12

$y=y+\operatorname{RND}(1)$

NEXT I

$y=y-6.0$

Resulting variable $y$ is a normally distributed random number with a range of $-6<y<6$, average of zero, and standard deviation of 1 (i.e. $95 \%$ of times $y$ has a value between -2 and 2 ). A brief discussion for justifying the utilized algorithm will be presented at the end of this appendix.

Since a normal distribution for errors was assumed the uncertainties in each parameter was equal to twice its standard deviation value.

Saturation - $S \pm \Delta S=S \pm 2 \sigma_{S}$

Therefore anytime during the calculations a parameter had to be perturbed, a random variable y was generated and multiplied by half the uncertainty of the parameter, or one standard deviation, and that was the amount of variation introduced to that parameter.

Perturbed saturation $=S+\left(\sigma_{S} \times y\right)=S+\frac{\Delta S}{2} \times y$

Sample \#3 was used for calculating perturbed values of unsaturated permeability $k(S(L))$. Calculations were repeated 51 times and results of calculated $k(S(L)$ ) for the first four runs of the sample \#3 (with end saturation levels $.692 \leq \mathrm{S}(\mathrm{L}) \leq .791$ ) are presented in Figures 55 to 58. Figures 59 to 62 present the histograms for same data. Following table summarizes the calculated results for relative permeability $(k(S) / k(s a t)$.$) . In this table "Best Estimate" stands for the values$ 
105

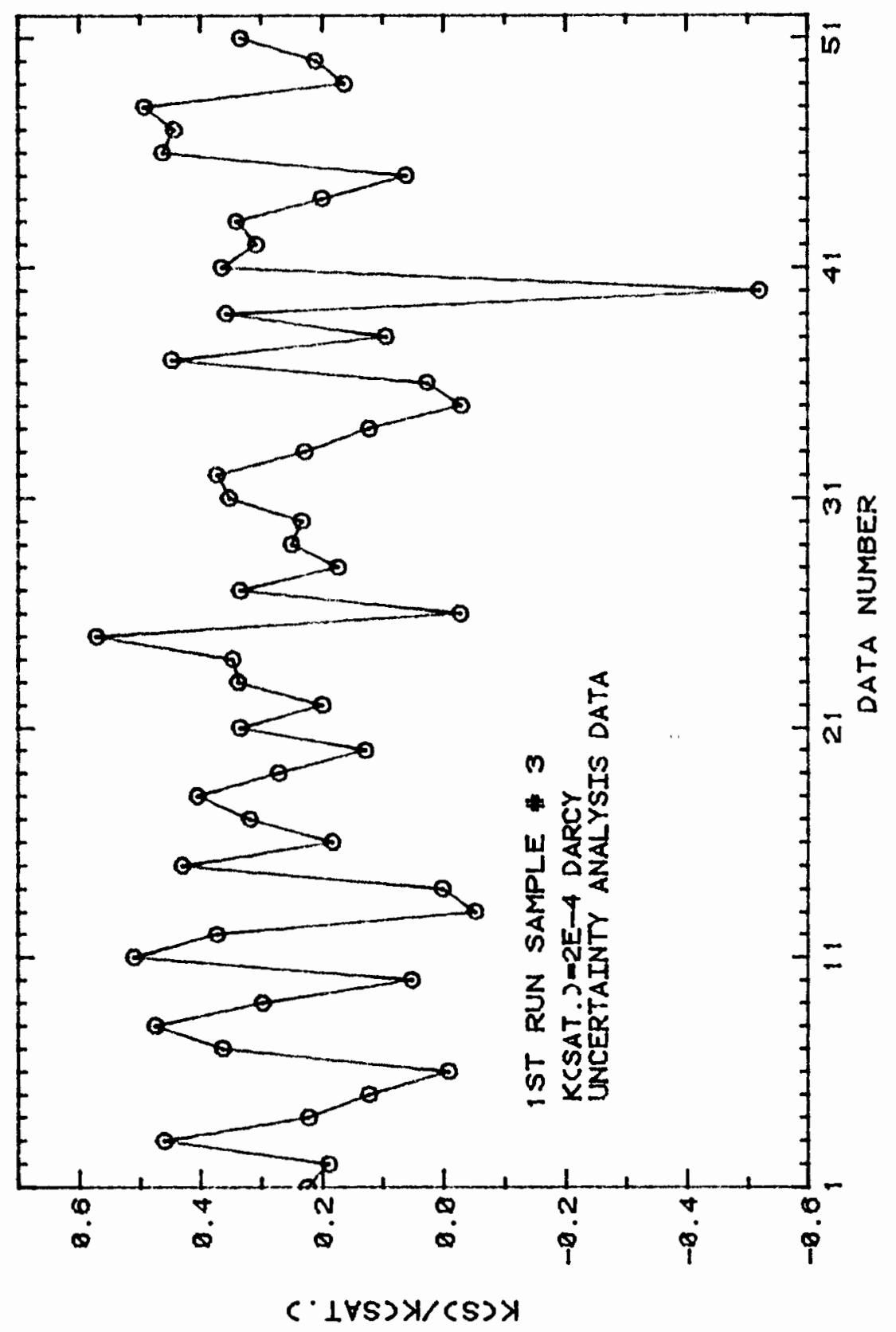

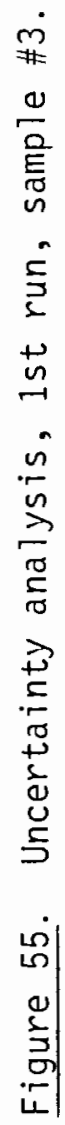




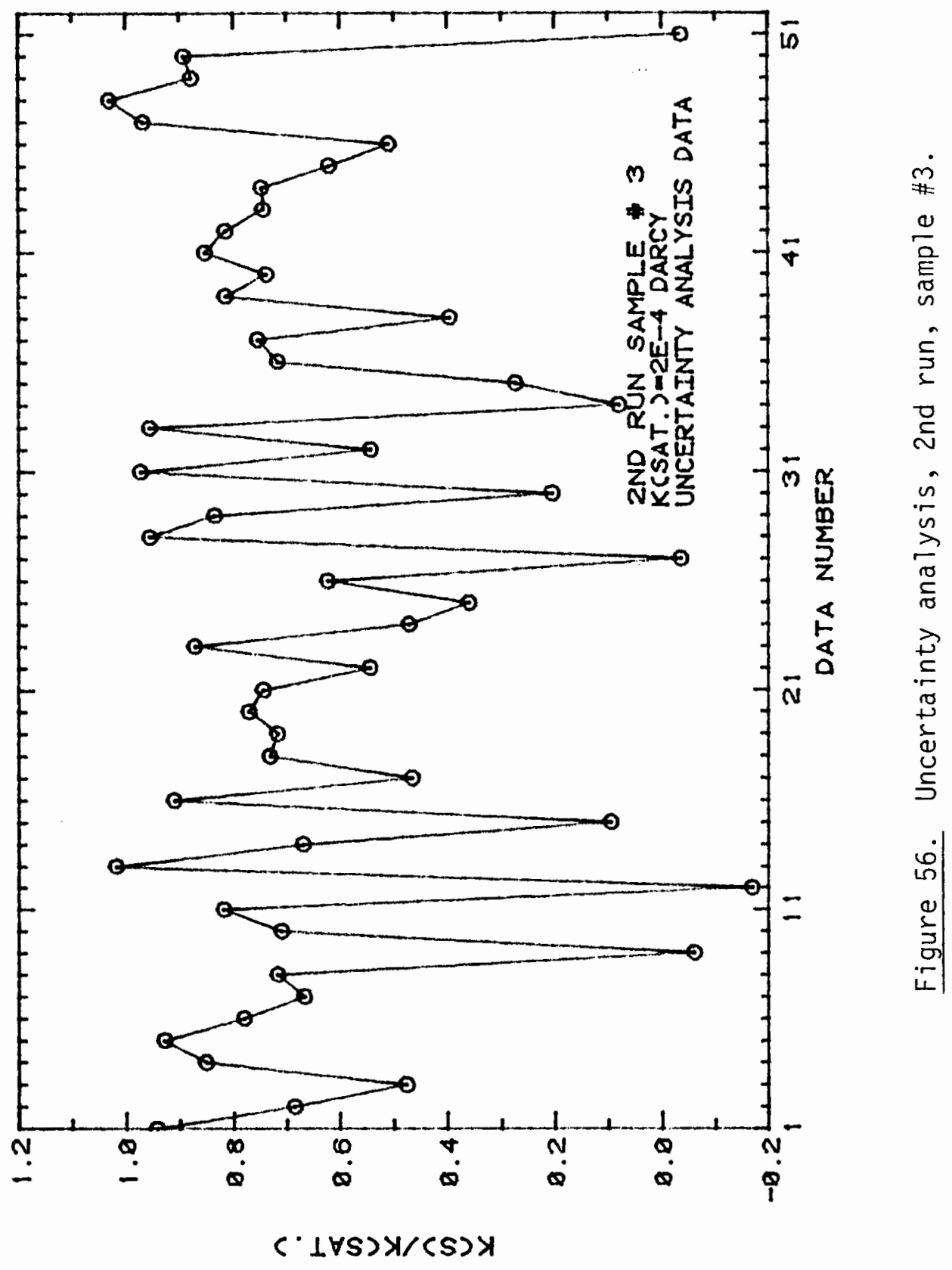




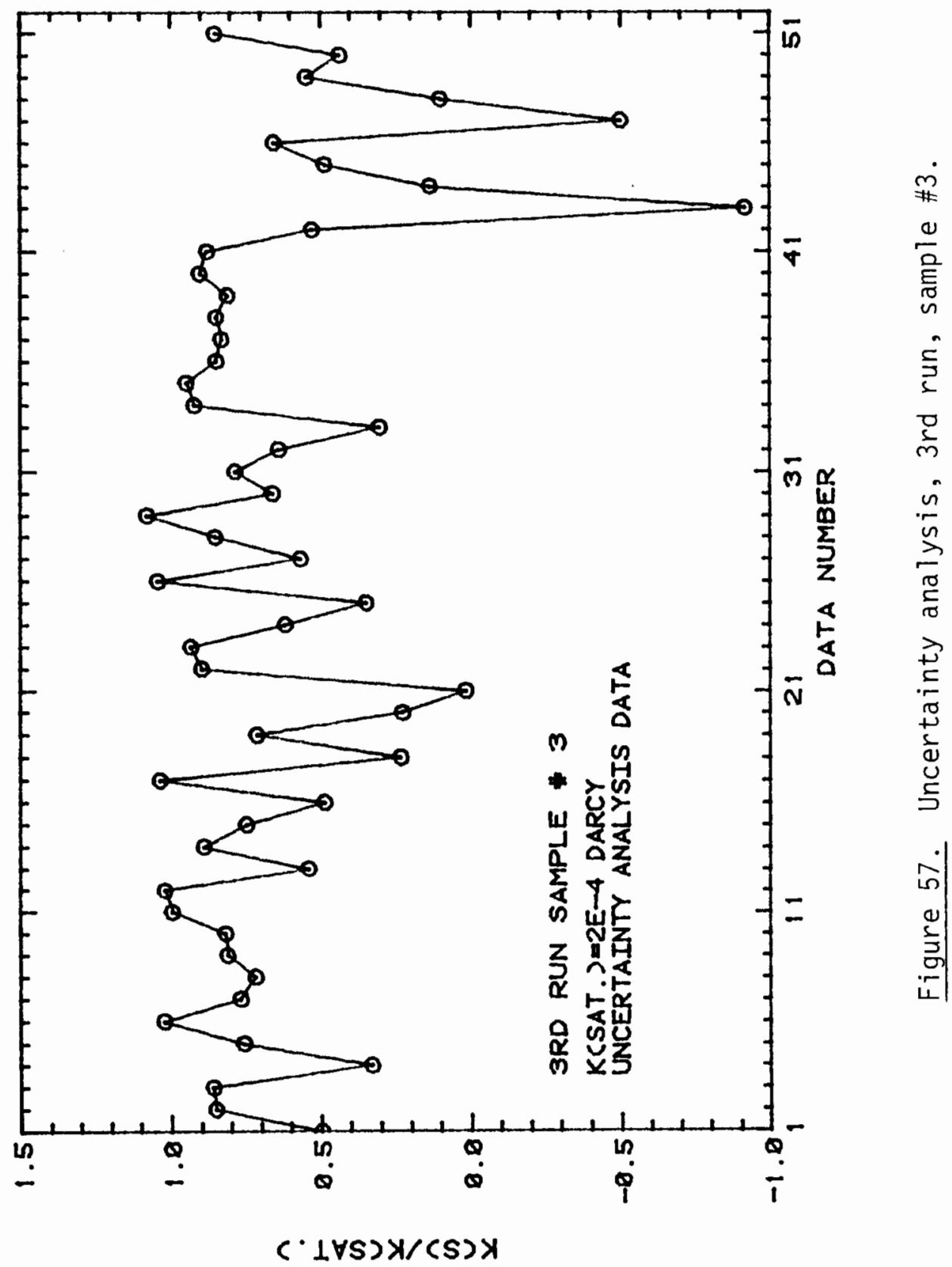




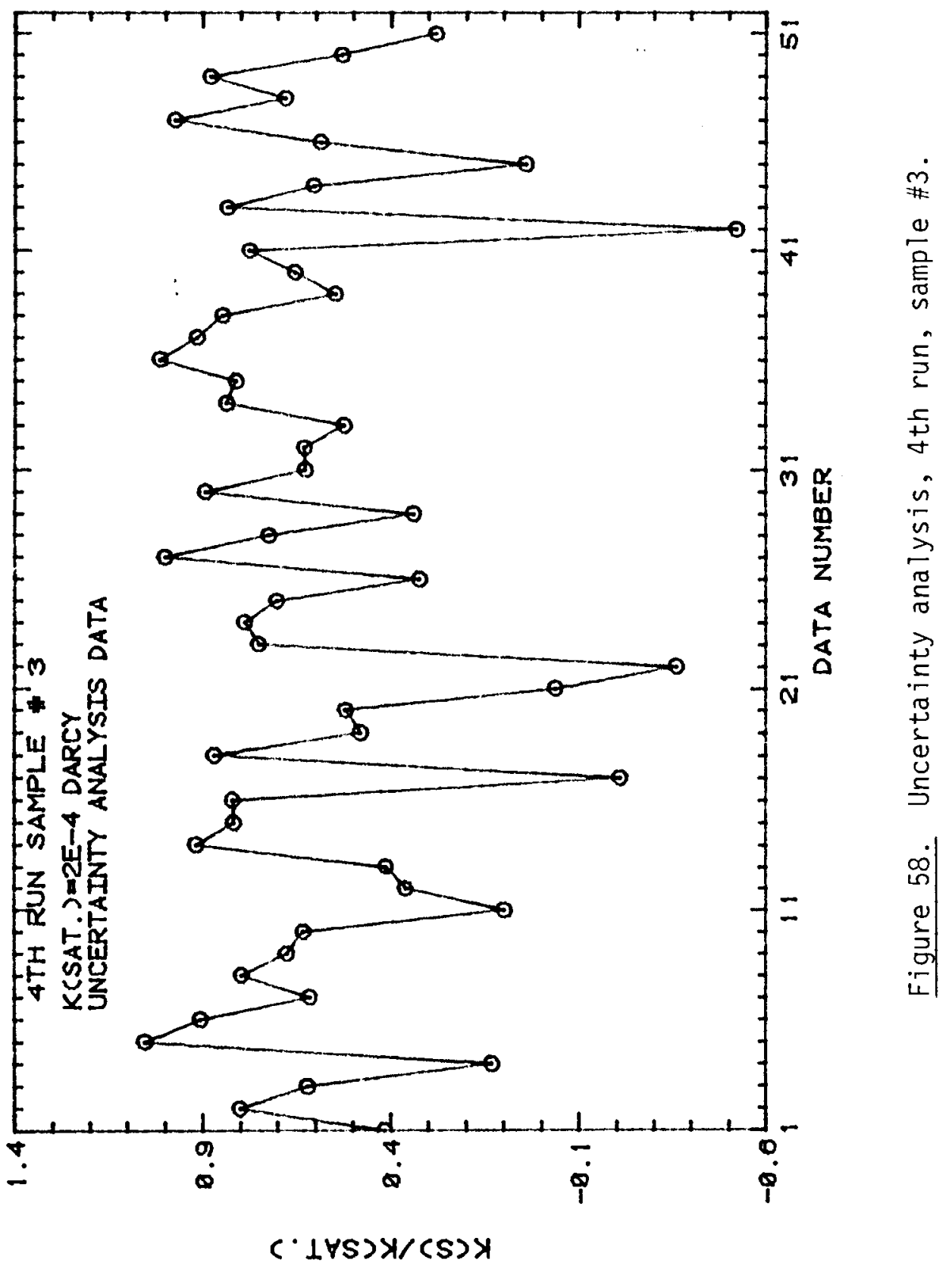




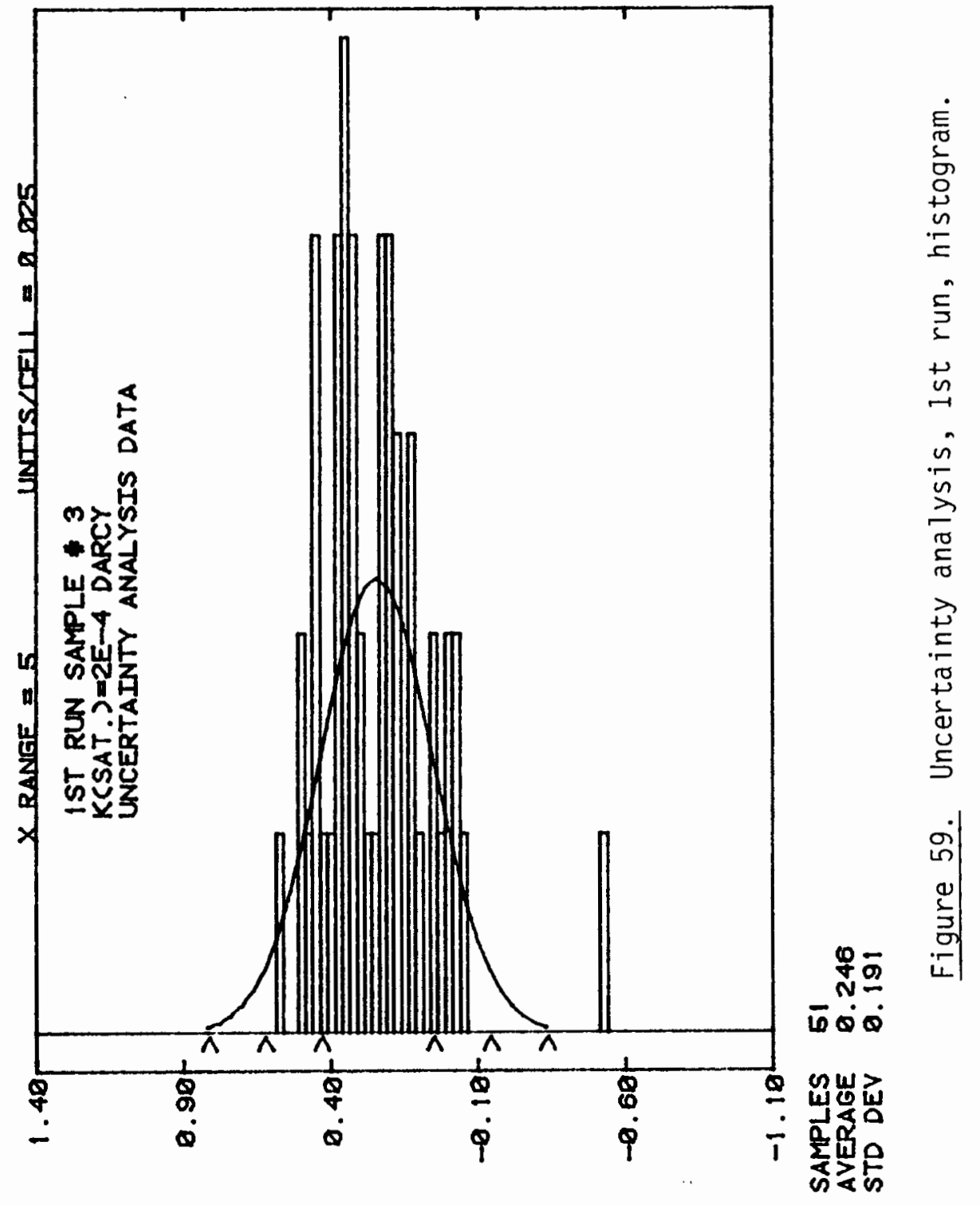

( 1 VS $) \times /(S) X$ 


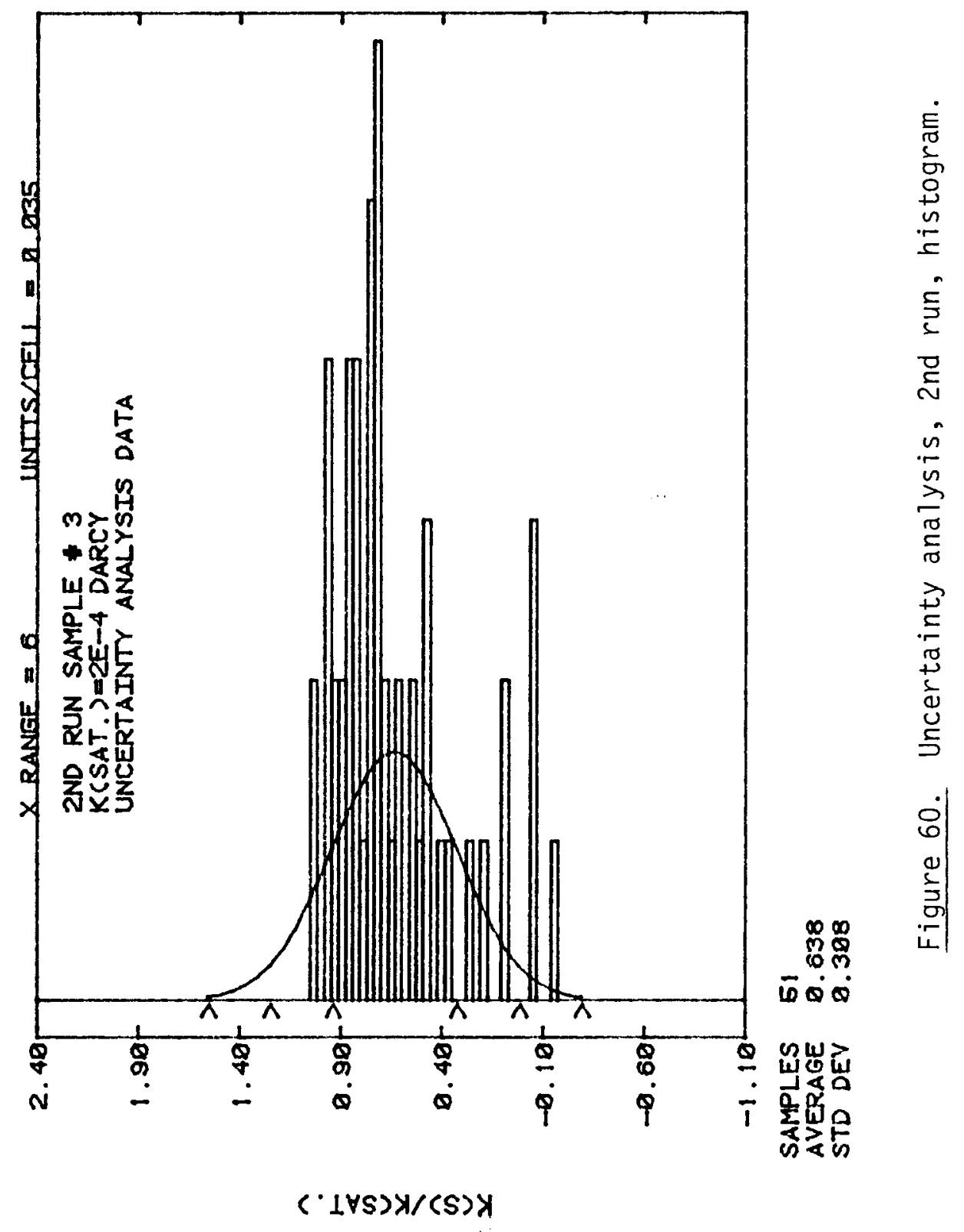




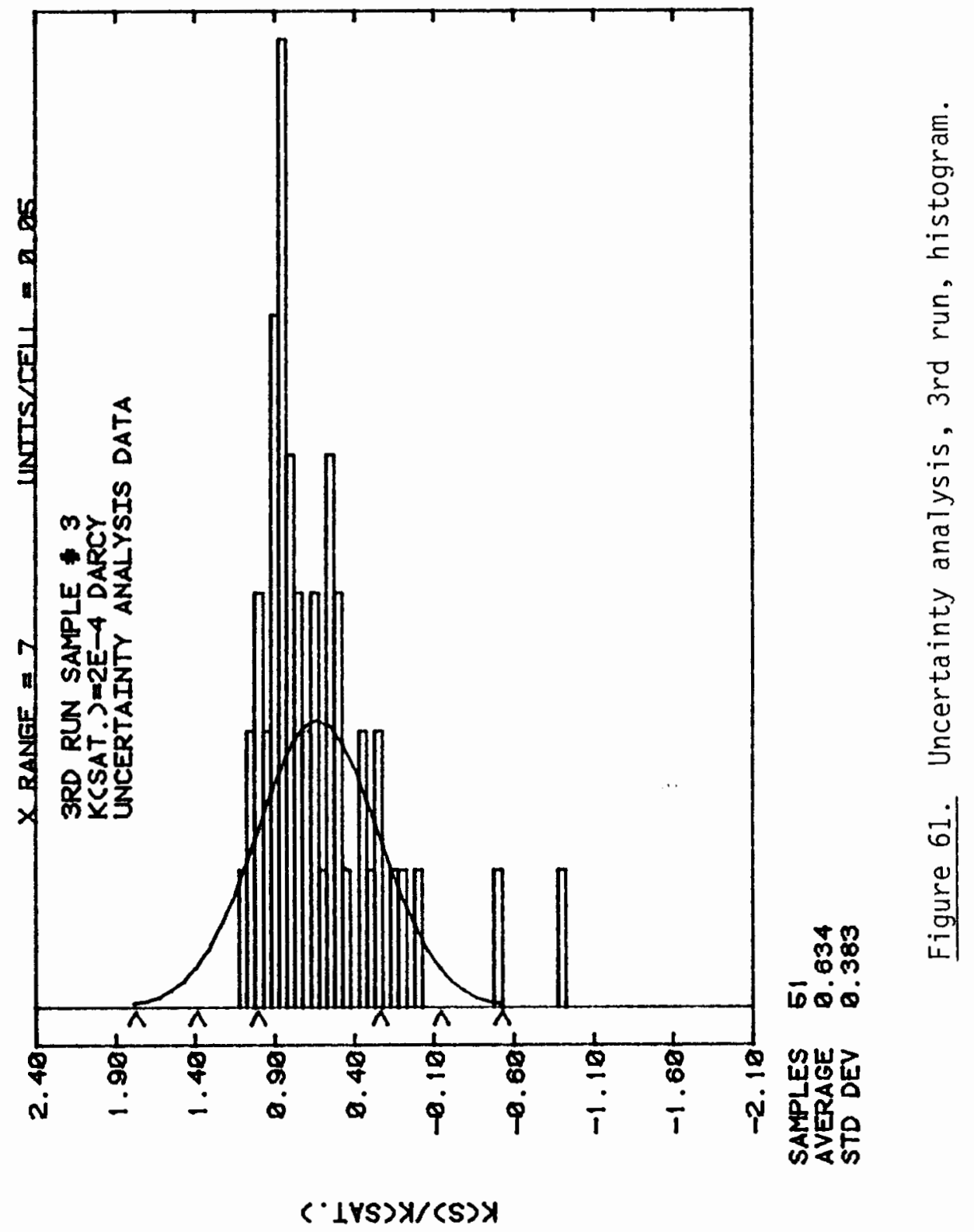




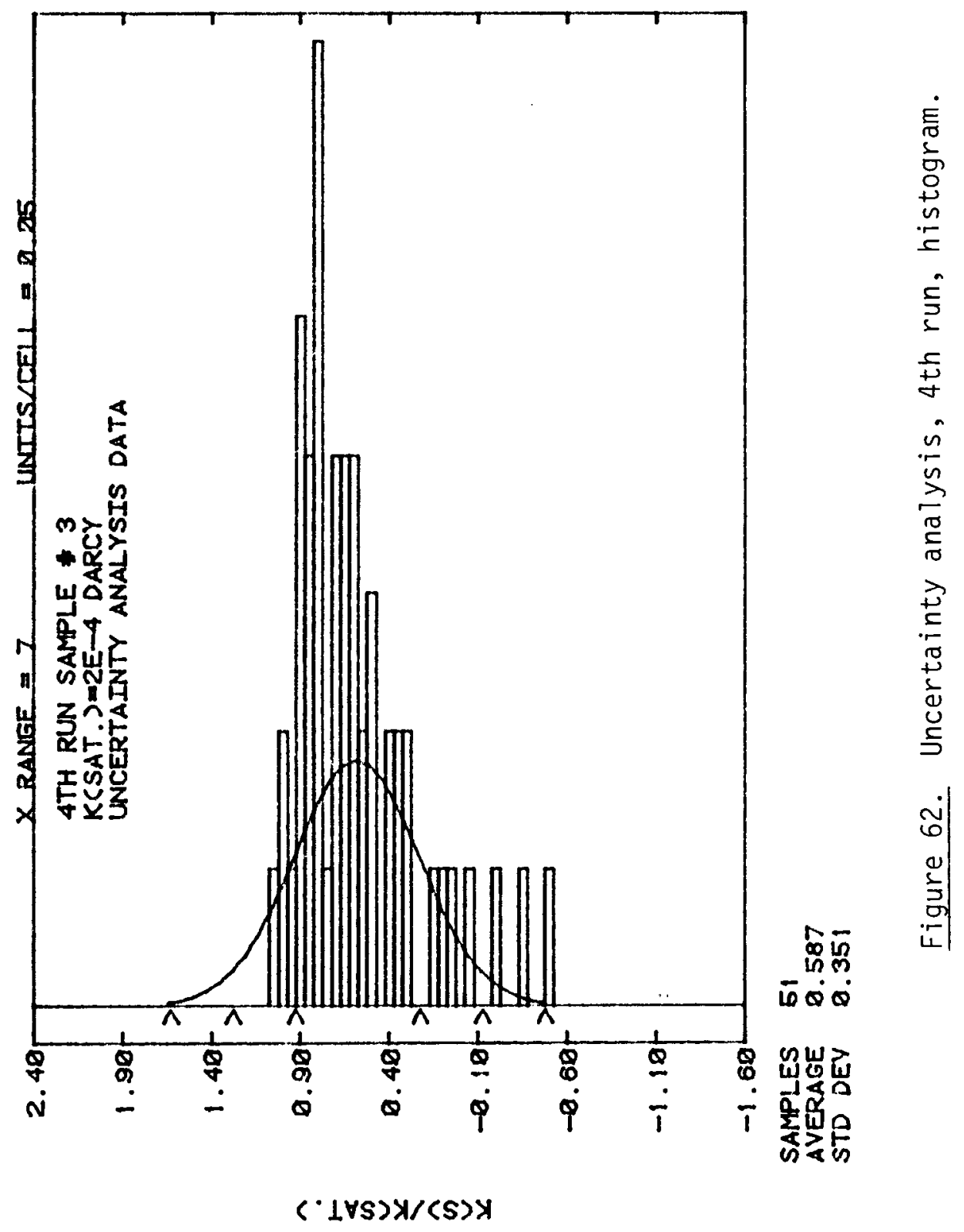


calculated with no perturbation and "Mean" stands for the calculated average from the perturbed calculations.

TABLE IV

RELATIVE PERMEABILITY UNCERTAINTY VALUES

\begin{tabular}{c|c|c|c|c|c} 
Run & $\begin{array}{c}\text { Scan } \\
\text { Time }\end{array}$ & $\begin{array}{c}k(S) / k(\text { sat.) } \\
\text { Best Estimate }\end{array}$ & $\begin{array}{c}k(S) / k(\text { sat.) } \\
\text { Mean }\end{array}$ & $\begin{array}{c}\sigma k(S) / k(\text { sat.) } \\
\text { Standard } \\
\text { Deviation }\end{array}$ & $\begin{array}{c}\text { Saturation } \\
\text { Best } \\
\text { Estimate }\end{array}$ \\
\hline 1 & $\emptyset \emptyset \rightarrow \emptyset 1$ & .2376 & .246 & .191 & .791 \\
2 & $\emptyset 1 \rightarrow \emptyset 2$ & .7219 & .638 & .308 & .745 \\
3 & $\emptyset 2 \rightarrow \emptyset 3$ & .7014 & .634 & .383 & .719 \\
4 & $\emptyset 3 \rightarrow \emptyset 4$ & .6108 & .587 &. .351 & .692
\end{tabular}

Using the results for the four runs to get an average standard deviation for the relative permeability $(k(S) / k(s a t)$.$) we have:$

$$
\sigma_{\text {ave }}=\left[\left(\sum_{i=1}^{4} \sigma_{i}^{2}\right) / 4\right]^{1 / 2}=0.3167
$$

since we have assumed normal distribution we have:

$$
\Delta(k(S) / K(\text { sat. }))=2 \sigma_{\text {ave }}=0.6334
$$

and relative error will be:

$$
\frac{\Delta(k(s) / k(\text { sat. }))}{k(s) / k(\text { sat. })}=\frac{0.6334}{0.5679}=112 \%
$$

In conclusion the results of this appendix indicate that for an average saturation value of 0.746 with a probability of $95 \%$ any measured saturation level is within $\pm 4.7 \%$ of correct measured value, and any calculated unsaturated permeability value is within $\pm 112 \%$ of correct calculated value. 


\section{DISCUSSION}

Despite the low level of uncertainty in saturation levels a very high level of uncertainty is observed in final result of $k(S(L))$. This is due to the fact that for each gradient term in equation (U1) 20 saturation points are used to evaluate a curve fit and also the integration part in equation (U1) utilizes 40 saturation point. Altogether the errors in saturation levlels effect $k(S(L))$ for 120 times. In addition to individual effect of saturation level errors, the fact that gradient of a set of data is much more sensitve to perturbation in a data point than the data points themselves indicate that high levels of uncertainty in $k(S(L))$ is not out of order.

Justification of algorithm used for generating normally distributed random numbers.

A uniform distribution with parameters $\alpha$ and $\beta$ is presented as:

$$
\begin{aligned}
& f(x) \\
& f(x)=\begin{array}{ll}
\frac{1}{\beta-\alpha} & \text { for } \alpha<x<\beta \\
\emptyset & \text { elsewhere }
\end{array}
\end{aligned}
$$

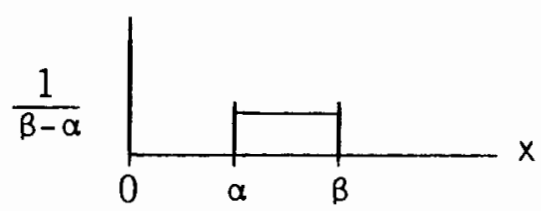

Mean and variance of this distribution are (Miller, 1977)

$$
\begin{aligned}
& \text { mean }=\bar{x}=\frac{\alpha+\beta}{2} \\
& \text { variance }=\sigma^{2}=\frac{1}{12}(\beta-\alpha)^{2}
\end{aligned}
$$

For random numbers $x$ between 0 and 1 we have

$$
\begin{aligned}
& \bar{x}=\frac{0+1}{2}=.5 \\
& \sigma_{x}^{2}=\frac{1}{12}(1-0)^{2}=\frac{1}{12}
\end{aligned}
$$


if variable $y$ is such that

$$
y=\left(\sum_{i=1}^{12} x_{i}\right)-6 \text { then }-6<y<6 \quad \text { where } 0<x_{i}<1 \text {. }
$$

and

$$
\text { Mean } y=\bar{y}=\left(\sum_{i=1}^{12} .5\right)-6=6-6=0
$$

and variances add up (note: subtracting constant 6 will not affect the variances).

$$
\sigma_{y}^{2}=\sum_{i=1}^{12} \sigma_{x}^{2}=12 \times \frac{1}{12}=1
$$

A theorem by Miller (1977) states that if a random variable has the value $y$ and a distribution with the mean $\bar{y}$ and variance $\sigma_{y}^{2}$, the corresponding normal standardized variable has the value $g=\frac{y-\bar{y}}{\sigma_{y}}$ and its distribution has zero mean and unit variance. Thus

$$
g=\frac{y-0}{1}=y
$$


APPENDIX B

RAW DATA GAMMA COUNTS FOR SAMPLE \#3 
SAMPLE \#3 INITIALIZATION DATA

FEFACI' -

SFHOLE H 3 HMTTIFLIZATIOH DATA

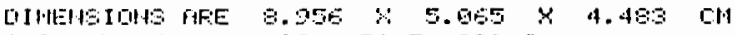

HWITIFL HET WFSS IS 473.5 GFFHS

HODO FTTEHIATIOH IS - 189

WITEF ATTEH HATIOH IS .201

GFHA FESORPTIOH TIME IS SE- 15 SECOHES 
SAMPLE \#3 RAW DATA GAMMA COUNTS

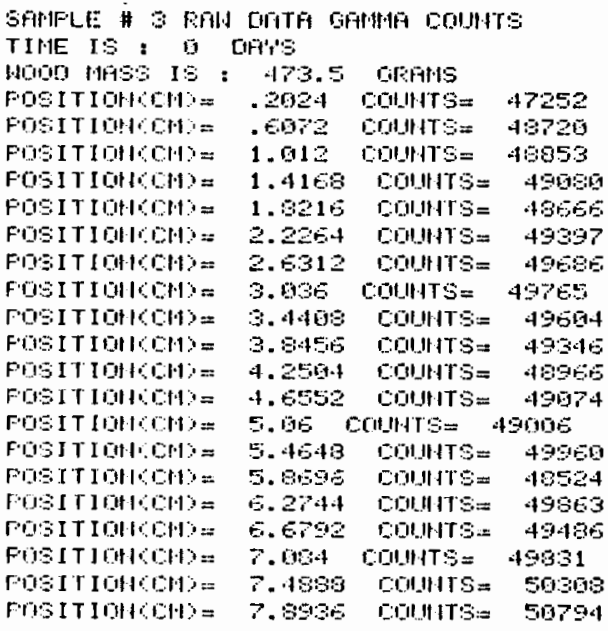

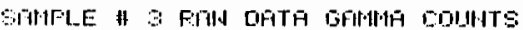

TJUIE $15 ; .75$ CIA'T'S

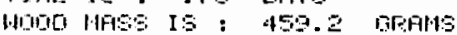

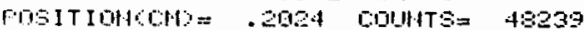

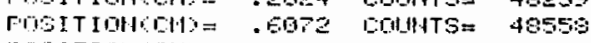

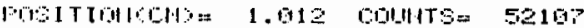

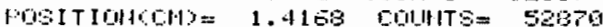

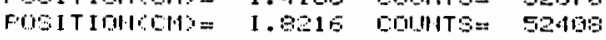

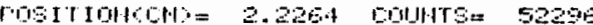

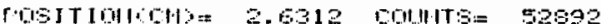

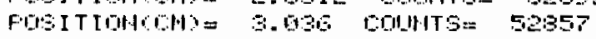

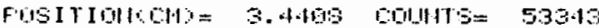

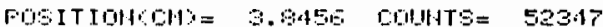

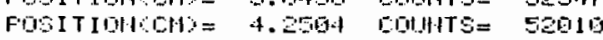

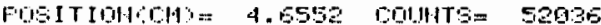

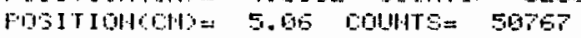

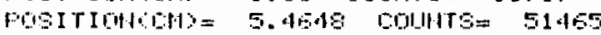

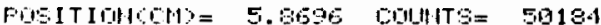

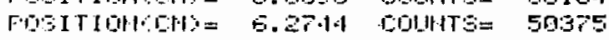

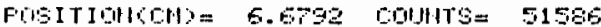

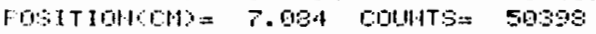

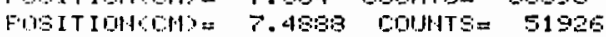

FUE1T[DHCCHA = 7.

SFHALE \# 3 FINI LATA GAHIITH COLHTS

TINE IS: 1.75 [AF'T'S

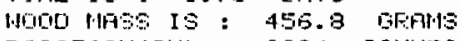

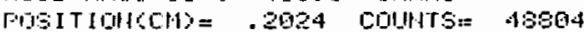

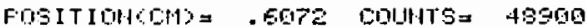

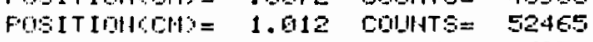

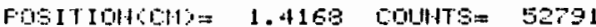

FOEITIOHCOH= 1.8215 COHHTS= 52191

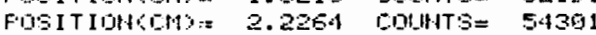

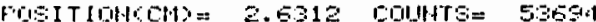

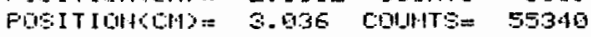

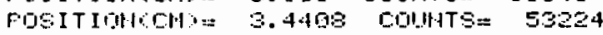

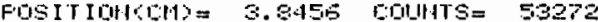

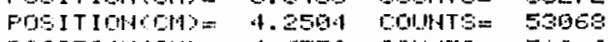




\begin{tabular}{|c|c|c|c|}
\hline & & & \\
\hline $1101+1=$ & 5 & $\operatorname{con}+4 T S=$ & 5 \\
\hline 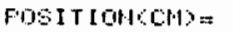 & $5 .+16+13$ & COUHATS= & $=$ \\
\hline $05 \operatorname{ITOH} \operatorname{con}=$ & 5.8690 & Couth $5=$ & \\
\hline TI $14042=$ & 5.2744 & CDINHTS= & 52 \\
\hline 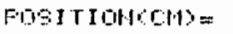 & 5.6992 & couttrs= & \\
\hline$+1 \%=$ & 7. & cons & \\
\hline 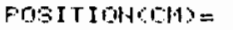 & 7.4868 & $T:=$ & \\
\hline Fos I T I & 7.0935 & & \\
\hline$A$ FAM & [IFTTA D & 101 & \\
\hline TIUE IS: 3.9 & Lna'rs: & & \\
\hline HODO HASS IS: & 452.5 & DFAAHS & \\
\hline Fos IT I $01+6 \mathrm{CH}=$ & .2024 & C:OU! & 48 \\
\hline$|+1\rangle=$ & .5072 & colol & $48590^{\circ}$ \\
\hline $25 \mathrm{I} T \mathrm{IOt}$ & 112 & Contht $3=$ & 52 \\
\hline$C M=$ & $1.41 E 3$ & $1 \mathrm{TS}=$ & 5 \\
\hline $1+12=$ & 1. & : & 53 \\
\hline$M i=$ & 2.2264 & $\mathrm{CO}$ & 5 \\
\hline $1 \cdot 13=$ & 5312 & ITS= & 5 \\
\hline EITIOH & 3.103 & con_t & 5.5954 \\
\hline$p=$ & 3. & $\mathrm{TS}=$ & 54205 \\
\hline$H:=$ & 3 & $5=$ & 5.3734 \\
\hline ओร) & 4.2504 & $\mathrm{r}=$ & 53 \\
\hline$y=$ & 552 & $\mathrm{COH}$ & 5234 \\
\hline $11=$ & 5. & coutstr:s= & 5,3509 \\
\hline FIEITIOHACH:= & 5.4548 & CDtHITS= & 5195 \\
\hline$H=$ & 5.506 & $\therefore: 1$ & 51 \\
\hline $19=$ & 44 & $5=$ & 52550 \\
\hline $119=$ & E. 6.892 & COHNITS:= & 51585 \\
\hline 0EITI & & collit & 51513 \\
\hline $19=$ & 7. & $1 \% S=$ & 5342 \\
\hline For 17 fald & 7.8936 & CDUHT:E= & 5.595 \\
\hline
\end{tabular}

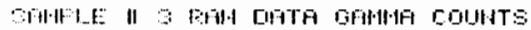

Tlit: 15 : 0.75 COA'T:

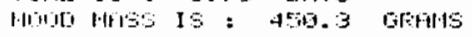

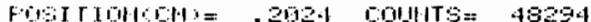

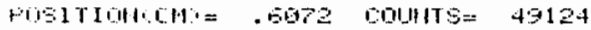

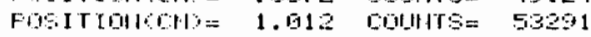

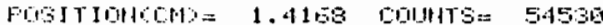

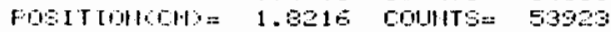

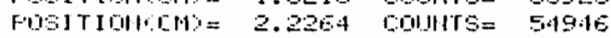

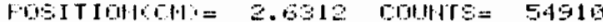

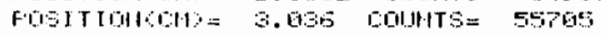

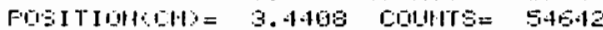

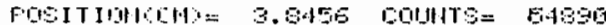

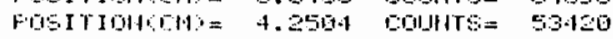

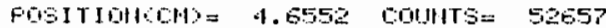

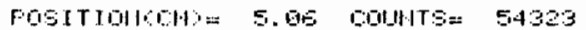

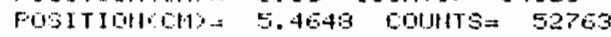

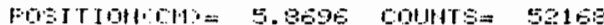

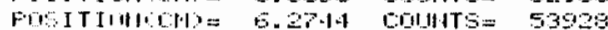

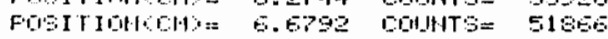

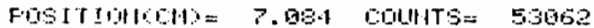

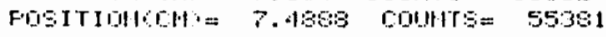

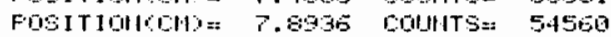

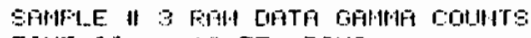

TIHE IS : 19.75 [AT'S

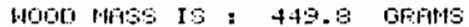

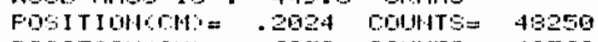

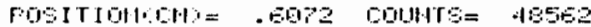

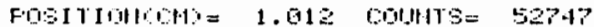

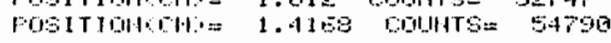

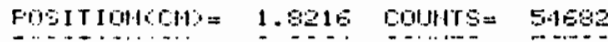




\begin{tabular}{|c|c|c|c|}
\hline & 22004 & Lot.JPt / S=ב & \\
\hline SIT I $04+2,0+1)=$ & 2.6312 & CONINTS $=$ & 56906 \\
\hline $0 \mathrm{SITIOH}$ Cons= & 3.055 & COUH TT $=$ & 55333 \\
\hline FOSI I IOHKCH)= & 3. 4469 & COUH+TS= & 54923 \\
\hline Fos I TIOHCOM $=$ & 3.9456 & COUUt+TS= & 796 \\
\hline Fos I I I H & 4.25144 & cout $19=$ & $544 E 6$ \\
\hline FOSI TIOH(CH)= & 4.6582 & COUUHT:S= & 54100 \\
\hline Fos $17101 \cdot(6)=$ & 5.06 & COUHTS:= & 523.3 \\
\hline 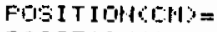 & $5.40+48$ & COLHATS= & 54598 \\
\hline 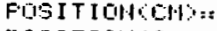 & 5.8096 & counts $=$ & 53371 \\
\hline 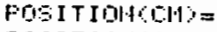 & 6.2744 & COHNTS:= & 53079 \\
\hline FOSI T IOHed & 6.6792 & COUNTS= & 54450 \\
\hline FosI TIOHCOD= & $\vec{\nabla} .00$ & CEIIH+TS= & 54253 \\
\hline POSITIOH $(0 \mathrm{H})=$ & 7.4898 & $\cot +475=$ & 59326 \\
\hline FosITIOHCEN = & 7.9936 & COI-1TS $=$ & $56: 01$ \\
\hline
\end{tabular}

SAMILLE $\| 3$ FIII DIATA GAHMA DOHNTS

TIME IS : 13.75 DAT'S

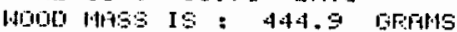

FOSITIOHKCH = .2924 DOINTS= 47761

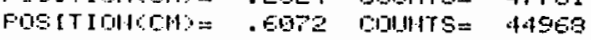

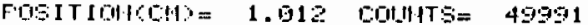

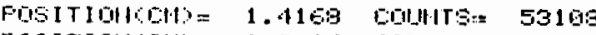

Fos ITIOHCH:= 1.8215 COHHTS= 54950

FOSITIOHOH = 2.226.4 COHITS= 57057

FOSITIOH:CH)= 2.6312 COHNTS= 55431

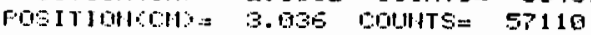

Fostrtollonly 3.4403 conlrs $=58027$

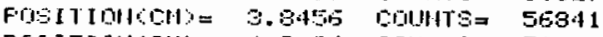

FOSITIOHCCH: $=4.2504$ COUHTS= 56205

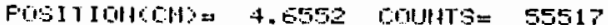

POITIOHCOH = 5.06 COHHTS= 56772

FOE 17 10HCOH: $=5.46 .43$ COUNHS=3 56324

FOSITLUHCH = 5.8696 COUHTS= $\mathbf{5 3 4 2 9}$

Fosmrowlow) $=6.274 .4$ Counts: 55492

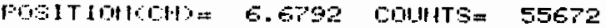

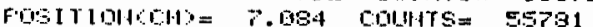

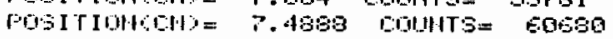

FOSITIOHCON= 7.5936 CONITS= 57573

SFHFLE \# 3 FFH DATA GRMHA COUHTS

TINE IS : 25.83 [IA'T'S

WOOO WFS IS : 443.7 GRFils

FOSITIOHACH $=$.2024 COUHTS= 48191

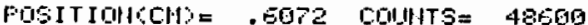

FOSITIDHCOW= 1.012 countT= 53135

FOSITIOHCOH= 1.4168 COHHTS= 55210

FOSITIDHCOND= 1.8216 COUHTS= 54969

FosITIOHCW:= 2.22E4 conHTS= 50100

FOSITIUWCH = 2.6312 CONHITS 57129

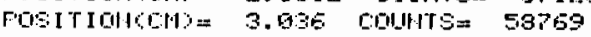

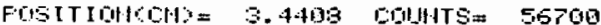

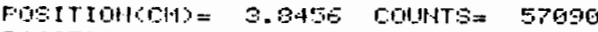

FüITIBHCH:= 4.2504 counts= 55517

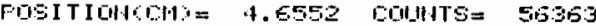

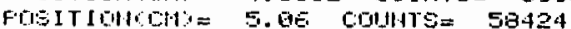

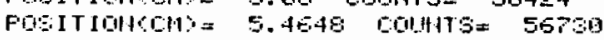

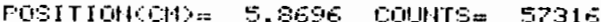

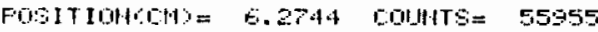

Fositiontow = 6.6792 Counts= 57420

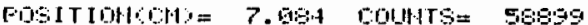

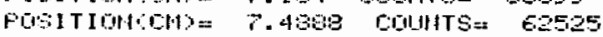

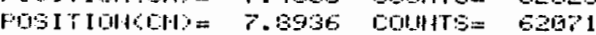

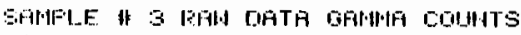

TIHE IS: 15.75 CIA'S 


\begin{tabular}{|c|c|c|c|}
\hline & & & \\
\hline 95 I т I $1040 \mathrm{CH}=$ & .2024 & CDINHTS= & 48692 \\
\hline FOSI TI IUACOH)= & .6072 & Cot_H+TS= & 48293 \\
\hline FOSIT IOH $(\mathrm{CH})=$ & 1.912 & DOMN:TS $=$ & 51075 \\
\hline Fos I T IOH $10 \mathrm{CH}=$ & 1.4150 & Counts= & 54353 \\
\hline FOSITIOHARY= & 1.8216 & EOLHTS $=$ & 50457 \\
\hline Frostionfoh) = & 2.204 & COUl_t $1 \mathrm{TS}=$ & $577+4$ \\
\hline FEITIBHCOH)= & 2.6012 & Cout $+5=$ & 57094 \\
\hline F"GS I T I & 0.936 & Colltits $=$ & 53332 \\
\hline FOSI I I DHA Chly= & 3.44013 & ConntT $S=$ & 57969 \\
\hline F0s I T IDHCCH = & 3.8456 & COHH:T= & 60065 \\
\hline Fog ITIOH $(10)=$ & 4.2564 & countrs= & 59436 \\
\hline Fos I T104-1019= & 4.0552 & Coullt:s= & 58088 \\
\hline FOEITIOH $(0,4)=$ & 5.95 & COHAt $1 \mathrm{TS}=$ & 59754 \\
\hline FDE I TIOH WOW = & 5.4649 & Loutts= & 59707 \\
\hline FOEITIOACLH= & 5.8096 & CON.114S= & 56013 \\
\hline 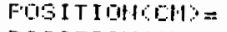 & 5.2744 & cout $45=$ & 59502 \\
\hline TOS1 TIOHed = & 0.6702 & $\operatorname{con}+1 \mathrm{~T} S=$ & 59754 \\
\hline 60 I T I & 7.094 & conllts $=$ & 60303 \\
\hline Ges [TI I & 7.4980 & conntrs= & 64539 \\
\hline 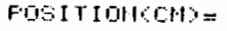 & 7.0906 & OHAts= & 1536 \\
\hline
\end{tabular}


FINALIZE DATA (DRY WOOD DATA) FOR SAMPLE \#3

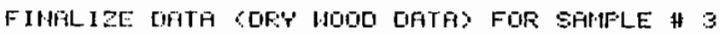

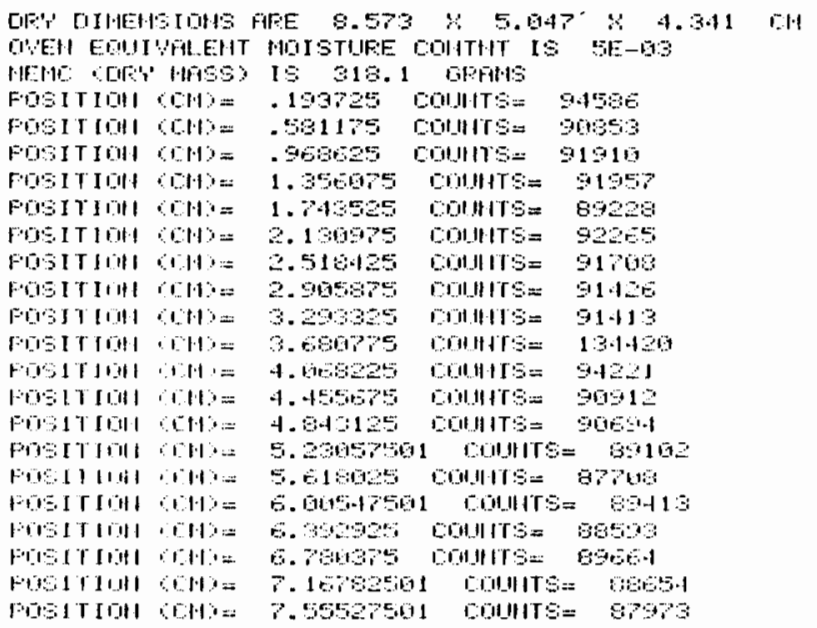


APPENDIX C

SATURATION LEVELS S(Z,T) FOR SAMPLE \#3 


\section{SPECIMEN \#3, SATURATION $(z, t)$}

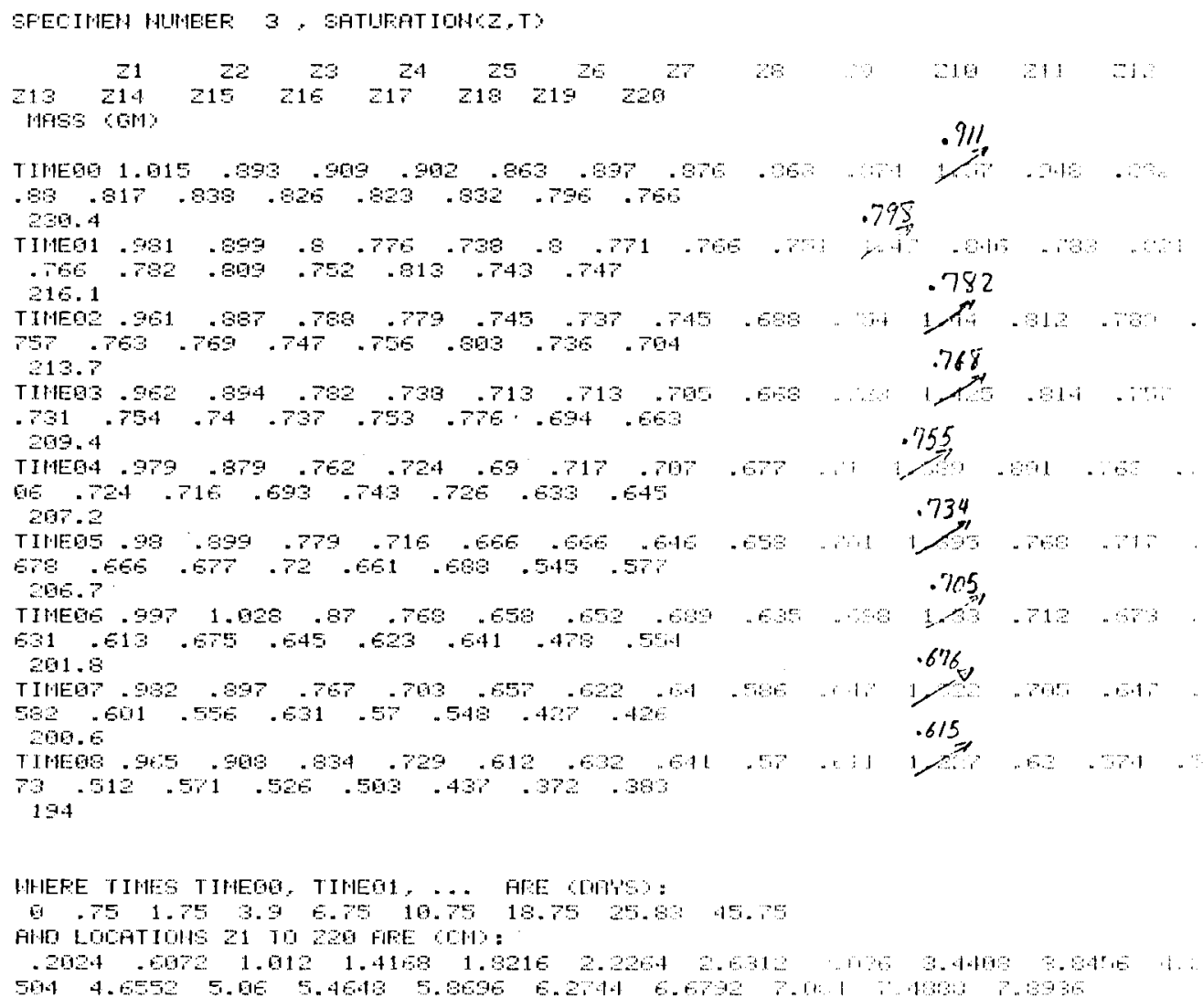


APPENDIX D

CURVE FIT RESULTS FOR SAMPLE \#3 


\section{SAMPLE \#3, SATURATION AS A FUNCTION OF LOCATION}

SFECIIEN \# 3

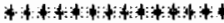

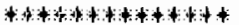

EATA FILE IS.9 3 SOFI DII:-

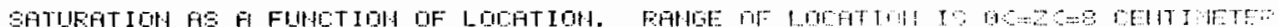

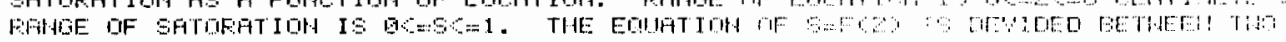

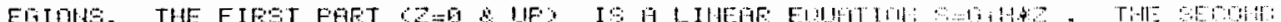

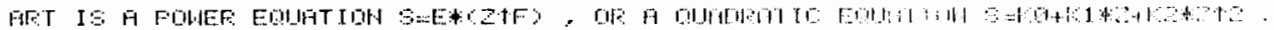
THE GOFFELATIOHA LOEFFIEIEHT -1 MESCF IS TO 1 THE EETTEF FTT WE HHIEE.

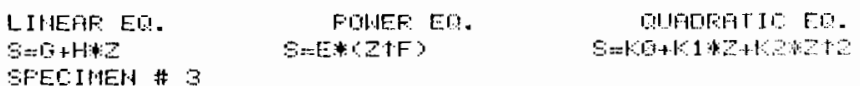

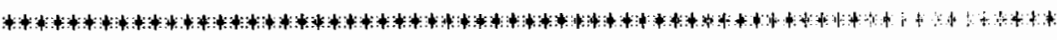

Fillt \# 0

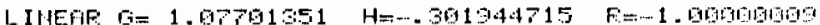

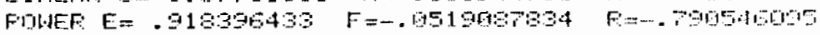

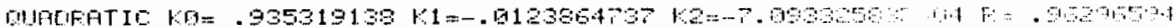

Finlt it 1

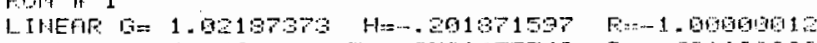

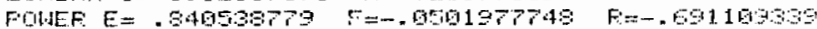

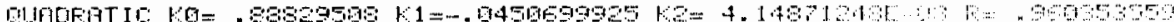

Fill \# 2

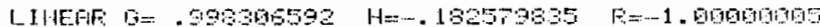

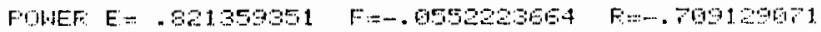

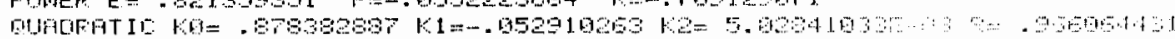

Fill \# 3

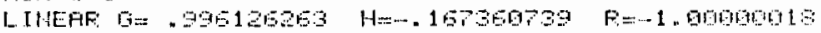

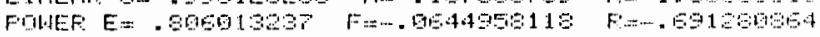

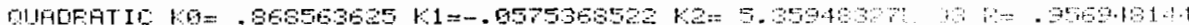

Fillt \# it

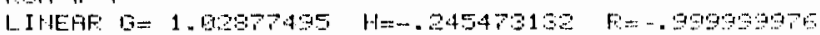

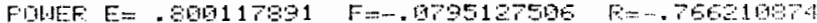

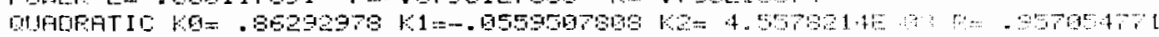

Filly \# 5

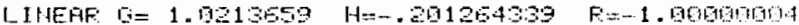

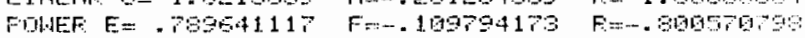

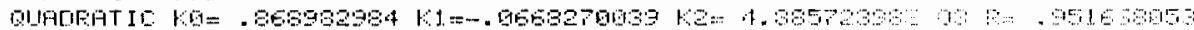

Fillt \# $\mathrm{S}$

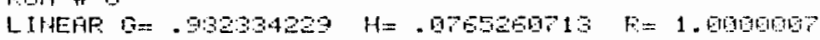

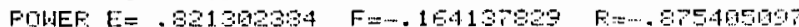

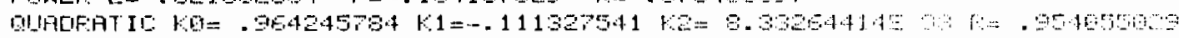

Fititi H 7

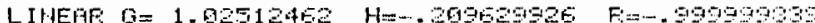

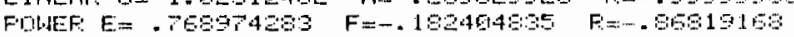

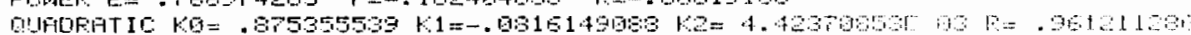

Fill \# 8

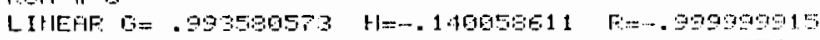

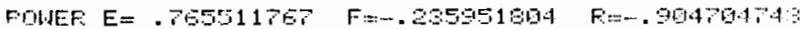

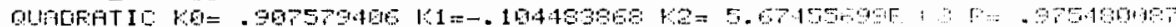

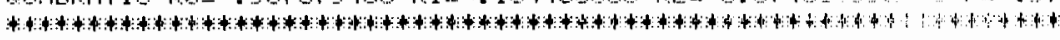




\section{SAMPLE \#3 AND \#4, CAPILLARY PRESSURE AS A FUNCTION OF SATURATION}

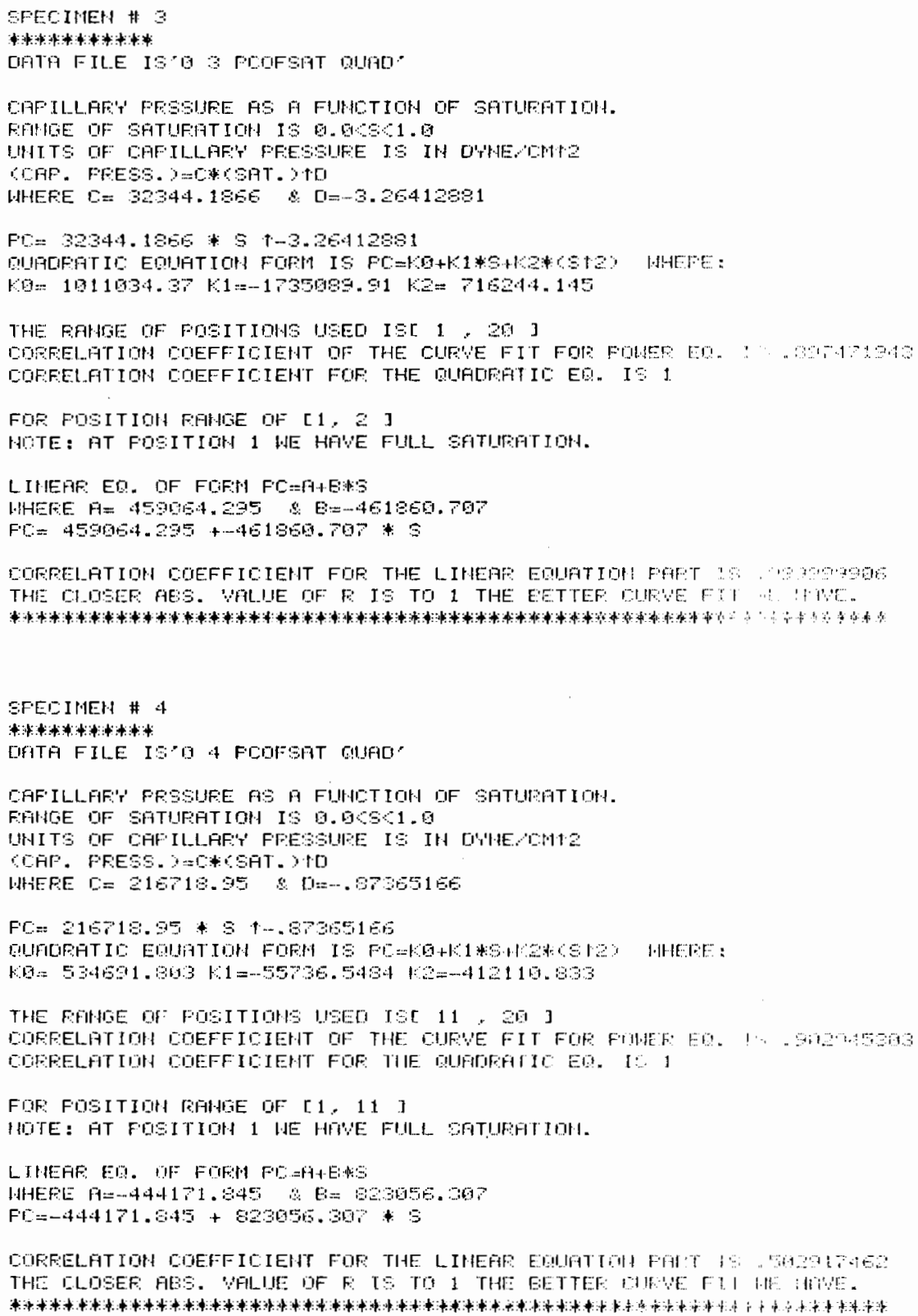


APPENDIX E

UNSATURATED PERMEABILITY VALUES FOR SAMPLE \#3 


\section{Specimen \#3, Unsaturated Permeability Values.}

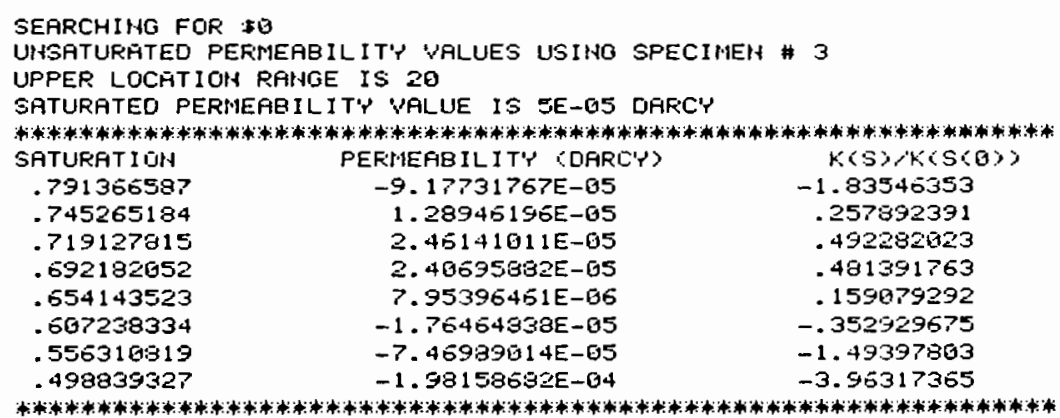

UNSATURATEO FERMEABILIT'Y YALUES USIHG SPECIMEH \#3

UPPER LOCATION RANGE IS 20

SATURATEL PERIERBILIT'Y YALUE IS 1 E-94 DAFC'Y

\begin{tabular}{|c|c|c|}
\hline SATURATION & PEFMEFB ILIT'P (OARC' $r^{\prime}$ ) & $K(S) \wedge(S\langle\theta)\rangle$ \\
\hline .791360587 & $-4.53420984 E-05$ & -.453426984 \\
\hline .745255194 & $5.67236562 E-65$ & .567235562 \\
\hline .719127815 & $6.31717445 E-05$ & .631717445 \\
\hline .692132052 & $5.67692141 E-05$ & .567692141 \\
\hline .654143523 & $2.75132414 E-65$ & .275132414 \\
\hline .607233334 & $-3.3177795 E-05$ & -.33177795 \\
\hline .556310319 & $-1.33415363 E-04$ & -1.33415308 \\
\hline .493339327 & $-3.9035 P 549 E-84$ & -3.90357549 \\
\hline
\end{tabular}

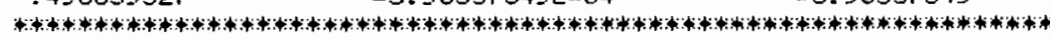

UNSATURATED PERMEFIILITQ VALUES USIMG SPECIMEN \#3

UPFER LOCATION RAINGE IS 20

SATURATEO PERIMEABILIT'P 'VALUE IS ZE-04 DARC'

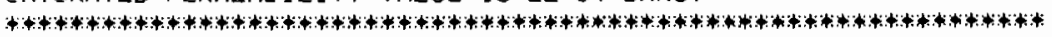

SATURATI IOH.

FERIAEABILIT'Y SDARCW

$K(S)>k(S(B))$

.791360587

.745255134

$4.75209581 \mathrm{E}-05$

1. $44399729 E-194$

1. $40287931 \mathrm{E}-\mathrm{Q4}$

$1.22163456 E-04$

$6.6531795 E-05$

.692182052

.654143523

$-6.42403875 E-05$

.507238334
.556310319

$-6.42463375 \mathrm{E}-05$
$-2.5084812 \mathrm{E}-194$

$-7.74755232 \mathrm{E}-04$

.237500291

.721998647

.711435156

.61084233

.333156975

$-.321201938$

.493339327

$-1.2542405$

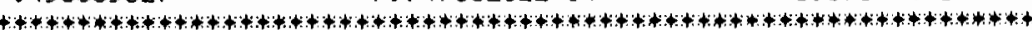

UINSATURÄTEO PERTERBILITY UALUES USING SFECIMEN \#3

UPPPER LOCATIOH F:ANGE IS 20

SATURATEO FERMEABILIT' WALUE IS 3E-04 OARC.

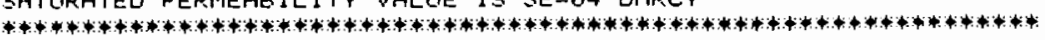

STTIIRATI IOH

.791366537

.745265194

PERTEABILIT'Y (OARCR'

$1.49332215 E-04$

2. $32069803 E-04$

2. $17402318 \mathrm{E}-04$

1. $37567 \% 13 \mathrm{E}-04$

1. $05756349 E-64$

.692132052

$-7.53929991 \mathrm{E}-\mathrm{CH}$

507233334

$-3.59280933 E-64$

$-1.15915302 \mathrm{E}-03$

$46794071=$

.773565099

.724574393

.025225726

.352501152

$-317676533$

.556310319

$-1.22760311$

$-3.8638+338$

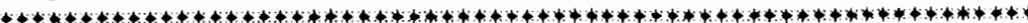




\section{Specimen \#3, Unsaturated Permeability Values Calculated at Varying Upper Range Locations.}

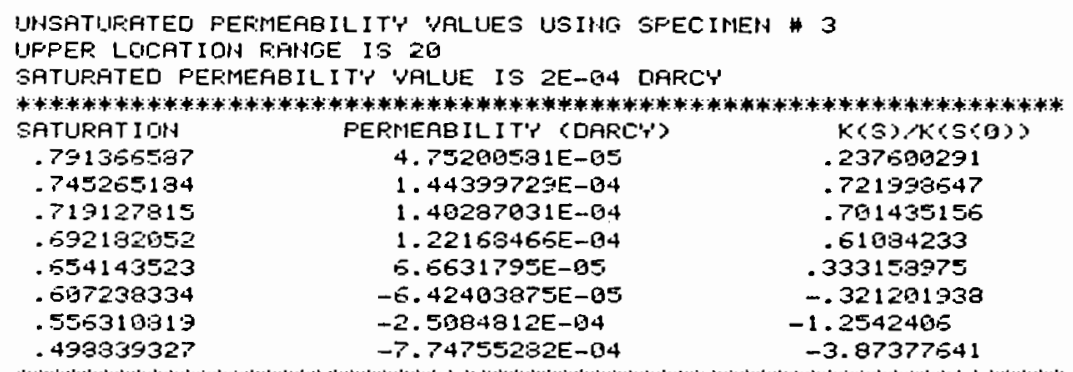

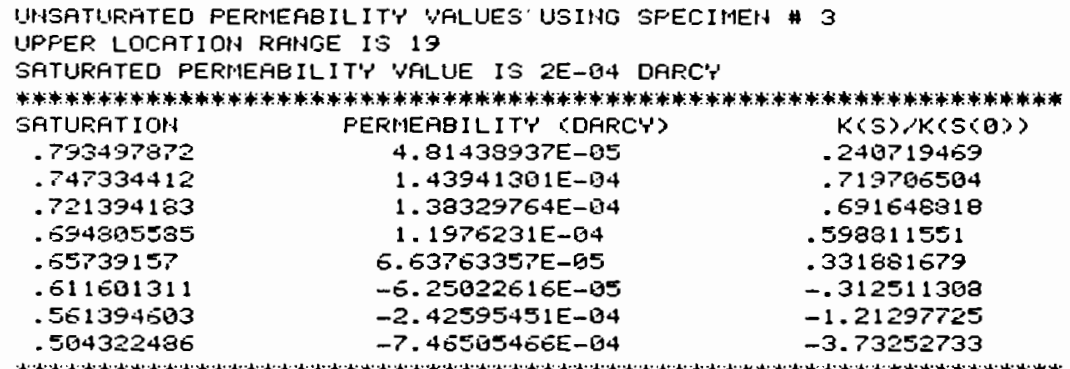

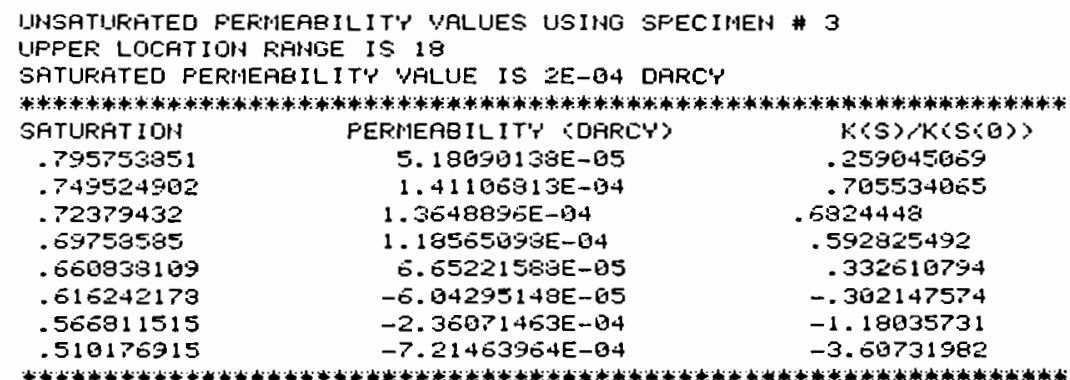

UHSATUFATED PERIMEABILIT'Y YALUES USIHG SFECIMEM \# 3 LIPFER LOC.FTIOH REAMGE IS 17 SATURATED FERIMEBILIT'Y 'YALUE IS 2E-04 [ARE'r'

\begin{tabular}{|c|c|c|}
\hline SATURATIOIA & PERMIEABILIT'' (DARC'r') & $k(S) r K(S(\theta) ;$ \\
\hline .798149602 & $5.23136853 E-95$ & .261568432 \\
\hline .751351331 & $1.38646327 E-04$ & .093231633 \\
\hline .726344479 & 1. $34318567 E-\overline{14}$ & .571592833 \\
\hline . .00542012 & 1. . $17200529 E-04$ & .586602642 \\
\hline .564507709 & $6.5731575 E-05$ & .32895788 \\
\hline .621136123 & $-3.86940509 E-05$ & -.293470254 \\
\hline .5 .72504332 & $-2.2953315 .5 E-84$ & -1.14766577 \\
\hline .515451253 & $-6.990013695 E-04$ & -3.49506344 \\
\hline
\end{tabular}




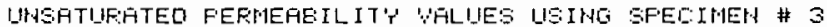
LFFEF: LOCATIDH RAHHOE IS 15

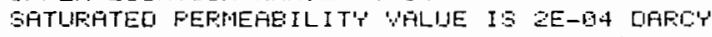

\begin{tabular}{|c|c|c|}
\hline EATUF:AT I OH: & FEFHEFEILIT' SUFFIC' $r$ & $k(s), k 6 s 0)$ \\
\hline .696703090 & $5.71736462 E-05$ & 205865231 \\
\hline .75431185 & $1.3546475: E-04$ & .67752984 \\
\hline .729064020 & 1. $3150956 \mathrm{BE}-64$ & .659947941 \\
\hline .703696931 & $1.14920464 E-94$ & .574802322 \\
\hline .659429715 & $6.59141149 \mathrm{E}-0.5$ & .329579574 \\
\hline .626505285 & $-5.71719102 E-65$ & -.255859551 \\
\hline .576024623 & $-2.24096105 E-04$ & -1.12048053 \\
\hline .523203979 & $-6.79723393 E-04$ & -3.39651692 \\
\hline
\end{tabular}

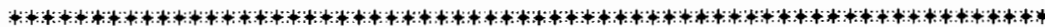

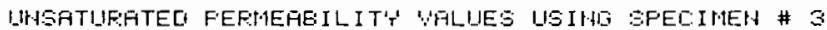
IIFPEF: LOCATI DHA FFH IOEE IS 15

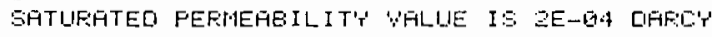

\begin{tabular}{|c|c|c|}
\hline SATURAT IBH & 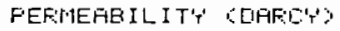 & $k(s)+k 60 \theta)$ \\
\hline .86343536 & 5.741055-SE-05 & 2965203 \\
\hline .750955519 & $1.35520915 \mathrm{E}-044$ & .082604576 \\
\hline .731976365 & 1. $29155242 E-04$ & .645920265 \\
\hline .707978162 & 1. $13596092 E-64$ & .508496457 \\
\hline .67263955 & $6.41943287 \mathrm{E}-65$ & .320971643 \\
\hline .632220081 & $-5.53986082 \mathrm{E}-05$ & -.276994941 \\
\hline .585534544 & $-2.1976234 \mathrm{TE}-94$ & -1.60851173 \\
\hline .530506199 & $-E .62682304 E-04$ & -3.31441152 \\
\hline
\end{tabular}

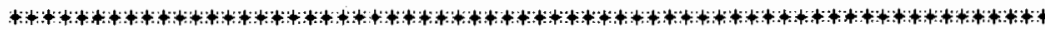

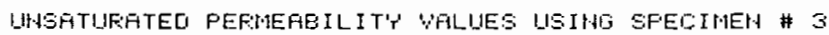

UIFFEF LIUETI IDH FEFHIOE IS 14

SATURATEL FERMEHEILIT'r' Y'TLLUE IS ZE-04 CIARC'r'

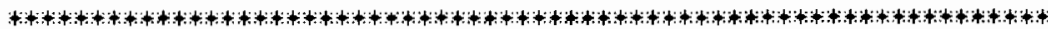

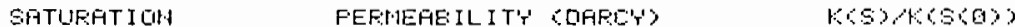

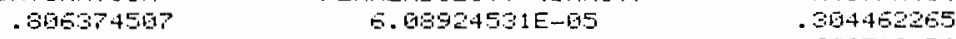

$.75930993 .4 \quad 1.34542095 E-194 \quad .072719475$

$.735100762 \quad 1.27507262 E-04 \quad .63526369$

$.71071934 \quad 1.12069524 E-014 \quad .5604+7619$

$.67716055 \quad 0.36956727 \mathrm{R}-055 \quad .313470363$

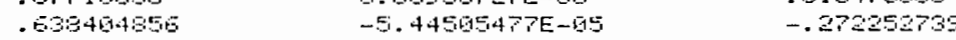

$.59281073 \quad-2.14452075 E-044-1.07226039$

$.539445477-6.4909235 \mathrm{E}-044-3.24961175^{\circ}$

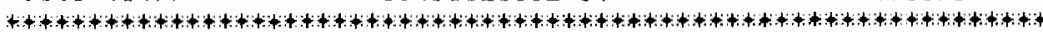

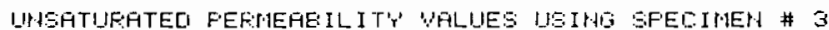

LIFFEF: LIUETIDHA FAFHE IS 13

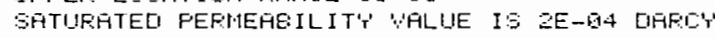

\begin{tabular}{|c|c|c|}
\hline SFTUEAFT I OHA & 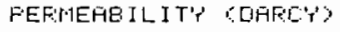 & $k(5) \times(5) 0)$ \\
\hline .85055130 & $6.372+8151 E-65$ & .319624075 \\
\hline .702020021 & $1.321695 \mathrm{LE}-6+4$ & .604047523 \\
\hline .70049578 & 1. $25096044 E-94$ & .025954222 \\
\hline $.71+602079$ & 1. $1072641 \mathrm{E}-04$ & .55363243 \\
\hline .082196505 & $6.3595172 E-55$ & .9179750 \\
\hline .64513559 & $-5.31295135 \mathrm{E}-05$ & -.205047500 \\
\hline $.0607+0002$ & -2.111 ESBSEE- 14 & -1.05578417 \\
\hline .547131206 & -E. $3527367>\mathrm{E}-64$ & $-3.191: 0935$ \\
\hline
\end{tabular}


APPENDIX $F$

SAMPLE DATA REDUCTION 
Step by step calculation for sample \#3.

Raw data in form of gamma counts is taken from computer floppy disk. The following constants are used in calculation (Spolek 1981a).

Cup weight $=243.1$ grams

$\mu_{w d}=.189 \mathrm{~cm}^{2} / \mathrm{gm}$

$\mu_{W}=.201 \mathrm{~cm}^{2} / \mathrm{gm}$

$G_{W d}=$ specific gravity of wood on a local basis

$$
G_{W d}=\bar{\rho}_{W d}
$$

FSP $=$ Fiber Saturation Point $=0.3$

$\emptyset=0.63$ porosity $=($ volume of wood-volume of cell walls)/(volume of wood)

$G_{C W}=1.53=$ Specific gravity of wood cell wall

Wet dimensions $8.956 \times 5.065 \times 4.483$ (absorption length) $\mathrm{cm}$

Initial wet mass (of wood sample itself) $=230.4 \mathrm{gm}$

Dry dimensions $8.573 \times 5.047 \times 4.341 \mathrm{~cm}$

$E M C=$ Equilibrium moisture content of oven $=5 \times 10^{-3}$

Final dry mass of sample $=75 \mathrm{gm}$

$$
\begin{aligned}
& V_{\text {wet }}=203.36 \mathrm{~cm}^{3} \text { volume } \\
& V_{\text {dry }}=187.83 \mathrm{~cm}^{3} \text { dry wood }+E M C \\
& \rho_{\text {measured }}=\frac{m_{w d}+E M C}{V_{w d+E M C}}=0.397 \mathrm{gm} / \mathrm{cm}^{3} \quad(\text { dry wood }) \\
& \bar{\rho}_{w d}=\frac{\rho_{\text {measured }}}{1+E M C\left(V_{w d} / V_{w d+E M C}\right)}=\frac{0.397}{1+(.005)(1)}=.395 \mathrm{gm} / \mathrm{cm}^{3} \\
& G_{w d}=\bar{\rho}_{w d}=.395
\end{aligned}
$$




$$
\Delta m=M_{\max }-F S P=\frac{G_{C W}-G_{W d}}{G_{C w} \times G_{w d}}=\frac{1.53-.395}{1.53 \times .395}=1.86
$$

Moisture difference (Spolek 1981a)

Gamma Count measurements are reduced as follow:

For dry wood,

$$
N_{w d}=N_{w d}+E M C \times \operatorname{Exp}\left(\mu_{w d} \cdot \rho_{w d} \cdot L_{w d} \cdot E M C\right)
$$

Where

$$
\begin{aligned}
& N_{w d}=\text { Corrected gamma count. } \\
& N_{\text {meas. }}=\text { Measured gamma count. } \\
& N_{\text {Wd+EMC }}=\frac{1}{\left(1 / N_{\text {meas }}-\tau\right)}=\frac{N_{\text {meas. }}}{1-\tau \times N_{\text {meas }} .}
\end{aligned}
$$

$\tau=8 \times 10^{-6}$ seconds/count, for 10 seconds count (instrument dead time in order to distinguish between two gamma radiation pulses).

$$
N_{\text {wd+EMC }}=\frac{N_{\text {meas. }}}{1-\tau \times N_{\text {meas }}}=\frac{N_{\text {meas. }} .}{1-8 \times 10^{-7} \times N_{\text {meas }} .}
$$

$N_{w d}=N_{w d}+E M C \times \operatorname{Exp}(0.189 \times 0.395 \times 4.341 \times 0.005)$

Wet wood gamma count correction is done by:

$$
N_{w d+w}=\frac{N_{w d+w(m e a s u r e d)}}{1-8 \times 10^{-7} \times N_{w d+w(m e a s u r e d)}}
$$

$M=$ Moisture content= (weight of water in wood)/(weight of bone dry wood). Moisture content is calculated using the following equation,

$$
M=\frac{-V_{w d+w}}{V_{w d}} \cdot \frac{1}{\mu_{w} \rho_{w d} L_{w d+w}}\left[\operatorname{Ln} \frac{N_{w d+w}}{N_{w d}}+\rho_{w d} \mu_{w d}\left(L_{w d+w}-L_{w d}\right)\right.
$$

$M=-\frac{203.36}{187.83} \cdot \frac{1}{0.201 \times 0.395 \times 4.483}\left[\operatorname{Ln} \frac{N_{w d+W}}{N_{w d}}+0.395 \times 0.189(4.483-4.341)\right]$ 


$$
M=-3.042\left[\operatorname{Ln} \frac{N_{W d+w}}{N_{w d}}+0.0106\right]
$$

Having calculated moisture contents, saturation leavels are reduced as follows:

$$
S=\frac{M-F S P}{M_{\max }-F S P}=\frac{M-F S P}{\Delta M}=\frac{M-0.3}{1.86}
$$

Sample results for saturation at different time intervals for location intervals of $\Delta Z=0.4048 \mathrm{~cm}(0<Z<8 \mathrm{~cm})$ are provided in appendix $C$. At final stage of experiment steady state conditions exist and body force equals $P_{C}$, at this stage very little moisture drains out of wood. At steady state capillary pressure is calculated as follows:

$$
P_{C}=\rho_{\ell} w^{2} Z\left(R-\frac{Z}{2}\right)
$$

where

$$
\begin{aligned}
& R=24 \mathrm{~cm} \\
& 0 \leq Z \leq 8 \mathrm{~cm} \\
& W=500 \mathrm{RPM}(\operatorname{Rev} . / \mathrm{min} .)=\frac{500 \times 2 \pi}{60}=52.36 \mathrm{rad} / \mathrm{sec} . \\
& \rho_{\ell}=1 \mathrm{gm} / \mathrm{cm}^{3} \\
& P_{C}=2741.57 \times Z(24-Z / 2) \\
&\left.P_{C}\right|_{Z=0}=0 \quad ;\left.\quad P_{C}\right|_{Z=8}=438651 \mathrm{gm} / \mathrm{cm} \cdot \sec ^{2} \quad\left(\mathrm{dyn} / \mathrm{cm}^{2}\right)
\end{aligned}
$$

The equation used to calculate the unsaturated permeability is:

$k(S(L))=\left[C(S(L)) \cdot S^{\prime}(L)-B(L)\right]^{-1} \times\left\{k(S(0))\left[C(S(0)) \times S^{\prime}(0)-B(0)\right]-\right.$

$$
\left.\mu \emptyset \int_{0}^{L}\left(\frac{\partial s}{\partial t}\right) \partial z\right\}
$$


where

$C(S(Z))=\frac{\partial{ }_{C}}{\partial S}$, curve fit values (power equation) are used.

$B(Z)=\rho_{\ell} g=\rho_{\ell} w^{2}(R-Z)=2741.57(24-Z) \frac{\mathrm{gm}}{\mathrm{cm}^{2} \sec ^{2}} \quad\left(\right.$ dyne $\left./ \mathrm{cm}^{3}\right)$

$S^{\prime}=\frac{d S}{d Z}$, curve fit values (power equation) are used.

$\mu=$ viscosity of water $=1.002 \times 10^{-2} \mathrm{gm} / \mathrm{cm} \cdot \mathrm{sec}$

Saturated tangential permeability is (Comstock, 1970):

$4.935 \times 10^{-13} \mathrm{~cm}^{2}=0.5 \times 10^{-4} \operatorname{darc} y \leq k\left(S(0) \leq 3.0 \times 10^{-4} \mathrm{darcy}=2.961 \times 10^{-12} \mathrm{~cm}^{2}\right.$

$\int_{0}^{L} \frac{\partial s}{\partial t} \partial z \simeq \frac{d}{d t} \int_{0}^{L} s \cdot d z$

in calculation for sample \#3 range of integration is from $Z_{1}$ to $Z_{20}$ where $Z$ (total length) is divided into 20 intervals, starting at $Z_{1}=0.2024 \mathrm{~cm}$ and ending at $Z_{20}=7.8936 \mathrm{~cm}$ with interval $\Delta Z=0.4048$ $\mathrm{cm}$. Thus

$$
\frac{d}{d t} \int_{1}^{L} S \cdot d z=\frac{1}{\Delta t}\left[\left(\sum_{i=1}^{2 Q} S\left(Z_{i}\right)\right) \times 0.4048 \mathrm{~cm}\left|t_{2}-\left(\sum_{i=1}^{2 Q} S\left(Z_{i}\right)\right) \times 0.4048 \mathrm{~cm}\right| t_{1}\right]
$$

values of time (for calculating $\Delta t$ ) are provided in appendix $D$ along with curve fit values for $S(Z)$. Curve fit values for $P_{C}(s)$ are also provided in appendix $D$.

Curve fit values for sample \#3 are done for the location range of $Z_{1}=0.2024 \mathrm{~cm}$ to $Z_{20}=7.8936 \mathrm{~cm}$ (appendix D). All initial starting points are at $1=Z_{1}$, and all ending points are at $L=Z_{20}$ throughout the calculations for scan time 03 (saturation profile) sample curve fit result is:

$$
\begin{aligned}
& S(Z)=.80601 \times Z^{-.06449} \text { therefore, } \\
& S^{\prime}(Z)=-.051979 \times Z^{-1.06449} \text { at } Z_{1} \text { and } Z_{20}
\end{aligned}
$$




$$
\begin{aligned}
& P_{C}(s)=32344 \times S^{-3.264} \text { therefore } \\
& \frac{\partial P_{C}}{\partial S}=-105571 \times S^{-4.264} \text { at } S_{Z_{1}} \text { and } S_{Z_{20}}
\end{aligned}
$$

for additiona values refer to appendix $D$. To calculate $S_{Z_{1}}$ and $\mathrm{S}_{Z_{20}}$ average values at each location are calculated between the two runs under consideration. Averages are calculated using curve fit values for saturation to both avoid actual data fluctuation and also provide a consistent pattern for saturation levels at end location $\mathrm{Z}_{20}$. Timing of runs are as follows (sample \#3).

TABLE XIII

SAMPLE \#3 EXPERIMENT TIME PERIODS

\begin{tabular}{|c|r|r|}
\hline Days & Seconds & $\Delta T$ (Seconds) \\
\hline$t_{1}=0$ & 0 & \\
$t_{2}=0.75$ & 64800 & 64800 \\
$t_{3}=1.75$ & 151200 & 86400 \\
$t_{4}=3.9$ & 336960 & 185760 \\
$t_{5}=6.75$ & 583200 & 246240 \\
$t_{6}=10.75$ & 928800 & 345600 \\
$t_{7}=18.75$ & 1620000 & 691200 \\
$t_{8}=25.83$ & 2231712 & 611712 \\
$t_{9}=45.75$ & 3952800 & 1721088 \\
\hline
\end{tabular}


Actual unsaturated permeability value $k(S(L))$ will be calculated for run 4 (values for scan time $\emptyset 3$ and $\emptyset 4$ ).

For Scan Time $\emptyset 3$ we have:

$$
\begin{aligned}
& S=.80601 \times Z^{-.06449} \\
& S^{\prime}=-.051979 \times Z^{-1.06449} \\
& S\left(Z_{20}\right)=.7055 ; \quad S\left(Z_{1}\right)=.962 \text { (for } S\left(Z_{1}\right) \text { actual data is used) } \\
& S^{\prime}\left(Z_{20}\right)=-.00576 ; S^{\prime}\left(Z_{1}\right)=-0.2847 \\
& 20 \\
& \sum_{i=1} S\left(Z_{i}\right)=15.0855 \text { (Note that } S\left(Z_{10}\right) \text { has been modified as an average } \\
& \text { of } \left.S\left(Z_{9}\right) \text { and } S\left(Z_{11}\right)\right)
\end{aligned}
$$

For Scan Time $\emptyset 4$ we have:

$$
\begin{aligned}
& S=.80012 \times Z^{-} .07951 \\
& S^{\prime}=-.06362 \times Z^{-1.07951} \\
& S\left(Z_{20}\right)=.6789 ; S\left(Z_{1}\right)=.979 \text { (for } S\left(Z_{1}\right) \text { actual data is used) } \\
& S^{\prime}\left(Z_{20}\right)=-.00684 ; S^{\prime}\left(Z_{1}\right)=-.3569 \\
& \underset{\sum}{20} S\left(Z_{i}\right)=14.7505 \text { (Note that } S\left(Z_{10}\right) \text { has been modified as an average } \\
& \text { of } S\left(Z_{9}\right) \text { and } S\left(Z_{11}\right) \text { ) }
\end{aligned}
$$

Taking averages we have:

$$
\begin{aligned}
& S\left(Z_{20}\right)=.6922 \text { (Note that this is the average based on curve fits) } \\
& S\left(Z_{1}\right)=.9705 \\
& S^{\prime}\left(Z_{20}\right)=-.0063 \\
& S^{\prime}\left(Z_{1}\right)=-.3208 \\
& C(S(Z))=\frac{d P}{d S}=-105571 \times S^{-4.264}
\end{aligned}
$$


Thus

$$
C\left(S\left(Z_{1}\right)\right)=-119949 ; C\left(S\left(Z_{20}\right)\right)=-506754
$$

and

$$
\begin{aligned}
& B\left(Z_{1}\right)=65243 \text { dyne } / \mathrm{cm}^{3} ; B\left(Z_{20}\right)=44157 \text { dyne } / \mathrm{cm}^{3} \\
& \int_{Z_{1}}^{Z_{20}}\left(\frac{\partial S}{\partial t}\right) d Z=\frac{.4048}{185760}(14.7505-15.0855)=-0.73 \times 10^{-6} \mathrm{~cm} / \mathrm{sec}
\end{aligned}
$$

Plugging in all the terms in equations used to calculate $k(S(L))$ we will have:

for $k$ (sat.) $=2 \times 10^{-4}$ darcy $=1.974 \times 10^{-12} \mathrm{~cm}^{2}$

$k(S(L))=\frac{1.974 \times 10^{-12} \times[-119949 \times(-.3208)-65243]-1.002 \times 10^{-2} \times .63\left(-.73 \times 10^{-6}\right)}{-506754(-.0063)-44157}$

$$
\begin{aligned}
& k(S(L))=\frac{-5.28 \times 10^{-8}+4.608 \times 10^{-9}}{-40964}=1.1772 \times 10^{-12} \mathrm{~cm}^{2} \\
& \frac{k(S(L))}{k(\text { sat. })}=.596 \simeq .6
\end{aligned}
$$

which indicates that at $S(L)=.69 k(S(L) / k($ sat. $)=0.6$

for $k$ (sat.) $=2 \times 10^{-4}$ darcy

Within the calculated saturation levels for all specimen there were two sets of data points that seemed to be wrong. One set of bad saturation level data points were due to a bad dry wood gamma count. This set was easily detected by using Chauvenet's criterion (Holman, 1978; Schenck, 1979) on dry wood gamma counts for all the samples. Since each sample had 20 dry wood gamma counts, within each sample any data point that was more than (2.23 $\times$ standard deviation) away from the average of data points was considered a bad data point. The resulting saturation levels at those locations for all the runs of each sample were not used for calculations of curve fits, and for calculation of intergral part in equation resulting in 
$k(S(L))$ their value was changed to the average of their adjacent data points in each gamma scan (experiment run). The other set of bad saturation level data points were caused by a bad wet wood gamma scan. Since the author knew of no statistical procedure to detect these point, visual observation of saturation versus location plots was utilized to detect these points. These data points were corrected to the average value of data points at the same location but at preceeding and following wet wood gamma scans. Total number of second set of bad data points was 12 out of a total 3720 data points. A list of second set of bad data is:

\section{TABLE XIV}

BAD DATA POINTS CAUSED BY WET GAMMA COUNTS

Sample \# $\quad S\left(S c a n\right.$ Time, location \#i( $\left.\left.z_{i}\right)\right)$ : 0ld value to modified value

1

2

6

6

10

10

12

14

16

17

17

18

$$
S(0,1)
$$

$S(0,1)$

$S(4,1)$

$S(6,6)$

$S(8,1)$

$S(9,1)$

$S(8,1)$

$s(0,1)$

$S(0,1)$

$s(0,1)$

$S(7,1)$

$S(3,1)$
1.419 to .795

1.278 to .740

0 to .782

1.011 to .829

1.3 to .811

.463 to .811

1.55 to .947

1.549 to .961

1.76 to .983

1.447 to .913

1.064 to .913

1.029 to .968 
A list for the first set of bad data caused by bad dry wood gamma count is:

\section{TABLE XV}

\section{BAD DATA POINTS CAUSED BY DRY GAMMA COUNTS}

Sample \# Rejected location $z_{i}$; Sample \# rejected location $z_{i}$

$\begin{array}{llll}3 & Z_{10} & 10 & Z_{17} \\ 4 & Z_{18} & 12 & Z_{8} \\ 5 & Z_{7} & 13 & Z_{1} \\ 7 & Z_{3} & 16 & Z_{13} \\ 8 & Z_{7} & 17 & Z_{12} \\ 9 & Z_{9} & & \end{array}$

Figures 63 to 66 show photocopies of some wood samples after they are oven dried. The cracks that have caused some bad data points are shown in these figures. 


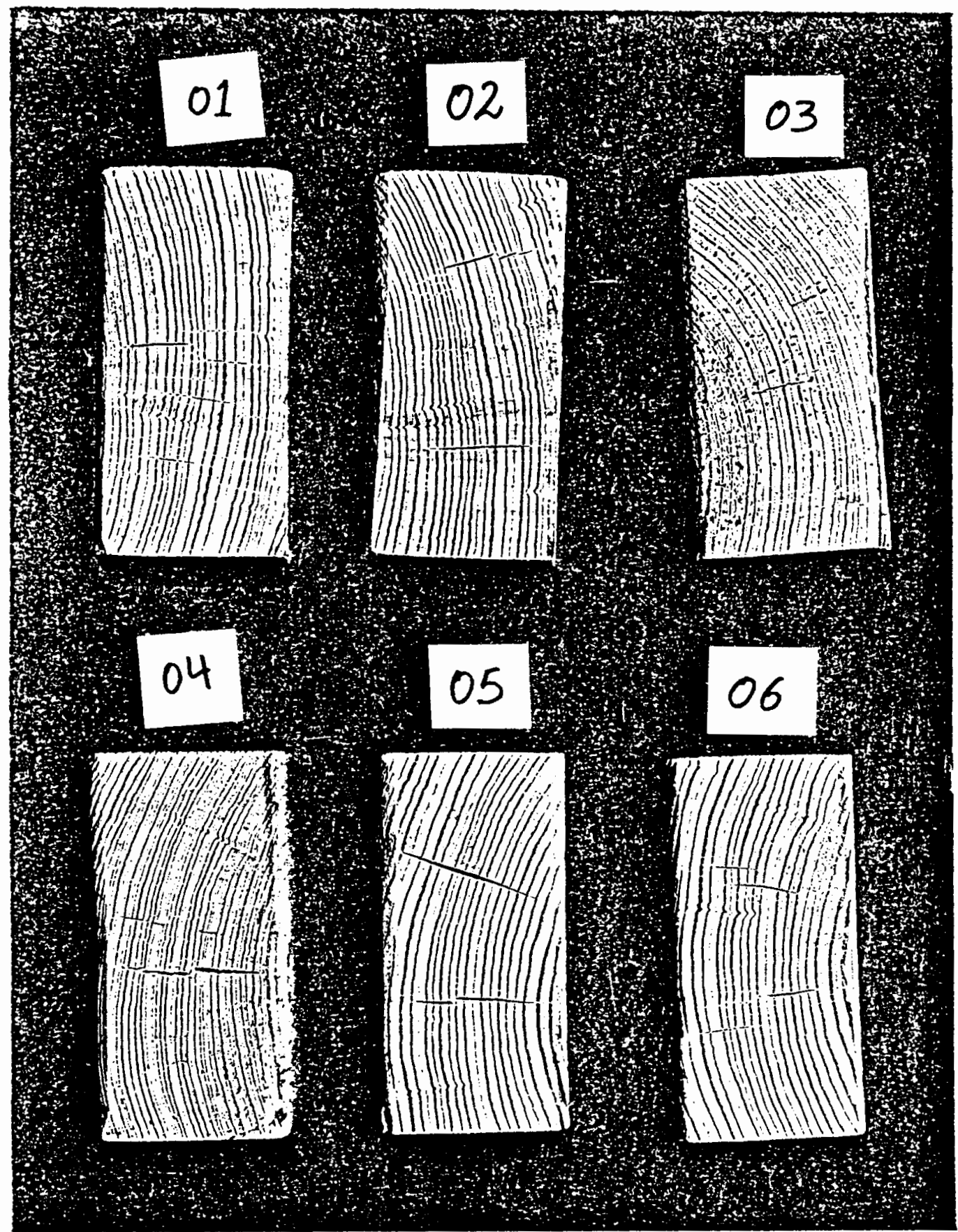

Figure 63. Photocopy of wood samples 1 to 6 reduced $65 \%$. 


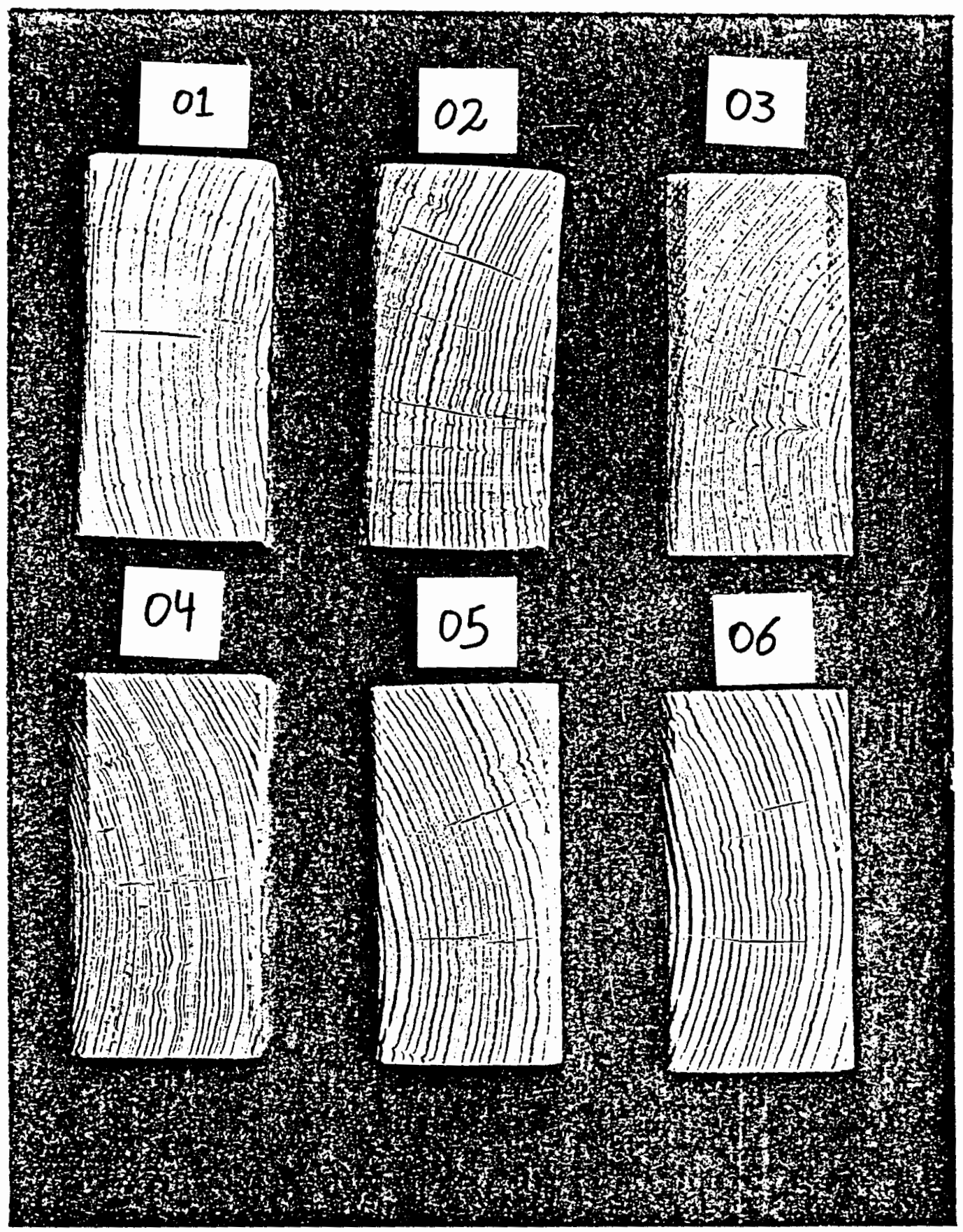

Figure 64. Photocopy of wood samples 1 to 6 reduced $65 \%$. 


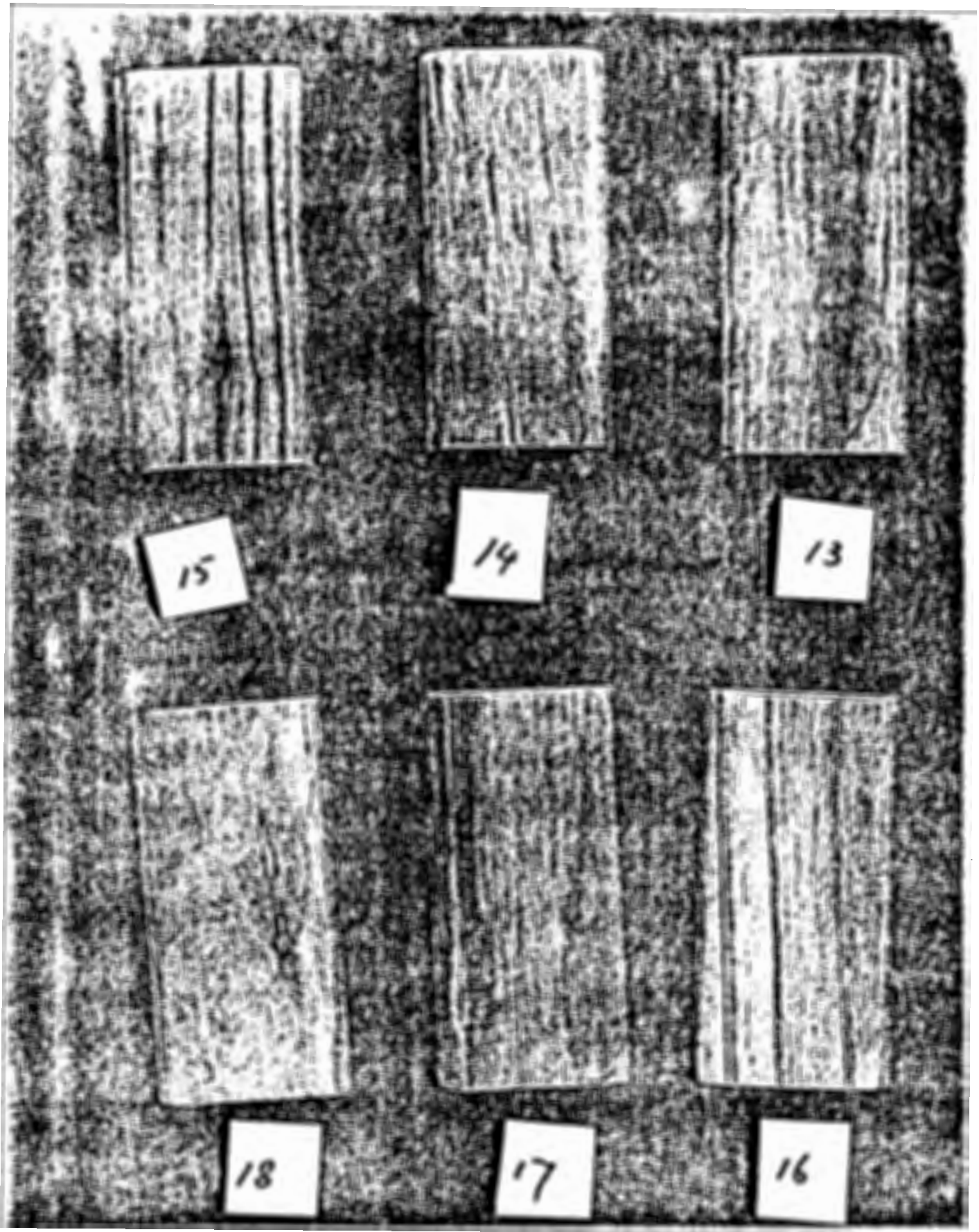

Figure 65. Photocopy of wood samples 13 to 18 reduced $65 \%$. 


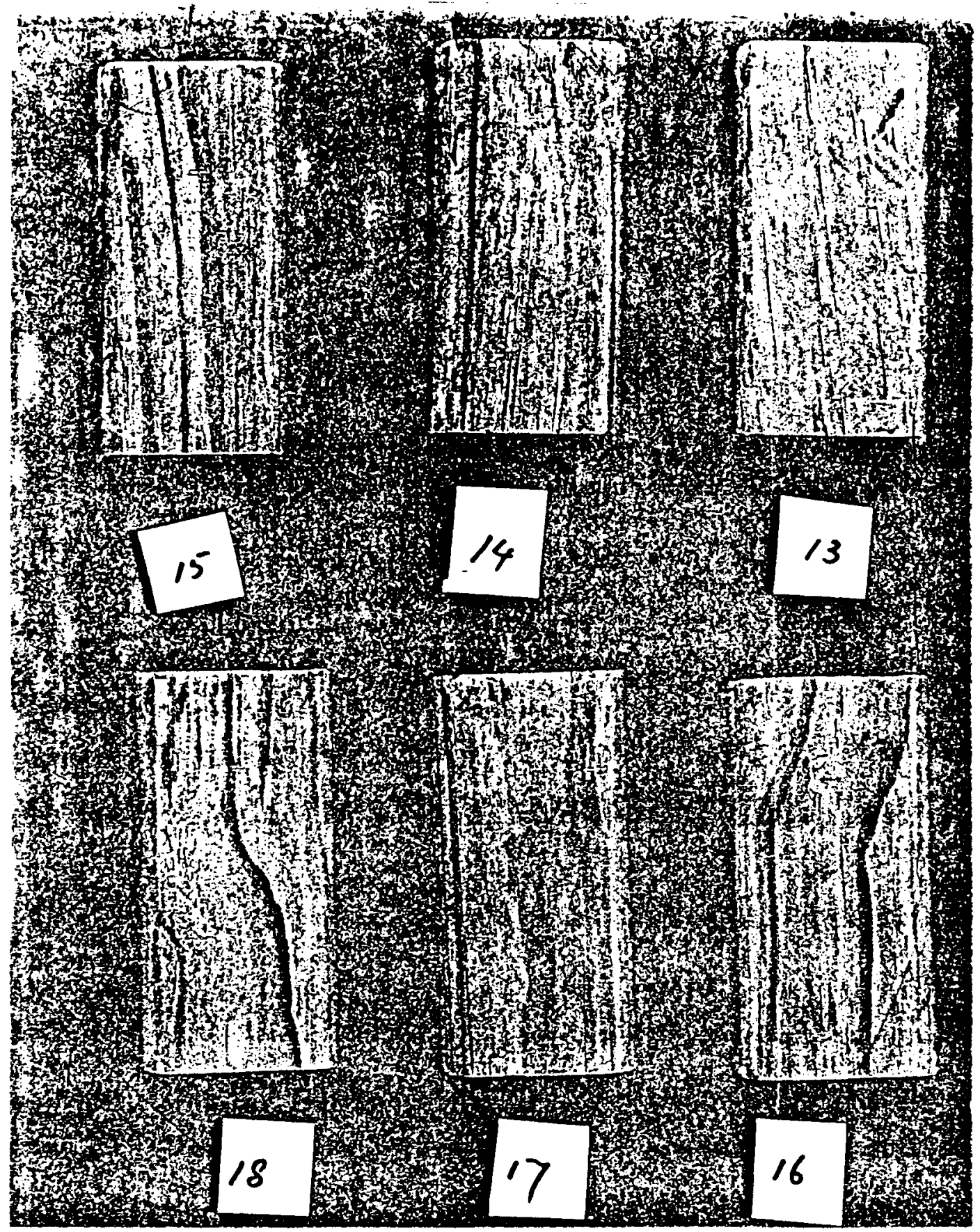

Figure 66. Photocopy of wood samples 13 to 18 reduced $65 \%$. 
APPENDIX G

COMPUTER SOFTWARES DEVELOPED IN BASIC FOR COMMODORE 64 
1 REM THIS PRCIGARM UHLOALS IATTA FROM THE

2 FEN TFFE FHIC LOAOS IT IHTO THE DISK FOR.

3 FEII THE IHITIALIZATIOHA FRET.

4 FEM FAFII FIFIOIZIAANCII AFPIL 23, 1963

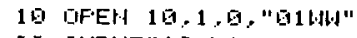

20 IHFOUT\#19.L

SB IHFUT\# 10, , H1

40 IHIFUT 19.01

50 IHFUTH $19, \mathrm{MI}$

60 IHFUT\#10. IH.JO

TE IHFUT 19,1 , IHOD

S0 IHFIIT\#10. TFIJ

G0 CLOGE 10

169 FPIITTL 1

119 FF:1HTH1

120 FF:INITI1

1.30 FF: IHTTHI

140 FFIHTIINO

150 FFI I TTIJHZO

$1 E 0$ FFIHTTRIJ

1 PQ REII

$150 \mathrm{REH}$

199 PEH

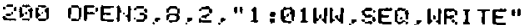

219 FF:IHT\#3.L 1CHF: $(13)$

220 FFIIHTH3.WICHF: (13)

230 FFIHT\#3, D1CHFE (13)

240 FFIHTA IOHICHF (13)

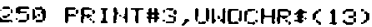

2EQ FRIHTHS, IJHZOC:HF: 213 )

27D FFIHT\#3, TAUICHF: 1 (13)

2ES LLOEES

FEFO'Y'. 
F:EFD'T'

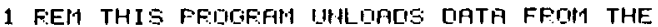

2 PEN THFE FHO LOHIS IT IHTO THE CISK FOR:

3 REM THE FIHHLIZE FAIRT.

4 FEH FAFID FIFOIOZMAHLI FFRIL 25, 1983

8 DIN FCSB? HMC 30 )

19 OFEH 19,1,0."910D"

20 IHAUTH 19. LOF''T'

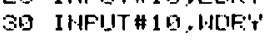

32 IHFIIT $10, \mathrm{DCF}$ '

34 IHFUT\# 19, EHC

36 IHFUT\#19.MEMC

40 FOR $J J=1$ TO 2 .

50 IHFUTH $10, F(J), H, H D(J)$

60 HEXT J.T

55 CLOSE 10

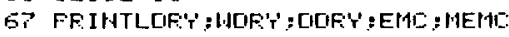

79 FOR, $J J=1$ TO 29

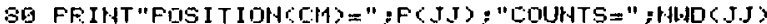

S5 NE:T JJ

100 CE=",

200 DFEH3,8,2, "1:0100,SEM, HR I TE"

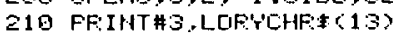

220 PRINTH3 HLFYCHF: $(13)$

222 FRIHTH3, LOR'YLHF: (13)

224 PRIHTHS, EMTCHF: 13 )

226 FRINTH 3 , MEMCCHF $(13)$

230 FOF: $J J=1$ TO 20

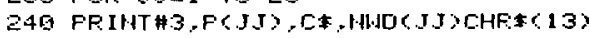

250 HEXT JI

269 CLOSE3

REAC'' 
FERI'T.

1 REM THIS FRIIIRFIM UHLORIS DATA FFOM THE

2 REII TAFE AHD LOAOS IT IHTO THE DISK FOF:

3 FEII THE DATA CIOLLECT FART.

4 REM FFIRIO FIROOZWAHIOI AFRIL 23, 1983

3 LIA F (30). CDIHTS 30 )

10 OPEN 19,1, $9, " 01090$

20 IHFUT\#19.TM

30 IHFIJT\#10,MI

40 FOF: $O C=1 \quad T O 20$

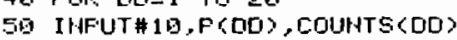

SB NEXT UD

ES CLOSE 19

70 FOR $O D=1$ TO 20

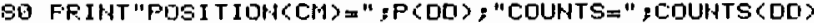

85 HEET OD

$100 \mathrm{C}+="$,

200 OFEH3,8,2,"1:0109,SEQ.WR I TE"

210 FEIHTH3. THLHF:E(13)

220 FFIHTH3, HICHF: $(13)$

2.59 FDR $\quad \square 0=1$ TO 29

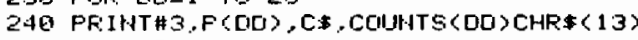

250 HEX'T DO

$2 E G$ CLOSE 3

FEFIYY. 
R.EAO'T'

1 REM THIS FROGRRM IS IJSED TO INAPUT DATA

2 FEH MAHUALY INTO THE EIISK FOR THE FINALIZE

3 FEEM FFRT.

4 PEM FFFID FIFGOZMAHUI JUHE 17TH, 1983

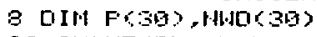

20 IHPIJT "DP'Y' LEHOTH" : LEF"'T

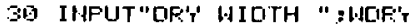

32 IHFIIT "DF'' DEFTH ":DLE'Y

34 IH HFUT "OVEH ENAC:" EIIC

36 IHFUT "LR'Y MASS PLUS EMC AHID COHTAIHER" :MEMC

49 FOR J J=1 TO 20 :PF:INT" [HATA SET \#":J.J

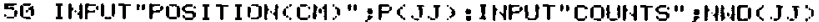

GB HEXT IJ

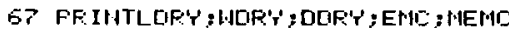

79 FOR $J J=1$ TO 20

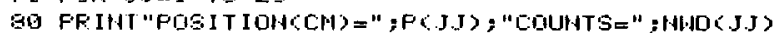

BS NEXT IT

$100 \mathrm{CH}=" . "$

2E1G UFEH $3,8,2, " 1: 1300$, SEQ, WR I TE"

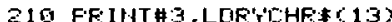

220 FRIITIA3. HEIR'TCHR: (13)

222 PRINTH 3 , DOR'TCHF: $(13)$

224 PPIHT\#3, EMCCHF 1 (13)

226 FRINT\#3, MENCCHP: (13)

230 FOF: J J $=1$ TOI 20

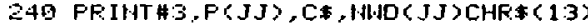

250 HE:T JJ

260 CLOSE3

FERD'. 
REAL'T'.

1 REM THIS FROGERT IHFUTS YRLUES OF THE

2 REN MASS OF THE CONTAINDRS FOR EACH

3 FEM SFEICIMEH FOE EACH SET OF DATA OH

4 FEM THE DATA IISK IH THE DISK DRIVE

5 REM HUMBEF 1.

6 REM FARIO PIFOODZHAHOI JIJHE 21, 1933

10 FEH IHFUT DATA.

29 DIM MC $(99)$

30 FUF: $I=1$ TO 5

40 FFINT "CONTAIHOR MASS FOR SPECIMEN \#"; 1 "IN GRANS"

50 IHFUT MC I )

6Q HE $\% T$ I

PQ FOF: $I=1$ TO 6

Q9 FFIHT"MASS OF COHTAINDR FDR SFECIMEH \#"; I,"IS ":MC(I)

90 HEXT I

1 GO REEM CHECK FOR FICCURRC'T OF INFUT.

110 FRIHT"IF YALIJES ARE GORRECT HIT RETURH"

120 FFIHT "OTHERWISE STOP THE FROGRRM AHD RUH IT RGAIH."

130 INFUTA:E

149 DPEN3,B.2."1:01NC, SEQ,WFITE"

150 FDR $I=1$ TO 6

160 FFIHTA3, MO I I CHR $\$$ (13)

170 HEYT I

180 CLOSES

$190 \mathrm{EHCI}$

FEFFC'r'. 
READ'.

1 REM THIS FFOGEAM REALIS DATA FFOM DISY

2 FEM FOF: LATA COLLEIT FAFT ANU FRIHTS IT

3 FEEM OUIT. THEH IT EFAGES THE DATA FILE

4 PEEY IN THE DISK. MODIFIES THE DATA AHD

5 REM LOADS THE MODIfIED DATA E:FCK INTO THE

6 FEM DISK.

9 FEIA FARID FIFCHIZIAFIUI APPIL 27, 1983

9 DIN P(99) . COINTSSC9g)

19 OFEN $8,9, " 1: 01694$, SEQ, REAQ"

11 D INFUTA 3.TM

111 IHFUTA:3.MI

112 FOF: $O C=1$ TO $2 D$

113 IHFUT\#3.P(CII), COINATSCOCD)

114 HEXYT DD

120 CLOSES

121 REM THIS FFRT ERASES DATF FILE IN DISK

122 OFEN1, 6.15

123 FFIHITH1, "S1:0604"

124 CLOSE 1

125 FEM THIS FRRT MOUIFIES THE DATA.

125 $\mathrm{TM}=5.7 \mathrm{~T}$

13 P FR:INTTH

140 PRIHTMI

$150 \mathrm{FOF}, \mathrm{DC}=1$ TO 20

160 FRIHT "FOSITIOH(CM)=" ; $($ OD), "COUHTS=", COUNTSCOCD

179 HEYT DD

198 CF=",

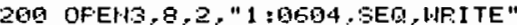

219 FFI IHT 3, THCHFA(13)

220 FFIHTHS, HICHR: $(13)$

239 FOF $[\mathrm{CI}[1=1$ TO 20

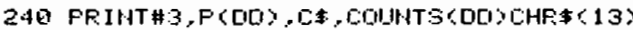

250 HEXT OD

260 CLOSE 3

270 ENI

FEAD't. 
FEFI'T'

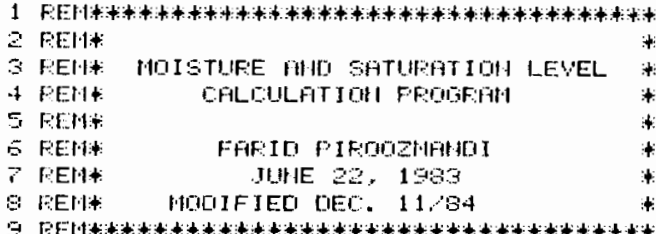

19 FEH THIS PROGFAl CFL CULATES THE

$2 O$ FEN WOISTUEE COMTEHT FHID FL SO THE

30 FEH SFTIFEFTIOH LEYEL OF HOOLI SFECHAEH

49 FEM FOF ERCH LOCATIOH IH THE WOWEI

59 FEV FI EHCH TIME IHTEFUAL.

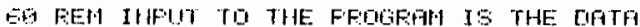

79 AEH DETAIHED E'T' THE EXFEFIPIEHTS

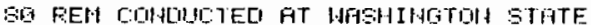

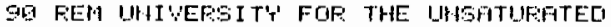

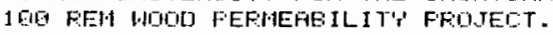

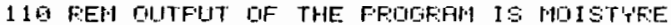

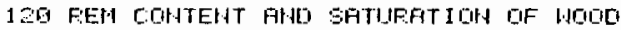

139 FEH SFECINEH AS A FUHCTIOH OF LOCATIOH

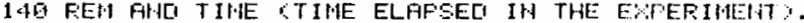

E160 FEH

OQI FEII

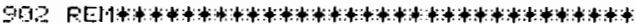

E10: FEllt

304 FENHFEQUIFECI MODIFICATIOHS TO THE

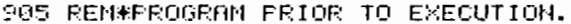

Q96. FElT.

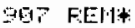

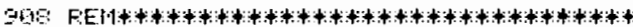

909 FEH

919 FEM THE FOLLOUIHIS LIHES SHGIIII BE

911 FEH WOCIFIEL FECOREIHG TO THE

912 FEVI SFECINEH UHIOEF CRLCULATIOH AHICI

913 FENA FLSO SET OF DATA UHLEF: STULI'r.

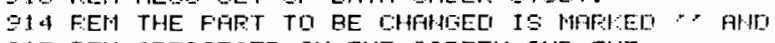

915 FEN GFECIFIEC OH THE ECFEEH FHH THE

915 REN CHFHISES FFE SFECIFIED IH $O$

DQS FEN

GQ1 FEM

922 FEH

923 FEF

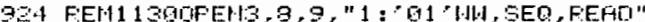

SO- FEH CSPECIMEH \#)

920 FEH

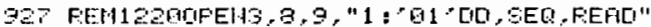

Q2E FEEN (SFECIMEH \#)

929 FEEN

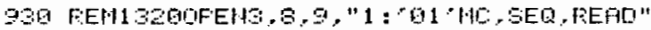

931 FET SOATA SET \#, Q1, G2, 60, B4,...?

932 F:Ell

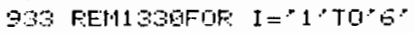

934 FEH CAOD COATA SET \#\$6 TD EFEH. T TO 12.13 TO $19 \ldots$.

995 F:EH

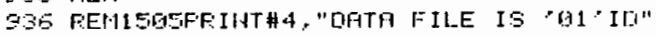

997 FEH (SFECTHEH \#)

930 REM

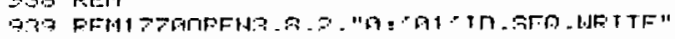




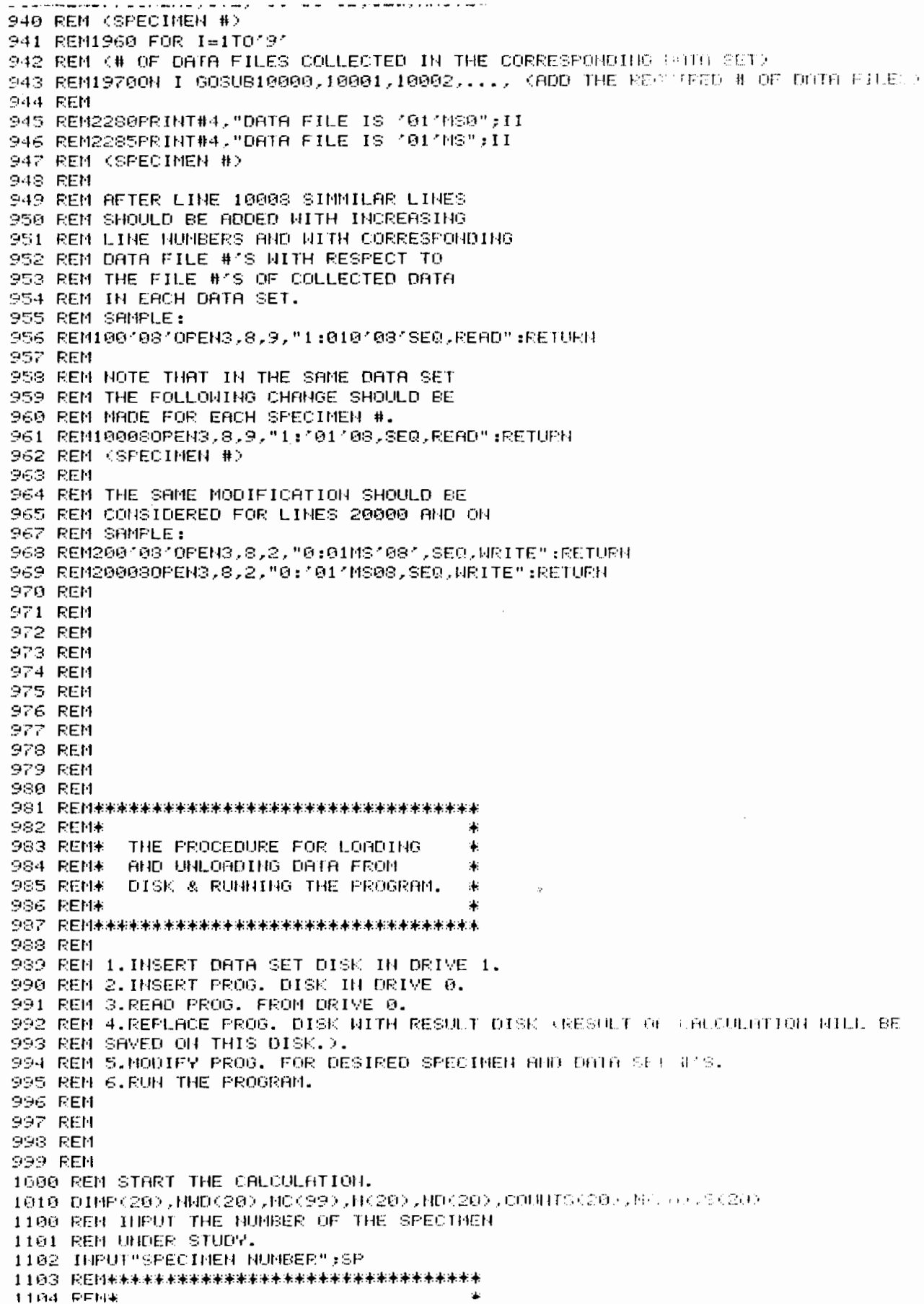




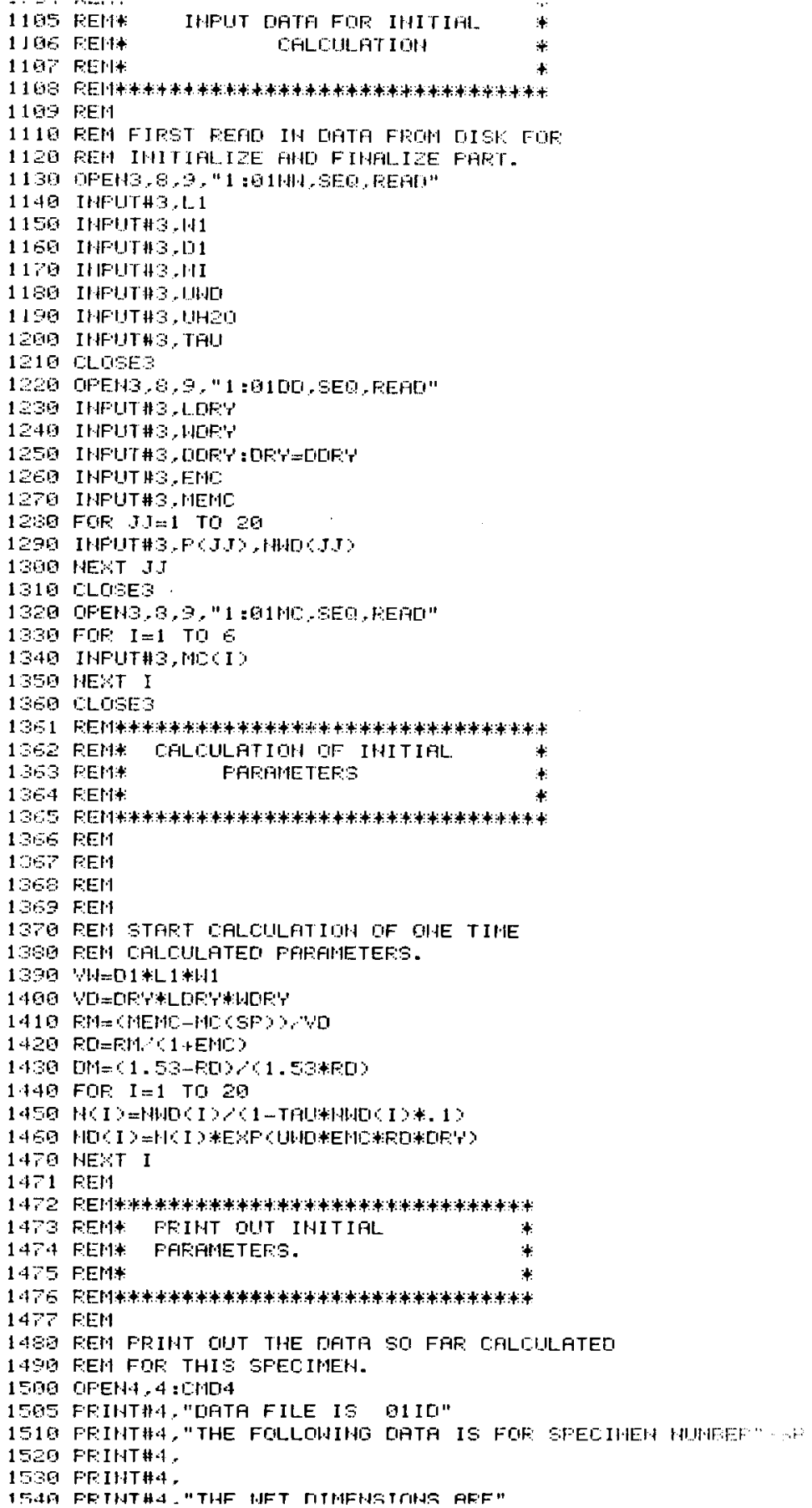




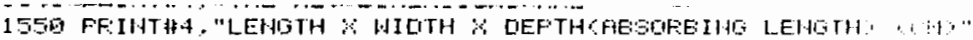

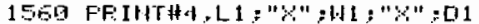

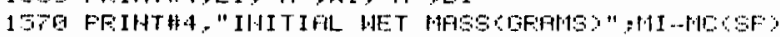

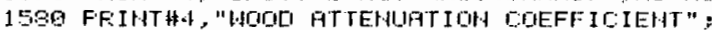

15:G FF: IHITH4 , 1,HLI

1 GGQ FFIHTH4, "IJFTEF: ATTEHUATI DHA COEFF."

1519 PRIHTH $4.1 \mathrm{H} 2 \mathrm{O}$

1620 FEIHTH4, "[EFA TIMECSECOHLS,":TAU!

1590 FRINTH 4. "THE CIF'T DINEHSIOHS AFE"

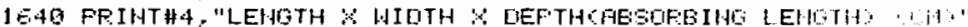

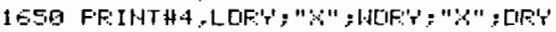

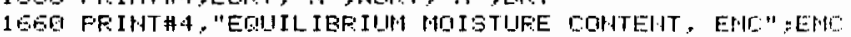

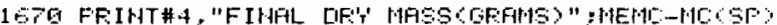

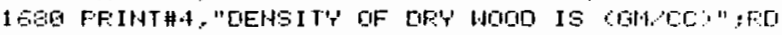

1 EOQ FFIHTH "WET WOLUME (CO)";

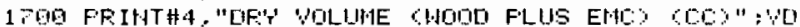

1719 FEIHT\#4, "DELLTA II IS ": [WH

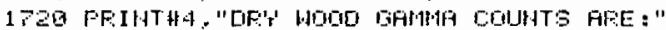

1730 FOF: $I=1$ TO 20

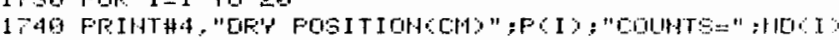

1756 HEST I

17ES FFEIHTH A CLOOSE4

$1761 \mathrm{FEH}$

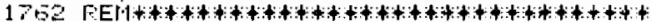

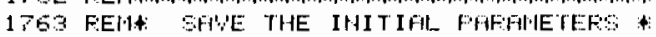

170.4 PEHT IH CISK.

17 ES FEMH:

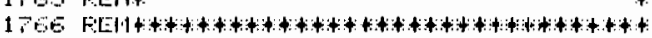

$17 E$ PEEN

$17 G E$ FEM

$1769 \mathrm{FEN}$

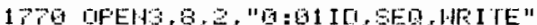

17 GQ FEIUTHS, SPEHF: 13

17 SO FRHAHS, FECHFE 19 \%

1010 FFIHTH

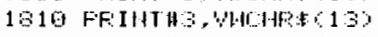

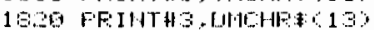

$1925 \mathrm{O}="$ " "

1030 FOP $I=1 \quad$ ra 20

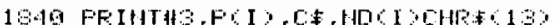

1859 HEXT I

1600 CLOSE:

$197 \mathrm{FEH}$

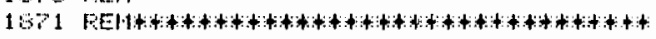

1982 FEHt

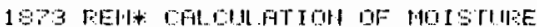

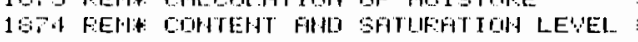

1 ERS FEHA: STARTS HEFE.

1870 FEPH

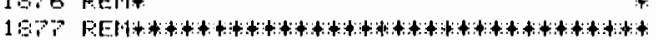

10 SEEH

1 S:G FEl

19 GQG FEH

1930 FE.

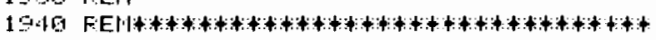

$19+11$ FENH+

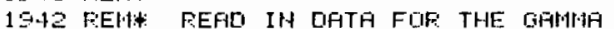

1 II3 FEMH COUHTS.

1944 FEII

1945 FEH t

$19+6$ FEII

1947 FEM

1348 FEEH

$1949 \mathrm{FEEH}$

1 ISC FEH

$+95.5 \quad T=-1.19$ 


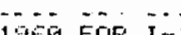

1965 I I $=I I+1$

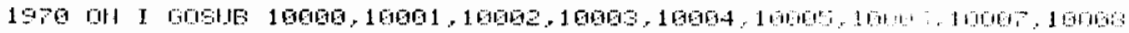

1900 IrIFUTHS.TH

1990 IHFIITH

2000 FOE: $\quad$ DOE=1 TO 20

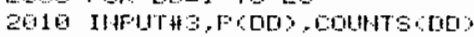

2020 HET TIC

2QSG TLOEES

2031 FEH

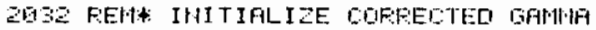

2093 FEHA COUHTS TO ZEFO. FHII THEH

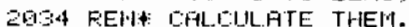

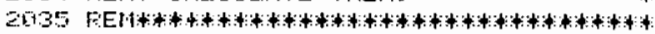

2036 FEEI

ZIST FEFI

2010 FOF: CID:=1 TO 2O

$2045 \mathrm{HCOCD}=\mathrm{O} . \mathrm{G}$

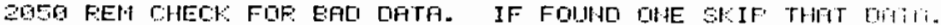

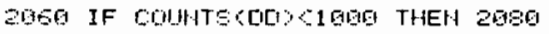

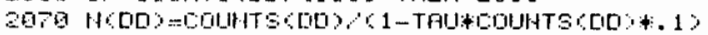

2090 HEYT [ILI

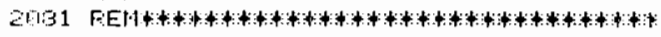

208 FEFH:

$2 Q 83$ FEH IHITIFLIZE MOISTUFE COOHTEHT

COEA FEN FHIO SHTUFATIOH LEVEL TO ZEFO *

2015 PENH

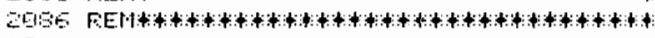

$2007 \mathrm{FEFH}$

2018 FEH

2099 PEEH

2096 FOP $D C=1$ TO 20

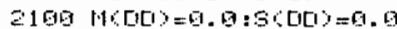

3119 HEKT $D E$

$2120 \mathrm{FEH}$

$2130 \mathrm{REH}$

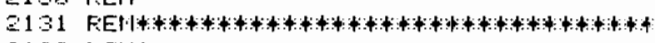

$2132 \mathrm{FEHTH}$

2133 FEEH CFILCIL_FTE THE MOISTIAFE

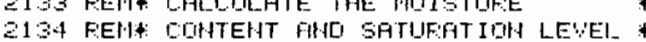

2135 FEFl'

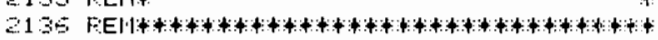

$2137 \mathrm{FEE}$

$213 \mathrm{PEH}$

$2139 \mathrm{FEH}$

$2149 \mathrm{A1}=\mathrm{G} . \mathrm{Q}: \mathrm{A2}=\mathrm{G} . \mathrm{G}$

$215 \mathrm{FEE}$

2160 FOP $Q 0=1$ TO 20

2162 ค1 $=9.9: F 2=0$.

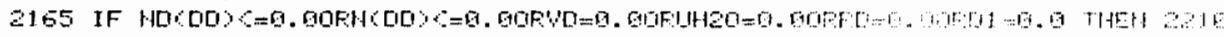

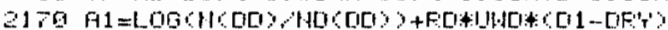

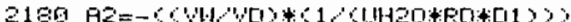

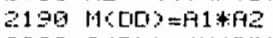

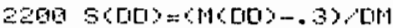

$2 \mathrm{ES} \mathrm{HEKT}$ [ICI

22:0 FEH

$2200 \mathrm{FEH}$

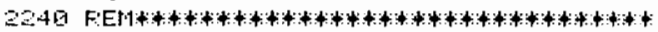

241 PEll:

2ZA2 FEHW FPIHT OUT RESULTS, MIISTUFE

2243 FENH: COHTEHT. FHO SATUEATIOH LEYELA:

2204 FEErt:

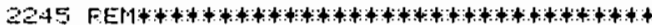

2246 FEVI

$2047 \mathrm{FEH}$

OSAR FFH 


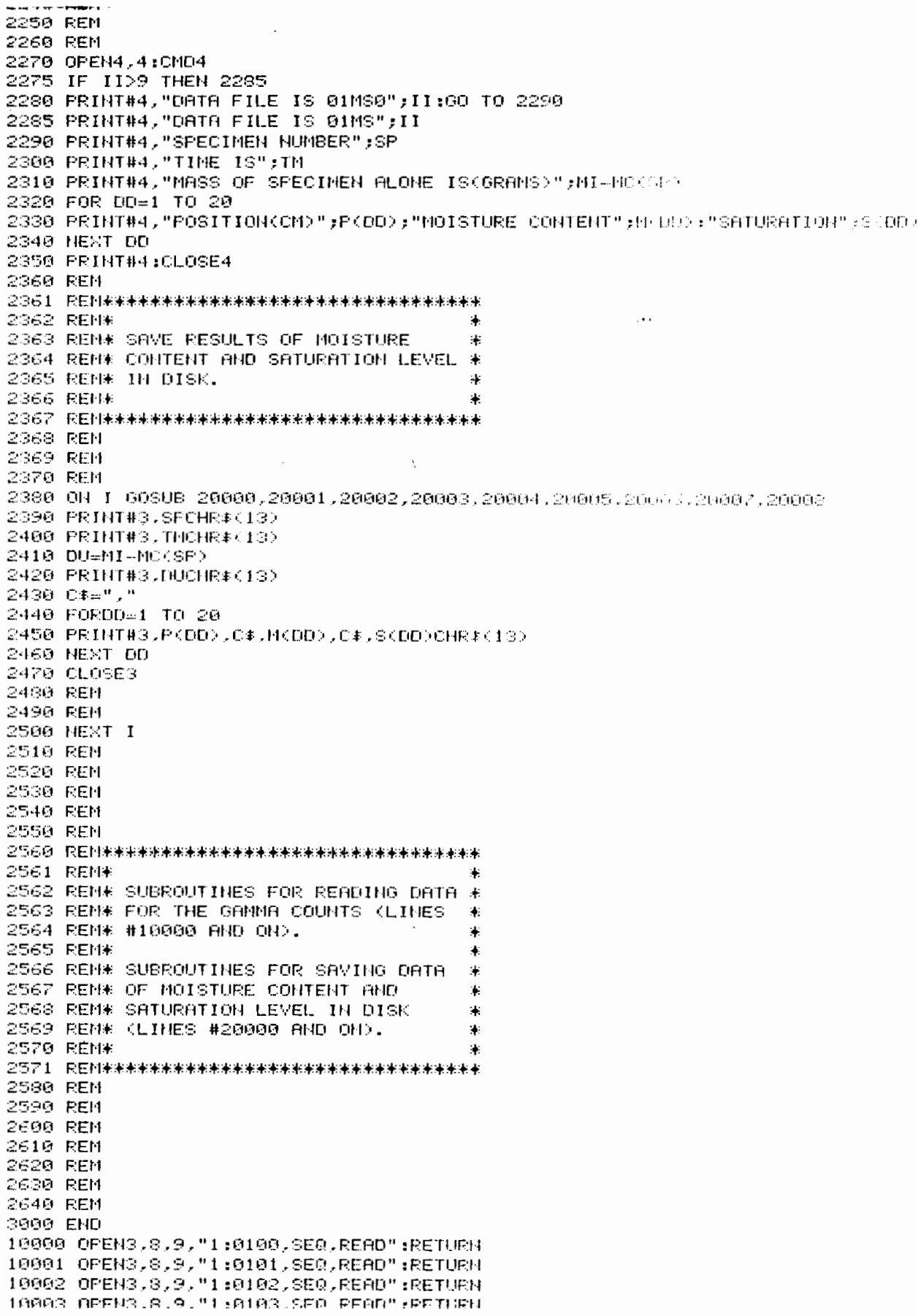




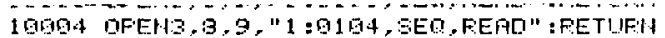

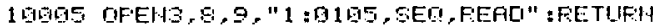

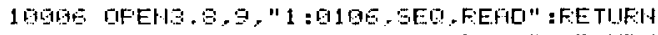

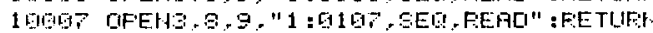

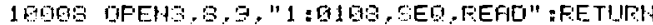

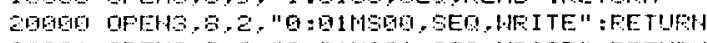

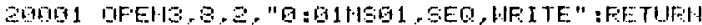

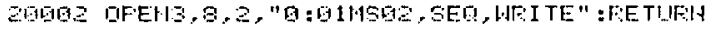

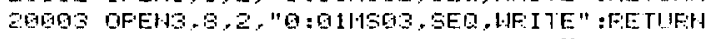

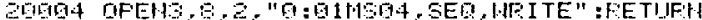

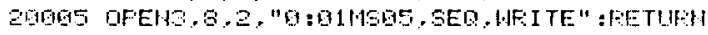

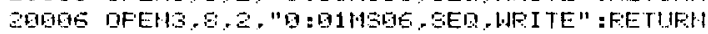

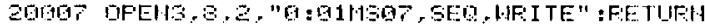

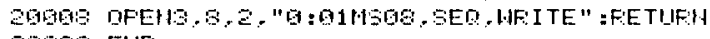
3010日 EHI

FEFICI'r'

F:EFI'I'

FEAE'r'. 


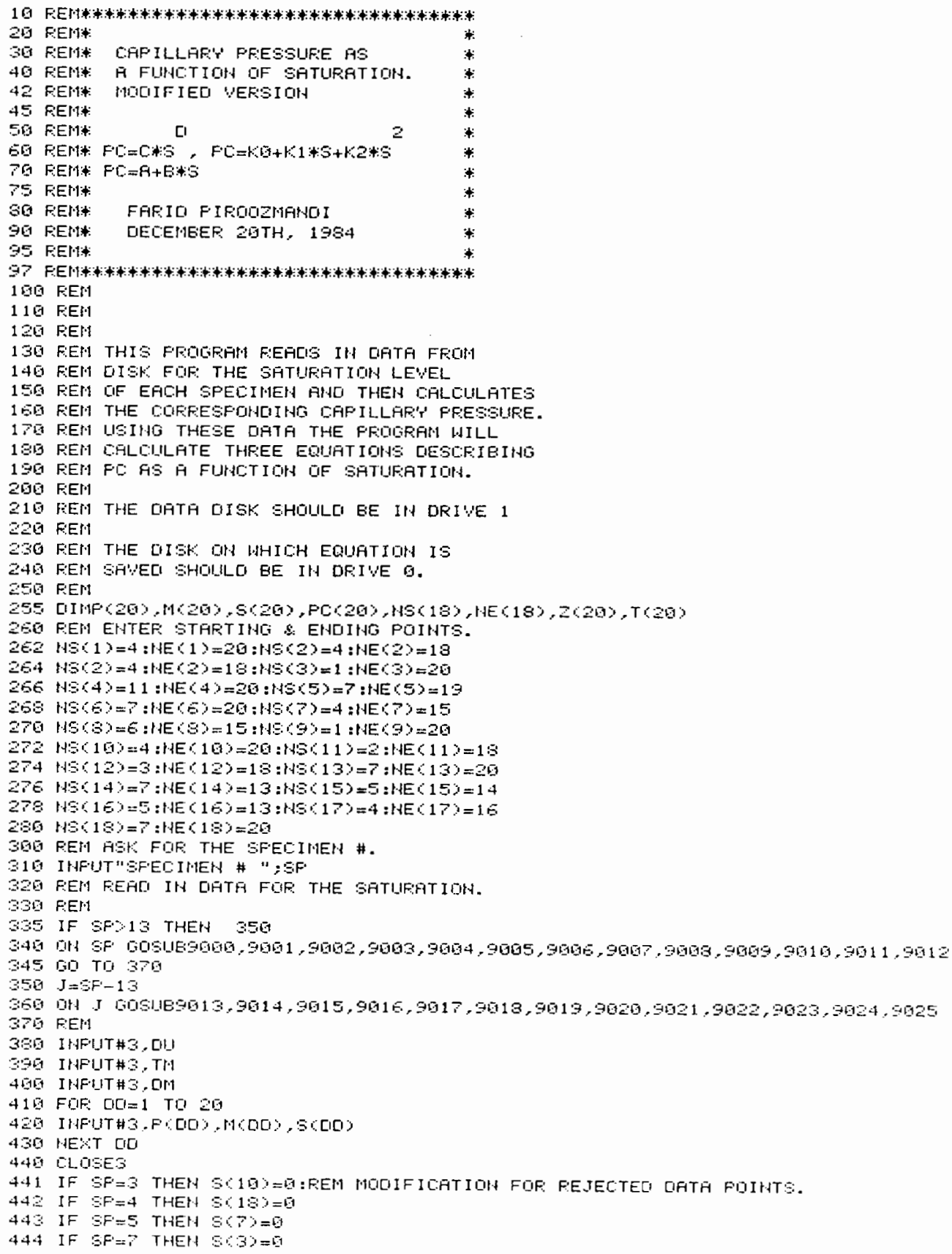




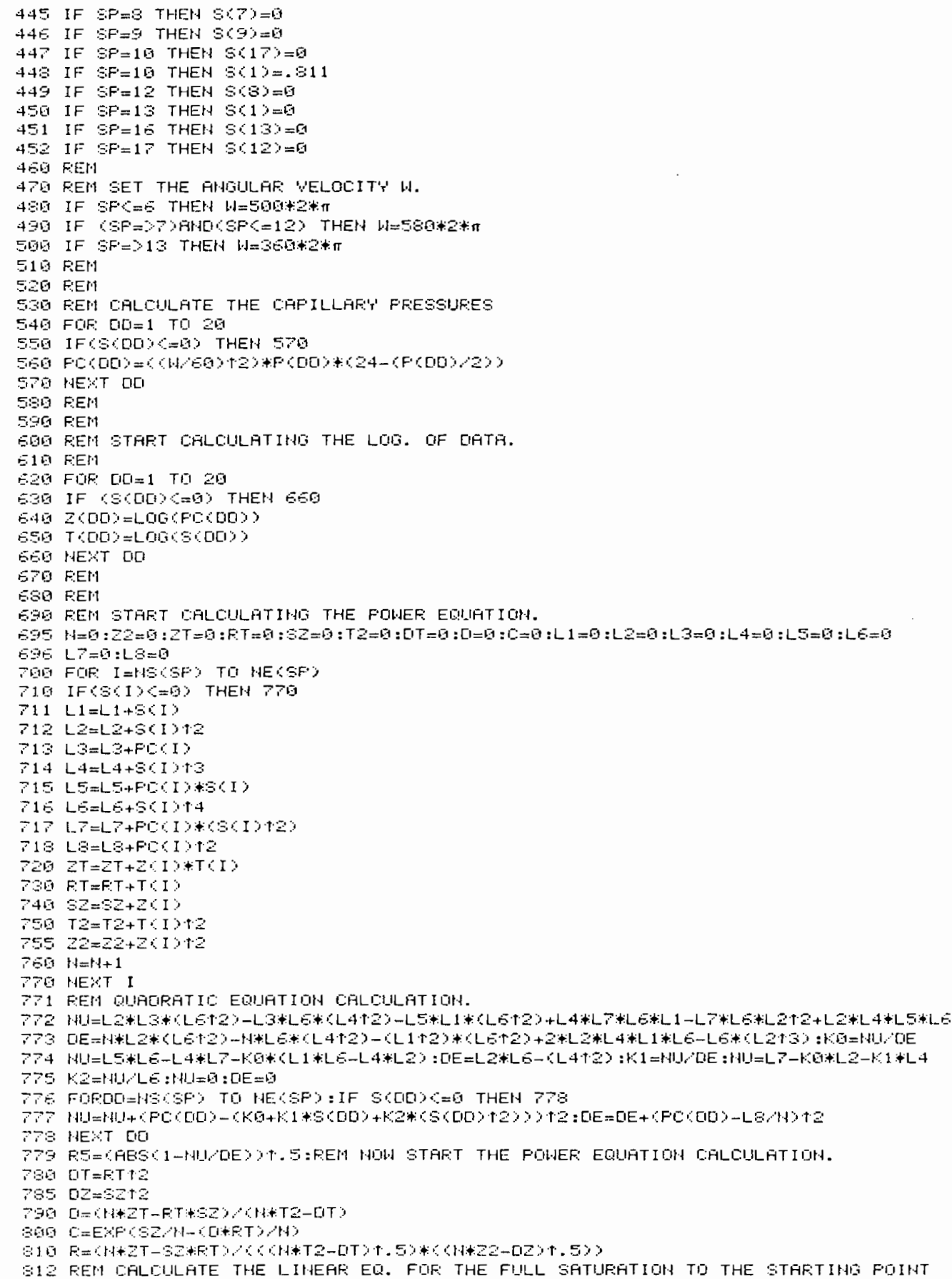


E13 FEM OF THE FIUHEF EQILFTI 매.

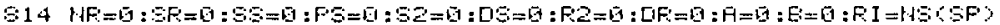

315. IF HSCSP $=1$ THEH RI $=2$

31E. FIF $I=1$ TO F:I

B17 IF $(S(1)=60)$ THEH

$919 S \mathrm{~F}=\mathrm{SF}+\mathrm{FC}(\mathrm{I})$

ज्ञC FEM

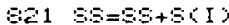

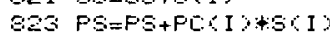

$325 \quad 5=52+512+2$

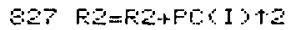

$525 \mathrm{HF}=\mathrm{HF}:+1$

SGE HE:T I

932 [15=5St?

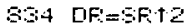

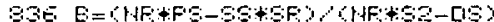

SSE $A=S F$ NF-ELCSSAHO

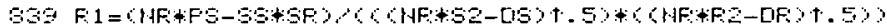

BAG FEH FFIHT OUT THE FESILTS

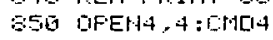

SGO FFINTH4. "SFECIITEH \#":SF

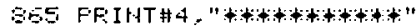

SES IF SFOg THEH SES

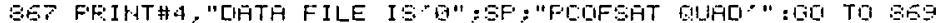

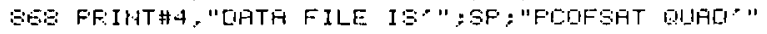

SEG FFIITHA,

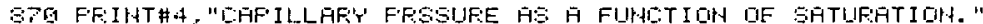

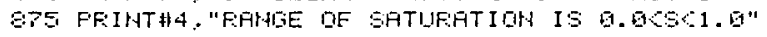

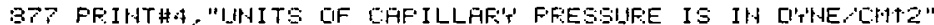

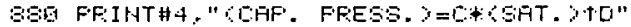

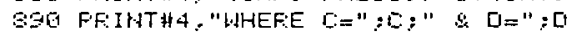

GES FFIHTH4.

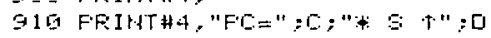

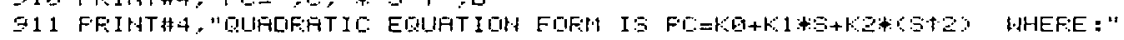

G1: FFIIHT

GS PFIIHTH4,

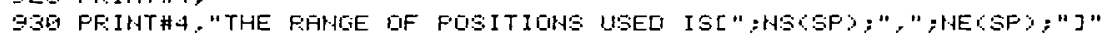

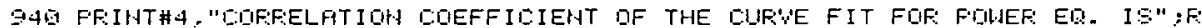

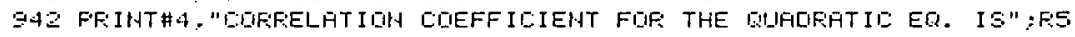

$94: 3$ FFIIHTH

944 FFIHT校, "FOF: FOSITIOH FHHLE DF [1,";FI;"]"

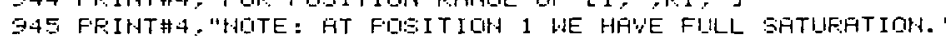

Q45 FPIHTH4.

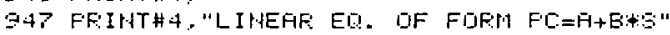

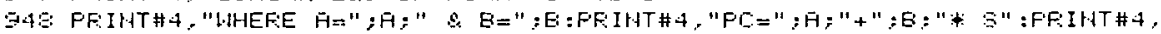

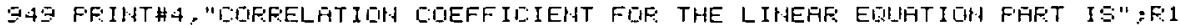

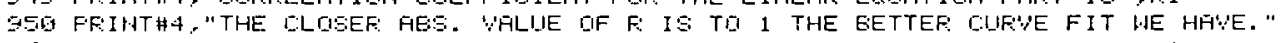

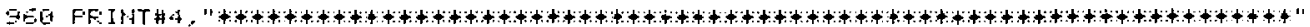

GT FFIHTHA.

SEG FFIHTH4," "LLOLEA

390 F:El|

$10605="$ "

$1010 \mathrm{FEH}$

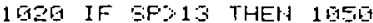

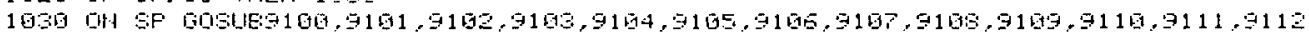

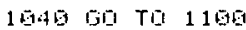

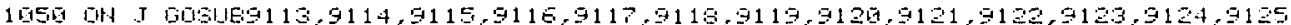

1 GE FEP

$1 . \bar{G} \mathrm{G}$ FEM

$19: 0$ FEM

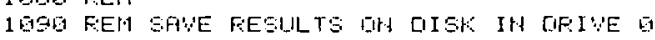

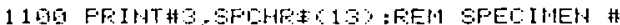

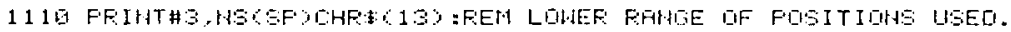

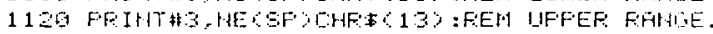

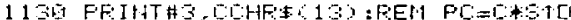

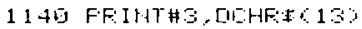




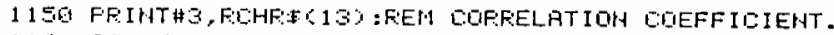

11 EG PFIHTHZ,WHFE

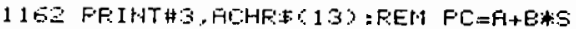

11 E.4 FFIIHTHS E EHF E 13 )

1135 FFIHTH3.F1LHF 13 : FEM COFFELATIOH CIEFFIEIEHT OF LIHEFR EQUATIOH.

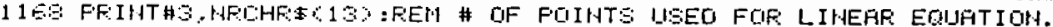

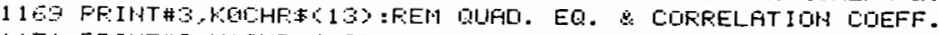

1171 FFIHTH, $1 \mathrm{HHF} 13 \mathrm{O}$

1173 FFIHTHS KOLHFEC13)

1175 FFINTHSFELHFEC13\%

1177 CLLOES

11 :DEFH

1190 FEW

$1210 \mathrm{RE}$

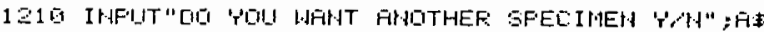

$12 \Xi G$ IF $\mathrm{AE}=$ " $\mathrm{T}$ " THEH $31 \mathrm{HE}$

$1230 \mathrm{EHC}$

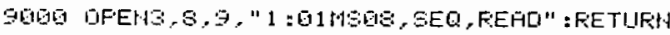

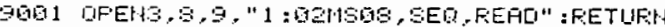

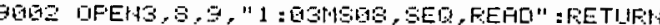

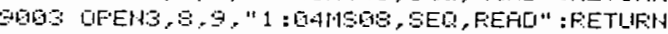

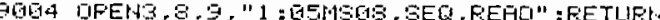

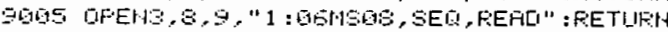

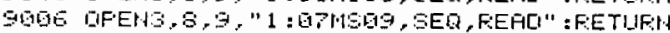

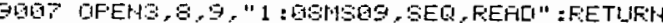

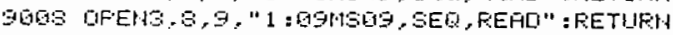

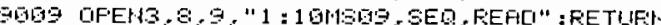

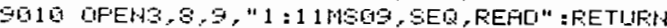

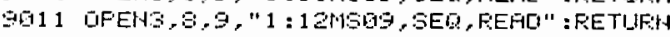

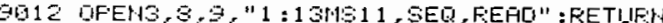

9113 DFEH

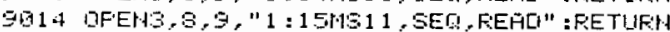

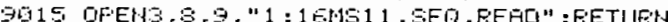

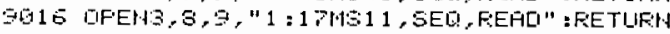

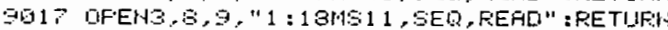

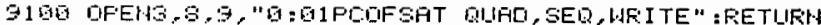

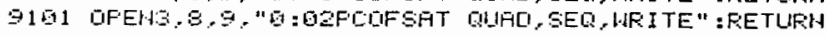

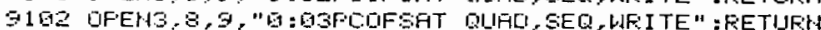

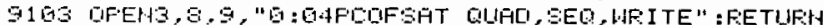

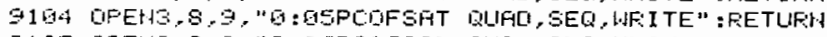

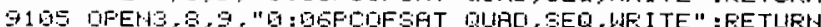

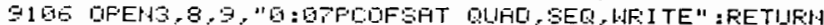

5197 DFEHOE.

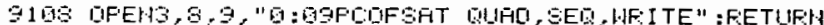

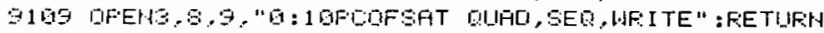

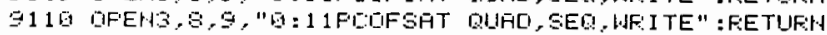

9111 DFENS.S. "B. "1:

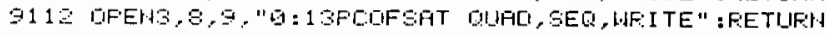

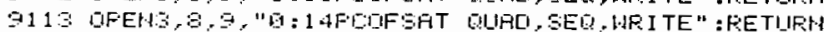

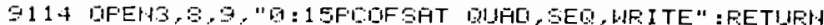

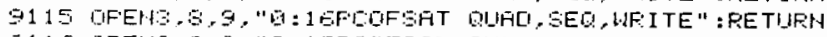

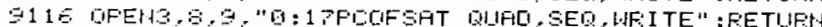

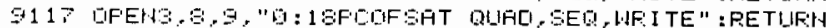

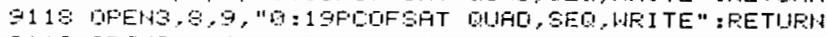

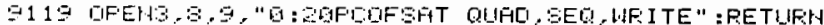

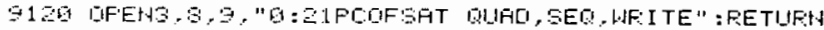

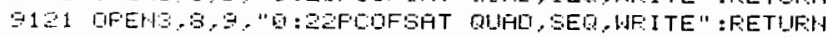

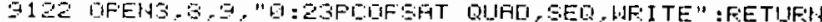

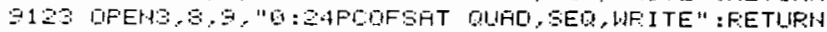

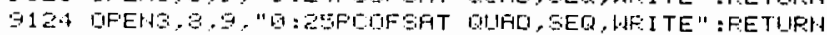

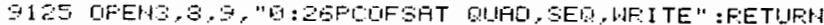
FEALI'r' 
FEFAO'T'

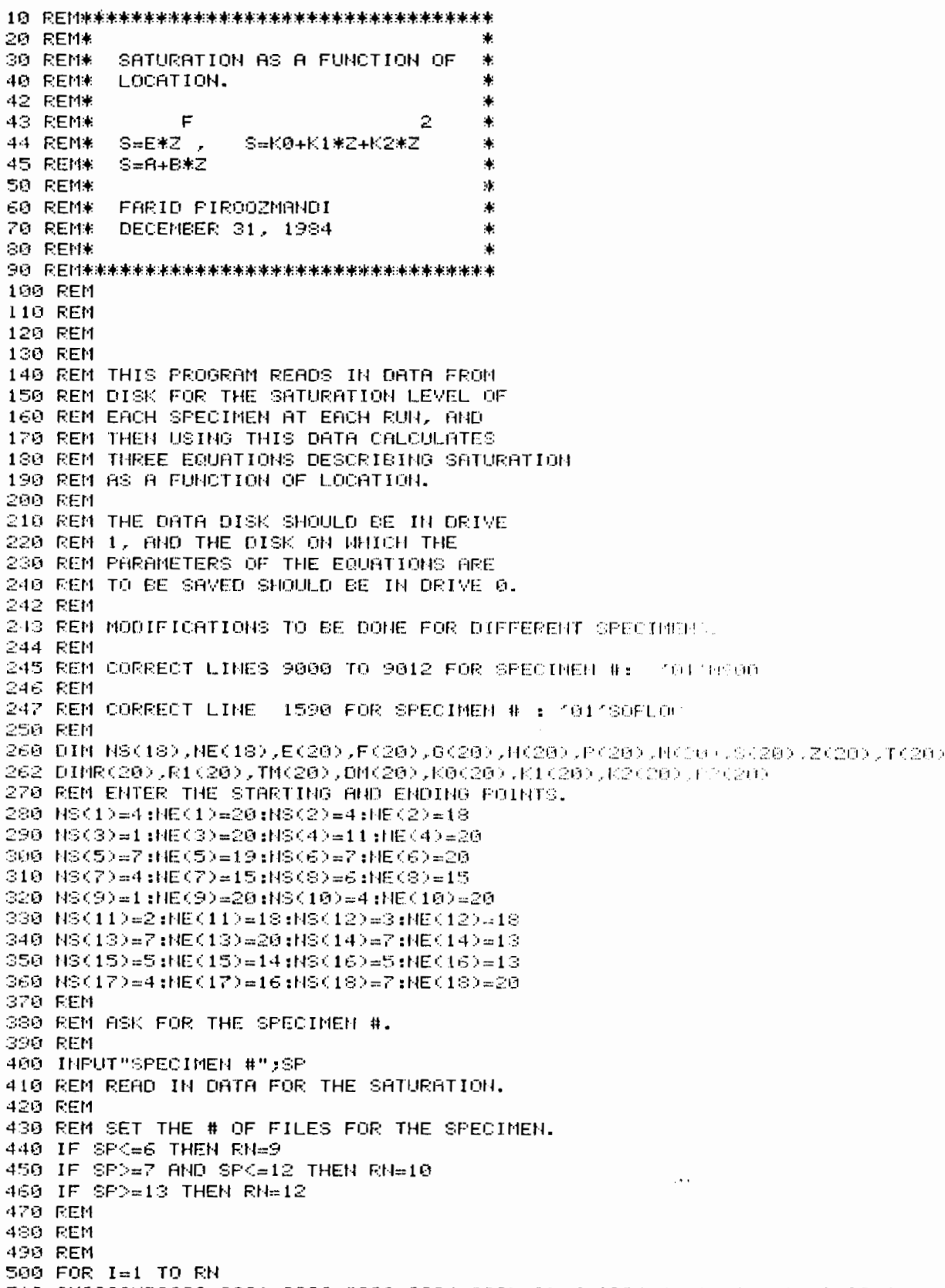




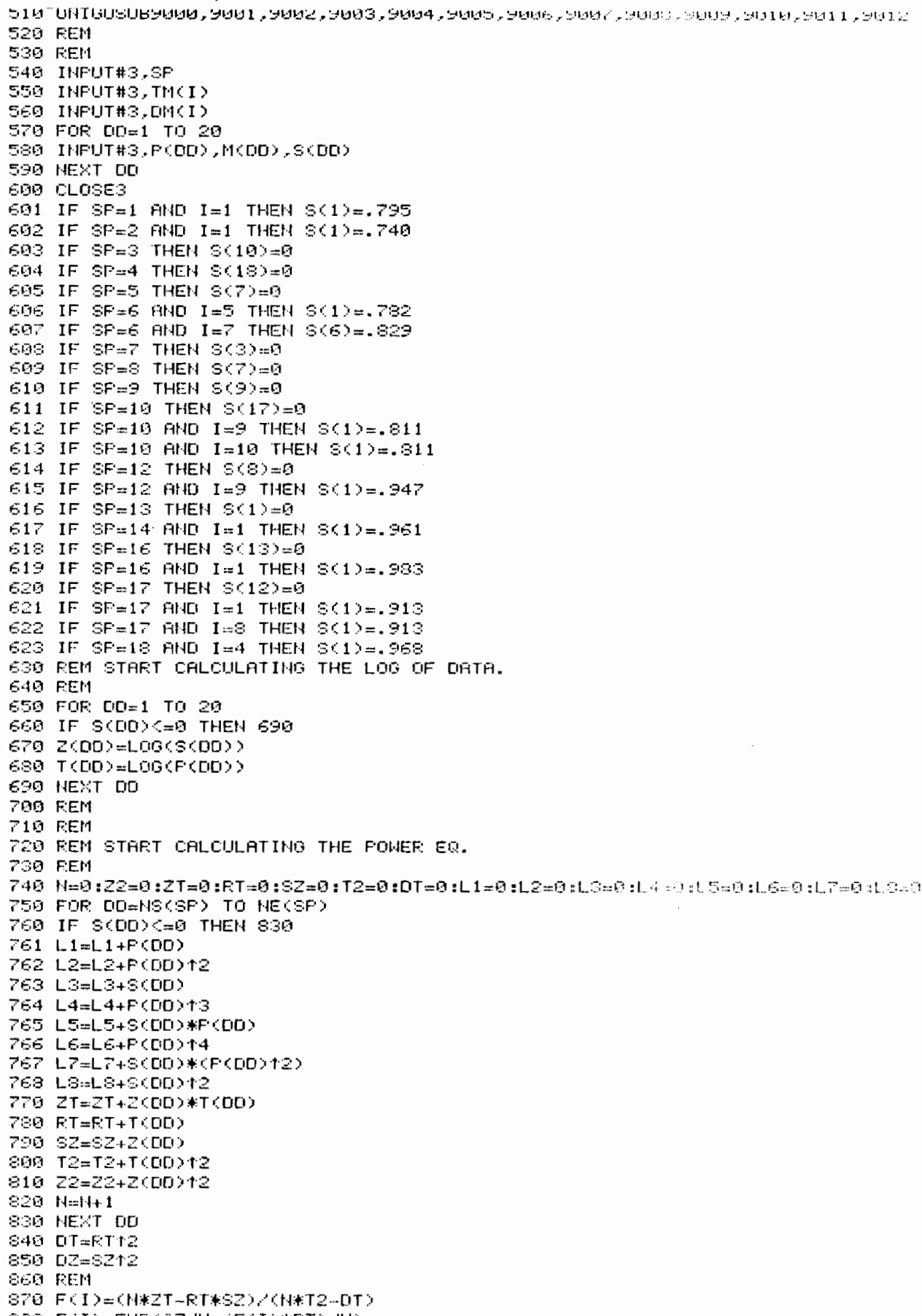




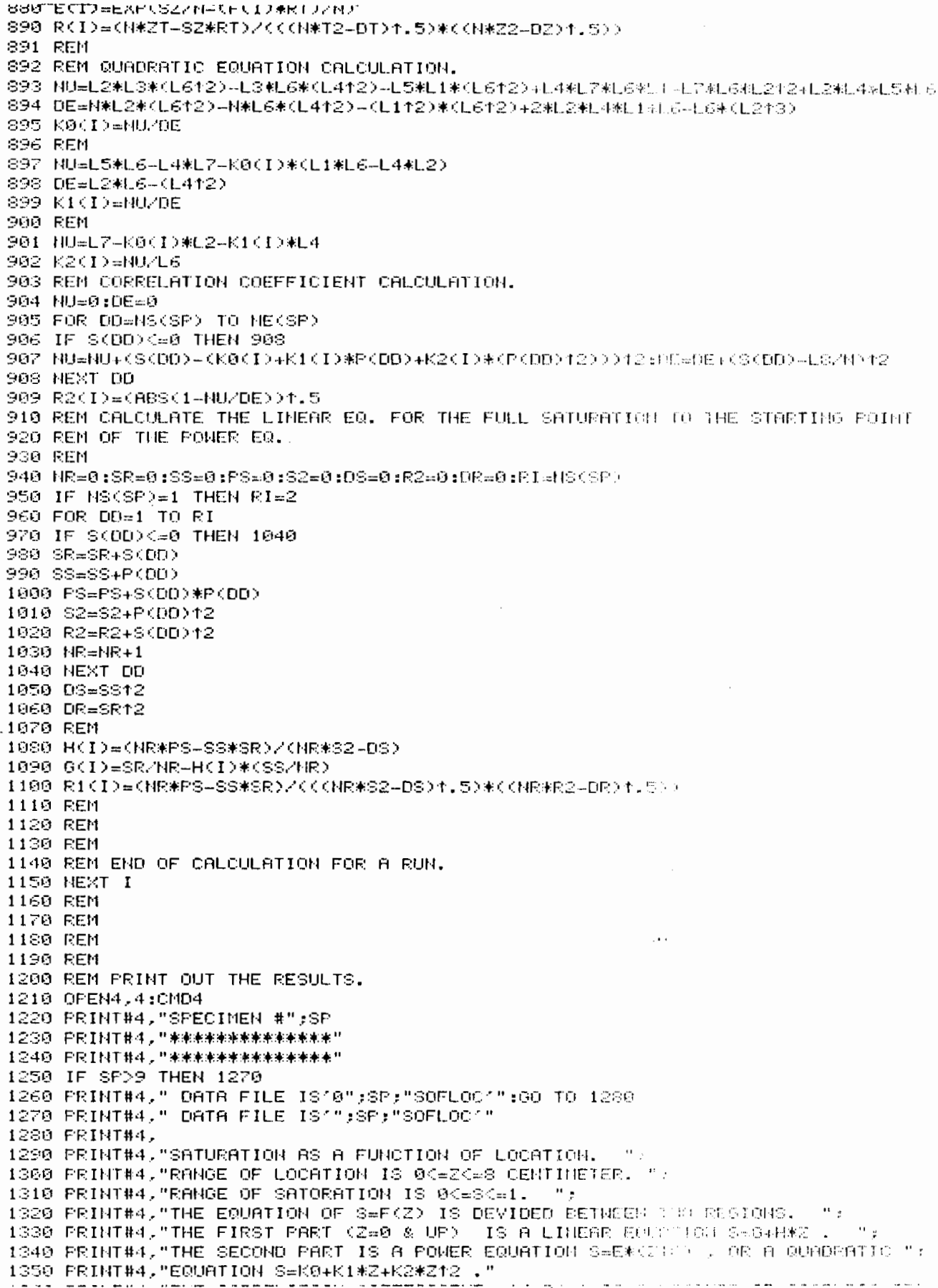




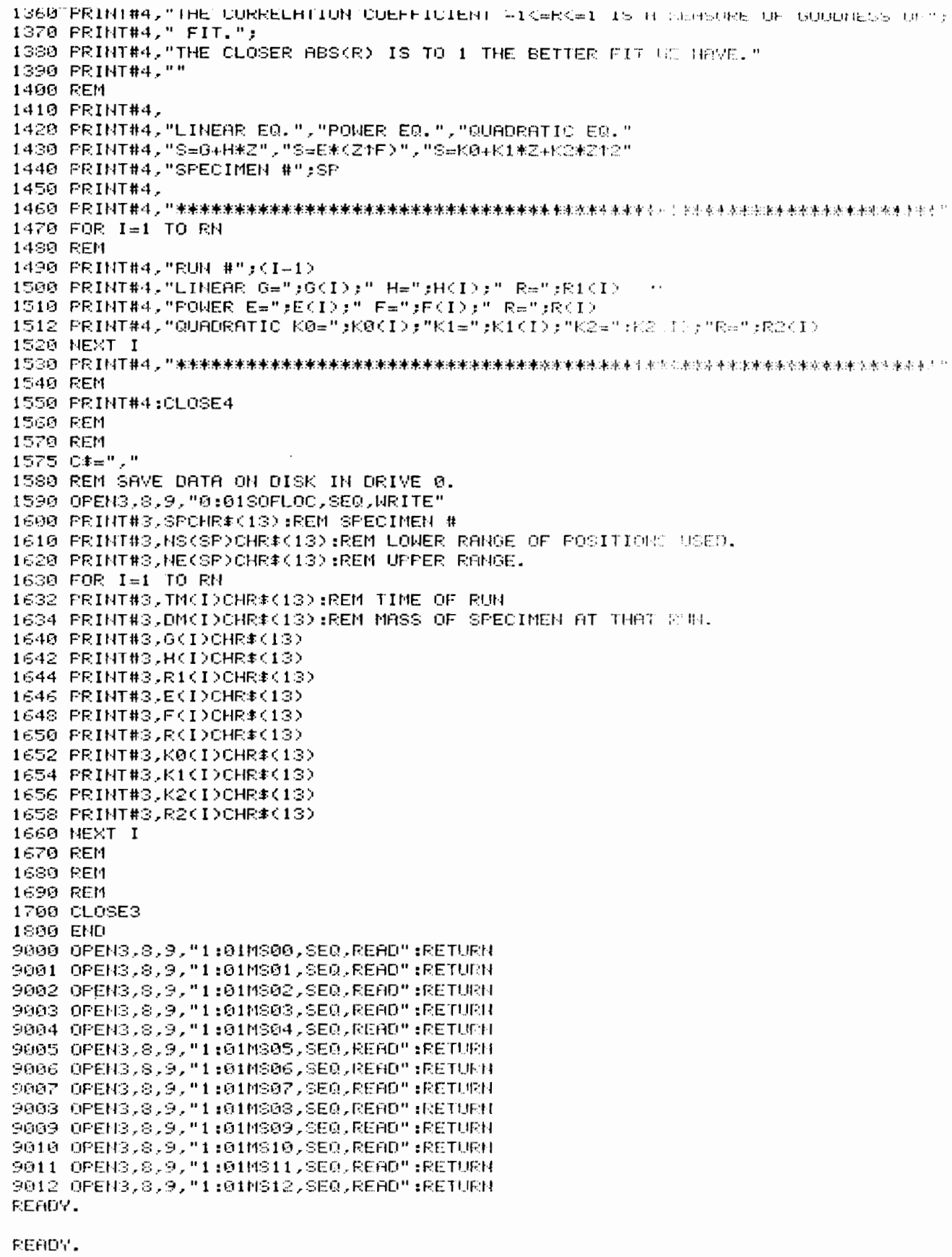


SERRIHIHE FOR \#G

FEAO'I'.

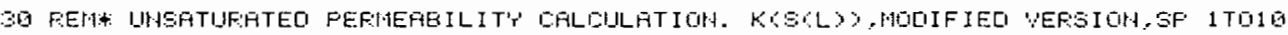

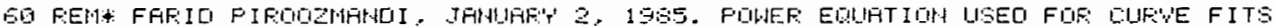

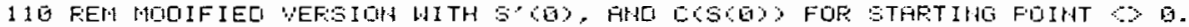

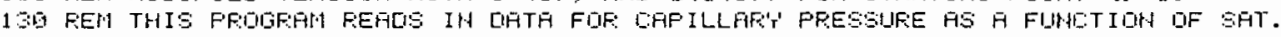

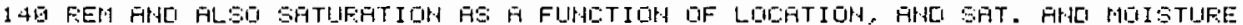

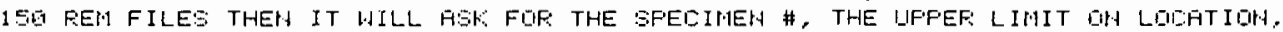

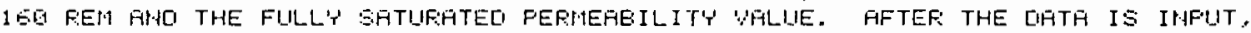

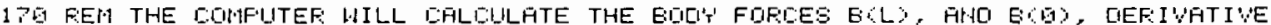

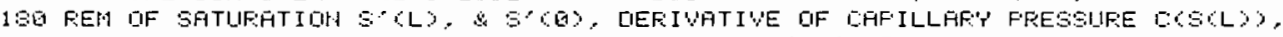

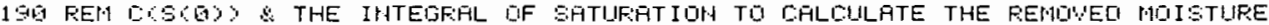

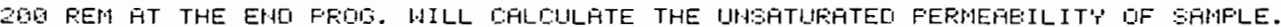

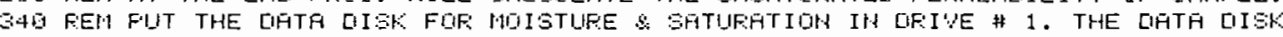

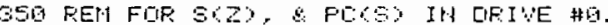

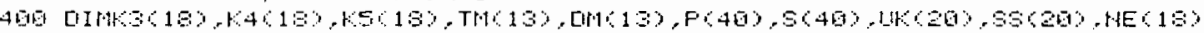

405 OIM 15613

$410 \mathrm{NE}(1)=20: H E(2)=16: H E(3)=20: H E(4)=20: H S 61)=4: H 5(2)=4: H 3(3)=1: H 5(4)=11$

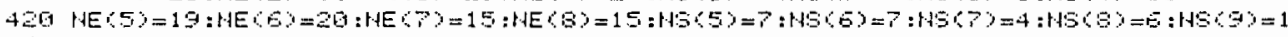

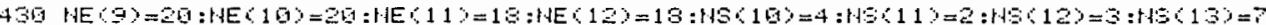

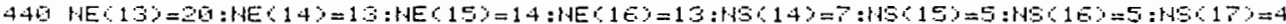

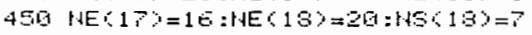

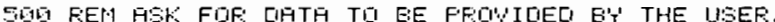

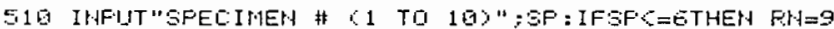

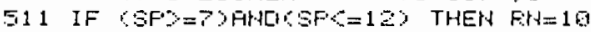

512 IF $S F=13$ THEH $F: H=12$

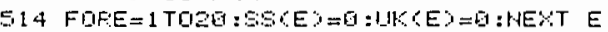

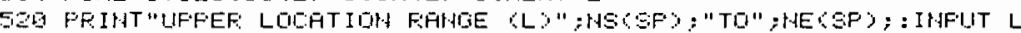

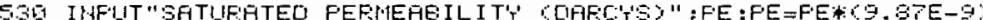

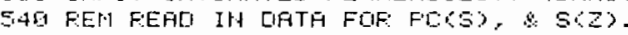

550 SF=EF-1S:IF EF 23 THEH 509

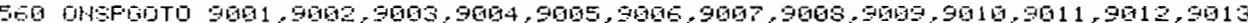

575 GO TO 590

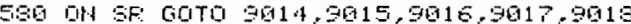

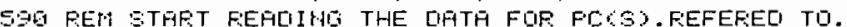

EGIG IHFIIT $\$ 3.0$

E16 IIFIITH3.

EZG IPFUTH 3. . O

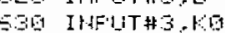

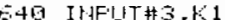

E5S IHFITH $3 .-$.

SOE IHFITHZ, D

670 IHFITH 3.

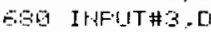

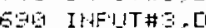

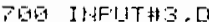

PIG INFITH $3 . \mathrm{O}$

712 IHFUTHS.

714 IHFI.UTHS.C

715 ILFIVITH3.G

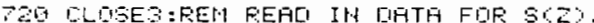

7 IG IF SF 13 THEH THO

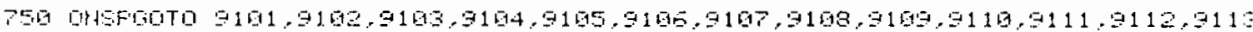

70 TOO TO 780

779 OH SF GQTQ $9114,9115.9115 .9117 .9113$.

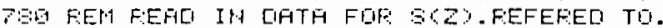

790 IHFITH $3, G \mathrm{P}$

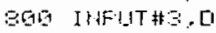

810 I IFIT 3 .

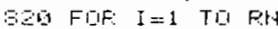

SSO IHFITHE.THKI:

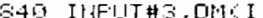

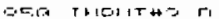




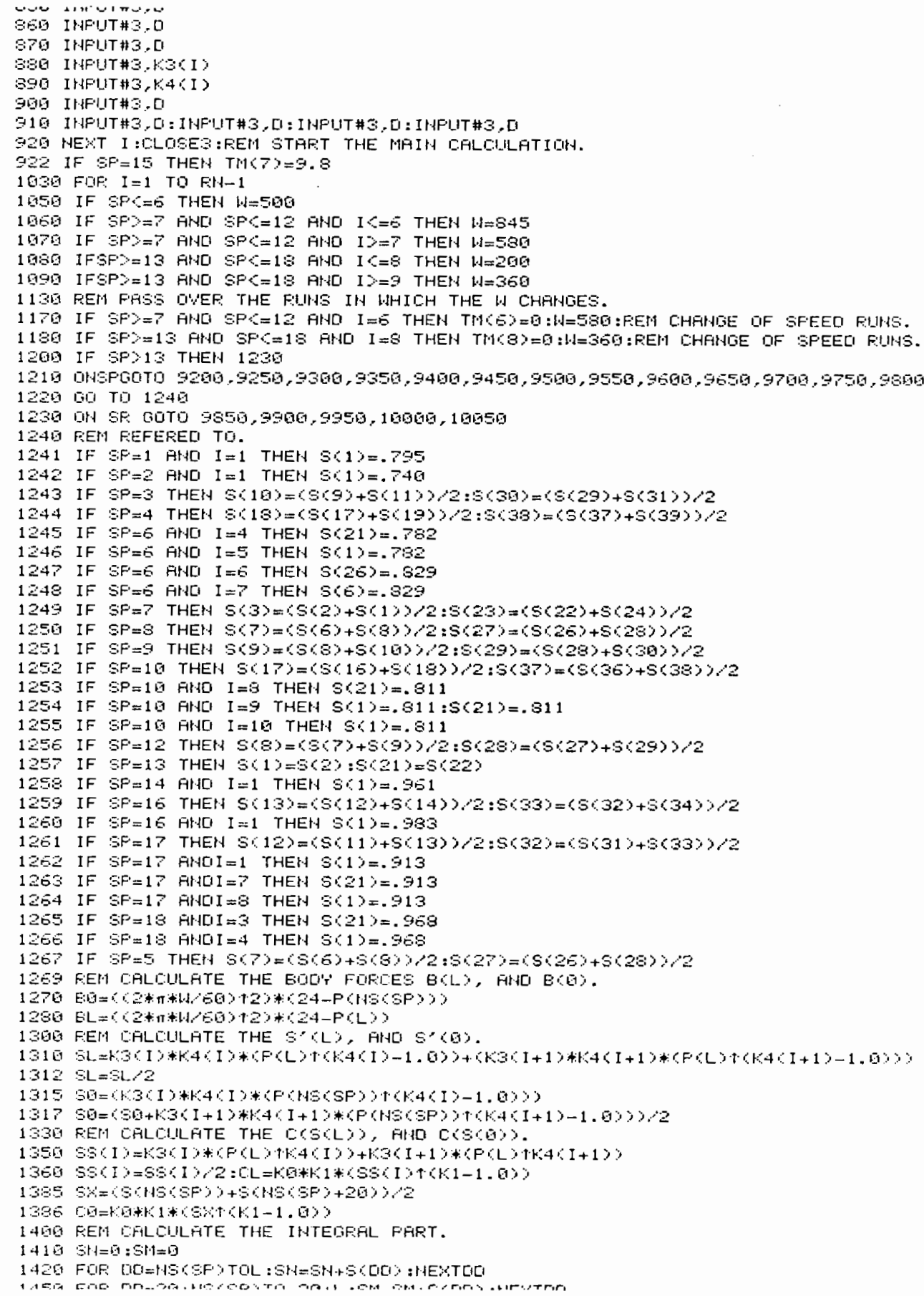




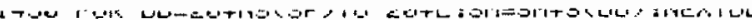

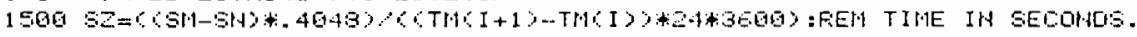

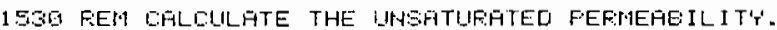

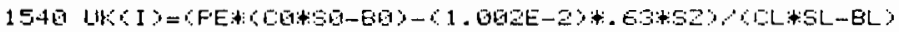

$201 G \mathrm{G}$ HEKT I

2EGE FENA FFIHT DULTT THE PESLILTS.

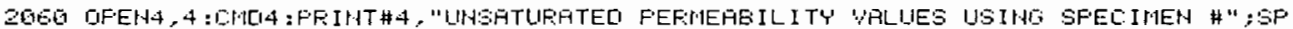

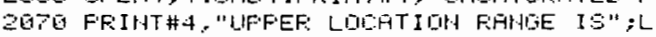

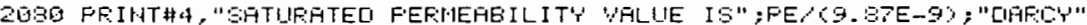

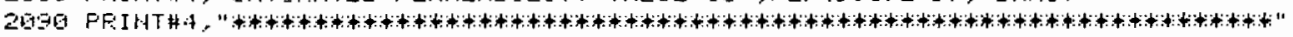

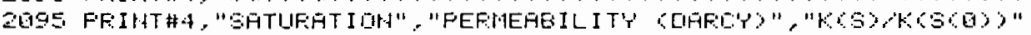

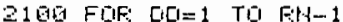

2105 IF $S S \times[D)=0$ THEH 2130

2110 FFIHTHA, SGC[I]

2112 IF $5 S C 00 \%=1$ THEH 2130

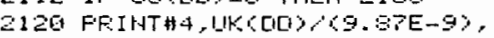

2125 FRIHTH4, HKCLODY PE

$\because 130$ HEXT

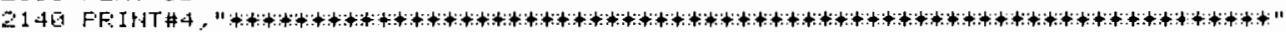

2150 FFIHTHA:LLOSE4

2180 FEM FELIO THE CFLEIJLATIOHA WITH HEW FFFATIETEFS.

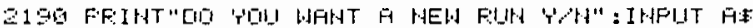

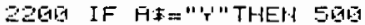

50 GQ EHCI

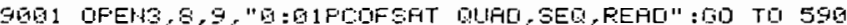

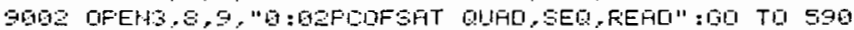

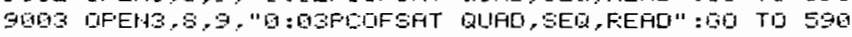

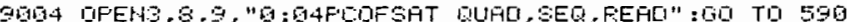

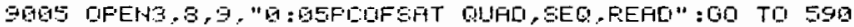

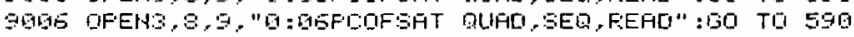

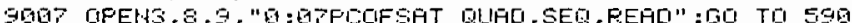

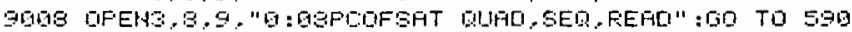

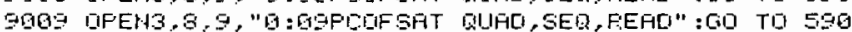

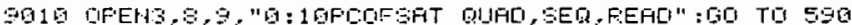

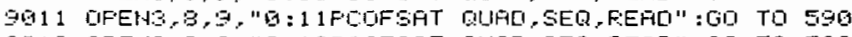

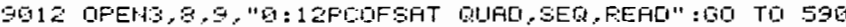

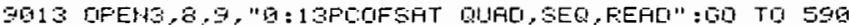

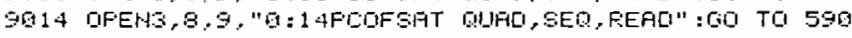

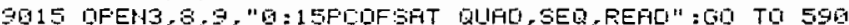

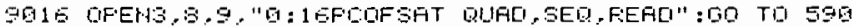

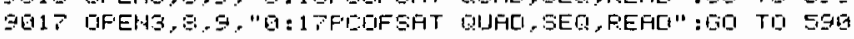

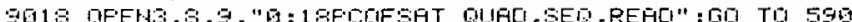

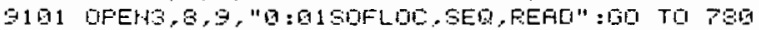

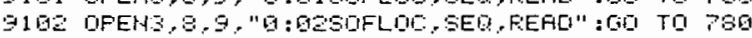

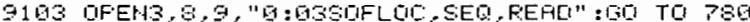

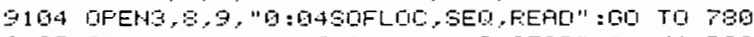

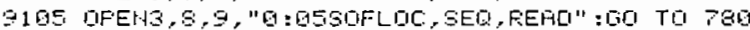

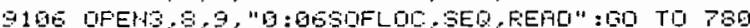

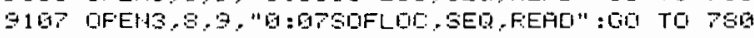

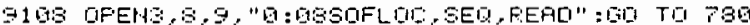

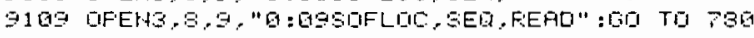

"119 DFEHS,

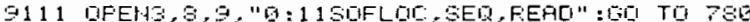

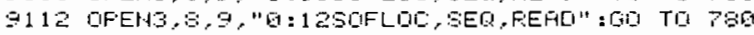

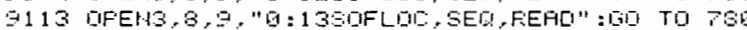

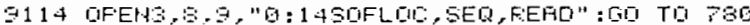

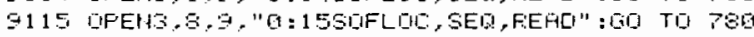

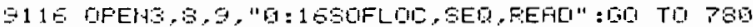

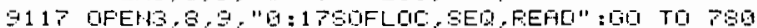

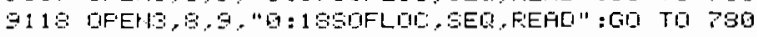

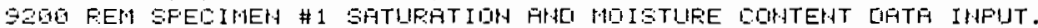

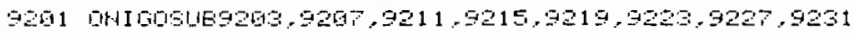

G202 G0 TO 1249

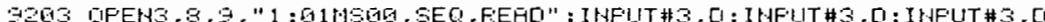

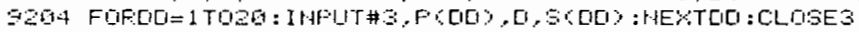

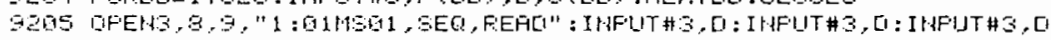

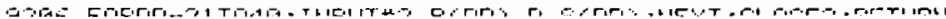




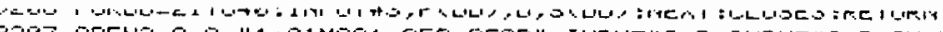

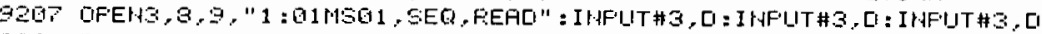

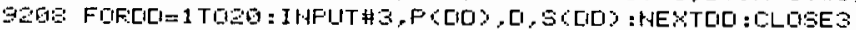

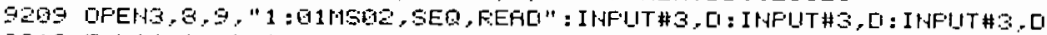

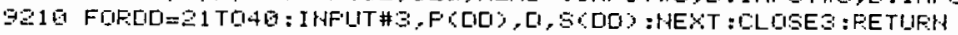

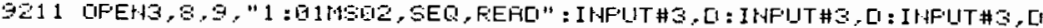

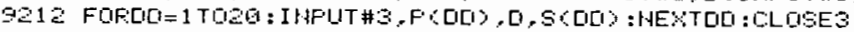

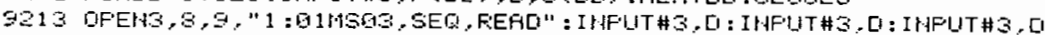

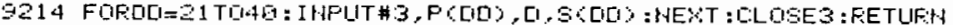

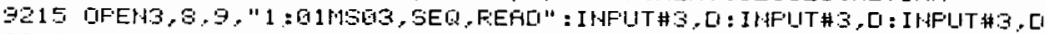

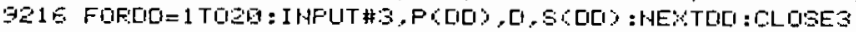

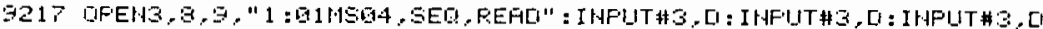

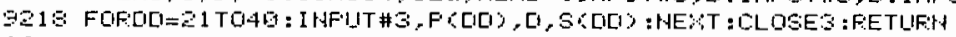

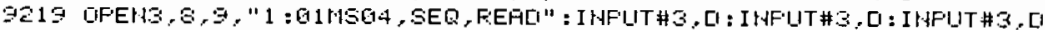

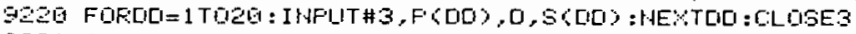

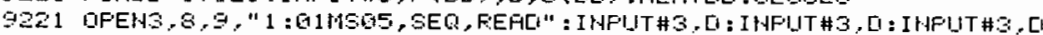

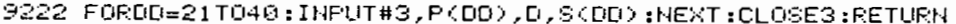

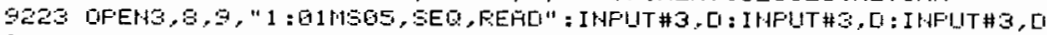

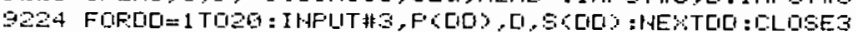

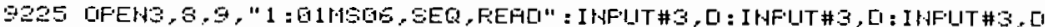

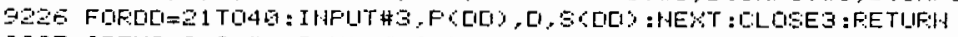

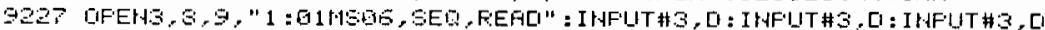

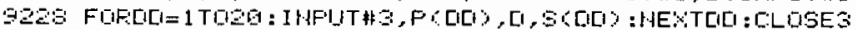

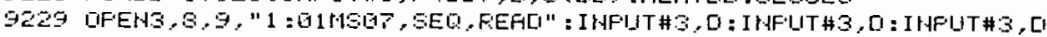

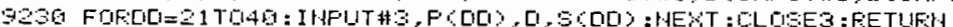

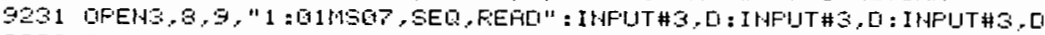

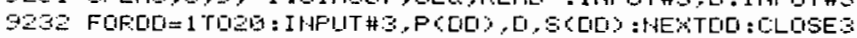

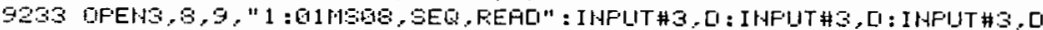

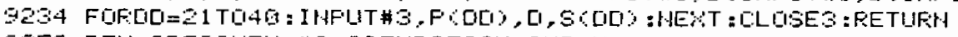

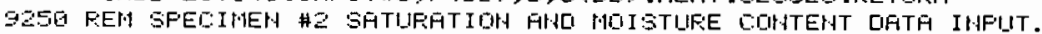

9251 마 $1051469253,9257,3261,5265,9269,9273,9277,9281$

925260 TO 1240

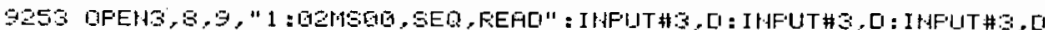

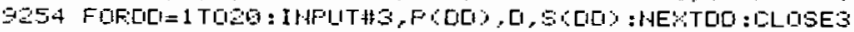

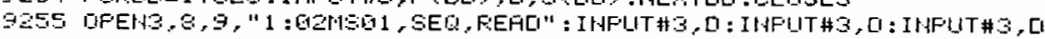

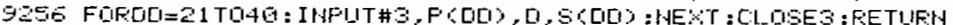

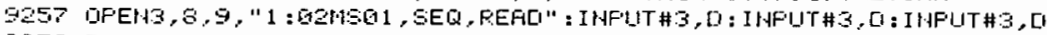

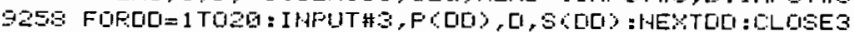

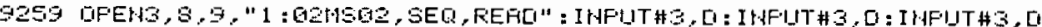

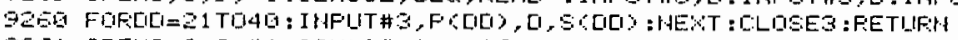

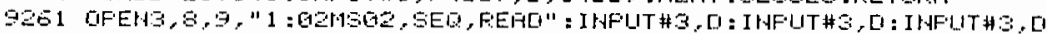

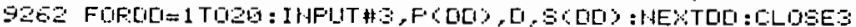

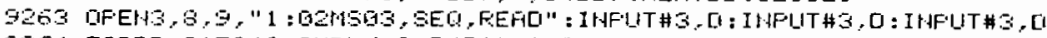

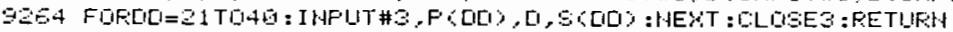

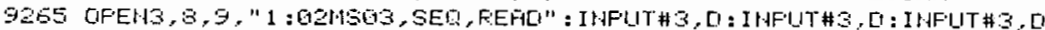

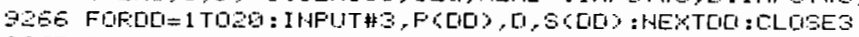

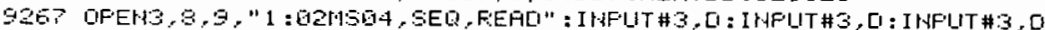

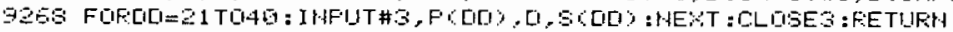

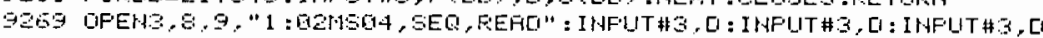

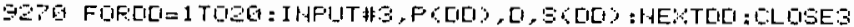

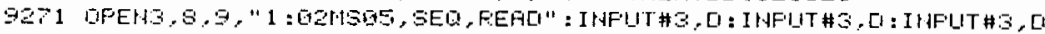

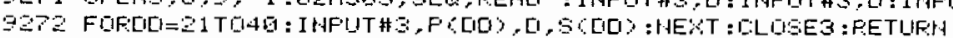

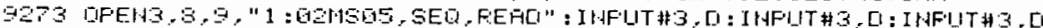

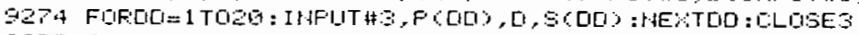

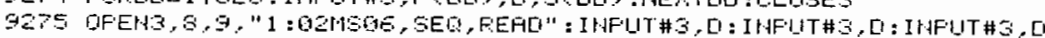

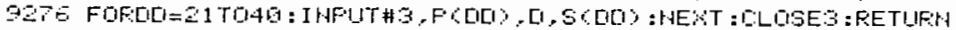

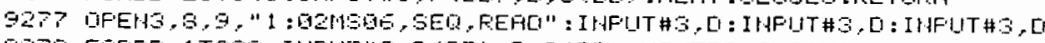

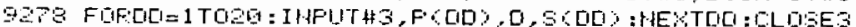

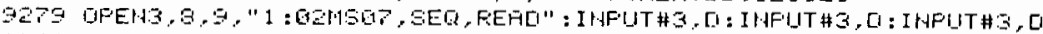

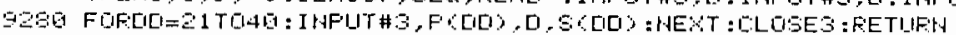

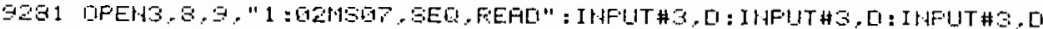

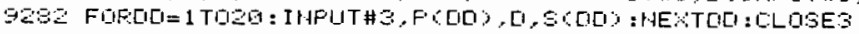

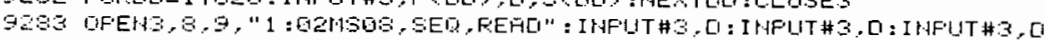

G

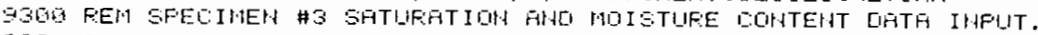

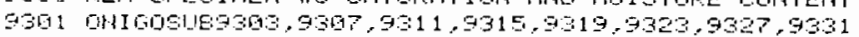

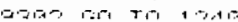


cac.

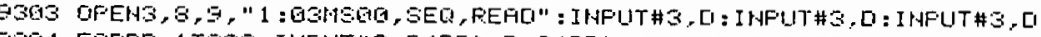

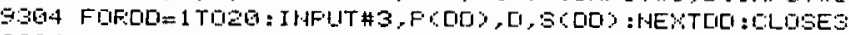

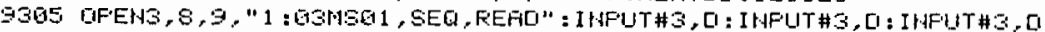

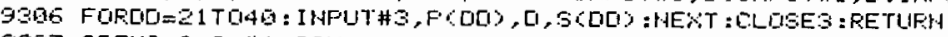

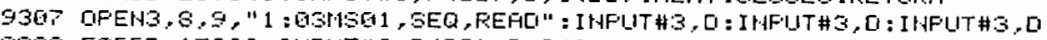

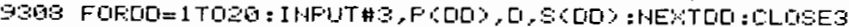

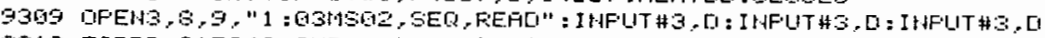

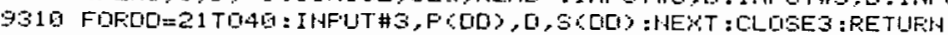

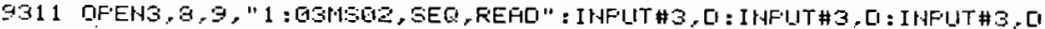

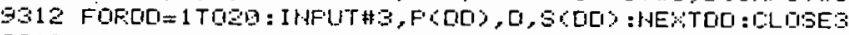

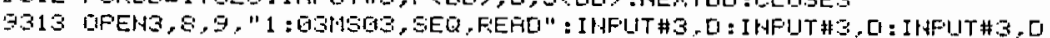

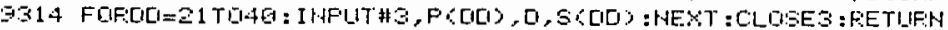

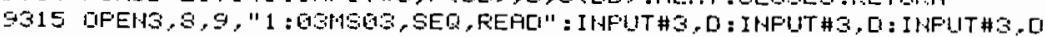

9316 FQFOCI=1 TOZE : IHAPUTA

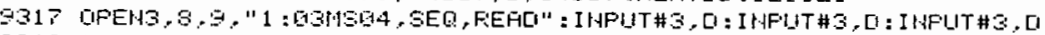

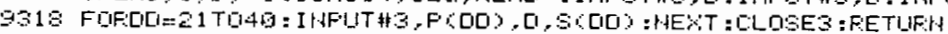

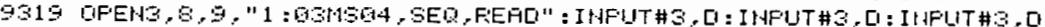

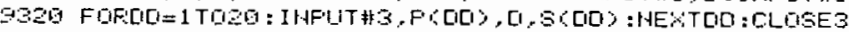

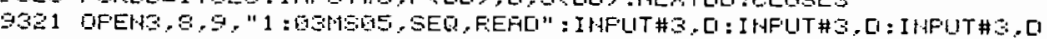

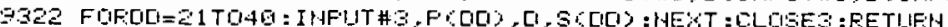

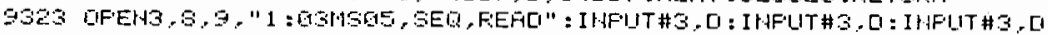

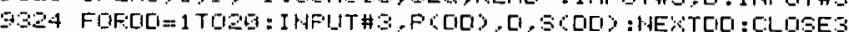

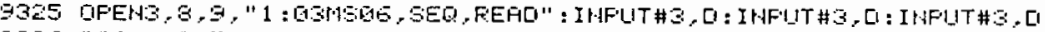

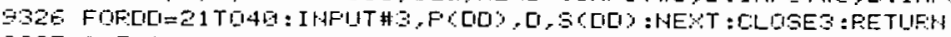

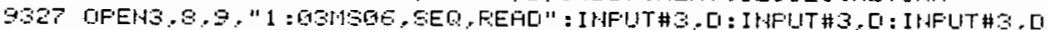

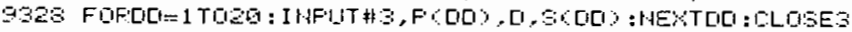

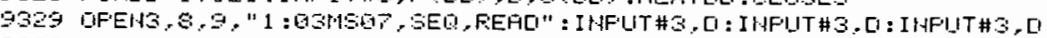

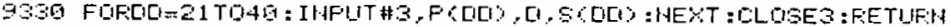

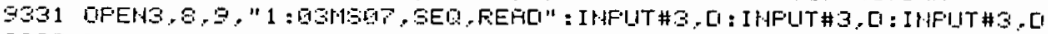

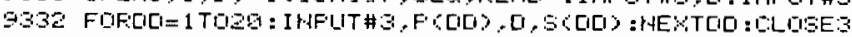

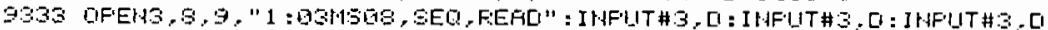

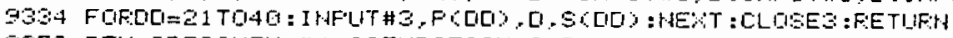

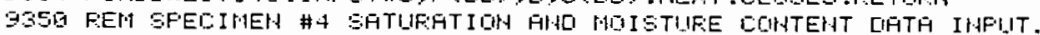

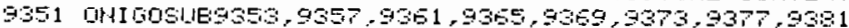

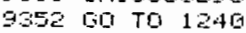

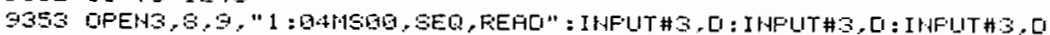

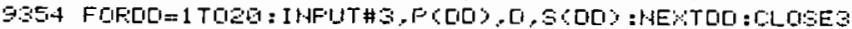

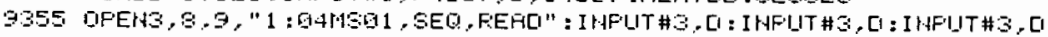

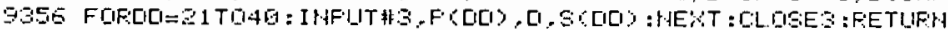

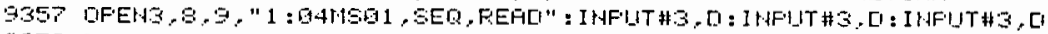

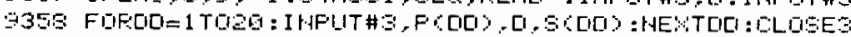

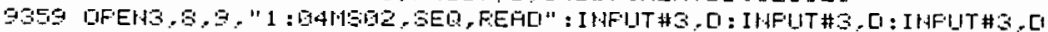

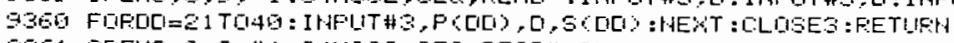

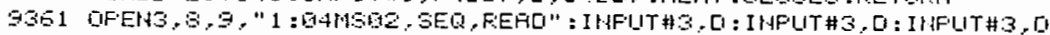

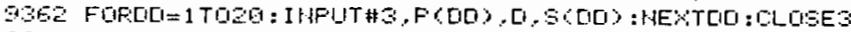

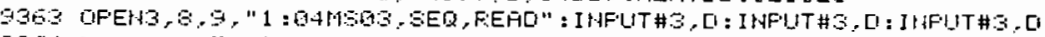

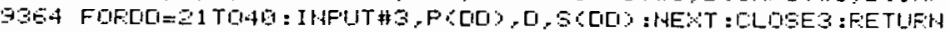

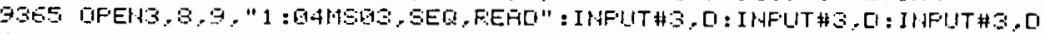

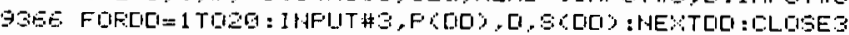

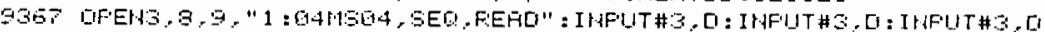

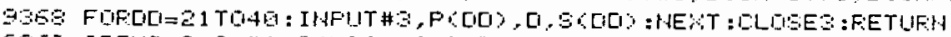

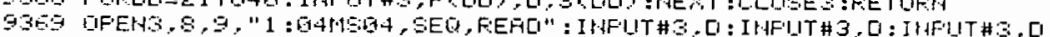

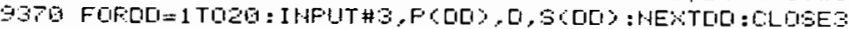

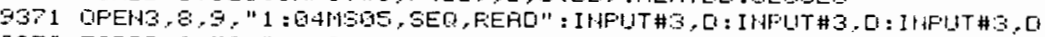

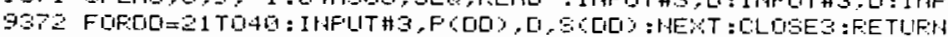

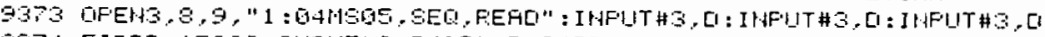

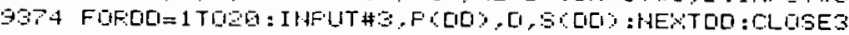

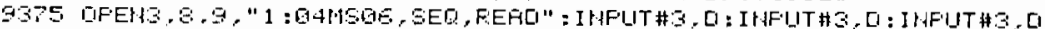

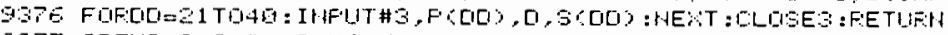

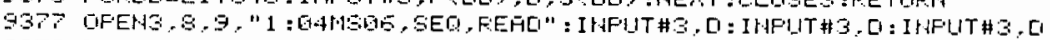

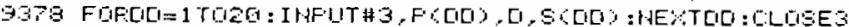

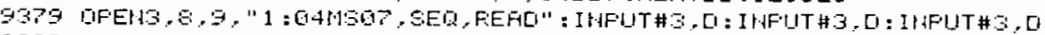

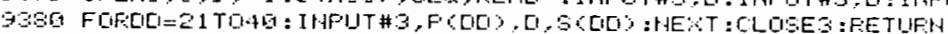

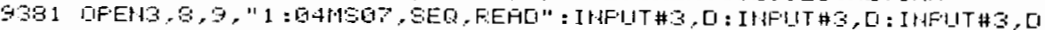

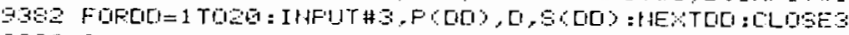

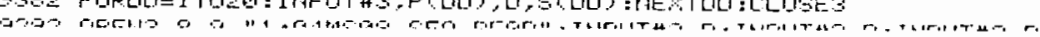


-

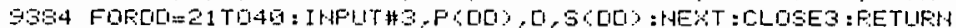

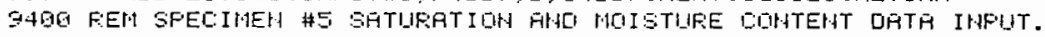

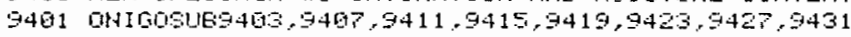

9402 GiO TO 1240

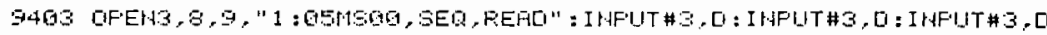

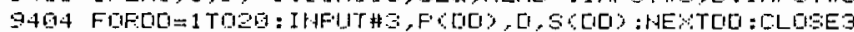

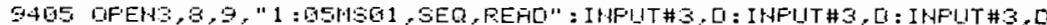

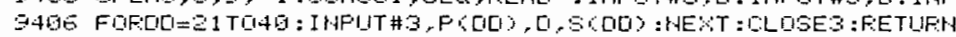

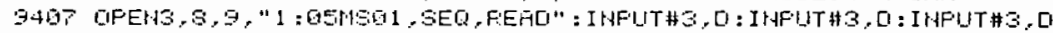

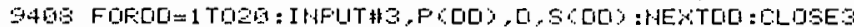

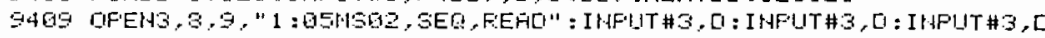

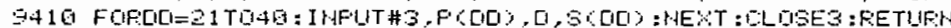

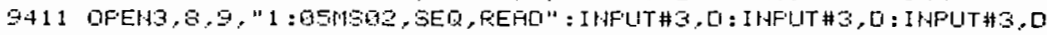

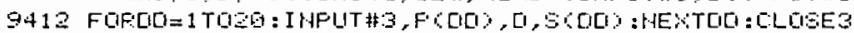

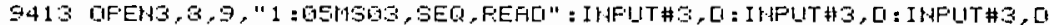

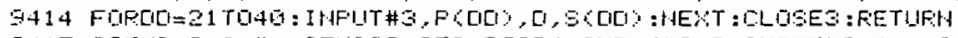

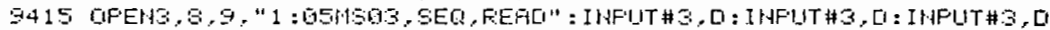

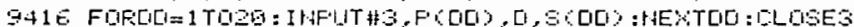

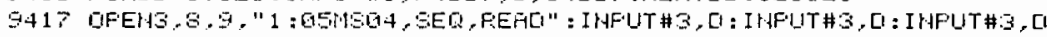

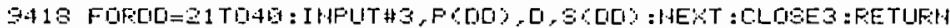

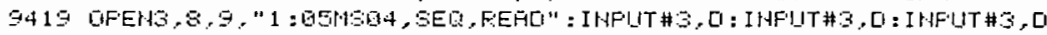

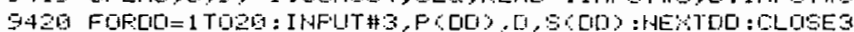

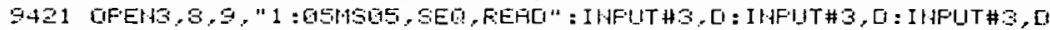

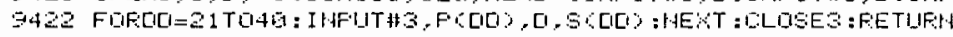

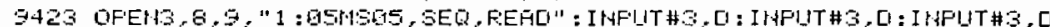

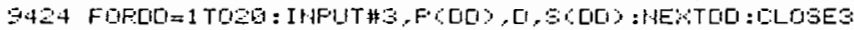

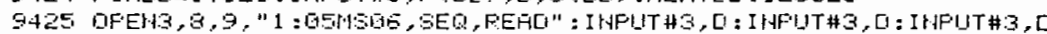

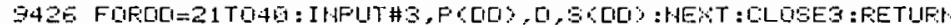

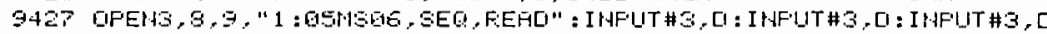

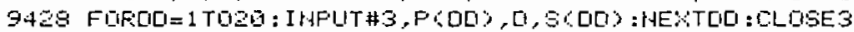

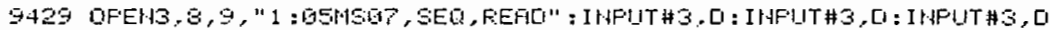

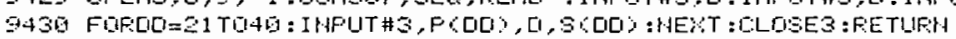

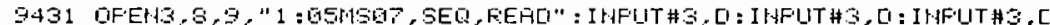

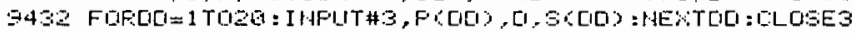

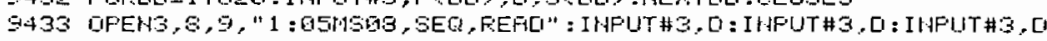

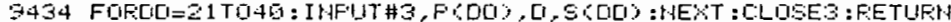

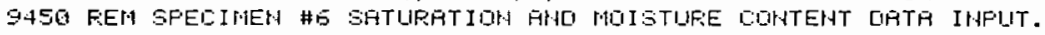

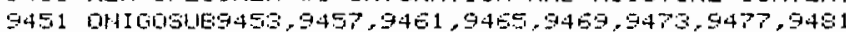

455200 TO 1240

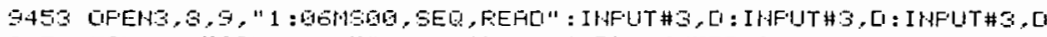

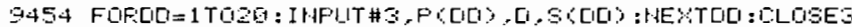

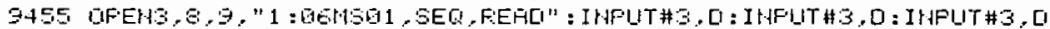

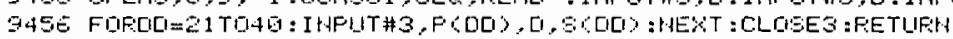

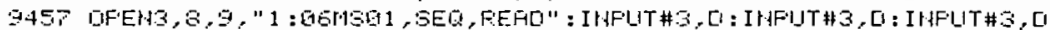

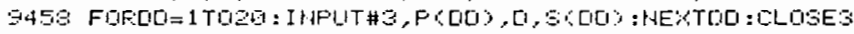

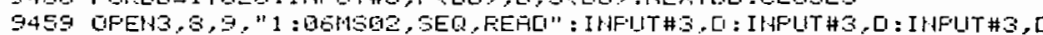

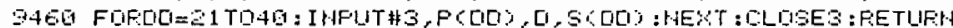

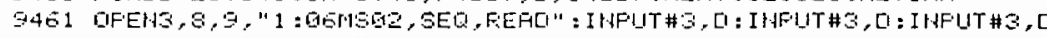

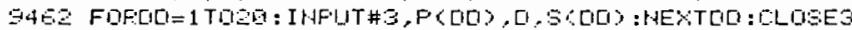

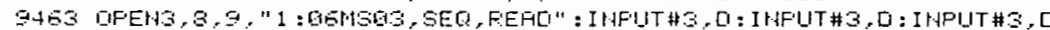

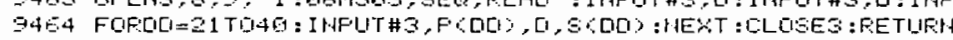

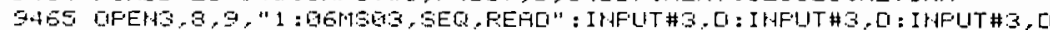

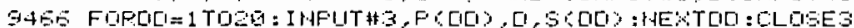

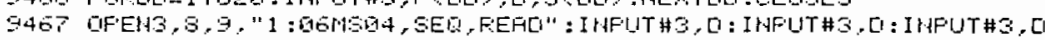

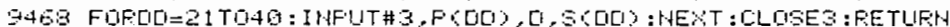

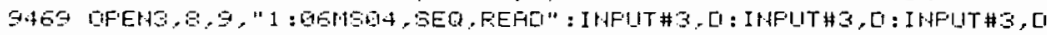

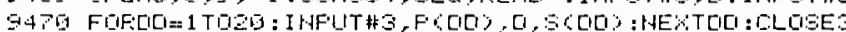

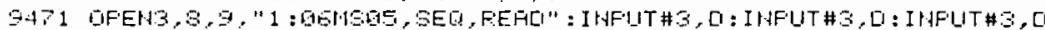

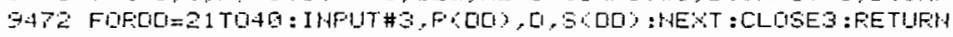

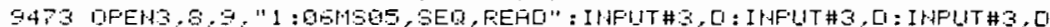

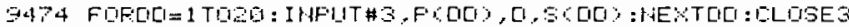

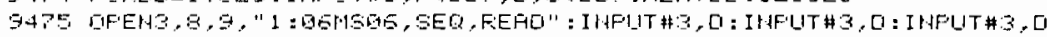

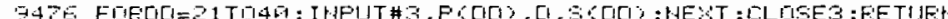

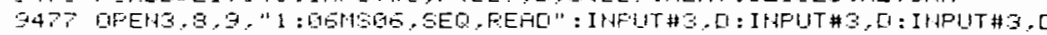

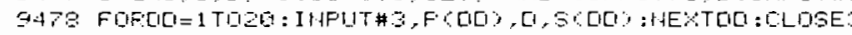

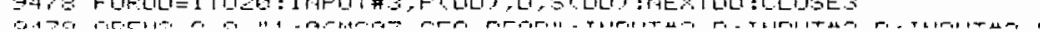




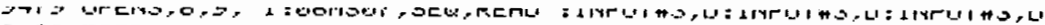

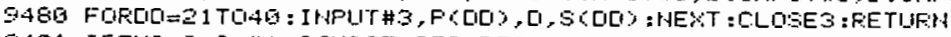

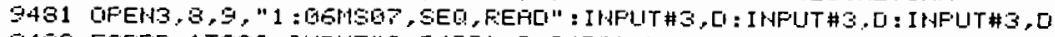

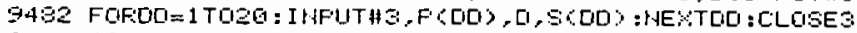

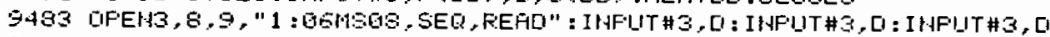

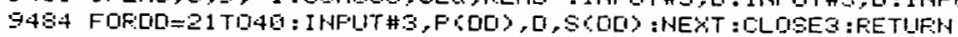

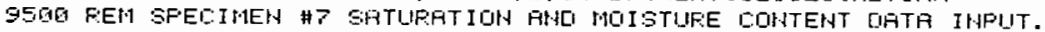

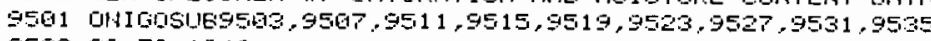
3562 GC TO 1240

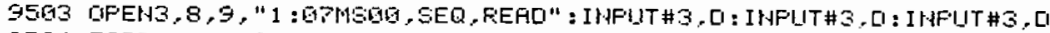

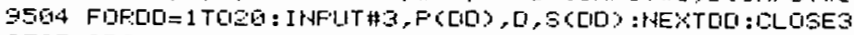

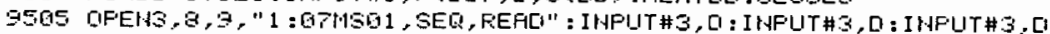

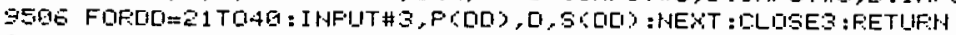

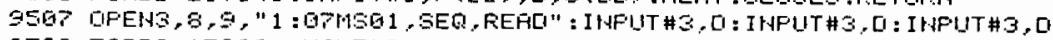

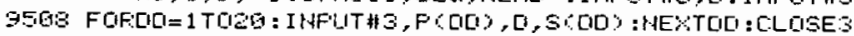

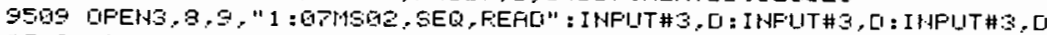

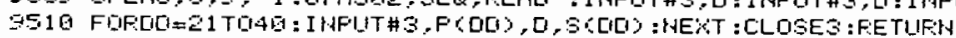

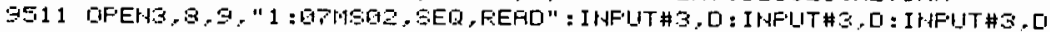

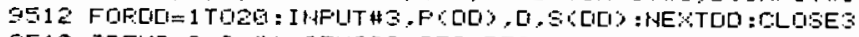

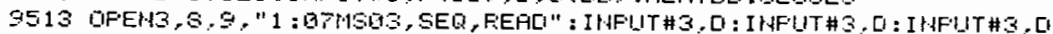

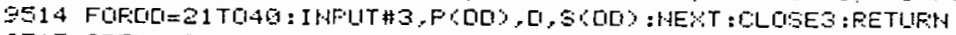

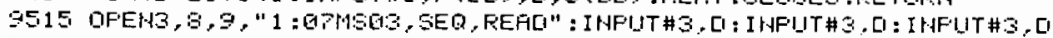

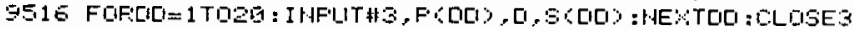

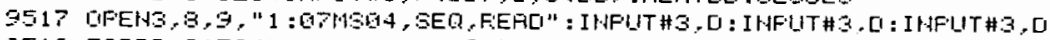

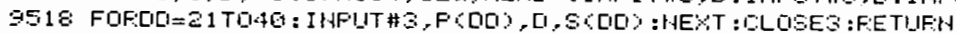

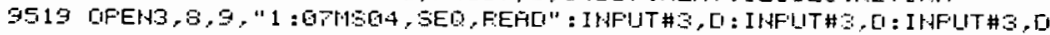

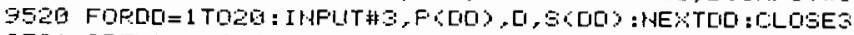

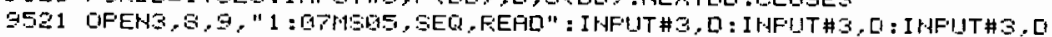

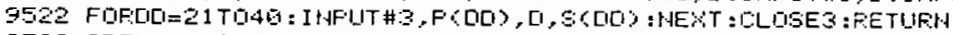

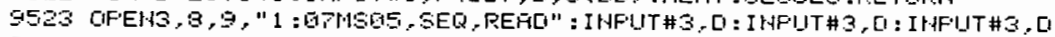

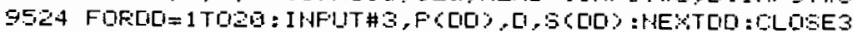

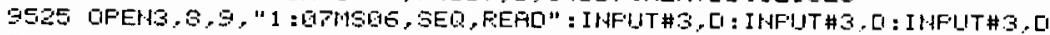

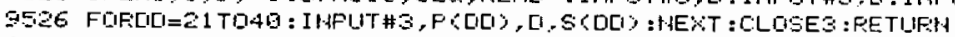

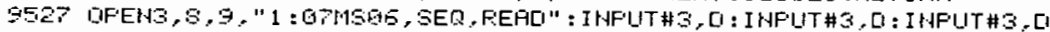

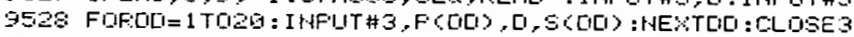

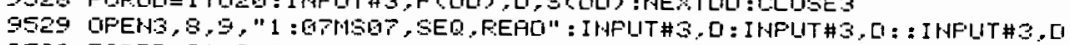

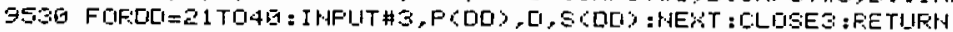

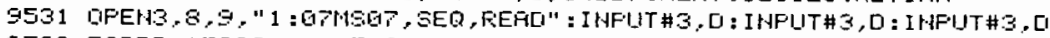

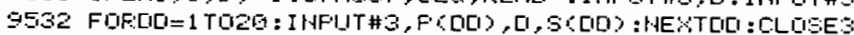

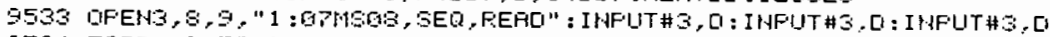

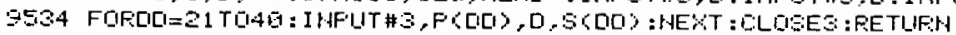

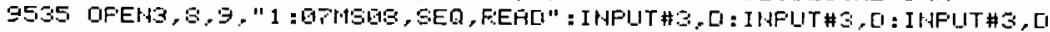

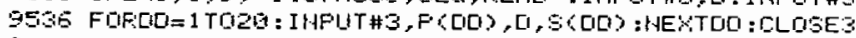

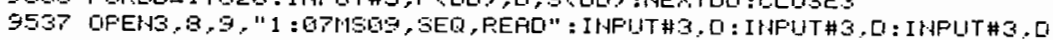

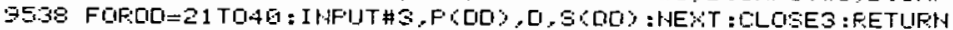

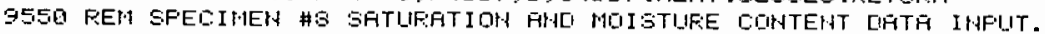
3551 ONI $1000109553,3557.9551,3565,9569,9573,9577,9581,9585$

9552 GiO TO 1240

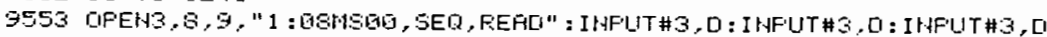

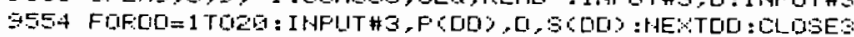

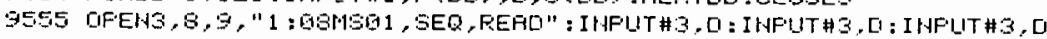

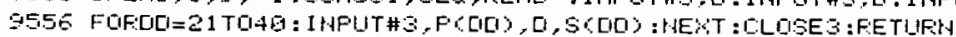

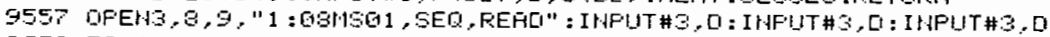

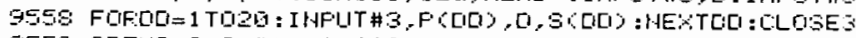

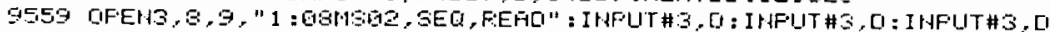

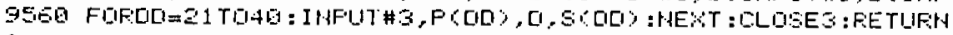

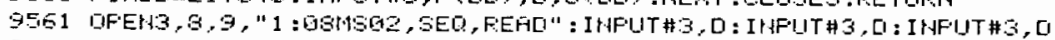

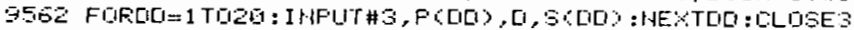

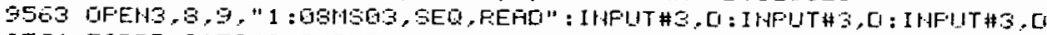

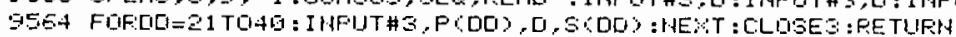

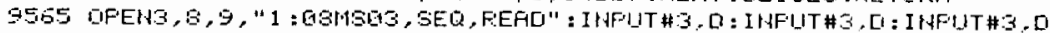

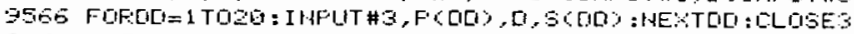

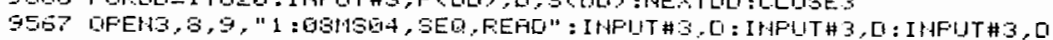

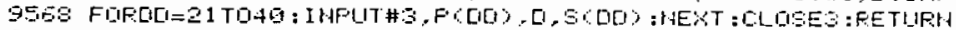

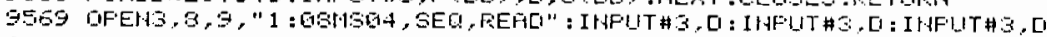

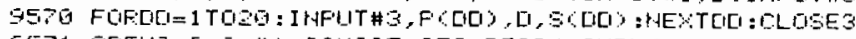

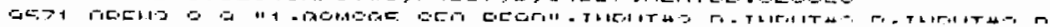




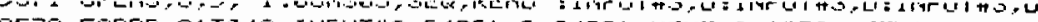

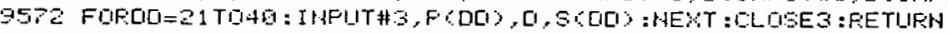

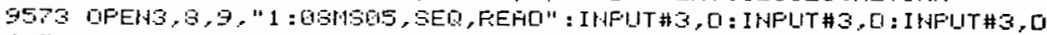

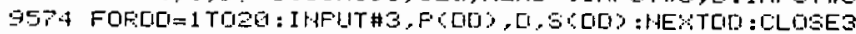

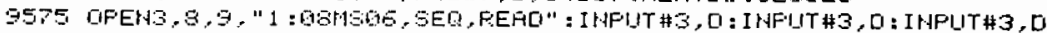

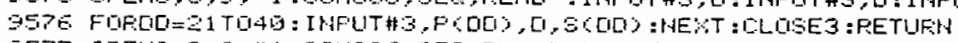

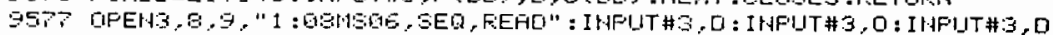

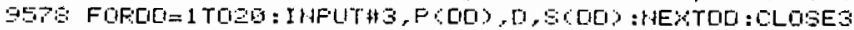

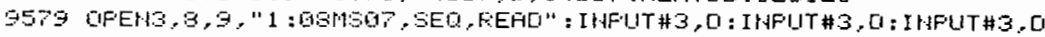

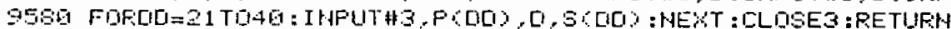

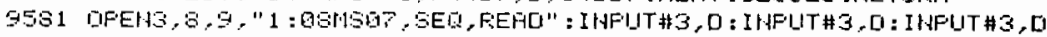

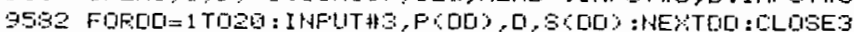

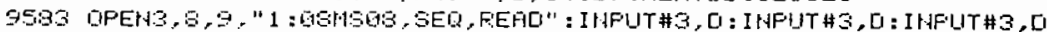

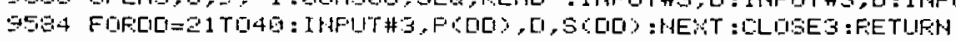

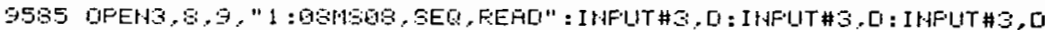

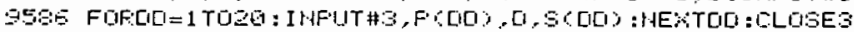

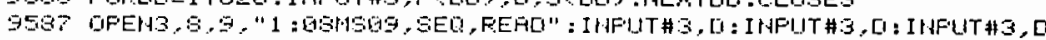

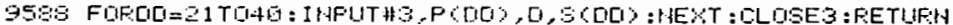

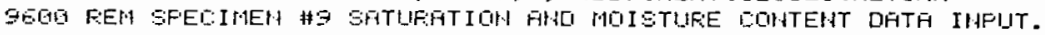

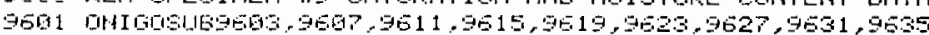

9302 10 TO 1246

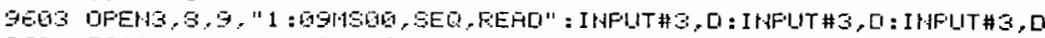

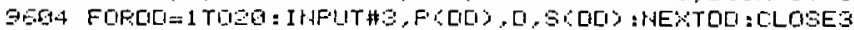

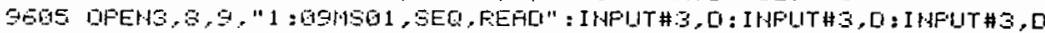

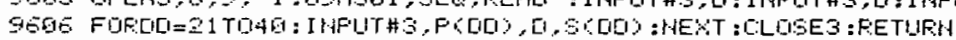

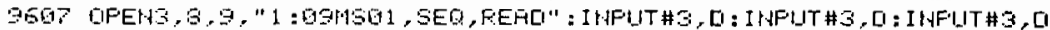

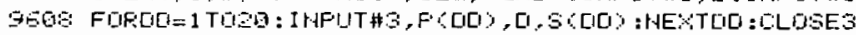

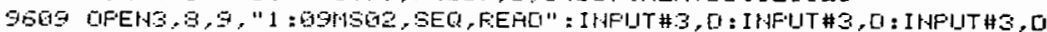

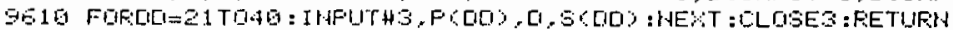

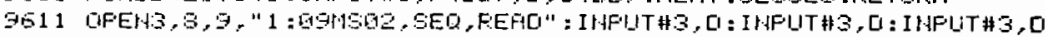

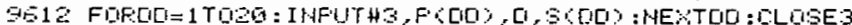

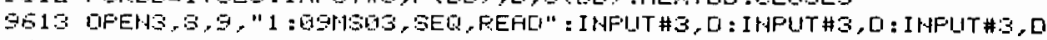

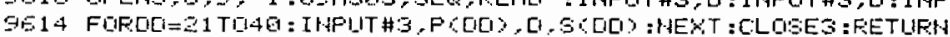

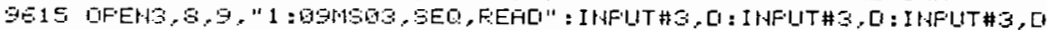

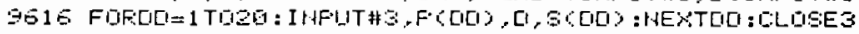

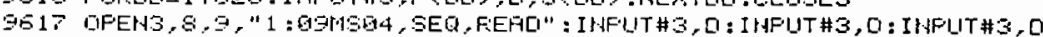

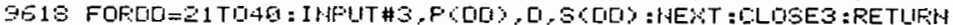

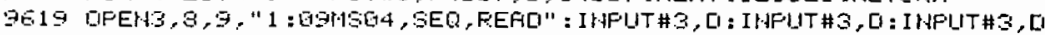

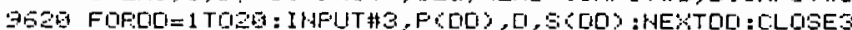

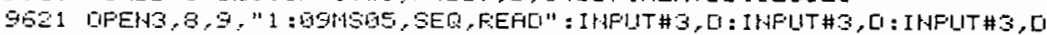

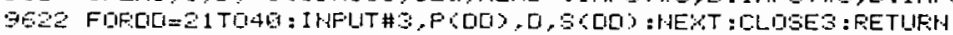

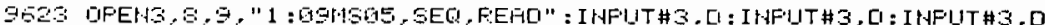

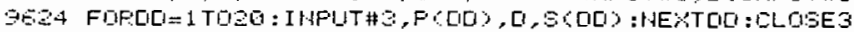

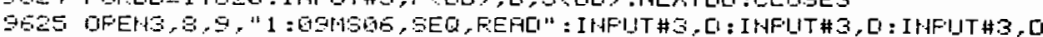

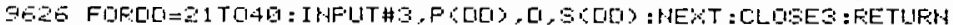

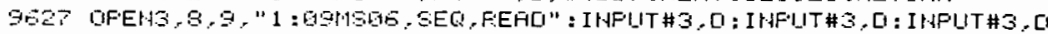

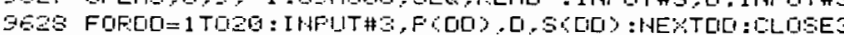

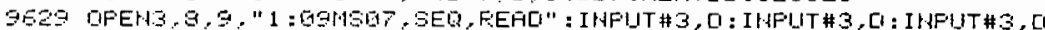

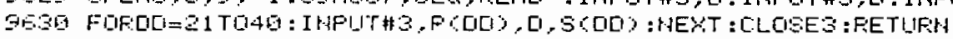

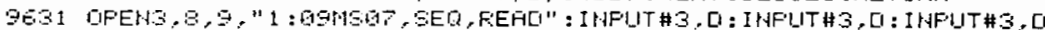

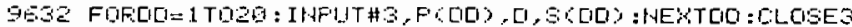

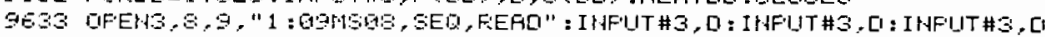

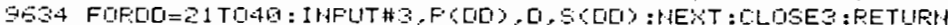

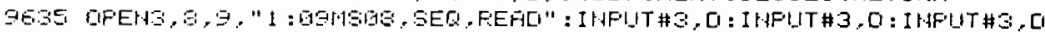

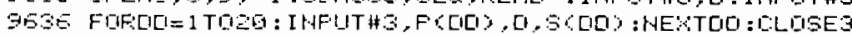

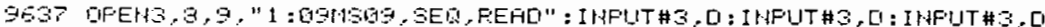

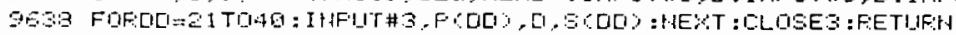

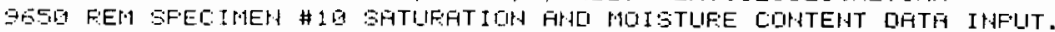

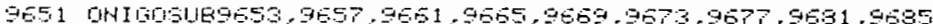

$985210 \mathrm{TO} 1245$

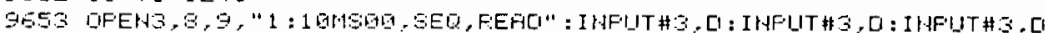

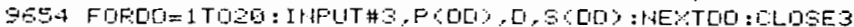

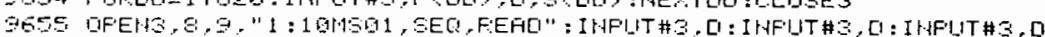

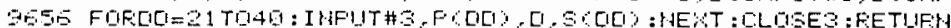

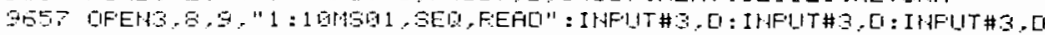

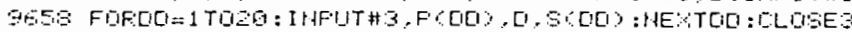

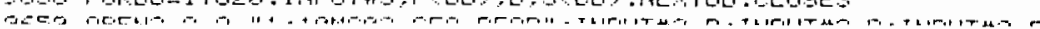




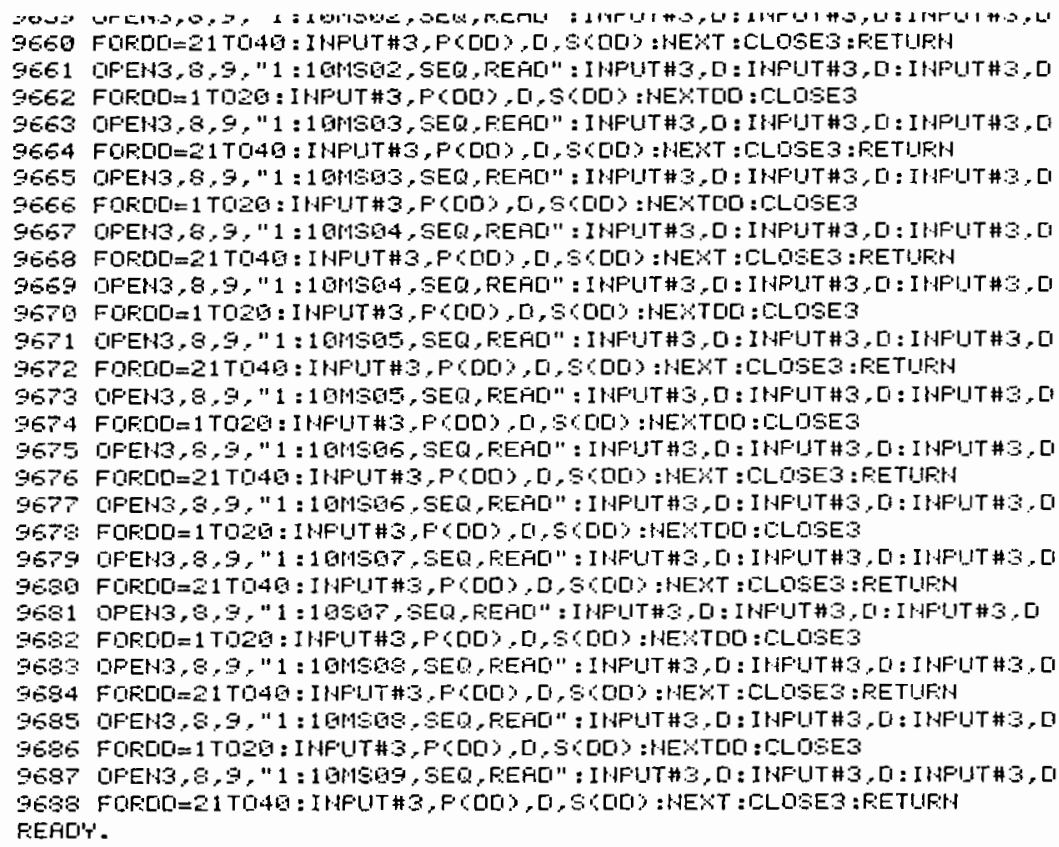


REALI'T

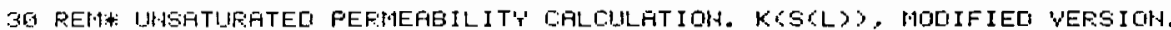

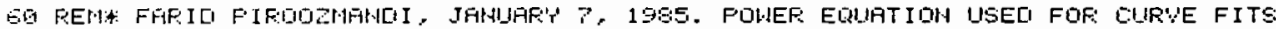

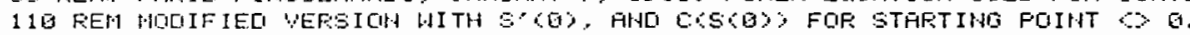

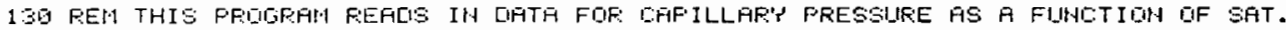

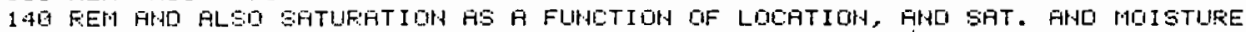

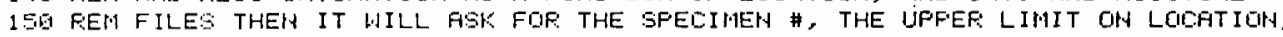

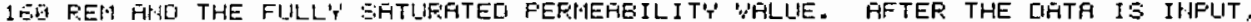

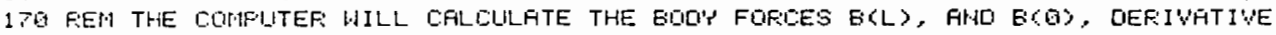

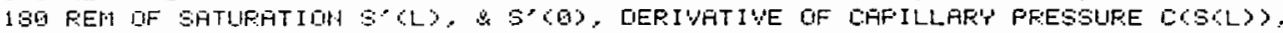

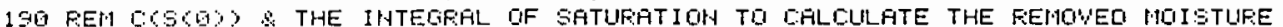

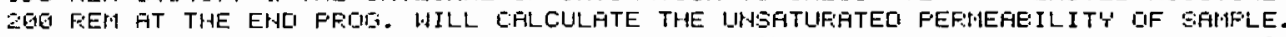

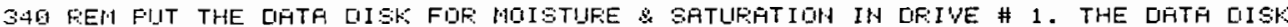

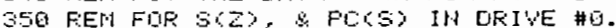

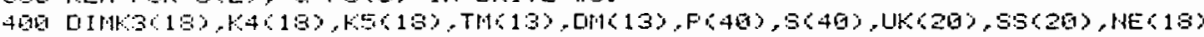

405 DIM HOC18.

$410 \mathrm{HE}(1)=2 \mathrm{Q}: \mathrm{HE}(2)=1 \mathrm{G}: \mathrm{HE}(3)=2 \mathrm{H}: \mathrm{HE}(4)=20: H S(1)=4: H S(2)=4: H S(3)=1: \mathrm{HS}(4)=11$

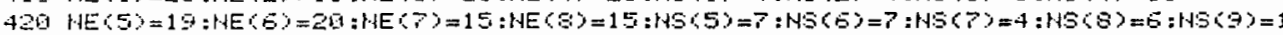

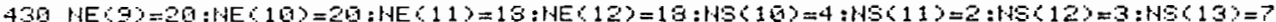

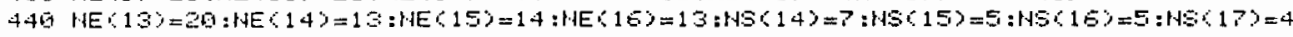

$4 S O H E(1 P)=15: H E(18)=20: H S(19)=7$

SOG FEH FOK FOR LIATA TI EE FFOUILEQ B'T' THE USER.

510 INFUIT "SFEC:IHEH \# 11 TQ 18 )":SF:IFEPC:=6THEH R:H $=9$

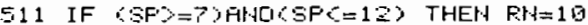

512 IFSFO=13THEH FH $=12$

514 FOR $E=1$ TO20: $: S S(E)=01:\{K(C E)=0: H E X T E$

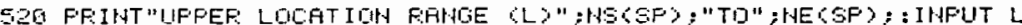

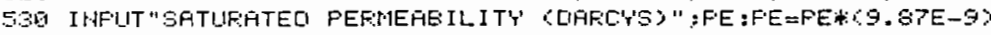

540 FEM FEFI IN LIATH FOR FC(S), \& S(Z).

55 SE: $=$ SF-13:IF SPO13 THEH 5EG

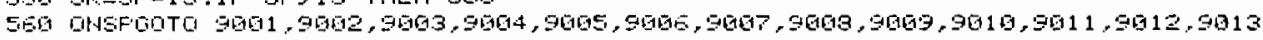

5,70 DOT TO 590

550 oH SR 60T0 $9014,9615,9016,9017,9013$

596 FEN STAFT FEFOIHG THE DATA FOR PCSS), REFEFED TO

GEDG IHFIIT\#3.0

610 IHFUTA 3.0

EEO IPHFUTHS.D

E39 IHFFIT \#3,KG

E.40 IHFUTT $3, K 1$

E50 IHFUTAO, O

EET IYHFIIT\#3.0

679 IHFUTH 3.0

639 IH.SIITH 3.0

80 IKFINTH 3.0

7 ISG IHFITH3,0

710 IHFUTH

712 IHFUTH $3 . \mathrm{O}$

$\rightarrow 14$ INFITHE, 0

716 IHFIIT\#3, O

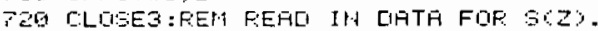

736 IF SFY 13 THEH $>70$

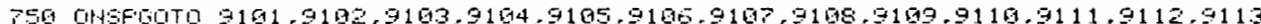

7 EO OOC TO 780

770 GIV SR COOTO $9114,9115,9116,9117,3119$

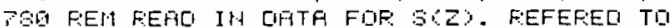

709 IHFUTH $3.6 \%$

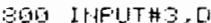

319 IMFILTH3.0

EQG FOF: $I=1$ TO FH

SOS IHFIITHO.THEI

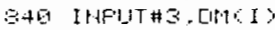

550 I IHEUTA 0 . 


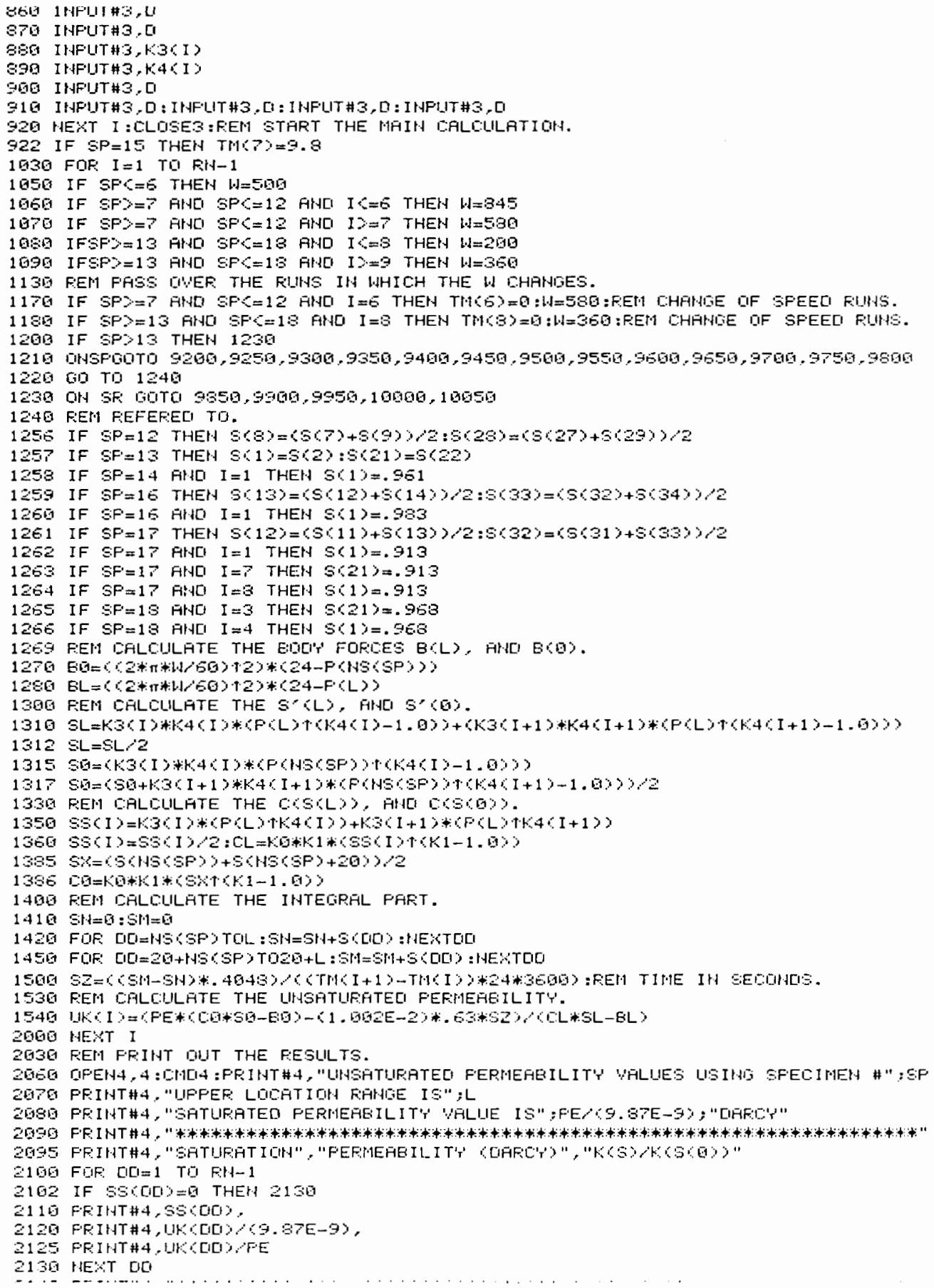




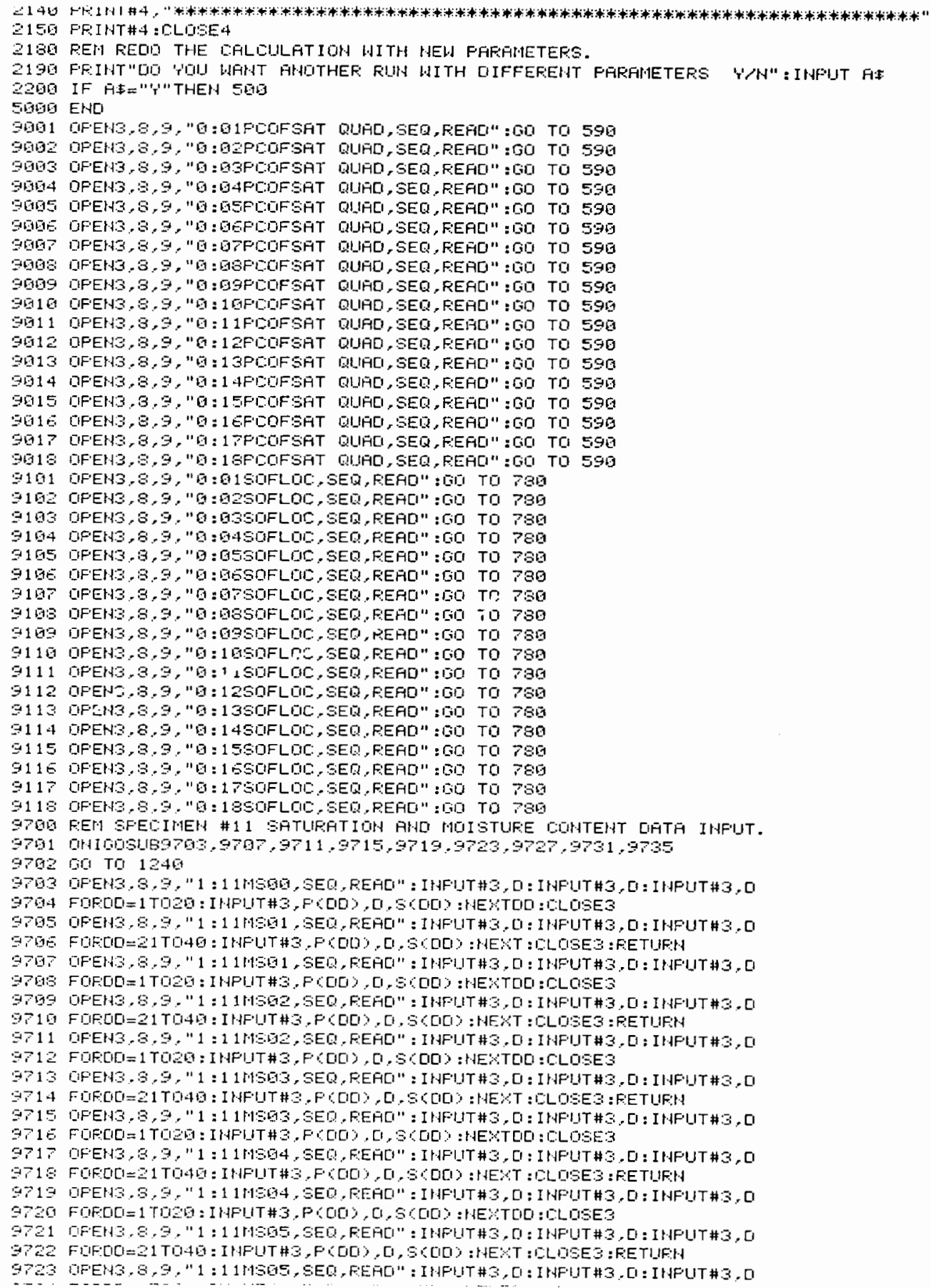




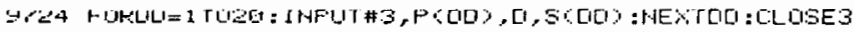

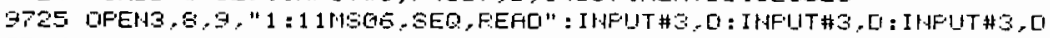

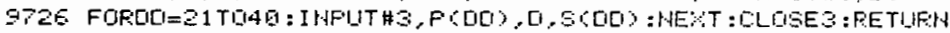

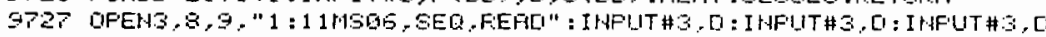

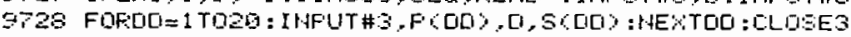

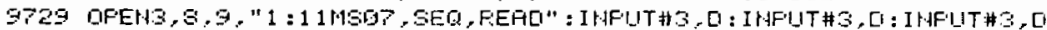

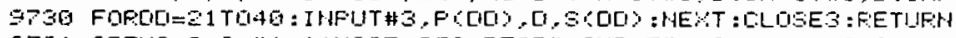

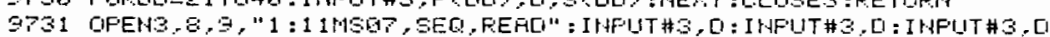

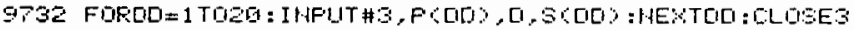

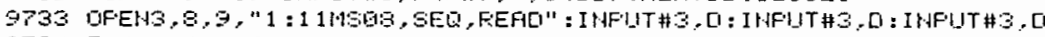

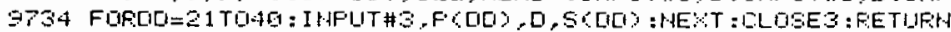

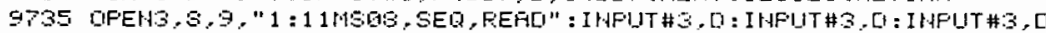

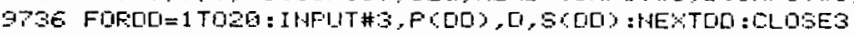

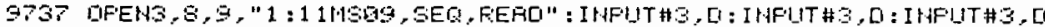

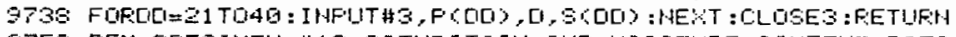

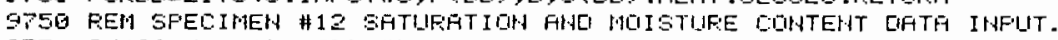

9751 0HI G0SIE:9753,9757.9751,9755, 9759.9773.9777.9701,9755

975200601240

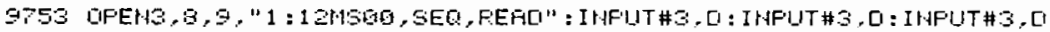

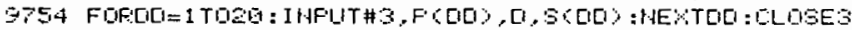

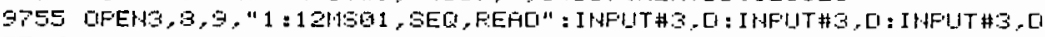

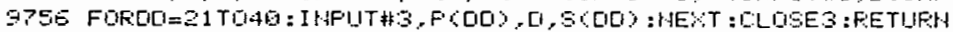

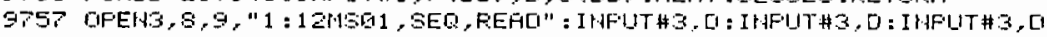

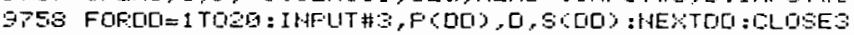

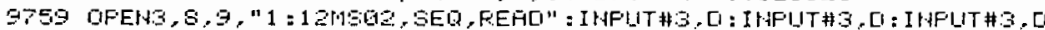

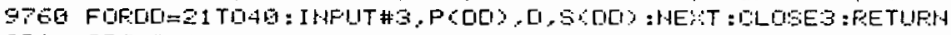

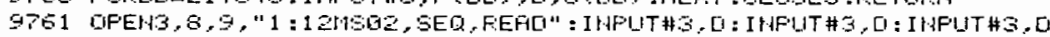

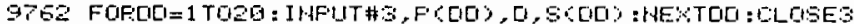

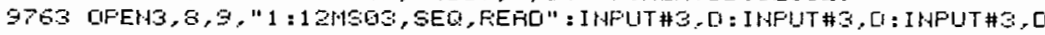

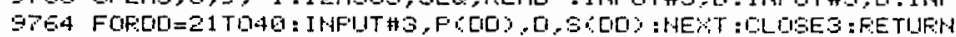

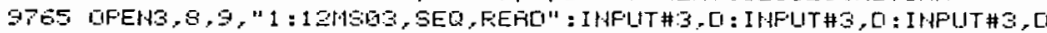

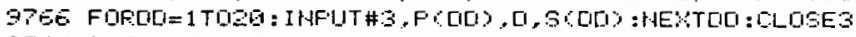

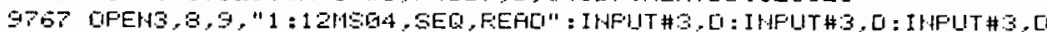

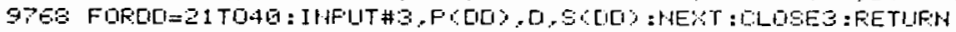

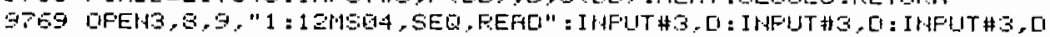

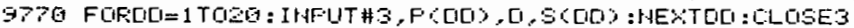

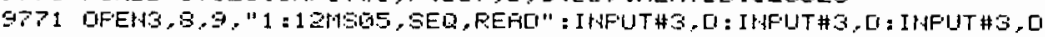

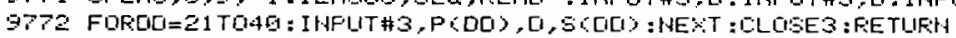

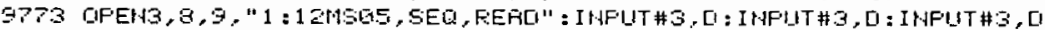

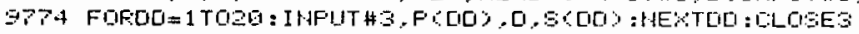

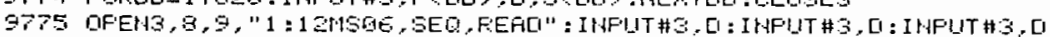

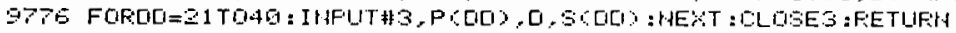

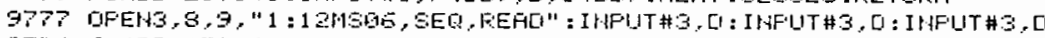

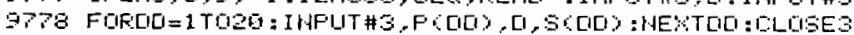

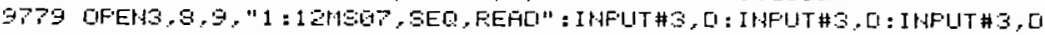

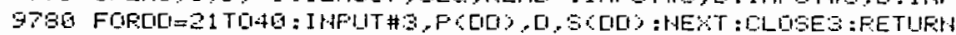

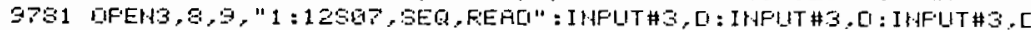

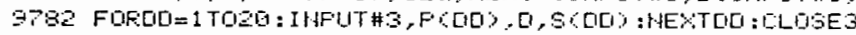

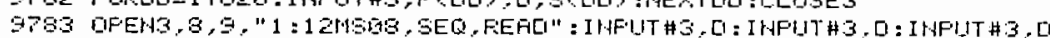

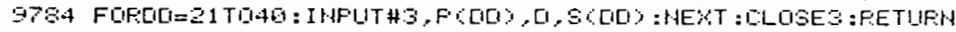

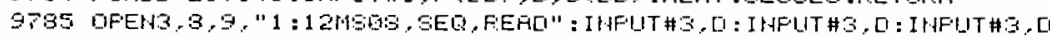

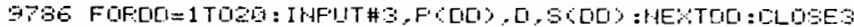

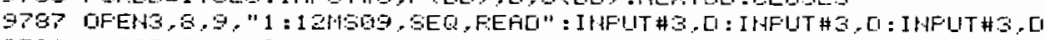

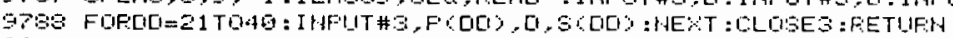

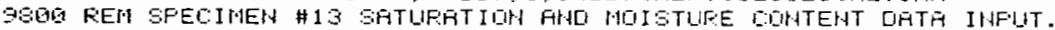

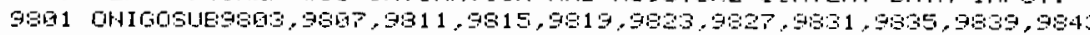

$9802 \mathrm{lOO}$ TO 1240

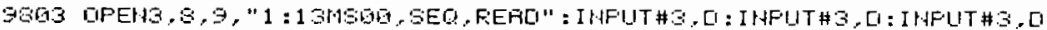

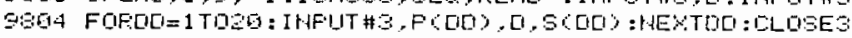

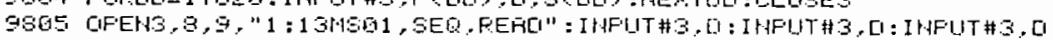

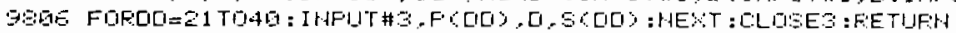

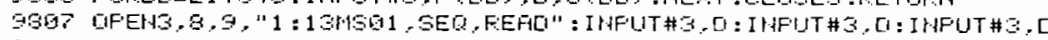

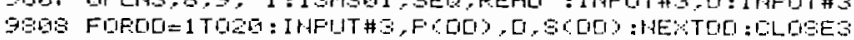

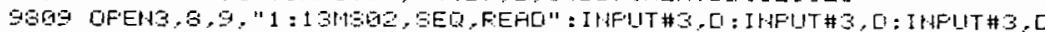

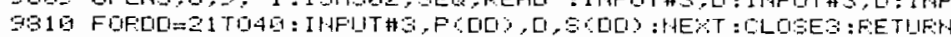

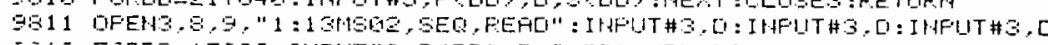




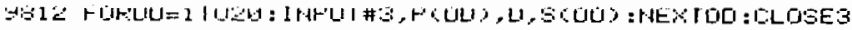

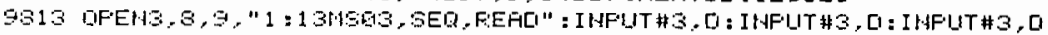

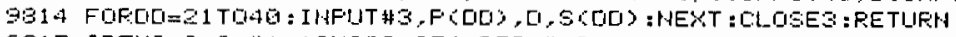

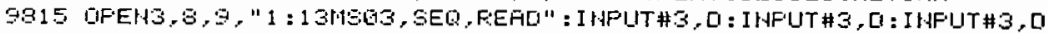

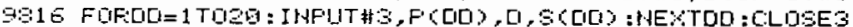

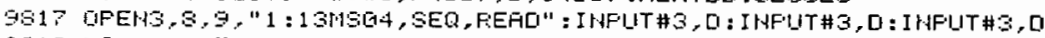

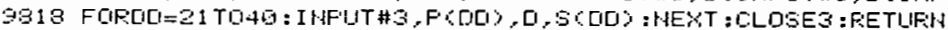

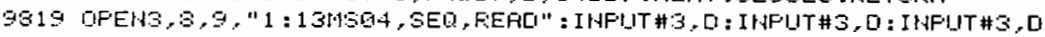

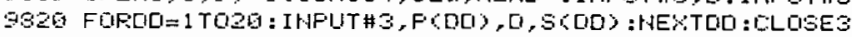

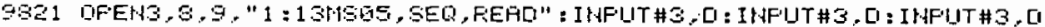

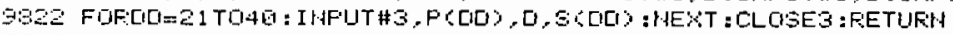

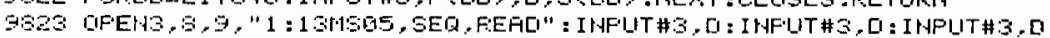

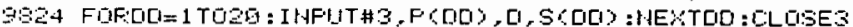

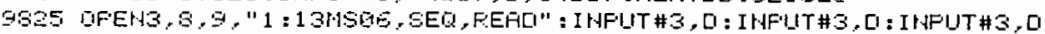

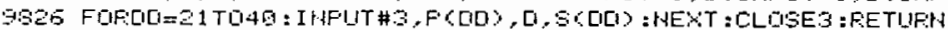

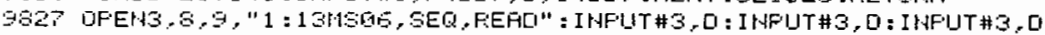

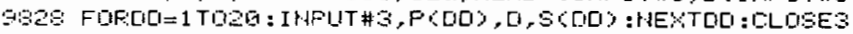

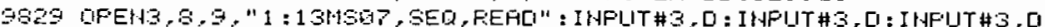

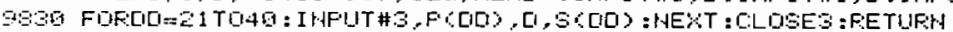

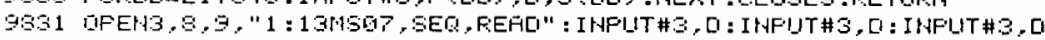

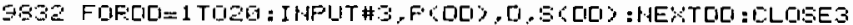

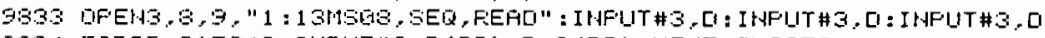

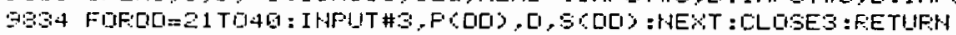

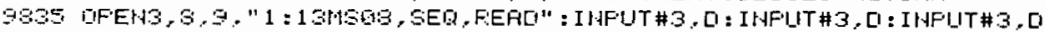

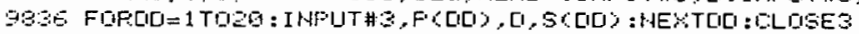

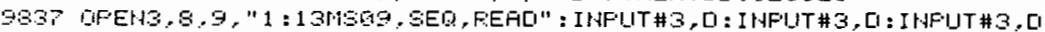

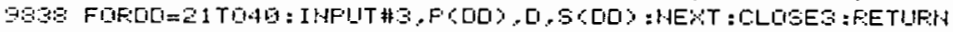

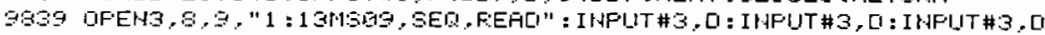

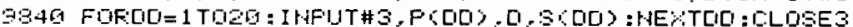

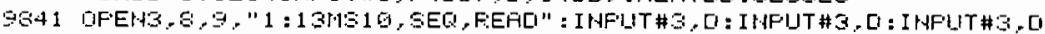

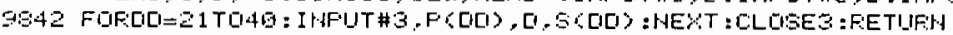

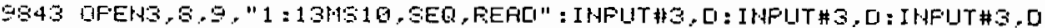

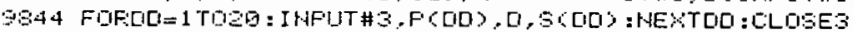

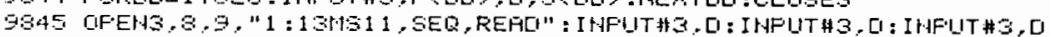

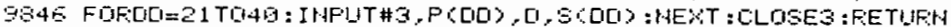

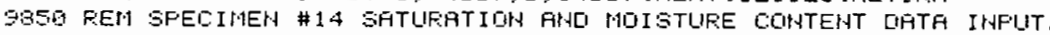

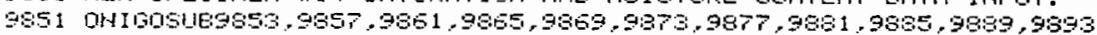
$9852 \quad 100$ TO 1240

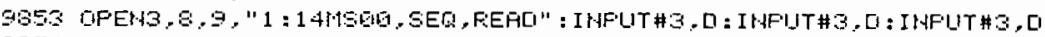

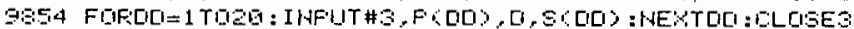

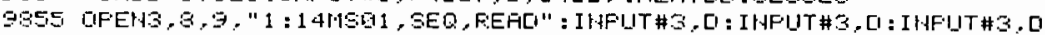

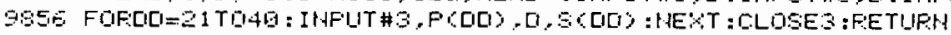

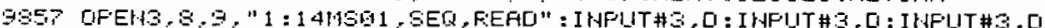

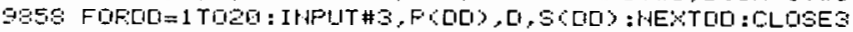

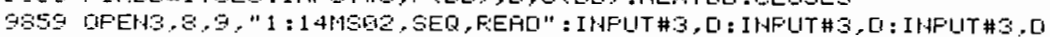

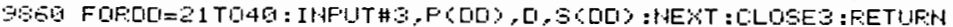

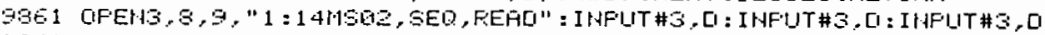

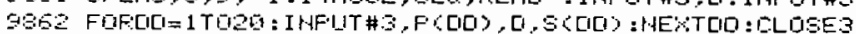

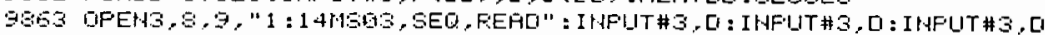

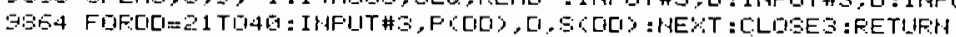

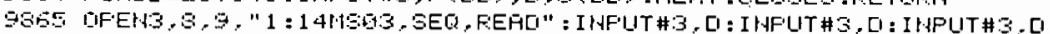

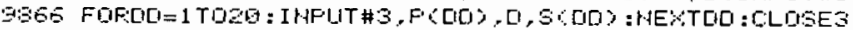

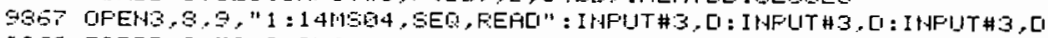

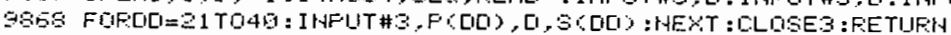

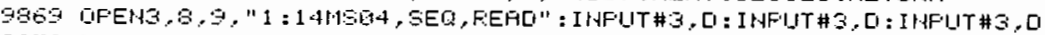

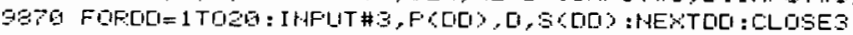

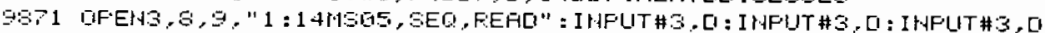

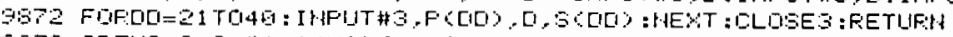

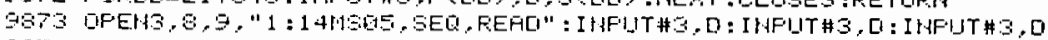

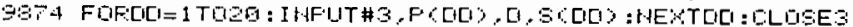

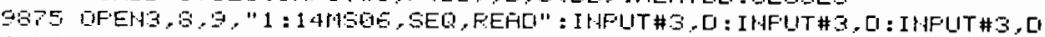

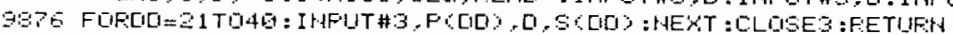

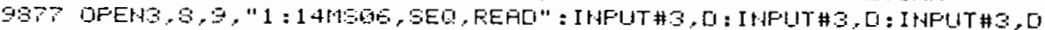

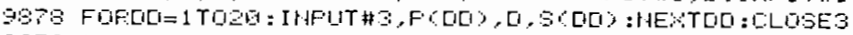

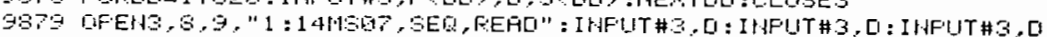

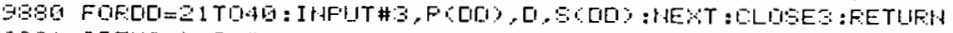




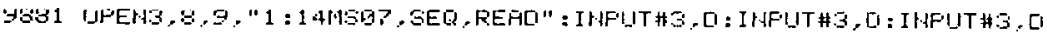

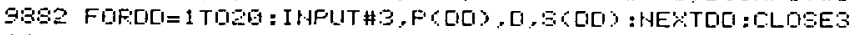

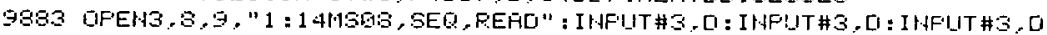

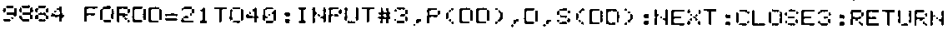

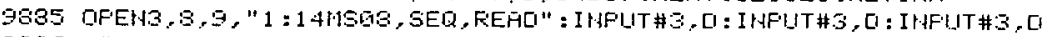

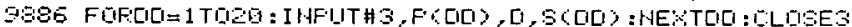

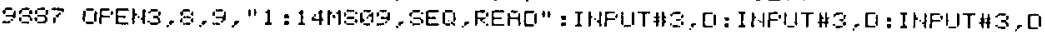

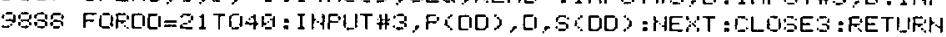

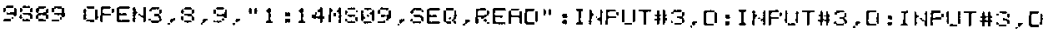

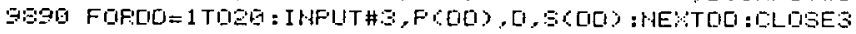

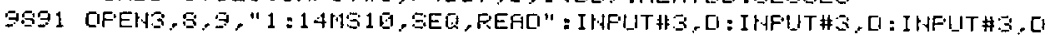

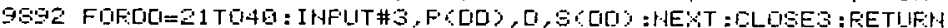

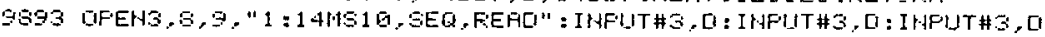

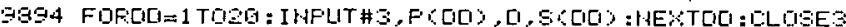

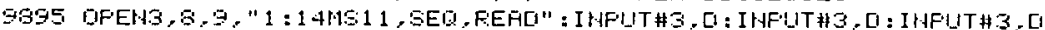

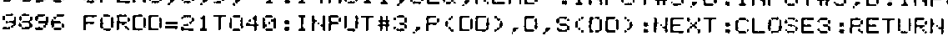

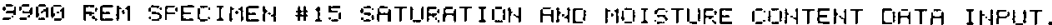

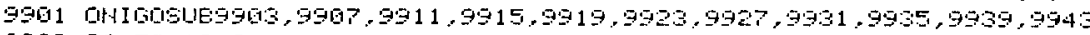

990200 TO 1240

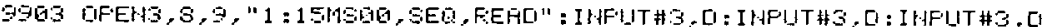

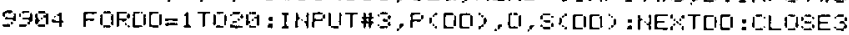

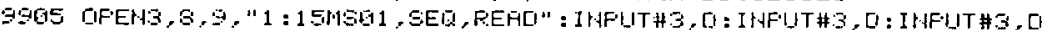

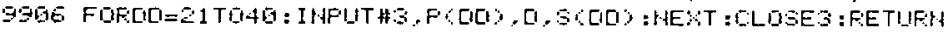

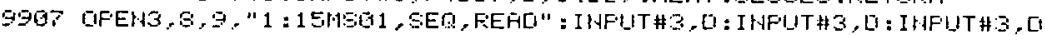

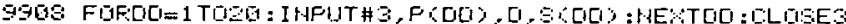

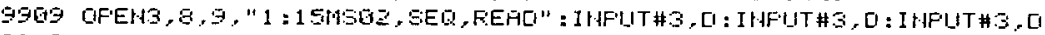

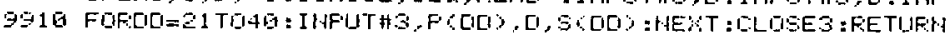

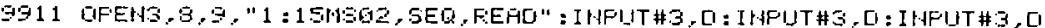

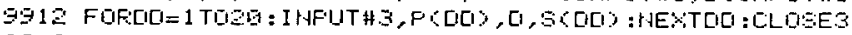

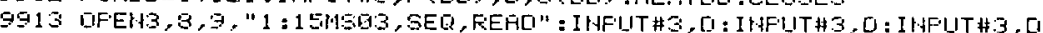

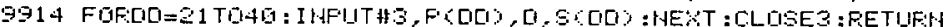

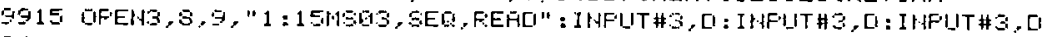

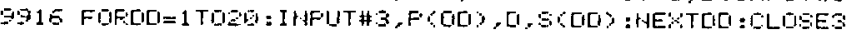

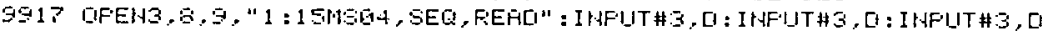

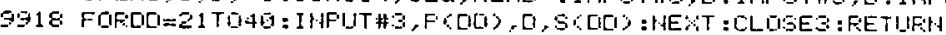

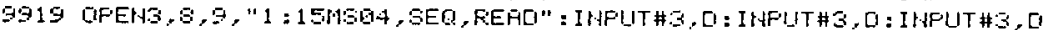

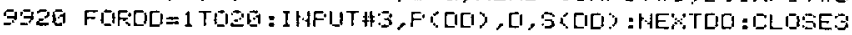

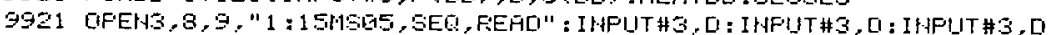

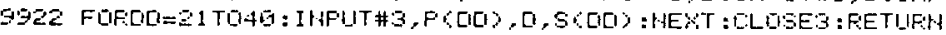

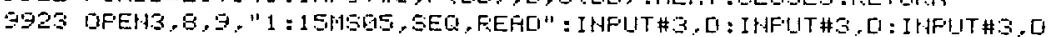

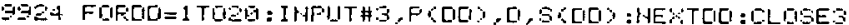

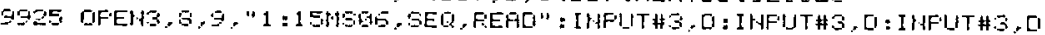

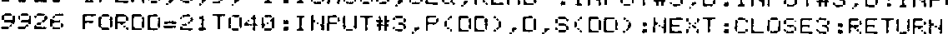

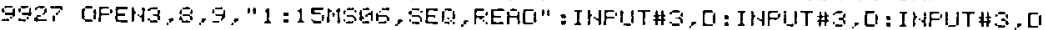

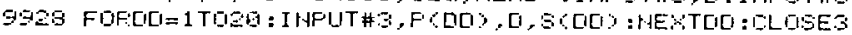

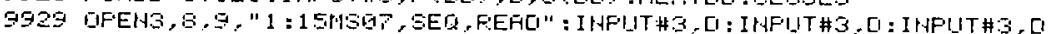

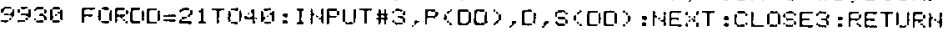

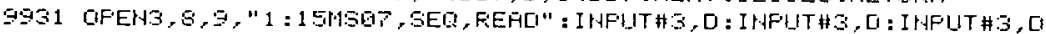

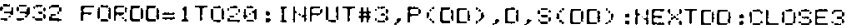

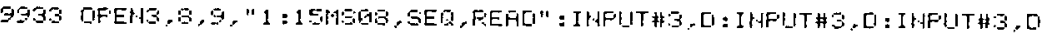

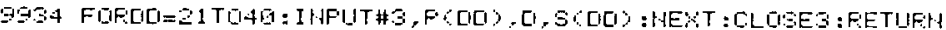

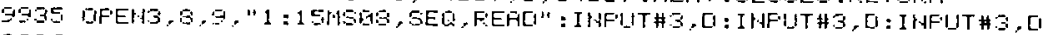

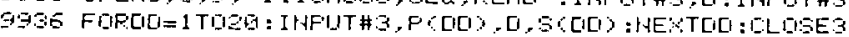

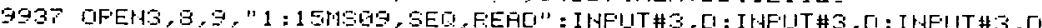

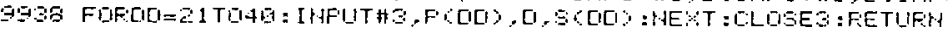

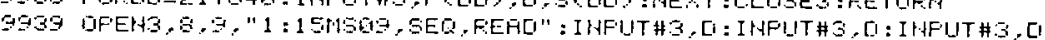

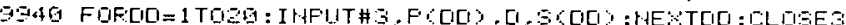

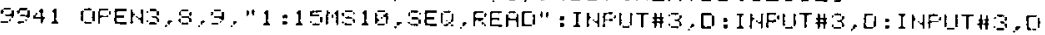

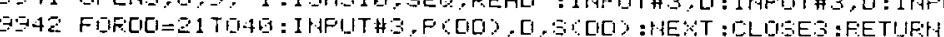

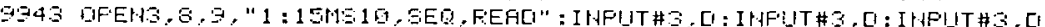

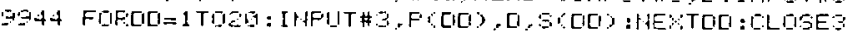

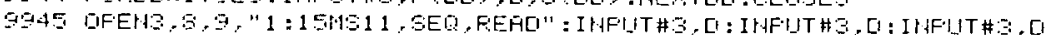

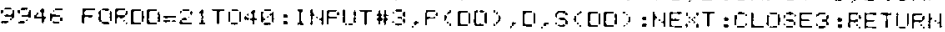

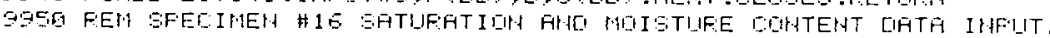

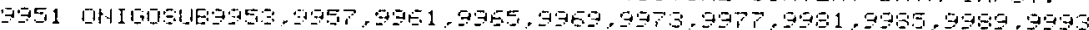

995200 TO 1240 


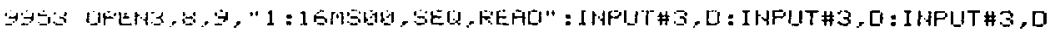

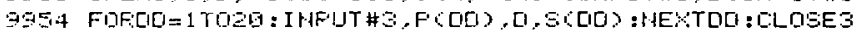

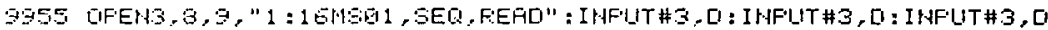

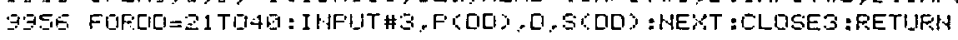

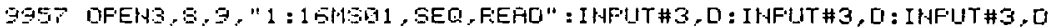

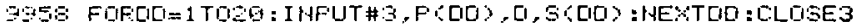

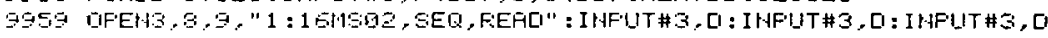

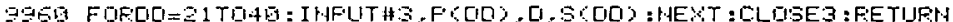

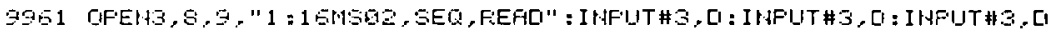

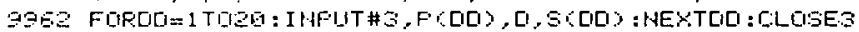

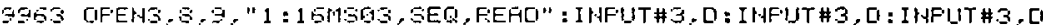

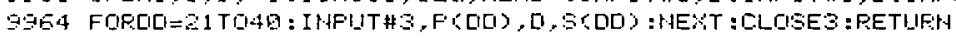

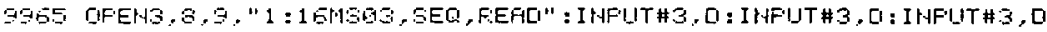

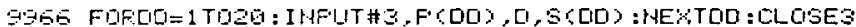

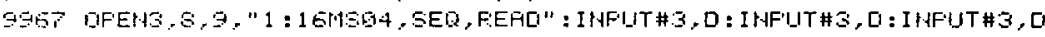

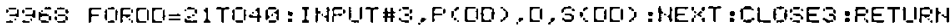

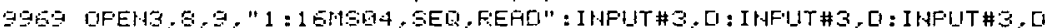

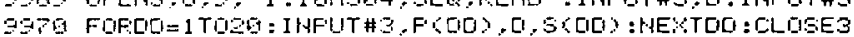

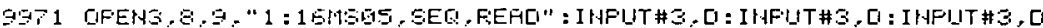

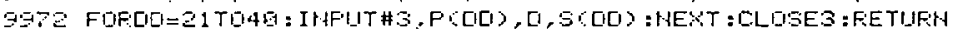

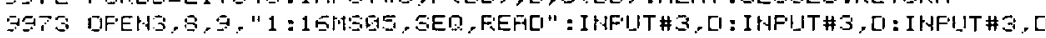

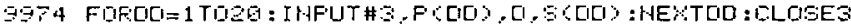

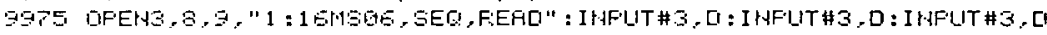

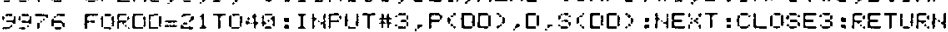

597 UFEHS.S.

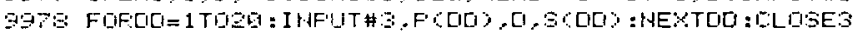

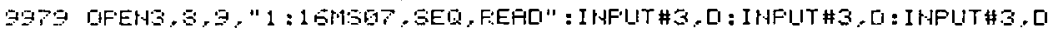

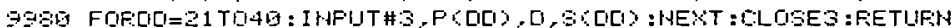

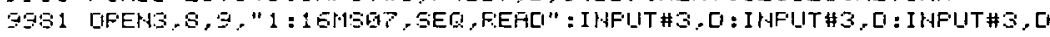

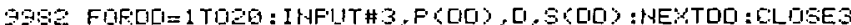

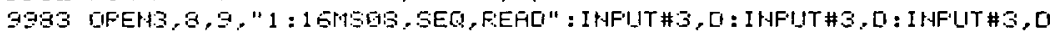

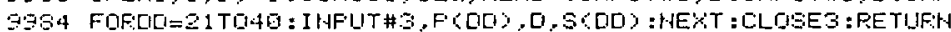

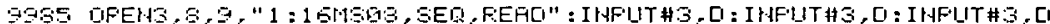

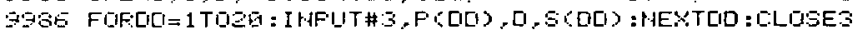

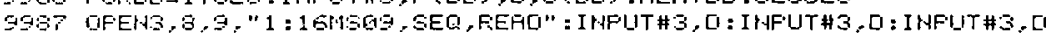

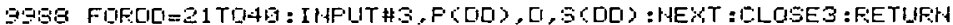

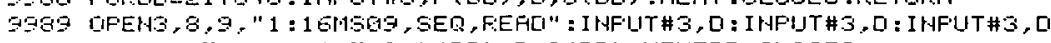

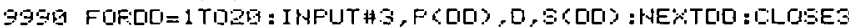

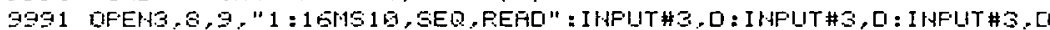

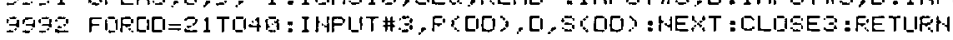

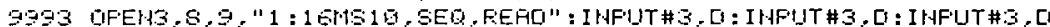

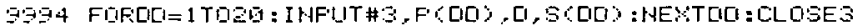

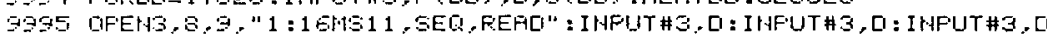

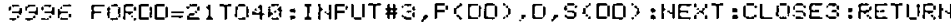

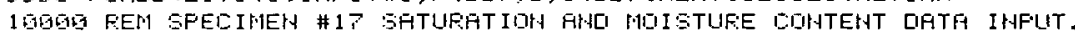

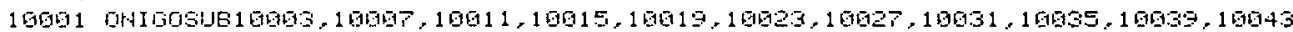

$100 \mathrm{G} 210 \mathrm{TO} \quad 1249$

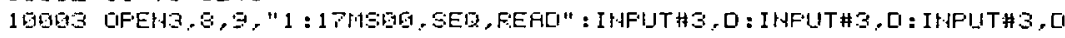

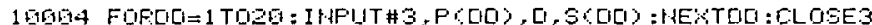

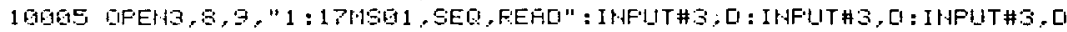

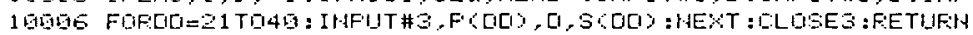

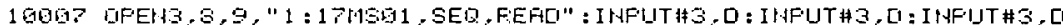

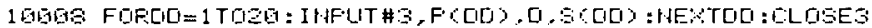

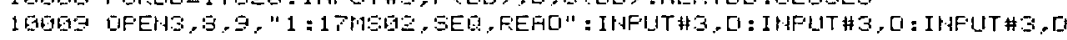

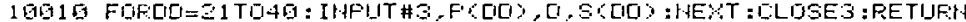

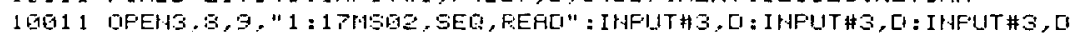

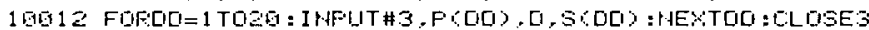

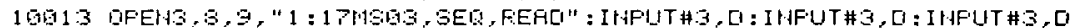

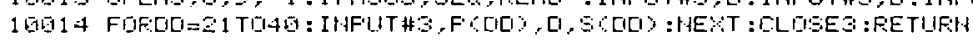

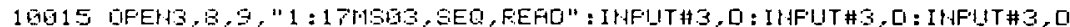

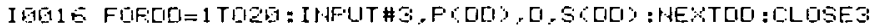

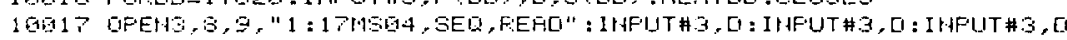

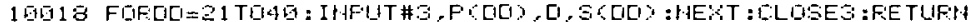

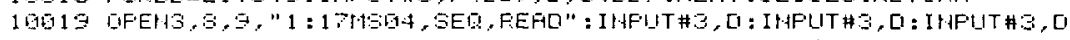

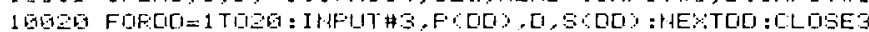

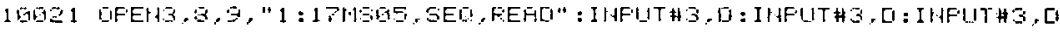




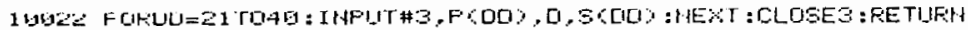

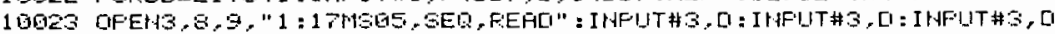

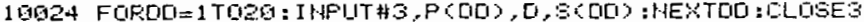

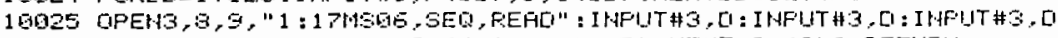

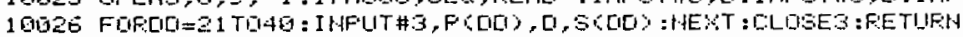

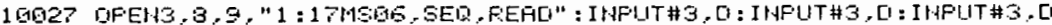

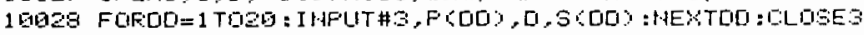

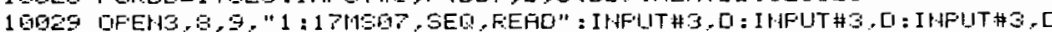

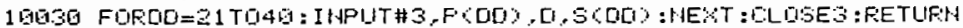

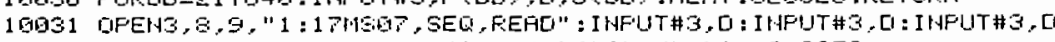

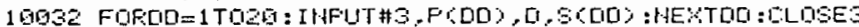

10035 DFEH3, $3.9,1$ : 1 ,

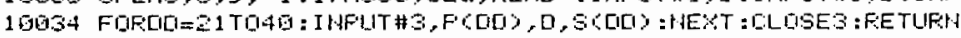

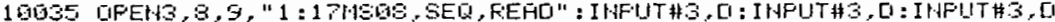

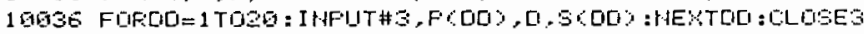

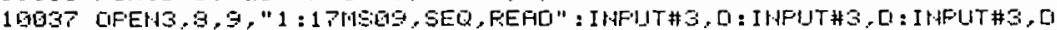

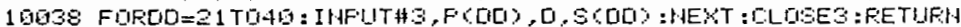

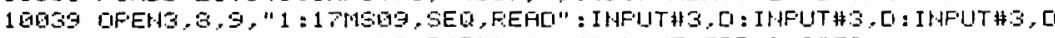

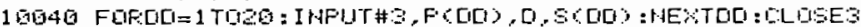

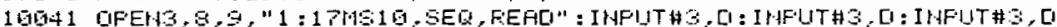

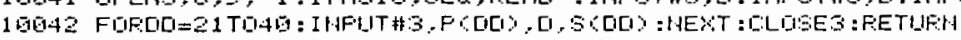

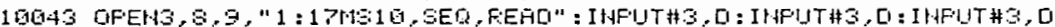

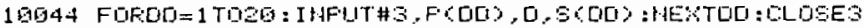

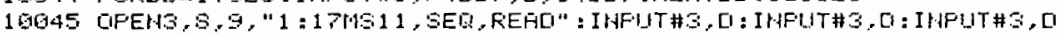

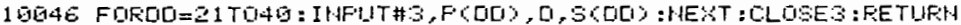

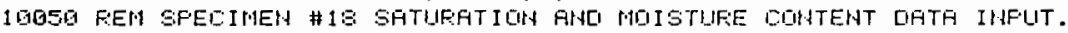

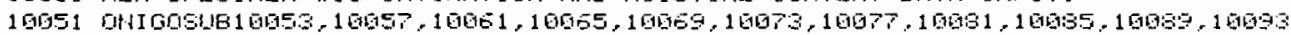

$1905260 \mathrm{TO} 1240$

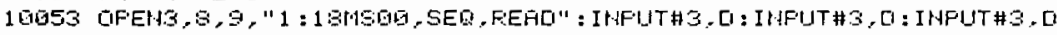

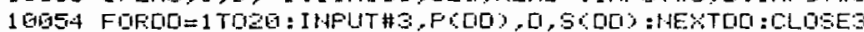

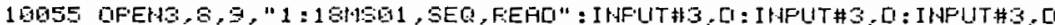

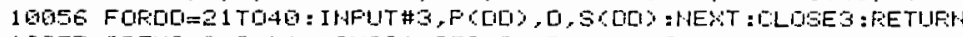

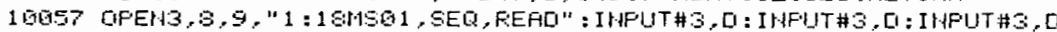

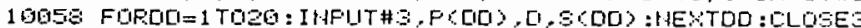

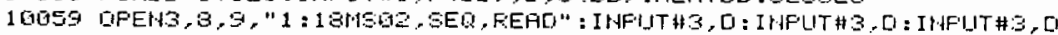

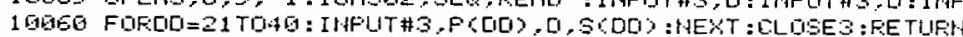

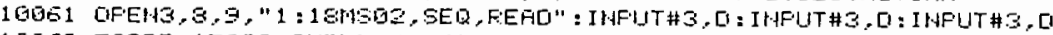

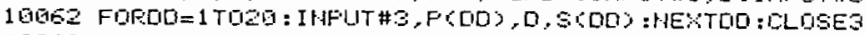

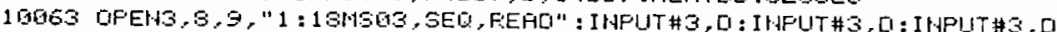

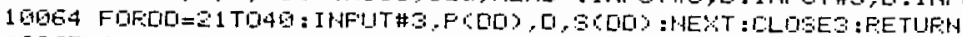

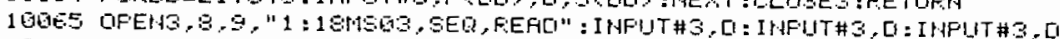

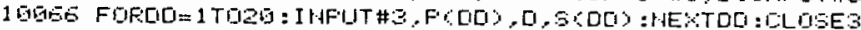

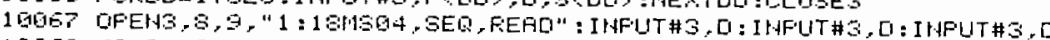

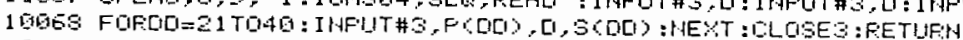

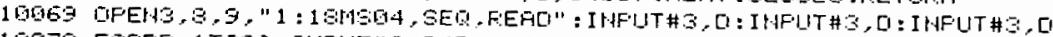

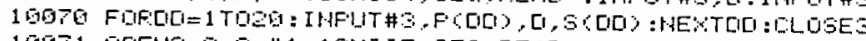

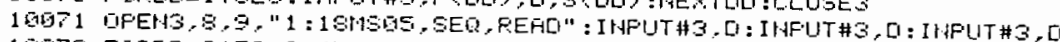

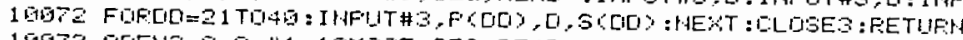

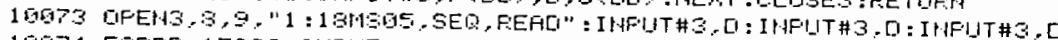

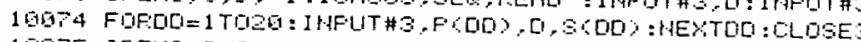

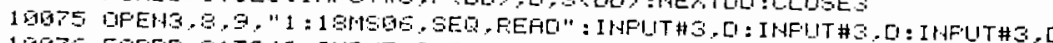

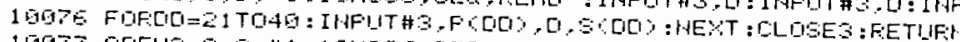

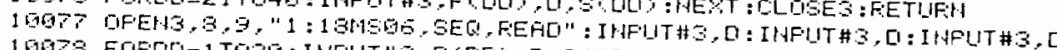

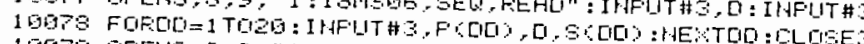

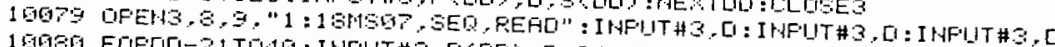

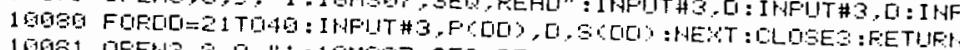

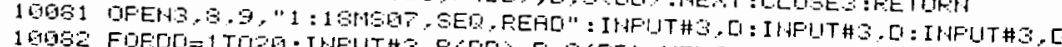

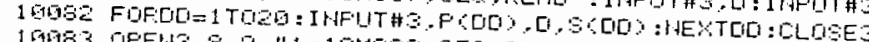

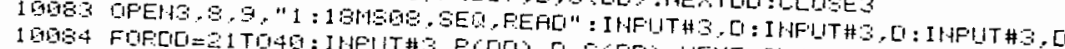

100ES DFEHS.

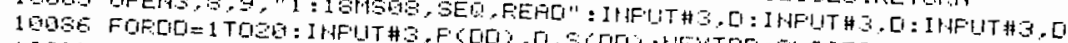

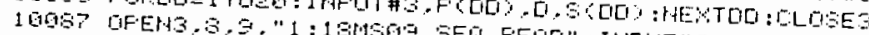

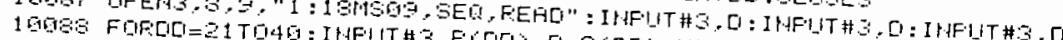

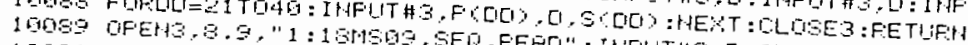

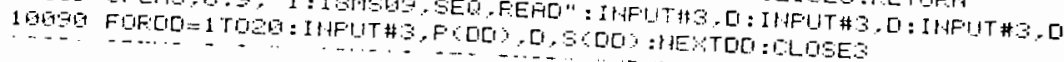




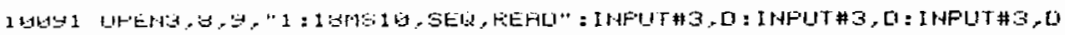

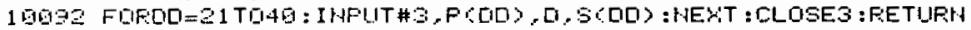

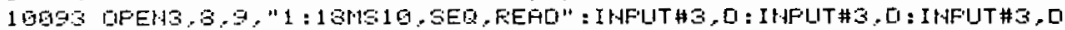

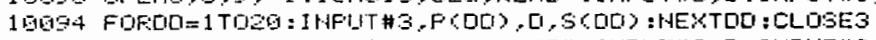

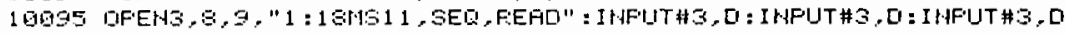

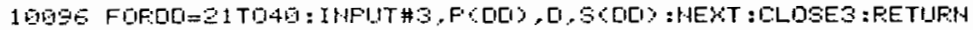

F:EF['T'

FEFAO'T' . 
FEAEI'Y .

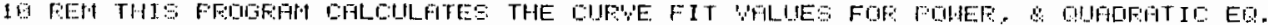

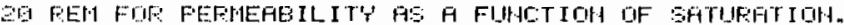

20 REEH

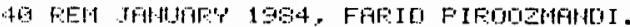

50 PEI

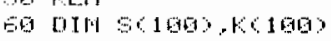

$7 \mathrm{PEH}$

BD FEE IHFUT DIATA FPDN [IFIUE \#1.

GE FEN

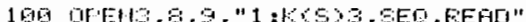

110 IHFOHT $3, H$

$12 \mathrm{FOF} \quad \mathrm{I}=1 \mathrm{TO}$ H

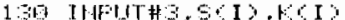

$1.10 \mathrm{HEOT}$ ।

$1501 \mathrm{HSE}$

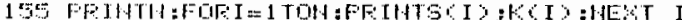

16 REN

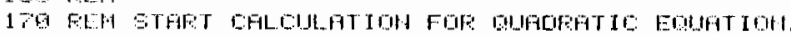

$190 \mathrm{REH}$

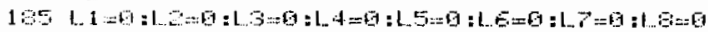

196 FLE $\mathrm{I}=1 \mathrm{Ta} \mathrm{H}$

$2011 L t=t+31$

$210 \quad L 2=L 2+C O C 1)+2$

$224 \quad L 3=13+1013$

$2094-1+4+6 \cos 13$

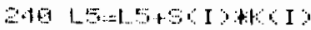

206 1. - L

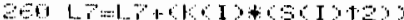

$2701010+101300$

उOH $\mathrm{HEOT}$ I

$20 \mathrm{PEH}$

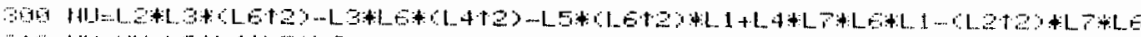

316 H.I HWHLELLAHLEHLE

उET EEW

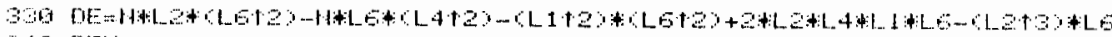

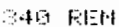

350 Po $=141,10 \mathrm{CH}$

$360 \mathrm{PE}$

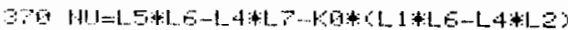

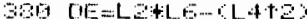

S9+ FEN

469 1 $1=10.6 \mathrm{CE}$

410 FEI

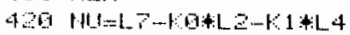

450 PE=INI. LE

4 40 FEI CALLLILATE COREELATIOH COEFFICIEHT.

$4.45 \quad$ L $9=\mathrm{B}: L \mathrm{~F}=\mathrm{G}$

4 TOT FOE: $I=1$ TOI H

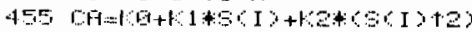

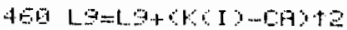

4GE FEIHTKCI D:CA

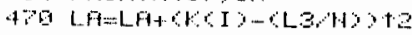

456 HEST I

409 FEL1

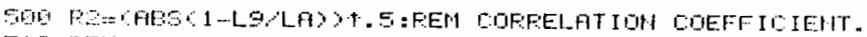

$519 \mathrm{FEF}$

S2A FEN

EO FEM STAFT CALCULATIOH OF THE POHEE EOUATIOH.

540 PEW

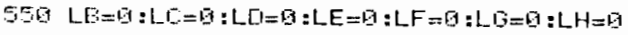


SEG FEH TAHE THE LOH. DF THE RATA FOIHTS.

STO FQF I $I=1$ TO $H$

sed $\sec \mathrm{I}=\mathrm{LOCOSCI}$

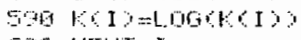

SELS HEST I

EJ Fell

QDO FOFE I=1 TO $\mathrm{H}$

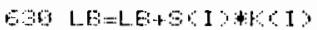

E4a $L C=L C+\operatorname{coc} I D+2$ ?

EAS LF $=L F+C I O+Z$

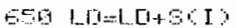

BQS LE:AE+RCI

EOG HEST I

Q9 FEN

$600+11 I=+1+L E-L-L+L E$

760 DE - H LLE-CLL112)

710 DL $=-1+1 .-1 \mathrm{CIE}$

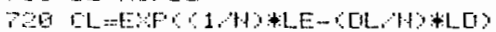

734 EEM FUIUEF EO. $1=$ CL $\$$ STLL

TAG FEH COAEELATIDH COEFFICIEMT.

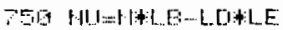

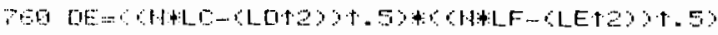

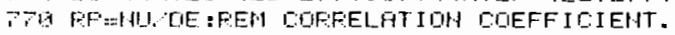

780 FEH

794 PEN

QOG FIEN FEIHT EUIT THE FESULTS.

E19 DFEHA $4: \mathrm{COHC14}$

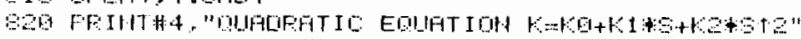

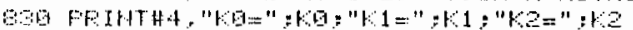

E19 FETHTHA "COFFELATIOH COEFFICIEHT IS ":FZ

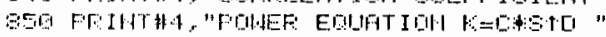

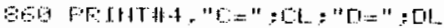

OC FETHTH . "OORFELAT IOH COEFFICIEHT $1 \mathrm{~S}$ ";FP

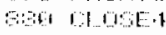

SEG EHC

FEATO'

FEATH'.

FEEFII'T' 